\title{
MEASUREMENT AND DETERMINATION OF RADON SOURCE POTENTIAL
}

\section{A LITERATURE REVIEW}

Allan B. Tanner

Consulting Geophysicist

Building and Fire Research Laboratory

Gaithersburg, Maryland 20899

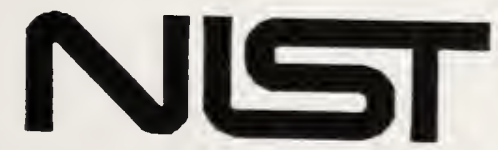

United States Department of Commerce

Technology Administration

QC

Institute of Standards and Technology

100

.056

1994

\#5399 



\title{
MEASUREMENT AND DETERMINATION OF RADON SOURCE POTENTIAL
}

\section{A LITERATURE REVIEW}

\author{
Allan B. Tanner \\ Consulting Geophysicist
}

\section{April 1994}

Building and Fire Research Laboratory

National Institute of Standards and Technology

Gaithersburg, MD 20899

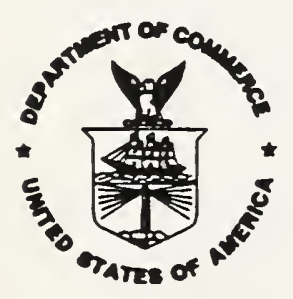

\section{U.S. Department of Commerce}

Ronald H. Brown, Secretary

Technology Administration

Mary L. Good, Under Secretary for Technology

National Institute of Standards and Technology

Arati A. Prabhakar, Director 
(12)

1.2.

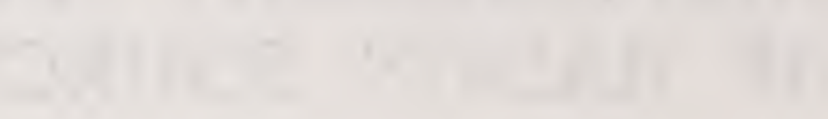

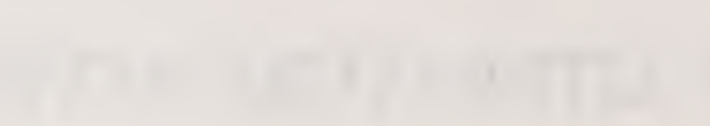




\section{ABSTRACT}

Radon source potential may be estimated for areas of a nation, state, county, housing development, or building lot. The critical characteristics of the soil are its radium concentration, emanation coefficient, permeability to gas, and diffusion coefficient for radon under typical conditions. Best estimates of these critical characteristics are applied to a scheme for obtaining a tiered ranking of subareas of the area of interest (radon potential mapping), or to a model for obtaining a single qualitative or quantitative estimate of the radon source potential of a single site (site-specific characterization). This report summarizes and evaluates available information on radon potential mapping and site-specific characterization. More than 100 reports have been found that bear on radon potential mapping, and indicate fair to good agreement with indoor radon results where correlations have been possible. Because site-specific characterization is not generally cost effective, it has not been extensively tested; however, it can readily discriminate the order of magnitude of indoor radon concentration to be expected in the absence of special measures to prevent radon infiltration. Several situations are proposed as being appropriate for its use.

Keywords: building technology; diffusion; indoor radon; permeability; predictive methods; pressure-driven flow; radium activity concentration; radon availability; radon potential mapping; sitespecific characterization; soil testing. 
ABSTRACT $\ldots \ldots \ldots \ldots \ldots \ldots \ldots \ldots \ldots \ldots \ldots \ldots \ldots \ldots \ldots \ldots \ldots \ldots \ldots \ldots$

EXECUTIVE SUMMARY $\ldots \ldots \ldots \ldots \ldots \ldots \ldots \ldots \ldots \ldots$ vii

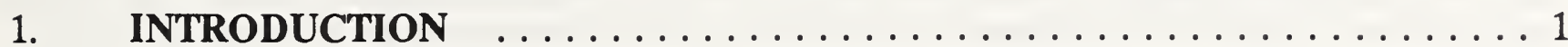

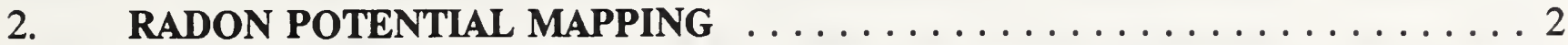

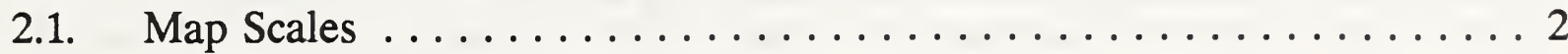

2.2. Radium and Radon Data ...................... 3

2.3. Permeability Data .......................... 4

2.4. Radon Diffusivity Data .................... 5

2.5. Indoor Radon Data ....................... 5

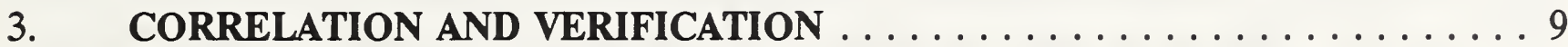

4. SITE-SPECIFIC CHARACTERIZATION OF RADON SOURCE

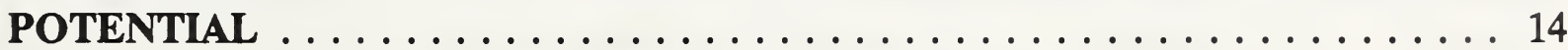

4.1. Methods and Instrumentation . .................. 12

4.1.1. Surrogate Methods . .................. 12

4.1.2. Soil-Probe Methods ........................ 13

4.1.3. Laboratory Methods ................... 18

4.2. Discussion . . . . . . . . . . . . . . . . . . . . . . . . . 19

4.3. Cost-Benefit Considerations for Site-Specific Characterization . . . . . 21

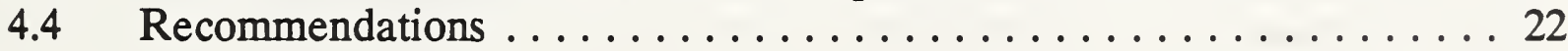

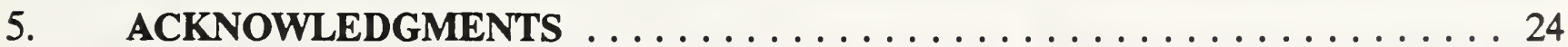

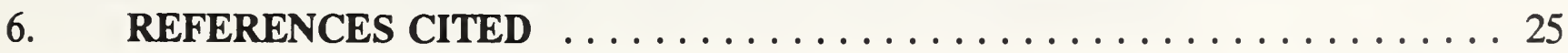

7. APPENDIX A. BIBLIOGRAPHY OF MEASUREMENT AND DETERMINATION OF RADON SOURCE POTENTIAL . . . . . . . . 43

8. APPENDIX B. LIST OF PERSONS OR INSTITUTIONS PRESENTLY OR RECENTLY ENGAGED IN RESEARCH RELATED TO MEASUREMENT AND DETERMINATION OF RADON SOURCE POTENTIAL OF SITES OR AREAS 


\section{LIST OF TABLES}

TABLE I: DESIRED AND SURROGATE CHARACTERISTICS FOR RADON POTENTIAL MAPPING AT SEVERAL MAP

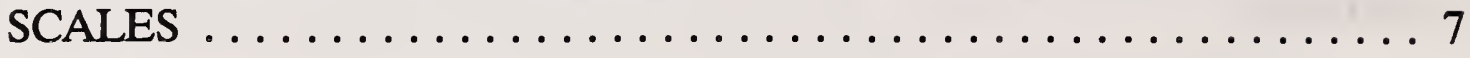

TABLE II: RADON POTENTIAL MAPPING AND CORRELATION EFFORTS 


\section{EXECUTIVE SUMMARY}

For a year or two after the discovery, in December 1984, of very high concentrations of radon and its decay products in houses, there was considerable interest in finding out where the "high radon areas" or the "hot spots" were in the United States. A need was also voiced for a method to assess the inherent ability of the ground at a proposed construction site to supply the structure with unacceptable amounts of radon. As a $148-\mathrm{Bq} / \mathrm{m}^{3}(4-\mathrm{pCi} / \mathrm{L})$ guideline became a rigid de facto standard in the real estate industry, as mitigation costs decreased, and as fairly inexpensive ways were found to prepare a new house for mitigation should it be found necessary, interest in preconstruction testing waned. However, as research on the influence of the soil and geological substratum progressed in many studies, it was shown that areas of various extent could be evaluated for their indoor radon potential. Such evaluations allow authorities to use their resources to better advantage. The mapping of radon potential of county and larger-sized areas has been undertaken for about 100 areas in the nation.

Both radon potential mapping and preconstruction site testing require an evaluation of the concentration of radon in soil pores and the mobility of radon in the soil. In turn, radon mobility is determined by its ability to diffuse through the soil and by the permeability of the soil to gas movement. Two of the three critical characteristics, radon concentration in soil pores and permeability, can be measured directly in situ, or estimated from laboratory measurements on soil samples. The third, radon diffusivity, can be estimated from soil moisture and density measurements made either in situ or on soil samples in the laboratory. These procedures are practical for testing a specific site, such as a building lot or development. For radon potential mapping of larger areas, direct measurements are generally impractical, and it is necessary to estimate the same factors indirectly from soil and climatic characteristics-surrogates-that are correlated with the critical characteristics. This report lists surrogate characteristics that are commonly available in data bases for areas of different sizes. Also contained in the report is a compilation of radon potential mapping efforts and studies to determine the degree to which indoor radon measurements correlate with radon potential estimates based on soil characteristics. Radon potential estimates have in general correlated satisfactorily with indoor radon measurements.

Determination of radon source potential of building-lot or neighborhood size is still at an experimental stage. The approaches range from the same surrogate methods as used in radon potential mapping to computer-assisted modeling of soil air flow and radon entry based on arrays of test holes. Some approaches are clearly suited for research only, and others have practical applications. In the United States even the simple, surrogate approach is not often sought, because it requires expert knowledge, and, like those approaches requiring on-site or laboratory determinations, is seen as more expensive than preparing a new structure for mitigation if it should be required. 
Six situations are proposed that could favor site characterization:

(1) The architectural design of an unusual house would be compromised by the usual means of providing a centrally located subslab vent pipe stub in the foundation or vertical piping to the roof. A site test could indicate whether such measures would be very likely unnecessary, necessary, or that some unusual custom approach toward radon-resistant construction would be necessary.

(2) The owner desired a passive-vent design, which is likely to be successful only if a modest reduction of indoor radon is needed. The site test could indicate the degree of reduction needed.

(3). The local building code required testing for commercial buildings, government required testing for public buildings, or public school policy required pre-construction testing.

(4) Builders of developments in areas where mapping or site-specific testing indicated low radon source potential could save enough money by neglecting radon-resistant construction on all houses to more than compensate for mitigation of a few houses that did not pass indoor radon tests after construction.

(5) A builder contested the high-risk classification of a site of his interest and wished to obtain a more reliable site-specific characterization that might justify less expensive construction.

(6) Uninhabited areas presumed on the basis of geological data to have very high indoor radon potential could be tested in advance, and local authorities could be forewarned if the tests verified the geologic estimate. Such areas could then be flagged as requiring special measures if building permits were requested for them.

Before site-specific characterization can be used, (1) greater field validation is needed for both in situ and laboratory methods, and (2) a recognized protocol and associated equipment for site-specific characterization prior to construction must be available.

The report concludes with an extensive annotated bibliography and a list of persons and institutions currently or recently engaged in characterization of radon source potential of sites, especially sites of building-lot or development size. 


\section{INTRODUCTION}

Until the late 1970s it was a common impression among people involved with radiation protection that if a house contained concentrations of radon $\left({ }^{222} \mathrm{Rn}\right)$ significantly greater than were found in the outdoor atmosphere, it was probably due to exhalation of radon from radium $\left({ }^{226} \mathrm{Ra}\right)$ contained in the materials used in the house's construction, or from soil artificially contaminated by radium. This view changed when investigators in Sweden and Canada found that elevated concentrations of airborne radon in some dwellings could be due mainly to infiltration of radon from naturally distributed radium in soils [ $\AA$ kerblom and Wilson, 1981; Swedjemark, 1982; Swedish Radon Commission, 1983; DSMA Atcon, Ltd., 1983]. Questions arose immediately as to how severe and widespread such indoor radon problems might be, and a systematic method of locating areas of high indoor radon potential ${ }^{1}$ was seen to be an important objective. It also appeared desirable to be able to predict the likely indoor radon concentrations in buildings before their construction, in order to anticipate the need for radon-resistant construction, and to avoid the considerably greater cost of post-construction mitigation. Although geological reasons could be found to explain elevated indoor radon levels, there was some doubt that geological and soil characteristics of areas, particularly of building-lot size, could be used to predict the approximate levels of indoor radon [Sachs et al, 1982].

The early investigations established that very high indoor radon levels are almost always caused by a combination of elevated radon concentrations in the interstitial gases in the soil, sufficient permeability of soil to permit easy movement of those soil gases to a house foundation, and cracks or other openings in the foundation to allow pressure-driven flow of the soil gases into the house [Nero and Nazaroff, 1984]. Later studies have indicated that molecular diffusion of radon through the soil pores [Tanner, 1991c] or through some concretes [Holub et al., 1985; Arvela and Winqvist, 1989; Borak et al, 1992; Rogers and Nielson, 1992] is sometimes sufficient to cause moderately elevated indoor radon concentrations.

In order to assess the radon source potential of a site or area of any size, one should evaluate the concentration and diffusivity of radon in the soil pores, and the permeability of the soil to gas flow. Some methods further attempt to evaluate the resistance of specific structures to radon entry and/or the efficiency of radon removal by ventilation, thus estimating the radon concentration to be expected in the structures. Such "predictive"

1 "Indoor radon potential" is a term commonly used to indicate the indoor radon concentration expected to be found in structures built on the characterized area using standard construction practice. The classification may be according to a "high," "normal," or "low" ranking, or may be a quantitative estimate by methods discussed in Section 4 . Because of variation in soil characteristics, in design of the structures, and in the care of construction, the radon concentrations in the actual structures are usually found to follow a log-normal probability frequency distribution approximately. 
methods have fallen generally into two categories: radon potential mapping and site-specific classification. For radon potential mapping, geological and soil characteristics of areas ranging in size from a few $\mathrm{km}^{2}$ to those comprising broad physiographic provinces (such as coastal plains or mountain ranges) are used to estimate the radon source potential of subareas, usually in three to five tiers. Site-specific classification is based on in situ measurements and/or laboratory analyses of soil samples from a site. The soil permeability and soil-gas radon concentration and diffusivity data that are needed for estimation of radon source potential are not usually available for small areas, and are very rarely available for areas of county or larger size; consequently, radon potential mapping requires the judicious selection of geological and soil characteristics that are available as data sets and that can be used as surrogates for the actual quantities needed. Site-specific methods apply to such local areas that it is practical to measure the needed quantities; the challenge then is to make measurements that accurately represent the site conditions at the time of the measurements, to devise means of correcting the results to typical conditions, and to use the results in a model that reliably assesses the radon source potential of the site. These steps need to be practical for a radon diagnostician or geotechnical engineer to accomplish quickly with equipment of moderate cost.

During the development of predictive methods since the late 1970s, hundreds of thousands of indoor radon measurements have been made in Europe, Canada, the United States, and to a lesser extent in other areas of the world. Scott [1992] contends that the existing indoor radon data are adequate to estimate radon potential, and that the cost of incorporating into new construction those elements of radon mitigation that are expensive to retrofit has been reduced to the point where site-specific methods are not cost effective. Although these contentions are valid under many and perhaps most circumstances, I believe that both radon potential mapp ng and sire-specific methods can meet needs for which existing and even future indoor radon dati. se not likely to be adequate.

This report is intended to give a survey of radon potential mapping at various map scales, to present site-specific methods in detail, to present annotated bibliographic references to the methods and closely related topics (Appendix A), and to list persons known to have participated in current or recent research in radon potential mapping, site-specific methods, instrumentation, or closely allied topics (Appendix B).

\section{RADON POTENTIAL MAPPING}

The purpose of radon potential mapping is to rank parts of a geographical area, usually the jurisdiction of a local, state, or federal government, so as to be able to make the most effective use of resources in locating buildings with elevated indoor radon and to anticipate future indoor radon problems in areas that are not currently inhabited. In Sweden, radon potential maps are used to advise builders whether radon-proof, radon-resistant, or normal construction methods should be used, corresponding to "high," "normal," or "low" ranking of the radon potential of the land. Building-code requirements for radon-resistant construction in high-radon areas have been considered in at least two of the United States. On July 1, 
1993, the State of Washington implemented prescriptive building-code requirements for radon-resistant construction for single-family dwellings and the first-floor units of multifamily dwellings, and special requirements for new construction in eight counties rated as high radon potential counties [Coleman, 1993]. The State of Florida has a program of research into mitigation methods, construction standards, and radon potential assessment methods [Sanchez et al, 1991].

\subsection{Map Scales}

The scale of a map is the ratio of the distance between two points on the map to the distance on the Earth between the two points. If the ratio is very small, the distance on the map is very small, and the map is said to be of "small scale," and conversely. Thus, a map of the nation will necessarily be a small-scale map, and a map of a neighborhood will probably be at fairly large scale. It should be obvious that a small-scale map cannot present house-to-house, neighborhood-to-neighborhood, or county-to-county variations in average radon potential, yet many people try to estimate whether they are in a radon-prone area on the basis of a national map. In fact, few areas of the United States are of such uniformly low or high radon potential as to justify using a map of small scale for such purposes. Washington [1988] found that uranium deposits in metamorphic rocks in southern Vermont were so localized that surveys employing sampling on a statistically based grid generally failed to find them.

The map scale determines what data bases will be available to compile a radon potential map, and consequently which surrogate characteristics to choose for the soil characteristics that are actually needed [Owen, 1989]. Table I lists the desired and surrogate characteristics that may be practical at several map scales.

\subsection{Radium and Radon Data}

At the smaller map scales, the primary source of information about the radium concentration in the topmost 20 to $30 \mathrm{~cm}$ of soil is the group of surveys made by means of $\gamma$-ray spectrometers flown at a nominal height of $122 \mathrm{~m}$ during the National Aerial Radiometric Reconnaissance part of the Energy Research and Development Administration/Department of Energy National Uranium Resource Evaluation (NURE) Program of the late 1970s and early 1980s. One form of data representation is a map shaded by dots proportional in radius to the average ${ }^{214} \mathrm{Bi}$ activity of $20 \mathrm{~km} \times 20 \mathrm{~km}$ areas [Revzan et al. 1988; Nazaroff et al, 1988; Nazaroff, 1992]. After considerable reprocessing to reconcile discrepancies, the data have been compiled by Duval et al. [1989] as colored maps showing near-surface equivalent uranium concentration in color-coded increments of 0.5 parts per million; the national map has been released in the form of a photographic slide. Although the NURE program covered nearly all the contiguous United States and half of Alaska, the flight line spacing was generally 5 to $10 \mathrm{~km}$, yielding information about less than 10 and 5 percent, respectively, of the ground. Because of this limited coverage, areas as large as $8 \mathrm{~km}$ in diameter may be completely unevaluated, and use of the aerial 
data for radon potential mapping at typical eastern county and neighborhood scales is not justified. In some areas where the flights were made at flight-line spacing of less than $2 \mathrm{~km}$, the data can be useful at county scales.

Aeroradiometric data are in some places adequate in themselves as a basis for radon potential mapping. For instance, Kline $e t$ al. [1988] stated that spectral $\gamma$-ray aerial surveys of Fairfax County, Virginia, and Montgomery County, Maryland were better correlated with indoor radon than were radon potential maps based on geology and soil characteristics. It is plausible that aeroradiometric surveys are sufficient for ranking radon potential where other factors are fairly uniform. In general, however, substantial variation of critical factors such as permeability, degree of soil saturation, depth of snow cover, topographic relief, or strong biological activity may interfere with good correlation between $\gamma$-ray flux density from the ground surface and radon source potential. In the Pacific Northwest, Duval and Otton [1990] found that townships having predominantly gravelly or coarse-grained soils had a significantly higher frequency of houses containing elevated radon than other townships showing similar ${ }^{214} \mathrm{Bi} \gamma$-radiation intensities to the airborne spectrometer. Biological activity can generate organic compounds that create very unequal radium distribution among the several soil layers [Greeman et al., 1990], so that the surface $\gamma$ radiation may not be a satisfactory indicator of the radium activity at basement slab depth, where most of the indoor radon source radium is located.

In those areas where the soil is so thin that buildings rest on or within less than a meter of bedrock, or where the soil is developed from bedrock, the conventional geologic maps can be used as indicators of radium concentration. In many areas, notably those of glacial till and flood or coastal plains, the bedrock may be unrelated to the soil above, and invalid for evaluating radium concentration; see Fakundiny et al. [1988], Gates et al. [1992], and Gundersen [1993].

In the smaller counties, it may be practicable to survey $\gamma$ radiation by means of carborne spectrometers. Soil samples may be obtained and analyzed for radium; some of the samples should $a^{1}{ }^{1} 0$ tested to determine the typical emanation coefficient of the soils (the fractional release : adon to the soil pores). A more direct approach is to measure the radon content of soil as along traverses across the major soil units of the county by means of reconnaissance methods [Reimer, 1990, 1991].

At the neighborhood scale, direct measurement of radon in soil gas, either to establish characteristic values for the local soil units or to survey the area in a systematic grid, appears to be the most accurate method. By the reconnaissance technique, a combined sampling and analytical cost in time of about a quarter-hour is much less than that of soil sampling, transportation, and laboratory analysis by $\gamma$-ray spectrometry and suitable occasional measurements of emanation coefficient. Gamma-ray spectrometry in boreholes, although seldom used, is faster, but does not discriminate between mobile and fixed ${ }^{222} \mathrm{Rn}$. Surveys by hand-held $\gamma$-ray survey meters can help to lay out the survey pattern for sampling, but are much less accurate than information derived from boreholes, especially 
if most structures will have basements and if the soil has been transported from its original source.

\subsection{Permeability Data}

In order for soil or rock permeability to be significant in the transport of radon to building foundations, the soil or rock must be well drained, a condition that is common but not universal. It is therefore necessary to consider not only whether a soil type (at any scale) comprises coarse and medium grains, without substantial silt and clay, but also whether the terrain is well drained over the area of consideration. At small and medium map scales, soil maps often describe the drainage characteristics of soil units; those characterized as "well drained" or "excessively drained" generally meet both requirements. Nielson and Rogers [1992] have provided typical diffusion and permeability coefficients as functions of soil textural class and typical matric (capillary) potential, which can be used in conjunction with soil maps to estimate these critical variables in the absence of specific data for an area of interest.

At medium scale, soil and engineering geology maps may carry both drainage and permeability information, and may show soils that are seasonally permeable because of shrinkage of certain clayey soils-otherwise impermeable-during dry periods. Compilations of water percolation tests may be available. In connection with hydrologic maps showing the depth to the water table, and topographic maps showing slopes from which runoff, drainage, and proportions of fines may be inferred, they provide a basis for estimating the areas of significant permeability. Also important are areas of permeability inversion, where a less permeable B soil horizon ${ }^{2}$ overlies a significantly permeable and generally welldrained $\mathrm{C}$ horizon at the level of the slabs of buildings with basements. Under such conditions, "earth breathing," caused by the rise and fall of barometric pressure, can route soil-air flow more easily through boreholes or wells than through the B horizon [Thomas et al., 1992].

In addition to the data above, water-well logs, road cuts, and trenches are useful at a local scale. Soil-probe permeability measurements and permeability estimates based on grain-size distribution, described later with site-specific methods, also become practicable.

${ }^{2}$ Soil is typically layered. A topsoil layer containing the most organic matter is often present and is designated the "A horizon"; it is usually fairly permeable. The next layer, the "B horizon," contains the greatest proportion of clay minerals and is relatively impermeable. The " $\mathrm{C}$ horizon" below it it a transition zone between the soil and the underlying bedrock and may contain rock fragments; it is usually significantly more permeable than the B horizon. Soil scientists recognize several subdivisions of these horizons. The A horizon is not always developed and is sometimes missing because of erosion. 


\subsection{Radon Diffusivity Data}

Radon diffusivity data are not mapped at any scale, and are not practical to measure in situ. However, radon diffusion in soils can be adequately characterized on the basis of the fractional water saturation of the soil and its porosity [Rogers et al., 1984; Rogers and Nielson, 1991]. In comparison with the ranges of the other variables in the determination of radon source potential, soil porosity is not highly variable. The radon diffusion length in a dry soil is reduced by about two orders of magnitude when the soil is nearly saturated with water. The problem is then one of assessing the typical degree of saturation of soils, which depends on climate, drainage, an the inherent water retentivity of the various soil types. Although grain and pore size are very important with respect to soil permeability and not important with respect to radon diffusivity, the same considerations noted above concerning drainage are of use in estimating both permeability and radon diffusivity.

At small scale, the national maps of climate, and national, regional, and state maps of soils can be used to estimate precipitation and its retention by fine and clayey soils. At county scale, more specific precipitation data and soil and engineering geology maps may be available. In adition to these data, results of nearby site investigations may be available for neighborhcud radon potential mapping.

\subsection{Indoor Radon Data}

Whether or not indoor radon data are available in sufficient density to eliminate the apparent need for radon potential mapping, they are useful in providing a "calibration" of the assessments of particular soil units, and in calling attention to some characteristics of soil units that may not have been mapped. Conversely, within areas of no radon problems found by indoor radon testing, radon potential mapping may find local subareas of distinctly different characteristics and possibly much greater indoor radon potential.

At small scale, the very large data base of indoor radon measurements, although subject to bias because of non-random motivations for the tests, provides a general picture of the susceptiti.ity of different subareas to indoor radon problems, and a calibration of radon potential mapping of physiographic provinces and major soil units. The data furnished by commercial testing services are usually linked to postal zone codes, which may cover several disparate radon potential units and give increasingly misleading comparisons at progressively larger map scales. Some states and counties have indoor data that are located with sufficient accuracy to permit correlation with specific soil units or geologic features such as shear or fracture zones.

The U.S. Environmental Protection Agency conducted a cooperative program with many of the states to make indoor measurements designed in part to test the principles of radon potential mapping. As a result, U.S.E.P.A.-sponsored radon potential mapping has been accomplished by the U.S. Geological Survey and the state geological agencies for nearly all the United States [Schumann, 1993a-k, 1994]. 
Table I: DESIRED AND SURROGATE CHARACTERISTICS FOR RADON POTENTIAL MAPPING AT SEVERAL MAP SCALES

\begin{tabular}{|c|c|c|}
\hline Desired Characteristic & Map Scale & Surrogate Characteristic \\
\hline \multirow[t]{3}{*}{$\begin{array}{l}\text { Radon concentration } \\
\text { in soil gas }\end{array}$} & $\begin{array}{l}\text { Small (state } \\
\text { or nation) }\end{array}$ & $\begin{array}{l}\text { Near-surface radium concentration by aerial survey of }{ }^{214} \mathrm{Bi} \\
\gamma \text { rays } \\
\text { Typical radium concentration of rock type indicated by } \\
\text { geologic map if soil is absent or derived from substrate }\end{array}$ \\
\hline & $\begin{array}{l}\text { Medium } \\
\text { (county) }\end{array}$ & $\begin{array}{l}\text { Same as above } \\
\text { Near-surface radium concentration by carborne survey of }{ }^{214} \mathrm{Bi} \\
\gamma \text { rays } \\
\text { Radium content of soil samples } \\
\text { Radon content of soil gas obtained by reconnaissance } \\
\text { technique }\end{array}$ \\
\hline & $\begin{array}{l}\text { Large } \\
\text { (neighbor- } \\
\text { hood) }\end{array}$ & $\begin{array}{l}\text { Radon content of soil gas } \\
\text { Radium content of soil samples, corrected for emanation } \\
\text { coefficient } \\
\text { Ground-based surveys of }{ }^{214} \mathrm{Bi} \text { gamma radiation } \\
\text { Typical radium concentration of rock type indicated by } \\
\text { geologic map if soil is absent or derived from substrate }\end{array}$ \\
\hline \multirow[t]{2}{*}{$\begin{array}{l}\text { Significantly high soil } \\
\text { permeability }\end{array}$} & $\begin{array}{l}\text { Small (state } \\
\text { or nation) }\end{array}$ & $\begin{array}{l}\text { Soil types characterized as well or excessively drained on soil } \\
\text { maps } \\
\text { Extensive areas of gravels, coarse or medium sands, or deep } \\
\text { saprolites indicated on soil maps }\end{array}$ \\
\hline & $\begin{array}{l}\text { Medium } \\
\text { (county) }\end{array}$ & $\begin{array}{l}\text { Same as above } \\
\text { Engineering geology maps giving soil drainage, permeability } \\
\text { information, depth to bedrock, and susceptibility to soil } \\
\text { expansion and shrinkage } \\
\text { Soil maps giving drainage and permeability data for soil units } \\
\text { Percolation test results } \\
\text { Hydrologic maps showing depth to water table } \\
\text { Topographic maps showing slopes }\end{array}$ \\
\hline
\end{tabular}




\begin{tabular}{|c|c|c|}
\hline Desired Characteristic & Map Scale & Surrogate Characteristic \\
\hline $\begin{array}{l}\text { Significantly high soil } \\
\text { permeability } \\
\text { (continued) }\end{array}$ & $\begin{array}{l}\text { Large } \\
\text { (neighbor- } \\
\text { hood }\end{array}$ & $\begin{array}{l}\text { Same as above } \\
\text { Water well logs } \\
\text { Soil-probe data } \\
\text { Geologic maps showing shear zones, fracture zones, and } \\
\text { medium-to-coarse glacial and alluvial deposits }\end{array}$ \\
\hline \multirow[t]{3}{*}{$\begin{array}{l}\text { Radon diffusivity in } \\
\text { soil and rock }\end{array}$} & $\begin{array}{l}\text { Small (state } \\
\text { or nation) }\end{array}$ & $\begin{array}{l}\text { Climatic maps showing degree of aridity (as an index of soil } \\
\text { moisture) } \\
\text { Soil maps (as an index of water-retentive clays) }\end{array}$ \\
\hline & $\begin{array}{l}\text { Medium } \\
\text { (county) }\end{array}$ & $\begin{array}{l}\text { Soil maps (as an index of water-retentive clays) } \\
\text { Engineering geology maps showing drainage and depth to } \\
\text { water table } \\
\text { Precipitation data }\end{array}$ \\
\hline & $\begin{array}{l}\text { Large } \\
\text { (neighbor- } \\
\text { hood) }\end{array}$ & $\begin{array}{l}\text { Same as above } \\
\text { Geologic maps showing shear zones, fracture zones, and } \\
\text { medium-to-coarse glacial and alluvial deposits } \\
\text { Results of nearby site investigations (water retention, fracture } \\
\text { systems, permeability inversions) }\end{array}$ \\
\hline \multirow[t]{3}{*}{ Indoor radon data } & $\begin{array}{l}\text { Small (state } \\
\text { or nation) }\end{array}$ & $\begin{array}{l}\text { Commercial contractor zip-coded data } \\
\text { State radon data bases } \\
\text { U.S. E.P.A. data }\end{array}$ \\
\hline & $\begin{array}{l}\text { Medium } \\
\text { (county) }\end{array}$ & County radon records \\
\hline & $\begin{array}{l}\text { Large } \\
\text { (neighbor- } \\
\text { hood) }\end{array}$ & $\begin{array}{l}\text { Same as above } \\
\text { Local contractor knowledge } \\
\text { News stories }\end{array}$ \\
\hline
\end{tabular}


Since the late 1970 s, numerous efforts at radon potential mapping have been made, some of which permit comparison of indoor radon measurements with soil characteristics and other geologic features. The scope, intentions, and subjects of these investigations have been quite varied. Table II provides a listing of references to these investigations and some indication of their scope. The column for "Indoor Data?" indicates whether results of indoor radon testing are included in the study; a double query indicates that indoor data may have been used, but are not cited. For further detail, see the references in Appendix A.

The correlation studies have generally shown satisfactory correlation between geology and indoor radon. Nearly all indoor radon surveys have yielded approximately log-normal probability frequency distributions. There is consequently much overlap of indoor radon values among subareas of different radon potential, as demonstrated by the frequency distributions for each of the five tiers classified by Otton et al. [1988b] for Fairfax County, Virginia. Although each subarea included most of the range of indoor radon values, the lognormal parameters of geometric mean (median) and geometric standard deviation for each of the classified areas were different.

\section{TABLE II: RADON POTENTIAL MAPPING AND CORRELATION EFFORTS}

\begin{tabular}{l|l|l}
\hline \hline Reference & Type of Study; Area & $\begin{array}{l}\text { Indoor } \\
\text { Data? }\end{array}$ \\
\hline $\begin{array}{l}\text { Agard and Gundersen, 1991 } \\
\text { Åkerblom, } 1986 \text { and 1987 }\end{array}$ & $\begin{array}{l}\text { Correlation; Boyertown and Easton, Pa. } \\
\text { Alkerblom, Andersson, and Clavensjö, 1984 }\end{array}$ & Yes \\
Åkerblom and Wilson, 1981 & Correlation; several localities near Stockholm & Yes \\
Barnet, ed., 1991 & Mapping; Sweden & No \\
Been, Reimer, and Szarzi, 1989 & Mapping and correlation; Czech Republic & Yes \\
Been, Szarzi, and Reimer, 1989 & Mapping; Prince Georges Co., Md. & Yes \\
Brookins, 1986 & Mapping; Frederick Co., Md. & No \\
Brooks, 1989 & Correlation; Albuquerque, N.M., and vicinity & Yes \\
Buchli and Burkart, 1989 & Correlation; Maryland & Yes \\
Burnett et al., 1989 & Correlation; Switzerland & Yes \\
Carlisle and Azzouz, 1991, 1993 & Correlation; Florida & Yes \\
Castrén, 1990 & Correlation; southern California & Yes \\
Castrén et al., 1985 & Correlation; Finland & Yes \\
\end{tabular}




\begin{tabular}{|c|c|c|}
\hline Reference & Type of Study; Area & $\begin{array}{l}\text { Indoor } \\
\text { Data? }\end{array}$ \\
\hline Castrén et al., 1987 & Correlation; Finland & Yes \\
\hline Castrén et al., 1991 & Mapping; Finland & Yes \\
\hline Cattafe et al., 1989 & Mapping and correlation; New Jersey & Yes \\
\hline Chadima, 1989 & Mapping; South Dakota & No \\
\hline Clavensjö et al., 1983 & Research and correlation; Sweden & Yes \\
\hline Cui, 1990 & Mapping; Salt Lake City area, Utah & No \\
\hline Czarwinski et al., 1993 & Correlation, mapping; southeastern Germany & Yes \\
\hline Damkjær and Korsbech, 1988 & Correlation; Denmark & Yes \\
\hline Dron, 1993 & Correlation in elevated areas; Great Britain & Yes \\
\hline Dulaney, 1992 & Mapping and correlation; New Mexico & Yes \\
\hline Duval, 1989 & Mapping; United States & Yes \\
\hline Duval, 1991 & Correlation; New Jersey & Yes \\
\hline Duval and Jones, 1988 & Mapping; Midwest & No \\
\hline Duval, Jones, Otton, 1989 & Mapping; Pacific Northwest & Yes \\
\hline Duval, Jones, Riggle, Pitkin, 1989 & Mapping; United States & No \\
\hline Duval and Otton, 1990 & Mapping and correlation; Pacific Northwest & Yes \\
\hline Fakundiny et al., 1988 & Mapping; New York State & Yes \\
\hline Fisher, 1978 & Mapping; Florida & Yes \\
\hline Fitzpatrick-Lins et al., 1990 & Mapping; United States & Yes \\
\hline Flood et al., 1990 & Mapping; Oklahoma & No?? \\
\hline Friedmann, 1993 & Correlation and mapping; Austria & Yes \\
\hline Frishman et al., 1993 & Mapping (Rn-in-water potential); Colorado & Yes \\
\hline Frohlich and Pearson, 1988 & Mapping; Rhode Island & No \\
\hline Goodknight and Peake, 1988 & Mapping; southeastern United States & Yes \\
\hline Grace, 1989 & Correlation; southern Michigan & Yes \\
\hline Grasty, 1989 & Correlation; Canada & Yes \\
\hline Grodzins et al., 1991 & Correlation; Maine & Yes \\
\hline Gross and Sachs, 1982 & Correlation; Pennsylvania & Yes \\
\hline Gundersen, 1989 & Correlation; United States & Yes \\
\hline Gundersen, 1991 & Correlation; Pa., Va., Md., N.J. & Yes \\
\hline
\end{tabular}




\begin{tabular}{|c|c|c|}
\hline Reference & Type of Study; Area & $\begin{array}{l}\text { Indoor } \\
\text { Data? }\end{array}$ \\
\hline Gundersen, 1993 & Correlation; eastern United States & Yes \\
\hline Gundersen, Peake et al., 1991 & Correlation; Tex, Ala., N.J. Coastal Plain & Yes \\
\hline Gundersen, Reimer, and Agard, 1988 & Correlation; Pennsylvania & Yes \\
\hline Gundersen, Reimer et al., 1988 & Mapping; Montgomery Co., Maryland & Yes \\
\hline Gundersen, Schumann et al., 1991 & Mapping; United States & Yes \\
\hline Hand, 1988 & Correlation; Onondaga Co., N.Y. & Yes \\
\hline Haque and Halls, 1993 & Correlation; Great Britain & Yes \\
\hline Harrell and Kumar, 1988 & Correlation; northeastern Ohio & Yes \\
\hline Hawthorne et al., 1984 & Correlation; eastern Tennessee & Yes \\
\hline Jacobs et al., 1993 & Correlation; southeastern Wisconsin & No \\
\hline Keller and Schütz, 1988 & Correlation; southwestern Germany & Yes \\
\hline Kline et al., 1988 & Correlation; Va. and Md. & Yes \\
\hline Kothari, 1983 & Correlation; United States & Yes \\
\hline Kullman, 1993 & Correlation and mapping; Sweden & Yes \\
\hline Laymon and Kunz, 1991 & Correlation; Onondaga Co., N.Y. & Yes \\
\hline Laymon et al., 1990 & Correlation; New York & Yes \\
\hline Lehtoviita et al., 1985 & Correlation; Finland & Yes \\
\hline Lilley et al., 1988 & Correlation; New York & Yes?? \\
\hline Lively and Steck, 1991 & Correlation; Minnesota & Yes \\
\hline Lloyd, 1983 & Correlation; Butte, Montana & Yes \\
\hline Lombardi and Etiope, 1993 & Correlation; Italy & No?? \\
\hline Matz, 1993 & Correlation; Albuquerque, New Mexico & Yes \\
\hline McFarland, 1991 & Correlation; Kentucky & Yes \\
\hline McLaughlin, 1987 & Correlation; Ireland & Yes \\
\hline McLemore and Hawley, 1988 & Mapping; New Mexico & No?? \\
\hline McLemore et al., 1991 & Mapping and correlation; New Mexico & Yes \\
\hline Miles, 1993 & Correlation, general principles; Great Britain & Yes \\
\hline Moed et al., 1984 & Mapping; California and Pacific Northwest & No \\
\hline Morley et al., 1991 & Correlation; British Columbia, Canada & Yes \\
\hline Moschandreas and Rector, 1982 & Correlation; Pennsylvania & Yes \\
\hline
\end{tabular}




\begin{tabular}{|c|c|c|}
\hline Reference & Type of Study; Area & $\begin{array}{l}\text { Indoor } \\
\text { Data? }\end{array}$ \\
\hline Mose, Chrosniak, and Mushrush, 1989 & Correlation; eastern United States & Yes \\
\hline Mose, Mushrush, and Kline, 1988 & Correlation; Va. and Md. & Yes \\
\hline Mushrush and Mose, 1988 & Correlation; Metropolitan D.C. & Yes \\
\hline Nason and Cohen, 1987 & Correlation; United States & Yes \\
\hline Nazaroff et al., 1988 & Mapping; United States & No \\
\hline Nero et al., 1993 & Correlation and mapping; Minnesota & Yes \\
\hline Ogden et al., 1987 & Correlation; Idaho & Yes \\
\hline Otton, 1987 & Mapping; United States & No \\
\hline Otton, 1988 & Mapping and correlation; Fairfax Co., Va. & Yes \\
\hline Otton, $1989 \mathrm{a}, \mathrm{b}$ & Mapping; United States & No \\
\hline Otton and Asher-Bolinder, 1993 & Correlation; Fla., Guam, Caribbean & Yes \\
\hline Otton and Duval, 1991 & Mapping and correlation; Pacific Northwest & Yes \\
\hline Otton and Gundersen, 1988 & Mapping; Va. and Md. & Yes \\
\hline Otton, Schumann, Owen, Chleborad, 1988 & Mapping; Colorado & No \\
\hline $\begin{array}{l}\text { Otton, Schumann, Owen, Thurman, Duval, } \\
1988\end{array}$ & Mapping; Fairfax Co., Va. & Yes \\
\hline Owen, 1989 & Mapping; United States & No \\
\hline Padovani and Malisan, 1993 & Correlation; Italian kindergartens & Yes \\
\hline Peake, 1988a,b & Mapping; United States & No \\
\hline Peake, 1990 & Mapping; United States & No \\
\hline Peake et al., 1988 & Correlation; E. and S. U.S. Coastal Plain & Yes \\
\hline Peake and Gundersen, 1989 & Correlation; E. and S. U.S. Coastal Plain & Yes \\
\hline Peake and Rush, 1988 & Mapping; United States & No \\
\hline Peake et al., 1991 & Mapping and correlation, United States & Yes \\
\hline Peake and Schumann, 1991 & Correlation; United States & Yes \\
\hline Phillips et al., 1991 & Correlation; United States & Yes \\
\hline Podsednik, 1991 & $\begin{array}{l}\text { Mapping and correlation; McLennan Co., } \\
\text { Tex. }\end{array}$ & No \\
\hline Poffijn et al., 1993 & Correlation and mapping; Visé, Belgium & Yes \\
\hline Ranger, 1993 & Correlation; Atlanta region, Georgia & Yes \\
\hline Reesman, 1988 & Mapping; Tennessee & No \\
\hline
\end{tabular}




\begin{tabular}{|c|c|c|}
\hline Reference & Type of Study; Area & $\begin{array}{l}\text { Indoor } \\
\text { Data? }\end{array}$ \\
\hline Reimer, 1988a & Mapping and correlation; Frederick Co., Md. & Yes \\
\hline Reimer, 1988b & $\begin{array}{l}\text { Mapping and correlation; Prince George's } \\
\text { Co., Md. }\end{array}$ & Yes \\
\hline Reimer, 1990 & $\begin{array}{l}\text { Mapping and correlation; Prince George's } \\
\text { Co., Md. }\end{array}$ & Yes \\
\hline Reimer and Gundersen, 1989 & Correlation; near Boyertown, $\mathrm{Pa}$. & Yes \\
\hline Reimer et al., 1991 & $\begin{array}{l}\text { Mapping and correlation; Prince George's } \\
\text { Co., Md. }\end{array}$ & Yes \\
\hline Revzan et al., 1988 & Mapping; United States & No \\
\hline Rizzuto, 1988 & Correlation; New York & Yes \\
\hline Roserens, 1993 & Correlation; Switzerland & Yes \\
\hline Ross et al., 1993 & Correlation and mapping; Great Britain & Yes \\
\hline Sachs et al., 1982 & Correlation; $\mathrm{Pa}$. & Yes \\
\hline Samuelson et al., 1988 & Correlation; Indiana & Yes \\
\hline Schumann et al., 1989 & Correlation; near Conifer, Colorado & Yes \\
\hline Schumann et al., 1991 & Correlation; Minnesota and North Dakota & Yes \\
\hline Schumann, 1993a-j & Mapping; 50 United States & Yes \\
\hline Sextro, 1987 & Mapping; United States & No \\
\hline Sextro et al., 1987 & Mapping; United States & No \\
\hline Singler et al., 1993 & Correlation; northeastern Ohio & Yes \\
\hline Siniscalchi et al., 1991 & Correlation; Connecticut & Yes \\
\hline Smith et al., 1989 & Correlation; Ohio & Yes \\
\hline Solomon et al., 1993 & Mapping and correlation; Utah & Yes \\
\hline Speer et al., 1993 & $\begin{array}{l}\text { Correlation between heat flow and soil-gas } \\
\text { radon }\end{array}$ & No?? \\
\hline Sprinkel, 1988 & Mapping; Utah & No?? \\
\hline Steck, 1988 & Correlation; S.W. Canadian Shield & Yes \\
\hline Surbeck and Piller, 1989 & Correlation; Switzerland & Yes \\
\hline Surbeck et al., 1991 & Correlation; Switzerland & Yes \\
\hline Swedish Radon Commission, 1983 & Correlation; Sweden & Yes \\
\hline Szarzi et al., 1990 & Mapping; Frederick Co., Maryland & No \\
\hline Tanner, 1986 & Correlation; general principles & No \\
\hline
\end{tabular}




\begin{tabular}{|c|c|c|}
\hline Reference & Type of Study; Area & $\begin{array}{l}\text { Indoor } \\
\text { Data? }\end{array}$ \\
\hline Terry and Shumeyko, 1988 & Correlation; Bergen Co., N.J. & Yes \\
\hline Thomas and Hollis, 1988 & Correlation; Connecticut & Yes \\
\hline Ulbak et al., 1988 & Correlation; Denmark & Yes \\
\hline van Assendelft and Sachs, 1982 & Correlation; Pennsylvania & Yes \\
\hline van den Boom and Ort, 1991 & Mapping; Thuringia, Germany & No \\
\hline Verger et al., 1993 & Correlation and mapping; France & Yes \\
\hline Voutilainen and Mäkeläinen, 1991 & Mapping and correlation; Tampere, Finland & Yes \\
\hline Vulcani and Wood, 1993 & Mapping; southern Michigan & Yes \\
\hline Wanty et al., 1990 & Mapping and correlation; United States & Yes \\
\hline Wilson, 1984 & Mapping; Sweden & No?? \\
\hline Wilson, 1985-1986 & Correlation; Sweden & Yes \\
\hline Wollenberg and Revzan, 1990 & Mapping; California & No \\
\hline Wollenberg and Smith, 1984 & Mapping; western U.S. & No \\
\hline
\end{tabular}

\section{SITE-SPECIFIC CHARACTERIZATION OF RADON SOURCE POTENTIAL}

\subsection{Methods and Instrumentation}

\subsubsection{Surrogate Methods}

In Scandinavia, the surrogate approach to radon potential mapping is also used to estimate the radon source potential at an individual building site.

Established correlations between rock/soil types and indoor concentrations of radon or radon progeny serve in Sweden to classify the site as "high-risk," "low-risk," and "normal-risk," based upon the expectation that the ${ }^{222} \mathrm{Rn}$ content of soil gas will exceed $50 \mathrm{kBq} / \mathrm{m}^{3}$ $(1351 \mathrm{pCi} / \mathrm{L})$, will not exceed $10 \mathrm{kBq} / \mathrm{m}^{3}(270 \mathrm{pCi} / \mathrm{L})$, or will fall between those limits, respectively (see several references by Åkerblom and colleagues). A similar ranking of the permeability of the soil modifies the risk category: highly permeable soil rates an increase of one step in the risk category, and a soil of low permeability, such as a clayey "moraine" (glacial till) rates a decrease of one step. Estimation of radon risk is required for new construction in Sweden, and an appropriate degree of radon resistance in the construction is advised. Åkerblom [1993] stated that in 14 years of site evaluation and radon risk mapping there had been no reports of new houses with high indoor radon levels which were the result of faulty evaluations of the radon risk. 
In Finland, radon potential mapping relies principally on a very extensive data base of indoor radon measurements, which is used to encourage local authorities to concentrate indoor air sampling in areas already known to have higher incidence of elevated indoor radon [Castrén, 1987]. Prognosis maps also consider permeability and composition of the glacial till that predominates in Finland, and the composition of bedrock [Voutilainen and Mäkeläinen, 1991]. Although the radon source potential of sites is apparently estimated from the prognosis maps, research is in progress on site characterization by means of soil sampling (see below).

In the United Kingdom, indoor survey results are used to guide further surveys, although some efforts are underway to develop radon potential mapping and site-specific techniques [Ball et al., 1991].

The State of Florida's Department of Community Affairs has for several years undertaken a substantial program of research [Sanchez et al., 1991] with the objective of classifying land as is done in Sweden, but with substantial additional measurements of soil radium or uranium concentration, soil permeability, soil radon concentration, and other factors [Nielson et al, 1991; Nielson and Rogers, 1992]. Building codes would have specific requirements for radon resistance, depending upon the high, normal, or low radon potential ranking of the land on which a building was to be constructed. It has been proposed that, as an alternative to following the appropriate building code requirement, a builder might perform a site-specific test according to a yet-unspecified protocol and be exempted from the more stringent requirements of the code if the test indicated that the radon potential of the site had been overrated.

LeGrand [1987] developed a predictive model for site-specific classification based on rock type, topographic slope and vertical emplacement of building (height of building in ground contact on one side), hydrogeologic setting and average water-table position, and water-table behavior and characteristics. Each factor is given a scale-of-ten ranking. The scores are combined by a formula and further adjusted for construction characteristics. The adjusted score is compared with a five-tiered table giving the degree of expectation that indoor radon in a building on the site will exceed the action level of $148 \mathrm{~Bq} / \mathrm{m}^{3}(4 \mathrm{pCi} / \mathrm{L})$. No field measurements are specified for the predictive model, but geologic and hydrologic data are prerequisites.

\subsubsection{Soil-Probe Methods}

Probes ("emanometers") for extracting soil gas for ${ }^{222} \mathrm{Rn}$ analysis in connection with uranium exploration date to the early 1950 s and even to the 1930s in the Soviet Union. Their use in Sweden for determining soil-gas radon concentrations is described by Hesselbom [1985] and by Åkerblom et al., [1990]. Rector [1992] reviewed soil-gas radon measurement methods. 
Lindmark and Rosén, of the Swedish Geotechnical Institute, described the use of soil probes for radon extraction and the importance of air permeability and water saturation of the soil in estimating radon potential [1985]. Permeabilities were judged by correlation with soil type.

Scott developed the first system for assessing both radon concentration and soil permeability [DSMA Atcon, Ltd., 1983], and a method for using the values obtained to yield a numerical predictive measure of indoor radon concentration at a site. Soil-gas radon production was to be determined by a gamma-ray spectrometric method appropriate to the area to be evaluated. It was assumed that the emanation coefficient is constant at about 0.35 to 0.4 for moist soils. Soil permeability was determined by injection of air through a soil probe into the ground under known conditions of pressure and flow rate. Formulation of a "Radon Index Number" (RIN) evolved to be $R I N=h E /\left(-\log _{10} K\right)$, where $h$ is the average ventilation period of a house, $E$ is the radon emanation rate in the soil, and $K$ is the reciprocal of the soil permeability [Eaton and Scott, 1984]. Units of radon activity concentration per length $(\mathrm{Bq} / \mathrm{m})$ can be inferred from their paper.

Workers at the University of California's Lawrence Berkeley Laboratory modified the Scott approach by using a single $1-\mathrm{cm}$-diameter probe, forced into a pre-drilled borehole, for both extraction of soil gas for on-line radon analysis and injection of air or suction of soil gas for permeability determination [R.G. Sextro, oral communication, 1986; Turk et al., 1987]. For a model basement house having a crack along the perimeter of the basement slab, numerical modeling and computation yielded the radon entry rate as a function of six dimensionless parameters. By converting the data for a particular site to dimensionless form, the sustainable steady-state radon entry rate can be estimated for a house at the site [Nazaroff and Sextro, 1989; Nazaroff, 1992].

On the basis of measurements made in U.S. Environmental Protection Agency programs, Peake [1988c] proposed a "radon entry efficiency" parameter (REE), equal to the percentage ratio of the indoor radon concentration to the radon concentration in soil gas. The indoor measurement was specified as being taken at the lowest level under closed-house, winter conditions, and the soil-gas sampling point was specified at $1-\mathrm{m}$ depth, $3-5 \mathrm{~m}$ from the house. For prediction, it was suggested that typical values of the REE for houses with basements would be in the range $\approx 0.3-0.7 \%$, that the REE for slab-on-grade houses would be lower, and the REE for houses with dirt floors would be higher. No formal allowance was made for soils of unusually low or high permeability, or for average soil moisture content.

Turk et al. [1990] defined a "soil gas entry potential" and a "222 $R n$ entry potential" for the purpose of computing radon entry into a structure from measurements of the pressure field in the ground outside the foundation and flow rates and pressure drops across the structure shell with test holes open and closed. The method, developed as a diagnostic procedure to guide mitigation, does not appear to be suitable for preconstruction site characterization. 
Kunz also modified the Scott approach by using the same probe for extracting soil gas for radon analysis and for determining permeability by suction instead of injection. Using primarily data obtained in high-permeability gravels near Albany, New York, Kunz formulated a radon index number ("RIN," different from that of Eaton and Scott) proportional to the radon concentration in the soil gas, the square root of the measured permeability, and a factor related to the depth to water or bedrock; the proportionality constant is empirically derived [Kunz, 1988a,b; Kunz et al., 1989a,b]. The units of this RIN can be inferred to be $\mathrm{Bq} / \mathrm{m}^{2}$.

Carlisle and Azzouz [1991, 1993] adopted the Kunz formulation of a radon index number for evaluation of soil-gas ${ }^{222} \mathrm{Rn}$ concentrations obtained from $75-\mathrm{cm}$ depth by the slim reconaissance probe of Reimer [1990], and permeability calculated from grain size distribution in a study of an area between Santa Barbara and Los Angeles, California. No moisture corrections were applied. A regression curve of indoor radon concentrations vs. soil-gas radon concentrations yielded a correlation coefficient $r=0.709$; a similar comparison of indoor radon $v$ s. RIN gave $r=0.826$.

Probe systems derived from the Kunz apparatus have been used extensively by the U.S. Environmental Protection Agency and its contractors. A commercial system is offered [Nielson et al, 1989]. In some early tests by an EPA contractor, the soil-gas radon concentrations and the measured permeabilities were used with an arbitrary standard diffusion coefficient to yield a radon availability number partly in accordance with the Tanner [1988b] protocol described below. Other data obtained with the EPA apparatus have not apparently been combined to yield a numerical evaluation, such as one of the radon index numbers, but a system of protocols for obtaining soil characteristics and computational models have been developed [see several papers by Nielson and others in Appendix A].

A probe invented by Hassler [1940] for extraction of soil gas for hydrocarbon analysis, and adapted by Tanner [1957] for uranium exploration, is the basis for a protocol developed by Tanner [1988a,b]. A hole is augered into the ground and the bottom cuttings are removed for laboratory determination of porosity and degree of water saturation, in order to evaluate radon diffusivity. The probe, fitted with two rubber packers separated a few centimeters along the its length, is inserted in the borehole and the packers are inflated. By means of independent tubes leading from the annular spaces created in the hole by the packers, suction is applied to the spaces so that no vertical flow of soil gas takes place across the horizontal plane at the level of the lower packer, which separates the spaces. Soil gas from the lower space is drawn through an alpha scintillation cell and a rotameter-type flow meter on its way to the suction pump. Separate static manometer tubes from the two spaces lead to pressure gauges for monitoring the pressures in the spaces, unaffected by pressure drops in the tubing through which the soil gas passes. As in the two procedures above, the soil permeability is calculated by assuming that soil gas flows radially toward the sampling space and that the permeability is proportional to the ratio of the flow rate to the pressure gradient across the surface of the sampling space. A "mean migration distance" is 
computed for a one-dimensional steady-state radon flux through soil having the radon diffusivity and permeability obtained by the measurements. Soil-gas flow is assumed to result from an arbitrary pressure difference of $5 \mathrm{~Pa}$, distributed over that distance which would result in no more than hundred-fold radon decay. The soil-gas radon concentration measured by the alpha scintillation cell is corrected for depletion due to exhalation to the atmosphere and is multiplied by the mean migration distance to obtain a "radon availability number" (RAN). The RAN $\left(\mathrm{Bq} / \mathrm{m}^{2}\right)$ yields the steady-state quantity of radon per unit area of soil that can be sustained external to the soil. The product of the RAN and the decay constant is the steady-state flux density, or fluence rate, across the interface between soil and atmosphere, or between soil and the disturbed zone in the vicinity of a building foundation, assuming that the radon is effectively removed from the zone. A modification to allow for a nonzero radon concentration in the disturbed zone has been given by Yokel and Tanner [1992].

Viljanen et al. [1987] and Slunga [1988] have described a method combining radon content of soil gas and soil permeability to yield a "radon activity number" that classifies a site into one of three categories, much as in the three-tiered Swedish style of radon potential mapping.

Stieff et al. [1987] devised a method of hermetically sealing and counting ${ }^{214} \mathrm{Bi} \gamma$ rays from soil cores so that the state of equilibrium among ${ }^{226} \mathrm{Ra},{ }^{222} \mathrm{Rn}$, and ${ }^{214} \mathrm{Bi}$ can be determined by counting promptly after sampling, again after secular equilibrium has been attained between ${ }^{222} \mathrm{Rn}$ and its short-lived progeny, and yet again after secular equilibrium has been attained between ${ }^{226} \mathrm{Ra}$ and ${ }^{222} \mathrm{Rn}$. The system yields information on the undepleted radon generation in the soil sample and the depletion of radon due to migration from the sample under undisturbed conditions, and could be adapted to site characterization by sampling soil near an excavation cut or test hole.

Surbeck and Piller [1989] used a probe having one inflatable packer and usually placed with the intake at a depth of $50 \mathrm{~cm}$. After extracting a soil-gas sample for ${ }^{222} \mathrm{Rn}$ analysis in a conventional scintillation cell, they injected air into the soil by reversing the pump, which resembled a bicycle pump with a heavy piston. The weight of the piston was adequate to produce a constant 4-kPa injection pressure. Their quantity for site characterization was the measured radon concentration divided by the time needed to force $1000 \mathrm{~cm}^{3}$ of air into the hole. A revised approach was reported by Surbeck et al. [1991], wherein their "radon availability" was the product of radon concentration and permeability $(\mathrm{Bq} / \mathrm{m})$.

Hall [1991a,b], using the RAN protocol, found good correspondence between the RANs measured near schoolroom walls and the indoor radon measurements in the rooms.

Lively and Steck [1991] reported a correlation study of two neighborhoods near Rochester, Minrisota, in which they made soil-probe measurements of radon in soil gas by circulating it through liquid scintillation cocktail. Other soil characteristics were measured in the laboratory: moisture content, bulk density, solid-particle density, grain-size distribution, 
mineralogy, radon emanation from bulk soil and fractions $<63 \mu \mathrm{m}$ and $64-149 \mu \mathrm{m},{ }^{210} \mathrm{Po}$, ${ }^{226} \mathrm{Ra}$, and ${ }^{232} \mathrm{Th}$. A good correlation was reported among average ${ }^{222} \mathrm{Rn}$ in soil gas, parent/daughter radionuclides, and indoor radon levels. No model for quantitative prediction was given in the report.

Using Monte Carlo methods to compute radon movement from a homogeneous soil into a house by means of diffusion through the basement slab and diffusion plus soil-gas flow through the foundation walls, Steck and Bergmann [1992] obtained a log-log plot of a "pressure" (soil-gas flow) parameter versus a "diffusion" parameter, on which are plotted the computed curves of equivalent "effective thickness" of soil from which radon can enter the model house. By evaluating the two dimensionless parameters from field or hypothetical values of the important soil characteristics and locating their common point on the plot, one can determine the corresponding effective thickness and the expected radon flux to the indoors. The pressure parameter is $\sqrt{2 k \tau \Delta P / \varepsilon \mu \pi \Gamma^{2}}$, where $k$ is the permeability, $\Delta P$ is the difference in pressure between outside and the basement, $\tau$ is the mean life of ${ }^{222} \mathrm{Rn}, \varepsilon$ is the soil porosity, $\mu$ is the viscosity of air, and $\Gamma$ is the basement depth. The diffusion parameter is $\sqrt{D \tau / \Gamma^{2}}$, where $D$ is the bulk effective diffusion coefficient. Although developed from a significantly different model by different algorithms, the "effective thickness" serves the same purpose as the "interstitial mean migration distance" of the Tanner [1988a,b, 1990] protocol.

A highly portable instrument for measuring the ${ }^{222} \mathrm{Rn}$ concentration in soil gas, the "Markus 10 ," is offered commercially. ${ }^{3}$ The instrument is designed to be driven or worked into the ground, and contains a soil-gas radon measurement device with built-in pump, timing, data reduction program, and a flow sensor that rejects the data if an adequate soil-gas flow rate cannot be achieved. The instrument does not obtain the soil's permeability, porosity, or moisture content.

For epidemiological purposes, Mäkeläinen et al. [1992] have constructed a model for sitespecific assessment of indoor radon concentrations in houses where measurements cannot be performed. The model, based on data from about 10,000 buildings, uses the linear product of factors derived from the geographical region, soil type, year of construction, and type of foundation. (See summary in Appendix A.)

Sherman [1992] described a model of air infiltration and radon entry into a house, focusing on the house's resistance to infiltration, on its ventilation, and other characteristics of the house, rather than on the site characteristics. The soil is characterized only as a homogeneous reservoir of radon of a particular interstitial concentration, and as having an inherent resistance to flow. A "radon leakage area" parameter $\left(\mathrm{m}^{2}\right)$, introduced in the

${ }^{3}$ Gammadata Mätteknik, Box 15120, S-750 15 Uppsala, Sweden. Mention of this instrument does not necessarily imply endorsement by NIST. 
report, is analogous to an established parameter, the "effective air leakage area," used to evaluate air infiltration into a structure [Turk et al., 1990]. Although dimensionally different from the interstitial mean migration distance of Tanner [1990], the radon leakage area serves a similar purpose in evaluating the ease of radon transport within the soil toward the house foundation, neglecting diffusion.

With the soil-probe techniques, the permeability is proportional to the ratio of the volumetric gas flow rate in the probe at the sampling point to the difference in pressure between the soil and the probe inlet. In some unpublished tests, I have found the ratio to be nearly independent of the pressure difference from 10 to as much as $1500 \mathrm{~Pa}$, and to be nearly as great for injection as for suction. For low pressure differences, $\sim 1 \mathrm{~Pa}$ and lower, the ratio usually decreases significantly but may instead increase. This anomalous behavior may be an artifact due to the difficulty of measuring the very small flow rates and pressure differences. For a similar test, Damkjær and Korsbech [1992] reported a permeability decrease of about $50 \%$ from a pressure difference of $1 \mathrm{~Pa}$ to $10 \mathrm{~Pa}$, an approximately constant value from 10 to $100 \mathrm{~Pa}$, and a slight rise between 100 and about $300 \mathrm{~Pa}$.

Permeability measurements made by single soil probes have assumed flow of soil gas or air to or from the probe along radii of a sphere centered at the inlet point, and have assumed that permeability is isotropic. As a development of the two-packer probe, Tanner [1991b] introduced a three-packer probe that can collect soil gas along the same spherical-radii flow lines, or can be adjusted to permit only horizontal radial flow into the collecting annulus. By use of a mathematical formula appropriate for cylindrical flow, the horizontal component of permeability can be determined [Tanner, 1991b, Appendix C]. In layered soils containing a significant fraction of platy or tabular mineral grains, the horizontal component is found to be several times greater than the result obtained by assuming isotropic flow.

Permeability determinations based on data from either a single soil probe or grain-size analysis are subject to criticism that they are representative of much smaller volumes than the volume of ground involved in a building site. In particular, they may be in error by orders of magnitude in ground that has shrinkage cracks, fractures, or clay lenses, or if they are based on data from the wrong soil horizon. Experiments are in progress at the Lawrence Berkeley Laboratory on a system to obtain permeability information on a scale of several meters [Garbesi, 1993; Garbesi et al., 1993]. A "dual-probe dynamic pressure" technique, involving transmission of $1 / 60 \mathrm{~Hz}$ sinusoidally varying air-flow pulses from one probe to a receiving probe at various distances up to several meters, yields increasing permeability with probe spacing, as calculated from a model that assumes that the ground is homogeneous and isotropic and that the $<1 \%$ deviations from atmospheric pressure can be ignored. The technique has been validated in one dimension in a soil column, and over a frequency range of $1 / 30$ to $1 / 120 \mathrm{~Hz}$. It is obvious that several determinations should be made at a particular site to result in a permeability value that can be used with confidence, but in addition, an adjustment for scale may be required. 


\subsubsection{Laboratory Methods}

In order for the soil-probe methods to define site radon potential, they must obtain values that represent the average (or perhaps a weighted average of) conditions at a site. Because of recent precipitation history, the conditions prevailing at the time of measurement may be significantly different from the average. As an alternative, Yokel [1989] proposed laboratory measurement of the properties of soil samples from the site after drying, in order to obtain reproducible "invariant" properties such as radium activity concentration, dry density, porosity, and gas permeability of the soil. Corrections to the typical conditions of the soil could then be made, for instance, by the correlations published by Rogers and Nielson [1991]. A hierarchical scheme for site-specific characterization of radon source potential by means of standard geotechnical measurements, supplemented by laboratory measurements of the "invariant properties," was reported by Yokel and Tanner [1992]. The scheme also allows alternative use of soil-probe determinations and/or evaluation according to the "RAN" protocol [Tanner, 1988a,b]. The laboratory option does not attempt to evaluate diffusion, but assigns a minimum value to permeability to take care of the diffusive component if it is dominant.

A scheme for radon classification of building sites using laboratory methods was introduced in Finland [Viljanen et al, 1987; Slunga, 1988]. The radon concentration in soil gas could either be measured directly or estimated from radium content. The soil would be classified by measurements of grain sizes, permeability, water content, porosity, and radium content, and translated into a "radon activity number," so formulated as to yield dimensionless number groups of $<1,1-2,2-3$, and $>3$, corresponding respectively to low, normal, high, and very high potential categories. I could not determine whether the classification by this method has been validated and used extensively.

\subsection{Discussion}

Swedish investigators in the early 1980 s had concluded that pressure-driven flow of soil gas was the primary radon entry mechanism in those houses having high indoor levels [Åkerblom et al., 1984]. Partly for that reason, the approaches used by Eaton and Scott [1984], by Kunz [1988], and by Nazaroff [1988] and Nazaroff and Sextro [1990] assumed that diffusion does not play a significant role in radon movement toward, or entry into, a structure. The study areas used by Kunz and by Nazaroff and Sextro in developing their methods were mainly areas of high permeability, some of the areas also of soils enriched in radium. Nazaroff and his colleagues at the Lawrence Berkeley Laboratory, in their modeling and field studies, observed that radon entry was strongly dependent on the degree of depressurization of a house at the lowest level, relative to the outside of the foundation and under-slab zone, and they observed rapid and dramatic changes in radon entry rate that were inconsistent with diffusion through concrete [Nazaroff, 1992]. Tanner [1991] cited examples of houses having moderately elevated indoor radon levels $\left(0.7-1.1 \mathrm{kBq} / \mathrm{m}^{3} ; 20-30\right.$ $\mathrm{pCi} / \mathrm{L})$ that were sited in ground having such low measured permeabilities that radon movement to the exterior of the foundation could not be accounted for by soil-gas flow, and 
that although the actual radon entry might be the result of pressure-driven flow, diffusion should be taken into account in modeling radon movement in the ground. It follows that a general protocol for site characterization should account for both advective and diffusive radon migration. In the field, however, it can usually be determined rather easily which mechanism is the dominant one at a particular point. The other mechanism can be neglected or assigned some minimum value, thus saving considerable effort.

Under some circumstances, diffusion may be important in radon entry also. Significant radon entry into a test structure having positive pressure, implying radon entry by means of diffusion, was reported by Borak et al. [1992]. Diffusion through concretes may be significantly greater than was recognized earlier. Rogers and Nielson [1992] measured radon diffusion coefficients and air permeabilities of 11 concrete samples from Florida and found that radon migration through those concretes would be diffusion dominated and capable of permitting modest radon entry from soil of elevated ${ }^{226} \mathrm{Ra}$ content; the diffusion lengths calculated from their coefficients range from $9 \mathrm{~cm}$ to $47 \mathrm{~cm}$, in comparison with $12.7 \mathrm{~cm}$ and $7.6 \mathrm{~cm}$ for diffusion through "ordinary concrete", reported by Culot et al. [1976], and $12.6 \mathrm{~cm}$ and $16.9 \mathrm{~cm}$ reported by Zapalac [1983]. Some of these diffusion lengths are greater than the typical basement slab thickness of $10 \mathrm{~cm}$ and imply that a diffusive radon stream would retain at least $1 / e=0.367$ of its interstitial radon concentration from the soil side of the slab. The radon flux density through the slab would be further reduced by a factor equal to the porosity of the concrete.

All approaches to site characterization noted have assumed steady-state conditions. Numerical modeling by Narasimhan et al. [1990] has shown that daily atmospheric pressure changes amplify the soil-gas flow into a bare-earth basement by more than an order of magnitude if the soil is of low permeability, and severalfold if the soil is of high permeability. (Specific assumptions and results are given in Appendix A.) Refinements of site characterization protocols need to consider adapting permeability and/or diffusion coefficients determined for steady-state conditions to effective values for normal barometric pumping cycles.

All in situ site characterization methods require that the measurements either be made when the soil conditions are fortuitously close to the typical conditions, or that corrections be made, primarily for the difference in soil moisture. The in situ methods have the advantages of measuring the critical variables under conditions that will in general more nearly approximate the typical conditions and require smaller corrections than those values obtained in the laboratory. They obtain permeability, in particular, from soil that is relatively undisturbed; and if the soil permeability is indicated by the field measurement to be high, the laboratory determination of diffusion coefficient is not needed, making the procedure quite expeditious. With the in situ methods, error is associated with the measurement of the actual radon concentration in the soil gas, whereas separate determinations of ${ }^{226} \mathrm{Ra}$ concentration and emanation coefficient each involve independent errors comparable to the single error of the soil-gas measurement. At present, however, the procedures are esoteric and only the probes from Rogers and Associates Engineering 
Corporation ${ }^{4}$ are commercially available (on order only). The principal in situ procedures described above have yielded more satisfactory correlation between their output numbers and actual indoor radon measurements than any other scheme, but none has been tested over a wide range of soils and conditions.

The laboratory method has the advantage of using methods that are fairly standardized, that use common and commercially available equipment, and do not require professional personnel. Procedures based entirely on laboratory measurements have yet to be validated against houses of known indoor radon concentration.

The utility of site characterization depends on the degree to which the generation and transport of radon in the soil to the building foundation is the limiting factor. Several papers by Turk and colleagues (see Appendix A) support the idea that the soil resistance is usually greater than the resistance of the structure to radon entry. It is difficult to backfill the foundation walls to as great a packing density as in the undisturbed soil, and modern building codes require a highly permeable layer under the foundation slab to break capillarity. These conditions tend to create a virtual plenum next to the below-grade walls and slab of a building foundation through which radon-bearing soil gas may move efficiently to entry points. A building that has not been thoroughly sealed below grade is likely to offer much less resistance to radon entry than the resistance of the soil to radon movement toward the exterior of the foundation. Without this enhanced permeability next to the foundation, site characterization would be so dependent on the locations of entry points as to be futile and misleading.

Retrospective site characterization, primarily for epidemiological purposes, is more problematical because buildings on the site may have been very old, constructed on compacted earth instead of coarse aggregate, and have well-settled and compacted backfill. The assumption that the resistance of the undisturbed soil is the limiting factor is quite possibly not met, and the site evaluation is apt to be in error. Use of a relatively impermeable backfill, although poor construction practice, would similarly violate the assumptions underlying site characterization.

\subsection{Cost-Benefit Considerations for Site-Specific Characterization}

Site-specific characterization of a lot for a single house is not generally cost beneficial. The cost of testing a single lot is comparable to the cost of preparing the structure for easy mitigation. Even if the site characterization were highly accurate, caprices of construction might make a building unusually leaky. Inaccuracies of indoor tests might yield a false positive result with respect to an action level. Inaccuracies are inherent in the devices used, and further error can result from atypical exposure (placement in the house, seasonal

${ }^{4}$ Rogers and Associates Engineering Corporation, P.O Box 330, Salt Lake City, Utah 84110. Mention of a specific product does not necessarily imply endorsement by NIST. 
variation, and unusual conditions during the test period). However, I envision several conditions under which site-specific characterization could prove worthwhile:

(a) The architectural design of an unusual house would be compromised by the usual means of providing a centrally located subslab vent pipe stub in the foundation or vertical piping to the roof. A site test could indicate that taking such measures would be very likely unnecessary, necessary, or that some unusual custom approach toward radonproof construction would be necessary.

(b) The owner desired a passive-vent design, which is likely to be successful if only a modest reduction of indoor radon is needed and unsuccessful if a large reduction is needed. The site test could indicate the approximate degree of reduction needed.

(c) The local building code required testing for commercial buildings, government required testing for public buildings, or public school policy required preconstruction testing.

(d) Builders of developments in areas where mapping or site-specific testing indicated low radon source potential could save enough money by neglecting radon-resistant construction on all houses to more than compensate for mitigation of a few houses that did not pass indoor radon tests after construction.

(e) A builder felt that a site had erroneously been included in a high-risk area, and site-specific characterization was needed to decide whether less radon resistance would be sufficient.

(f) Uninhabited areas presumed on the basis of geological data to have severe indoor radon potential could be tested in advance, and local authorities could be forewarned if the tests verified the geologic estimate.

\subsection{Recommendations}

Greater field validation is needed for both in situ and laboratory methods.

A recognized protocol and associated equipment for site-specific characterization of ground prior to construction should be available to meet the needs cited above.

\section{ACKNOWLEDGMENTS}

This report employed a bibliographic data base accumulated during employment with the U.S. Geological Survey, 1951-1990, and under a grant from the U.S. Department of Energy, Office of Health and Environmental Research, No. DE-FG05-90ER61089. Preparation of this report was done under NIST Order No. 43NANB116585, Task 2, and was aided by discussi with Dr. Felix Y. Yokel, the Technical Representative for NIST. 


\section{REFERENCES CITED}

Note: Abstracts or summaries for most of the references may be found in Appendix A.

Agard, Sherry S., and Linda C.S. Gundersen, 1991, The geology and geochemistry of soils in Boyertown and Easton, Pennsylvania, in Gundersen, Linda C.S., and Richard B. Wanty, eds., Field studies of radon in rocks, soils, and water: U.S. Geol. Survey Bulletin no. 1971, p. 51-63

Åkerblom, Gustav, 1986, Investigation and mapping of radon risk areas: Luleå, Sweden: Swedish Geological AB, Rept. IRAP 86036, 15 p.

Åkerblom, Gustav, 1987, Investigations and mapping of radon risk areas, in Geology for Environmental Planning, Proceedings of the International Symposium on Geological Mapping in the Service of Environmental Planning, Trondheim, 1986: Trondheim, Norwegian Geological Survey, P.O. 3006, Trondheim, Norway, p. 96-106

Åkerblom, Gustav, 1993, Ground radon-monitoring procedures in Sweden, manuscript of lecture given 12 February 1993 at the 'JAG' Discussion Meeting at "Radon Workshop-Geology, Environment, Techniques" at Royal Astronomical Society, Burlington House, London: Stockholm, Swedish Radiation Protection Institute, 14 manuscript p. +31 illustrations

Åkerblom, G., P. Andersson, and B. Clavensjö, 1984, Soil gas radon-a source for indoor radon daughters: Radiation Protection Dosimetry, 7(1-4): 49-54

Åkerblom, Gustav, Berndt Pettersson, and Bengt Rosén, 1990, Radon i bostäder. Markradon [Radon in the soil. Handbook of radon]: Stockholm, National Council for Building Research Rept. R85:1988 [Revised 1990], 160 p.

Åkerblom, G.V., and Carole Wilson, 1981, Radon gas - A radiation hazard from radioactive bedrock and building materials: Internat. Assoc. Engineering Geology Bull., 23: 51-61

Arvela, H., and K. Winqvist, 1989, A model for indoor radon variations: Environment Internat., 15: 239-246

Ball, T.K, D.G. Cameron, T.B. Colman, and P.D. Roberts, 1991, Aspects of radon potential mapping in Britain, [abs.], in International Symposium on the Natural Radiation Environment, 5th, Salzburg, Austria, 22-28 September 1991, Abstracts: Salzburg, Univ. Salzburg, Inst. for General Biology, Biochemistry and Biophysics, abs. no. 58

Barnet, I., ed., 1991 Radon investigations in Czechoslovakia II: Prague, Czech Geological Survey, 51 p.

Been, J.M., G.M. Reimer, and S.L. Szarzi, 1989, Soil-gas radon distribution in Frederick County, Maryland [abs.]:

Eos, Am. Geophys. Union Trans., 70(5): 500

Been, Josh M., S.L. Szarzi, and G.M. Reimer, 1989, Radon as a geologic mapping tool [abs.]: Geol. Soc. America, Abstracts with Programs, 21(6): A143

Brookins, Douglas G., 1986, Indoor and soil Rn measurements in the Albuquerque, New Mexico, area: Health Physics, 51(4): 529-533

Brooks, J.R., 1989, Maryland geology and indoor radon [abs.]: Eos, Am. Geophys. Union Trans., 70(15): 500

Borak, T.B., D.C. Ward, and M.S. Gadd, 1992, Characterization of ${ }^{222} \mathrm{Rn}$ entry into a basement structure surrounded by low permeability soil, in The 1992 International Symposium on Radon and Radon Reduction 
Technology, Minneapolis, Minnesota, September 22-25, 1992: U.S. Environmental Protection Agency, Preprints, v. 2 , no. VI-1, 20 p.

Buchli, R., and W. Burkart, 1989, Influence of subsoil geology and construction technique on indoor air ${ }^{222} \mathrm{Rn}$ levels in 80 houses of the central Swiss Alps: Health Physics, 56(4): 423-429

Burnett, Bill, Jim Cowart, Dave Clark, Renata van der Weijden, and Peter Cable, 1989, Radon in shallow groundwater in Florida - A possible relationship to soil flux? [abs.]: Eos, Am. Geophys. Union Trans., 70(15): 500

Carlisle, Donald, and Haydar Azzouz, 1991, Geological parameters in radon risk assessment-A case history of deliberate exploration, in The 1991 International Symposium on Radon and Radon Reduction Technology, Philadelphia, Pa., 2-5 April 1991: Preprints, v. 5, no. IX-6, 14 p.

Carlisle, Donald, and Haydar Azzouz, 1993, Discovery of radon potential in the Rincon Shale, California-a case history of deliberate exploration: Indoor Air, 3: 131-142

Castrén, O., 1987, Dealing with radon in dwellings: the Finnish experience, in Second APCA International Specialty Conference on Indoor Radon, New Jersey, April 6-10, 1987: Pittsburgh, Air Pollution Control Assoc. Spec. Pub.

Castrén, Olli, 1990, Radon in Finland: Finnish Features, November 1990, Classification 6.3.7.4., 4 p., Helsinki, Finnish Government Printing Office

Castrén, O., H. Arvela, I. Mäkeläinen, and A. Voutilainen, 1991, Indoor radon survey in Finland: Methodology and applications, [abs.], in International Symposium on the Natural Radiation Environment, 5th, Salzburg, Austria, 22-28 September 1991, Abstracts: Salzburg, Univ. Salzburg, Inst. for General Biology, Biochemistry and Biophysics, abs. no. 130

Castrén, O., I. Mäkeläinen, K. Winqvist, and A. Voutilainen, 1987, Indoor radon measurements in Finland: A status report, Chap. 8, in Hopke, Philip K., ed., Radon and Its Decay Products; Occurrence, Properties, and Health Effects: Washington, Am. Chem. Soc. Symposium Ser. 331, p. 97-103

Castrén, O., A. Voutilainen, K. Winqvist, and I. Makelainen, 1985, Studies of high indoor radon areas in Finland: The Science of the Total Environment, 45: 311-318

Cattafe, Joseph S., Colleen A. Ranney, Keith E. Miller, and Robert H. Andolsek, 1989, Regional NURE, geology and soils data as predictors for indoor radon, in Osborne, M.C., and Jed Harrison, Symposium Cochairmen, The 1988 Symposium on Radon and Radon Reduction Technology, Proc., Vol. 2, Symposium Poster Papers: Research Triangle Park, N.C., Radian Corp., U.S. Environmental Protection Agency Pub. EPA/600/9-89/006b [Springfield, Va., NTIS Order No. PB89-167498], p. 3-25--3-39.

Chadima, Sarah A., 1989, Generalized potential for radon emission based on estimated uranium content in geologic rock units, South Dakota: Vermillion, S.D., Univ. South Dakota Science Center, South Dakota Division of Geological Survey Circ. 44, 23 p.

Clavensjö, B., Åkerblom, G.V., and Andersson, P., 1983, Radon in dwellings. The effect of the ground on radon levels and gamma radiation indoors [in Swedish]: Stockholm, Statens rad for byggnadsforskning, Rept. R9: 1983, 442 p. [ISBN 91-540-3866-9] 
Coleman, K.A., 1993, Washington's radon construction standards: The building code process, in The 1993 International Radon Conference, Denver, Colo., Sept. 20-22, 1993: Denver, Colo., Am. Assoc. Radon Scientists and Technologists, Rocky Mountain Chapter, Preprints, 7 p.

Coleman, K.A., G.C. Hughes, and E.J. Scherieble, 1993, Where's the radon? The Geographic Information in Washington State [abs.], in First International Workshop on Indoor Radon Remedial Action, The Scientific Basis and Practical Applications, Rimini, Italy, 27 June-2 July 1993: Commission of the European Communities et al., Book of Abstracts, p. 75

Coleman, K.A., and E.J. Scherieble, 1993, Radon and the Geographic Information System, in The 1993 International Radon Conference, Denver, Colo., Sept. 20-22, 1993: Denver, Colo., Am. Assoc. Radon Scientists and Technologists, Rocky Mountain Chapter, Preprints, 7 p.

Cui, L.-P., 1990, Radiometric methods in regional radon hazard mapping: Nuclear Geophysics, 4(3): 353-364

Culot, Michel VJ., Hilding G. Olson, and Keith J. Schiager, 1976, Effective diffusion coefficient of radon in concrete, theory and method for field measurements: Health Physics, 30(3): 263-270

Czarwinski, R., R. Lehmann, and W. Röhnsch, 1993, Radon in Eastern German houses-Surveys and outcomes [abs.], in First International Workshop on Indoor Radon Remedial Action, The Scientific Basis and Practical Applications, Rimini, Italy, 27 June-2 July 1993: Commission of the European Communities et al., Book of Abstracts, p. 102

Damkjær, A., and U. Korsbech, 1988, A search for correlation between local geology and indoor radon concentrations: Radiation Protection Dosimetry, 24(1-4): 51-54

Damkjær, A., and U. Korsbech, 1992, A small-diameter probe for in-situ measurements of gas permeability of soils, in Janssens, A., W. Lowder, M. Olast, J. Sinnaeve, and F. Steinhäusler, eds., The Natural Radiation Environment, Proceedings of the Fifth International Symposium on the Natural Radiation Environment, Salzburg, Austria, September 22-28, 1991: Radiation Protection Dosimetry, 45(1-4), Supplement: 85-89

Dron, Elizabeth M., 1993, UK Radon Programme: Policy and progress [abs.], in First International Workshop on Indoor Radon Remedial Action, The Scientific Basis and Practical Applications, Rimini, Italy, 27 June-2 July 1993: Commission of the European Communities et al., Book of Abstracts, p. 110

DSMA Atcon, Ltd., 1983, Review of existing instrumentation and evaluation of possibilities for research and development of instrumentation to determine future levels of radon at a proposed building site: Ottawa, Atomic Energy Control Board Research Rept. INFO-0096, 74 p.

Dulaney, Richard A., 1992, Analysis of indoor radon in New Mexico using geographic information systems (GIS) [abs.], in The 1992 International Symposium on Radon and Radon Reduction Technology, Minneapolis, Minnesota, September 22-25, 1992: U.S. Environmental Protection Agency, Preprints [poster papers], v. 5, no. VIIIP-4

Duval, J.S., 1989, Indoor radon prediction using gamma-ray spectrometric data [abs.]: Eos, Am. Geophys. Union Trans., 70(15): 496

Duval, Joseph S., 1991, Use of aerial gamma-ray data to estimate relative amounts of radon in soil gas, in Gundersen. :inda C.S., and Richard B. Wanty, eds., Field studies of radon in rocks, soils, and water: U.S. Geol. Survey Bulizin no. 1971, p. 155-162 
Duval, Joseph S., and William J. Jones, 1988, Regional aerial gamma-ray maps for Illinois and parts of Wisconsin, Iowa, Michigan, Indiana, Missouri, and Kentucky, in Marikos, Mark A., and Robert H. Hansman, eds., Geologic Causes of Natural Radionuclide Anomalies, Proceedings of the GEORAD Conference, St. Louis, Mo., April 21-22, 1987: Rolla, Mo., Missouri Dept. Nat. Resources Spec. Pub. No. 4, p. 157-165.

Duval, J.S., W.J. Jones, and J.K. Otton, 1989, Radium distribution map and radon potential in northwestern United States, in Osborne, M.C., and Harrison, Jed, Symposium Cochairmen, The 1988 Symposium on Radon and Radon Reduction Technology, Proc., Vol. 2, Symposium Poster Papers: Research Triangle Park, N.C., Radian Corp., U.S. Environmental Protection Agency Pub. EPA/600/9- 89/006b [Springfield, Va., NTIS Order No. PB89-167498], p. 3-41--3-49.

Duval, Joseph S., William J. Jones, Frederick R. Riggle, and James A. Pitkin, 1989, Equivalent uranium map of conterminous United States: U.S. Geological Survey Open-file Rept. 89-478, 12 p. + two-part plate and color slide

Duval, Joseph S., and James K. Otton, 1990, Radium distribution and indoor radon in the Pacific Northwest: Geophys. Research Letters, 17(6): 801-804

Eaton, R.S., and A.G. Scott, 1984, Understanding radon transport into houses: Radiation Protection Dosimetry, 7(1-4):251-253

Fakundiny, Robert H., Philip R. Whitney, and John M. Matuszek, 1988, Inappropriateness of bedrock maps for predicting radon in soil [abs.], in Radon in the Northeast: Perspectives and Geologic Research (conference), Troy and Albany, New York, May 31-June 2, 1988: Northeastern Environmental Science, 7(1): 5

Fisher, D.R., 1978, Risk evaluation and dosimetry for indoor radon progeny on reclaimed Florida phosphate lands [Ph.D. thesis]: Gainesville, Fla., Univ. Florida: 140 p.

Fitzpatrick-Lins, Katherine, Thomas L. Johnson, and James K. Otton, 1990, Radon potential defined by exploratory data analysis and geographic information systems, in Wiltshire, D[enise] A., ed., Selected Papers in the Applied Computer Sciences 1990, Chapter E: U.S. Geological Survey Bulletin 1908, p. E1-E10.

Flood, James R., Tom B. Thomas, Neil H. Suneson, and Kenneth V. Luza, 1990, Radon potential map of Oklahoma: Oklahoma Geol. Survey Map GM-32, Scale 1:750,000

Friedmann, Harry, 1993, The Austrian Radon Project [abs.], in First International Workshop on Indoor Radon Remedial Action, The Scientific Basis and Practical Applications, Rimini, Italy, 27 June-2 July 1993: Commission of the European Communities et al., Book of Abstracts, p. 107

Frishman, David, W.C. Day, P.F. Folger, R.B. Wanty, P.H. Briggs, and Eileen Poeter, 1993, Bedrock geologic controls on radon abundance in domestic well water, Conifer, Colorado, in The 1993 International Radon Conference, Denver, Colo., Sept. 20-22, 1993: Denver, Colo., Am. Assoc. Radon Scientists and Technologists, Rocky Mountain Chapter, Preprints, p. IV 20-IV 30

Frohlich, Reinhard K., and Carl A. Pearson, 1988, Potential radon hazard in Rhode Island estimated from geophysical and geological surveys: Northeastern Environmental Scierce, 7(1): 30-34

Garbesi, Karina, 1993, Toward resolving model-measurement discrepancies of radon entry into homes [Ph.D. Thesis]: Berkeley, Calif., Univ. California, Energy and Resources Group, and Lawrence Berkeley Laboratories, Energy and Environment Div. Rept. LBL-34244, 169 p. 
Garbesi, K., R.G. Sextro, WJ. Fisk, M.P. Modera, and K.L. Revzan, 1993, Soil-gas entry into an experimental basement: Model measurement comparisons and seasonal effects: Environmental Science and Technology, 27(3): 466-473

Gates, Alexander E., Lawrence Malizzi, and John Driscoll III, 1992, Soil radon distribution in glaciated areas: An example from the New Jersey Highlands, in Gates, Alexander E., and Linda C.S. Gundersen, eds., Geologic Controls on Radon: Boulder, Colo., Geological Soc. America Special Paper 271, p. $45-52$

Goodknight, Craig S., and R. Thomas Peake, 1988, Preliminary estimation of high radon potential areas in EPA Regions 3 and 4 as indicated by geologic factors [abs.]: Geol. Soc. America, Abstracts with Programs, 20(7): A337

Grace, John D., 1989, Radon anomalies in southern Michigan [abs.]: Geol. Soc. America, Abstracts with Programs, 21(6): A144

Grasty, R.L., 1989, The relationship of geology and gamma-ray spectrometry to radon in homes [abs.]: Eos, Am. Geophys. Union Trans., 70(15): 496

Greeman, Daniel J., and Arthur W. Rose, 1991, Geochemical controls on radon emanation in soils; importance of "organic: radium [abs.]: Geol. Soc. America, Abstracts with Programs, 23: A202

Greeman, Daniel J., Arthur W. Rose, and William A. Jester, 1990, Geochemical dynamics of radon precursors in eastern U.S. soils [abs.]: Geol. Soc. America, Abstracts with Programs, 22(7): A247-A248

Grodzins, L., T. Bradstreet, and E. Moreau, 1991, The State of Maine schools radon project, in The 1991 International Symposium on Radon and Radon Reduction Technology, Philadelphia, Pa., 2-5 April 1991: Preprints, v. 3, no. VI-6, 15 p.

Gross, S., and H.M. Sachs, 1982, Regional (location) and building factors as determinants of indoor radon concentrations in eastern Pennsylvania: Princeton, NJ, Princeton Univ. Center for Energy and Environmental Studies, PU/CEES Rept. 146, 117 p.

Gundersen, Linda C.S., 1989, Predicting the occurrence of indoor radon: A geologic approach to a national problem [abs.]: Eos, Am. Geophys. Union Trans., 70(15): 280

Gundersen, Linda C.S., 1991, Radon in sheared metamorphic and igneous rocks, in Gundersen, Linda C.S., and Richard B. Wanty, eds., Field studies of radon in rocks, soils, and water: U.S. Geol. Survey Bulletin no. 1971, p. $39-50$

Gundersen, Linda C.S., 1993, The correlation between bedrock geology and indoor radon: Where it works and where it doesn't-Some examples from the eastern United States, in The 1993 International Radon Conference, Denver, Colo., Sept. 20-22, 1993: Denver, Colo., Am. Assoc. Radon Scientists and Technologists, Rocky Mountain Chapter, Preprints, p. IV 1-IV 8

Gundersen, Linda C.S., R. Thomas Peake, Gary D. Latzke, Lisa M. Hauser, and Calvin R. Wiggs, 1991, A statistical summary of uranium and radon in soils from the Coastal Plain of Texas, Alabama, and New Jersey, in The 1990 International Symposium on Radon and Radon Reduction Technology, Atlanta, Ga., 19-23 February 1990: Research Triangle Park, N.C., U.S. Environmental Protection Agency Rept. EPA600/9-91-026c, Proceedings, Vol. 3: Symposium Poster Papers, Paper No. C-IV-4, p. 6-35-6-47 [NTIS Order No. PB91234468/AS] 
Gundersen, L.C.S., G.M. Reimer, and S.S. Agard, 1988, Correlation between geology, radon in soil gas, and indoor radon in the Reading Prong, in Marikos, Mark A., and Robert H. Hansman, eds., Geologic Causes of Natural Radionuclide Anomalies, Proceedings of the GEORAD Conference, St. Louis, Mo., April 21-22, 1987: Rolla, Mo., Missouri Dept. Nat. Resources, Div. Geology and Land Survey Spec. Pub. No. 4, p. 91-102

Gundersen, L.C.S., Reimer, G.M., Wiggs, C.R., and Rice, C.A., 1988, Map showing radon potential of rocks and soils in Montgomery County, Maryland: U.S. Geol. Survey Misc. Field Studies Map MF-2043.

Gundersen, Linda C.S., R. Randall Schumann, James K. Otton, Russel F. Dubiel, Douglass E. Owen, Kendell A. Dickinson, R. Thomas Peake, and Sharon J. Wirth, 1991, Preliminary radon potential map of the United States, in The 1991 International Symposium on Radon and Radon Reduction Technology, Philadelphia, Pa., 2-5 April 1991: Preprints, no. IX-4, 23 p.

Hall, Stephen T., 1991a, Combining mitigation \& geology: Indoor radon reduction by accessing the source, in The 1991 International Symposium on Radon and Radon Reduction Technology, Philadelphia, Pa., 2-5 April 1991: Preprints, v. 5, no. IX-1, 10 p.

Hall, Stephen T., 1991b, Correlation of soil radon availability number with indoor radon and geology in Virginia and Maryland, in The 1991 International Symposium on Radon and Radon Reduction Technology, Philadelphia, Pa., 2-5 April 1991: Preprints, v. 4, no. VIIIP-3, 9 p.

Hand, Bryce M., 1988, Geologic factors affecting indoor radon in Onondaga County, N.Y. [abs.], in Radon in the Northeast: Perspectives and Geologic Research (conference), Troy and Albany, New York, May 31-June 2, 1988: Northeastern Environmental Science, 7(1): 6

Haque, A.K.M.M., and C. Halls, 1993, Radon migration related to structure and plutonism in high heat production province [abs.], in First International Workshop on Indoor Radon Remedial Action, The Scientific Basis and Practical Applications, Rimini, Italy, 27 June-2 July 1993: Commission of the European Communities et al., Book of Abstracts, p. 76

Harrell, James A., and Ashok Kumar, 1988, Radon hazards associated with outcrops of the Devonian Ohio shale. Final report for a grant awarded by the Ohio Air Quality Development Authority: Toledo, Ohio, Univ. Toledo, $163 \mathrm{p}$.

Hassler, Gerald L., 1940, Soil gas sampling device and method: U.S. Patent no. 2,210,546, Aug. 6, 1940, 6 p.

Hawthorne, A.R., R.B. Gammage, and C.S. Dudney, 1984, Effects of local geology in indoor radon levels, in International Conference on Indoor Air Quality and Climate, 3d, Stockholm, August 20-24, 1984; Vol. 2;: Radon, Passive Smoking, Particulates and Housing Epidemiology, Birgitta Berglund, Thomas Lindvall, and Jan Sundell, eds.: Stockholm, Swedish Council for Building Research, Vol. 2, p. 137-142

Hes : ᄀ. Åke, 1984 [Pub. 1985], Radon in soil gas: A study of methods and instruments for determining radon cona cons in the ground: Uppsala, Sveriges geologiska undersökning, ser. C., no. 803, p. 1-58

Holub, R.F., R.F. Droullard, T.B. Borak, W.C. Inkret, J.G. Morse, and J.F. Baxter, 1985, Radon-222 and ${ }^{222}$ Rn progeny concentrations measured in an energy-efficient house equipped with a heat exchanger: Health Physics, 49(2): $377-277$

Jacot. M., M.G. Mudrey, Jr., C.V. Weiffenbach, and D.M. Mickelson, 1993, Comparison of soil profile characieristics and radon potential with soil gas radon along hillslope transects in southeastern Wisconsin [abs.], 
in The 1993 International Radon Conference, Denver, Colo., Sept. 20-22, 1993: Denver, Colo., Am. Assoc. Radon Scientists and Technologists, Rocky Mountain Chapter, Preprints, p. IV 9

Keller, G., and M. Schütz, 1988, Radon exhalation from the soil: Radiation Protection Dosimetry, 24(1/4): $43-46$

Kline, Stephen W., Douglas G. Mose, and Isidore Zietz, 1988, Use of aeroradioactivity maps in indoor radon prediction: A case study from Fairfax County, Virginia and Montgomery County, Maryland [abs.]: Geol. Soc. America, Abstracts with Programs, 20(7): A337-A338

Kothari, Brajesh K., 1983, Use of NURE data for natural radiation exposure: indoor radon and gamma-ray radiation [abs.], in Health Physics Soc. Ann. Mtg., 28th, no. P/246: Health Physics, 45(1): 254

Kullman, Frej, 1993, Radonrisk mapping-a method of predicting problem areas on geological grounds [abs.], in First International Workshop on Indoor Radon Remedial Action, The Scientific Basis and Practical Applications, Rimini, Italy, 27 June-2 July 1993: Commission of the European Communities et al., Book of Abstracts, p. 78

Kunz, Charles O., 1988a, Indoor radon: Source characterization: Environmental Progress, 7(4): 236-240

Kunz, C.O., 1988b, Field measurements to characterize the availability of radon in soil-gas for transport into homes [abs.], in Radon in the Northeast: Perspectives and Geologic Research (conference), Troy and Albany, New York, May 31-June 2, 1988: Northeastern Environmental Science, 7(1): 7

Kunz, C., C.A. Laymon, and C. Parker, 1989a, Empirical relationship between soil parameters and indoor radon [abs.]: Eos, Am. Geophys. Union Trans., 70(15): 497

Kunz, C., C.A. Laymon, and C. Parker, 1989b, Gravelly soils and indoor radon, in M.C. Osborne, and Jed Harrison, Symposium Cochairmen, The 1988 Symposium on Radon and Radon Reduction Technology, Proc., Vol. 1, Symposium Oral Papers: Research Triangle Park, N.C., Radian Corp., U.S. Environmental Protection Agency Pub. EPA/600/9-89/006a [Springfield, Va., NTIS Order No. PB89-167480], p. 5-75--5-86.

Laymon, Charles, and Charles Kunz, 1991, Geologic factors and house construction practices affecting indoor radon in Onondaga County, New York, in The 1990 International Symposium on Radon and Radon Reduction Technology, Atlanta, Ga., 19-23 February 1990: Research Triangle Park, N.C., U.S. Environmental Protection Agency Rept. EPA600/9-91-026b, Proceedings, Vol. 2: Symposium Oral Papers, Paper No. VI-4, p. 6-37-6-50 [NTIS Order No. PB91-234450/AS]

Laymon, Charles, Charles Kunz, and Lawrence Keefe, 1990, Indoor radon in New York State: Distribution, sources and controls: Albany, N.Y., State of New York Dept. Health Tech. Rept. [unnumbered], 49 p.

LeGrand, Harry E., 1987, A predictive model for indoor radon occurrences--A first approximation, in Graves, Barbara, ed., Radon, Radium, and Other Radioactivity in Ground Water. Hydrogeologic Impact and Application to Indoor Airborne Contamination. National Well Water Association Conference, Somerset, N.., April 7-9, 1987, Proceedings: Chelsea, Mich., Lewis Publishers, Inc., p. $477-487$

Lehtoviita, Timo, Jussi Holkko, Martti Viljanen, and Eero Slunga, 1985, Radonin merkitys talonrakennustekniikassa. Tutkimuskohteiden rakennustekninen tarkastelu [Radon in building technology. Structural comparison on the research sites]: Espoo, Finland, Helsinki Univ. Technology, Dept. Civil Engineering, Div. Structural Engineering Rept. 73, 145 p. 
Lilley, William D., Charles Kunz, and B. Kothari, 1988, Geologic factors in predicting indoor radon in New York [abs.], in Radon in the Northeast: Perspectives and Geologic Research (conference), Troy and Albany, New York, May 31-June 2, 1988: Northeastern Environmental Science, 7(1): 7

Lindmark, A., and B. Rosén, 1985, Radon in soil gas--exhalation tests and in situ measurements: The Science of the Total Environment, 45: 397-404

Lively, Richard, and Daniel Steck, 1991, A site study of soil characteristics and soil gas radon, in The 1991 International Symposium on Radon and Radon Reduction Technology, Philadelphia, Pa., 2-5 April 1991: Preprints, v. 5, no. IX-5, 15 p.

Lloyd, Larry L., 1983, Evaluation of Radon Sources and Phosphate Slag in Butte, Montana: U.S. Environmental Protection Agency Rept. EPA 520/6-83-026, 75 p.

Lombardi, S., and G. Etiope, 1993, 222-Rn soil-gas in sedimentary basin in Central Italy: its implications radioprotection zoning [abs.], in First International Workshop on Indoor Radon Remedial Action, The Scien sis Basis and Practical Applications, Rimini, Italy, 27 June-2 July 1993: Commission of the European Communities et al., Book of Abstracts, p. 70

Mäkeläinen, I., A. Voutilainen, and O. Castrén, 1992, Prediction of indoor radon concentration based on residence location and construction, in Cross, Fredrick T., ed., Indoor Radon and Lung Cancer: Reality or Myth? Twenty-ninth Hanford Symposium on Health and the Environment, Richland, Wash., October 15-19, 1990, Proceedings: Columbus, Ohio, Battelle Press, Part 1, p. 55-63 [NTIS]

Matz, Barbara, 1993, Compilation of radon levels found in Albuquerque, New Mexico, in 1992 and 1993 [abs.], in The 1993 International Radon Conference, Denver, Colo., Sept. 20-22, 1993: Denver, Colo., Am. Assoc. Radon Scientists and Technologists, Rocky Mountain Chapter, Preprints, p. IVP 1

McFarland, David, 1991, A comparison of radon results to geologic formations for the State of Kentucky [abs.], in The 1991 International Symposium on Radon and Radon Reduction Technology, Philadelphia, Pa., 2-5 April 1991: Preprints, v. 5, no. IX-2

N hlin, J[ames] P., 1987, Population doses in Ireland, Chap. 10, in Hopke, Philip K., ed., Radon and Its I. . roducts; Occurrence, Properties, and Health Effects: Washington, Am. Chem. Soc. Symposium Ser. 331, p. $113-123$

McLemore, Virginia T., and John W. Hawley, 1988, Preliminary geologic evaluation of radon availability in New Mexico: Socorro, New Mexico Bureau of Mines and Mineral Resources Open-file Rept. 345, 31 p.

McLemore, Virginia T., John W. Hawley, and Ralph A. Manchego, 1991, Geologic evaluation of radon availability in New Mexico: A progress report, in The 1991 International Symposium on Radon and Radon Reduction Technology, Philadelphia, Pa., 2-5 April 1991: Preprints, v. 5, no. IXP-1, 20 p.

Miles, J.C.H., 1993, Mapping the proportion of the housing stock exceeding a radon reference level [abs.], in First International Workshop on Indoor Radon Remedial Action, The Scientific Basis and Practical Applications, Rimini, Italy, 27 June-2 July 1993: Commission of the European Communities et al., Book of Abstracts, p. 74

Moed, B.A., W.W. Nazaroff, A.V. Nero, M.B. Schwehr, and A. Van Heuvelen, 1984, Identifying Areas with Potential for High Indoor Radon Levels: Analysis of the National Airborne Radiometric Reconnaissance data for California and the Pacific Northwest: Berkeley, CA, Univ. California Lawrence Berkeley Lab. Rept. LBL16955, 70 p. [Also published with additional pages i and ii by Bonneville Power Administration, 1985] 
Morley, D.R., M.M. Ghomshei, C. Van Netten, and B.G. Phillips, 1991, Radon studies in British Columbia, Canada, in The 1991 International Symposium on Radon and Radon Reduction Technology, Philadelphia, Pa., 2-5 April 1991: Preprints, v. 3, no. VI-5, 10 p.

Moschandreas, D.J., and H.E. Rector, 1982, Indoor radon concentrations: Environment Internat., 8(1-6): 77-82

Mose, Douglas G., Charles E. Chrosniak, and George W. Mushrush, 1989, State-size radon hazard maps based on zip-code compilations [abs.]: Geol. Soc. America, Abstracts with Programs, 21(6): A143-A144

Mose, Douglas G., George W. Mushrush, and Stephen W. Kline, 1988, The interaction of geology, weather, and home construction on indoor radon in northern Virginia and southern Maryland, in Radon in the Northeast: Perspectives and Geologic Research (conference), Troy and Albany, New York, May 31-June 2, 1988: Northeastern Environmental Science, 7(1): 15-29

Murane, David M., 1993, Model standards and techniques for control of radon in new buildings [abs.], in First International Workshop on Indoor Radon Remedial Action, The Scientific Basis and Practical Applications, Rimini, Italy, 27 June-2 July 1993: Commission of the European Communities et al., Book of Abstracts, p. 3

Mushrush, George W., and Douglas G. Mose, 1988, Regional variation of indoor radon over three seasons: Environmental Toxicology and Chemistry, 7: 879-887

Narasimhan, T.N., Y.W. Tsang, and H.Y. Holman, 1990, On the potential importance of transient air flow in advective radon entry into buildings: Geophys. Research Letters, 17(6): 821-824

Nason, Richard, and Bernard L. Cohen, 1987, Correlation between ${ }^{226} \mathrm{Ra}$ in soil, ${ }^{222} \mathrm{Rn}$ in soil gas, and ${ }^{222} \mathrm{Rn}$ inside adjacent houses: Health Physics, 52(1): 73-77

Nazaroff, William W., 1992, Radon transport from soil to air: Reviews of Geophysics, 30(2): 137-160

Nazaroff, William W., Barbara A. Moed, and Richard G. Sextro, 1988, Soil as a source of indoor radon: Generation, migration, and entry, in Nazaroff, W.W., and A.V. Nero, eds., Radon and Its Decay Products in Indoor Air: New York, John Wiley and Sons, p. 57-112

Nazaroff, William W., and Richard G. Sextro, 1989, Technique for measuring the indoor ${ }^{222}$ Rn source potential of soil: Environmental Science and Technology, 23(4): 451-458

Nero, Anthony V., Jr., 1993, Risk evaluation and control strategies for indoor radon [abs.], in First International Workshop on Indoor Radon Remedial Action, The Scientific Basis and Practical Applications, Rimini, Italy, 27 June-2 July 1993: Commission of the European Communities et al., Book of Abstracts, p. 111

Nero, A.V., S.M. Leiden, D.A. Nolan, P.R. Price, S. Rein, K.L. Revzan, H.A. Wollenberg, and A.J. Gadgil, 1993, Statistically-based methodologies for mapping of radon "actual" concentrations: The case of Minnesota [abs.], in First International Workshop on Indoor Radon Remedial Action, The Scientific Basis and Practical Applications, Rimini, Italy, 27 June-2 July 1993: Commission of the European Communities et al., Book of Abstracts, p. 77

Nero, A.V., and W.W. Nazaroff, 1984, Characterising the source of radon indoors: Radiation Protection Dosimetry, 7(1-4): 23-39; [orig. pub.: Lawrence Berkeley Laboratory Rept. LBL-16636, 1983]

Nielson, K.K., M.K. Bollenbacher, V.C. Rogers, and G. Woodruff, 1989, Users guide for the MK-II Radon/Permeability Sampler [draft]: Salt Lake City, Utah, Rogers and Associates Engineering Corp. Rept. RAE$8719 / 1-2,47$ p. 
Nielson, Kirk K., and Vern C. Rogers, 1992, Radon transport properties of soil classes for estimating indoor radon entry, in Cross, Fredrick T., ed., Indoor Radon and Lung Cancer: Reality or Myth? Twenty-ninth Hanford Symposium on Health and the Environment, Richland, Wash., October 15-19, 1990, Proceedings: Richland, Wash., Battelle Memorial Press, Part 1, p. 357-372 [NTIS]

Nielson, K.K., V.C. Rogers, R.B. Brown, W.G. Harris, and J.K. Otton, 1992, Soil radon potential mapping and validation for central Florida, in The 1992 International Symposium on Radon and Radon Reduction Technology, Minneapolis, Minnesota, September 22-25, 1992: U.S. Environmental Protection Agency, Preprints [poster papers], v. 5, no. VIIIP-2, 19 p.

Ogden, Albert E., William B. Welling, Robert D. Funderburg, and Larry C. Boschult, 1987, A preliminary assessment of factors affecting radon levels in Idaho, in Graves, Barbara, ed., Radon in Ground Water: Chelsea, Mich., Lewis Publishers, p. 83-96

Otton, James K., 1987, Potential for indoor radon hazards: A first geologic estimate, in Radon and the Environment, Conference Proceedings, Mahwah, N.J., May 8-10, 1986, Makofske, William J., and Michael R. Edelstein, eds.: Mahwah, N.J., Ramapo College of New Jersey, Inst. for Environmental Studies, p. 28-33

Otton, J.K., 1988, Radon potential of rocks and soils: a Fairfax County case history [abs.], in Proceedings of the 1988 Symposium on Radon and Radon Reduction Technology, Denver, Colorado, Oct. 19-22, 1988: U.S. Environmental Protection Agency, Washington, D.C.

Otton, J.K., 1989a, Mapping the radon potential of rocks and soils: The Professional Geologist, 26(5): 8; also Virginia Minerals, 35(1): 2-3

Otton, J.K., 1989b, Using geology to map and understand radon hazards in the United States: U.S. Geol. Survey Yearbook, Fiscal Year 1988, p. 52-54

Otton, James K., and Sigrid Asher-Bolinder, 1993, Elevated indoor radon associated with soils developed on Pleistocene limestones in tropical and subtropical latitudes, in The 1993 International Radon Conference, Denver, Colo., Sept. 20-22, 1993: Denver, Colo., Am. Assoc. Radon Scientists and Technologists, Rocky Mountain Chapter, Preprints, p. IV 32-IV 39

Otton, James K., and Joseph S. Duval, 1991, Geologic controls on indoor radon in the Pacific Northwest, in The 1990 International Symposium on Radon and Radon Reduction Technology, Atlanta, Ga., 19-23 February 1990: Research Triangle Park, N.C., U.S. Environmental Protection Agency Rept. EPA600/9-91-026b, Proceedings, Vol. 2: Symposium Oral Papers, Paper No. VI-5, p. 6-51-6-62 [NTIS Order No. PB91-234450/AS]

Otton, James K., and Linda C.S. Gundersen, 1988, Geologic assessments of radon potential at county scales [abs.], in Radon in the Northeast: Perspectives and Geologic Research (conference), Troy and Albany, New York, May 31-June 2, 1988: Northeastern Environmental Science, 7(1): 7

Otton, James K., R. Randall Schumann, Douglass E. Owen, and Alan F. Chleborad, 1988, Geological assessments of radon hazards: A Colorado case history [poster abstract], in Marikos, Mark A., and Robert H. Hansman, eds., Geologic Causes of Natural Radionuclide Anomalies, Proceedings of the GEORAD Conference, St. Louis, Mo., April 21-22, 1987: Rolla, Mo., Missouri Dept. Nat. Resources, Div. Geology and Land Survey Spec. Pub. No. 4, p. 167

Otton, J.K., R.R. Schumann, D.E. Owen, Nelson Thurman, and J.S. Duval, 1988, Map showing radon potential of rocks and soils in Fairfax County, Virginia: U.S. Geol. Survey Misc. Field Studies Map MF-2047. 
Owen, Douglass E., 1989, Characterization of radon: Constraints of scale, Sec. O, in Duray, John R., et al., eds., Proceedings of the Technical Exchange Meeting on Assessing Indoor Radon Health Risks, Grand Junction, Colo., September 18-19, 1989: Grand Junction, Colo., U.S. Dept. Energy, Grand Junction Projects Office, Tech. Measurements Center, Rept. CONF-8909190, 2 p.

Padovani, Renato, and Maria Rosa Malisan, 1993, Assessment of radon exposure in kindergartens in north-east Italy [abs.], in First International Workshop on Indoor Radon Remedial Action, The Scientific Basis and Practical Applications, Rimini, Italy, 27 June-2 July 1993: Commission of the European Communities et al., Book of Abstracts, p. 105

Peake, R. Thomas, 1988a, An update on EPA radon geology activities [abs.], in Radon in the Northeast: Perspectives and Geologic Research (conference), Troy and Albany, New York, May 31-June 2, 1988: Northeastern Environmental Science, 7(1): 8

Peake, R.T., 1988b, Radon and geology in the United States: Radiation Protection Dosimetry, 24(1/4): 173-178

Peake, R. Thomas, 1988c, Radon entry efficiency: A new look at radon entry into homes [abs.], in Radon in the Northeast: Perspectives and Geologic Research (conference), Troy and Albany, New York, May 31-June 2, 1988 : Northeastern Environmental Science, 7(1): 8

Peake, R. Thomas, 1990, Preliminary identification of high radon potential areas in twenty-five States [abs.], in The 1990 International Symposium on Radon and Radon Reduction Technology, Atlanta, Ga., 19-23 February 1990: Preprints, Vol. III, no. C-VI-1

Peake, R. Thomas, and L.C.S. Gundersen, 1989, An assessment of the radon potential of the U.S. Coastal Plain [abs.]: Geol. Soc. America, Northeastern Section, Abstracts with Programs, 21(2): 58

Peake, R. Thomas, Linda C.S. Gundersen, R. Randall Schumann, Julie James, and Melinda Ronca-Battista, 1991, Determination of radon-geologic provinces in the United States, in The 1990 International Symposium on Radon and Radon Reduction Technology, Atlanta, Ga., 19-23 February 1990: Research Triangle Park, N.C., U.S. Environmental Protection Agency Rept. EPA600/9-91-026c, Proceedings, Vol. 3: Symposium Poster Papers, Paper No. C-VI-1, p. 6-1-6-12 [NTIS Order No. PB91-234468/AS]

Peake, R.T., L.C.S. Gundersen, and C.R. Wiggs, 1988, The Coastal Plain of the eastern and southern United States--An area of low radon potential [abs.]: Geol. Soc. America, Abstracts with Programs, 20(7): A337

Peake, R. Thomas, and Susan M. Rush, 1988, An initial identification of areas with a potential for high indoor radon levels [poster abs.], in Marikos, Mark A., and Robert H. Hansman, eds., Geologic Causes of Natural Radionuclide Anomalies, Proceedings of the GEORAD Conference, St. Louis, Mo., April 21-22, 1987: Rolla, Mo., Missouri Dept. Nat. Resources, Div. Geology and Land Survey Spec. Pub. No. 4, p. 173

Peake, R. Thomas, and R. Randall Schumann, 1991, Regional radon characterizations, in Gundersen, Linda C.S., and Richard B. Wanty, eds., Field studies of radon in rocks, soils, and water: U.S. Geol. Survey Bulletin no. 1971, p. 163-175

Phillips, Jeffrey L., Jane Bergsten, and S.B. White, 1991, A cumulative examination of the State/EPA Radon Survey, in The 1991 International Symposium on Radon and Radon Reduction Technology, Philadelphia, Pa., 2-5 Apri! 1991: Preprints, unnumbered, 17 p. 
Podsednik, Mary L., 1991, Geologic assessment of radon-222 in McLennan County, Texas, in The 1991 International Symposium on Radon and Radon Reduction Technology, Philadelphia, Pa., 2-5 April 1991: Preprints, v. 5, no. IXP-4, 14 p.

Poffijn, A., G. Eggermont, S. Hallez, and P. Cohilis, 1993, Radon in Belgium: Mapping and mitigation in the affected area of Visé [abs.], in First International Workshop on Indoor Radon Remedial Action, The Scientific Basis and Practical Applications, Rimini, Italy, 27 June-2 July 1993: Commission of the European Communities et al., Book of Abstracts, p. 31

Ranger, L. Scott, 1993, Geologic control of radon in the greater Atlanta region, Georgia, in The 1993 International Radon Conference, Denver, Colo., Sept. 20-22, 1993: Denver, Colo., Am. Assoc. Radon Scientists and Technologists, Rocky Mountain Chapter, Preprints, p. IVP 2-IVP 11

Rector, Harry E., 1991, Soil gas measurement technologies, in The 1991 International Symposium on Radon and Radon Reduction Technology, Philadelphia, Pa., April 2-5, 1991, Proc., Volume 1, Symposium Oral Papers, Opening Session and Technical Sessions 1 through 5: U.S. Environmental Protection Agency Rept. EPA/600/991/037A, p. 3-13-3-28 McLean, Va., Cohen (S.) and Associates, Inc. [Springfield, Va., NTIS Order No. PB92115351]

Reesman, A.L., 1988, Geomorphic and geochemical enhancement of radon emission in middle Tennessee, in Marikos, Mark A., and Robert H. Hansman, eds., Geologic Causes of Natural Radionuclide Anomalies, Proceedings of the GEORAD Conference, St. Louis, Mo., April 21-22, 1987: Rolla, Mo., Missouri Dept. Nat. Resources, Div. Geology and Land Survey Spec. Pub. No. 4, p. 119-130

Reimer, G.M., 1988a, An integrated approach to assess potential radon content of soils using geologic, gammaray and soil-gas data [abs.]: Geol. Soc. America, Abstracts with Programs, 20(7): A354

Reimer, G.M., 1988b, Radon soil-gas survey in Prince Georges County, Maryland: U.S. Geol. Survey Open-file Rept. 88-52, 10 p.

Reimer, G.M., 1990, Reconnaissance techniques for determining soil-gas radon concentrations: An example from Prince Georges County, Maryland: Geophys. Research Letters, 17(6): 809-812

Reimer, G.M., 1991, Simple techniques for soil-gas and water sampling for radon analysis, in Gundersen, Linda C.S., and Richard B. Wanty, eds., Field studies of radon in rocks, soils, and water: U.S. Geol. Survey Bulletin no. 1971 , p. $19-22$

Reimer, G.M., 1992, Methodology for rapid assessment of the radon potential of soils: Jour. Radioanalyt. Nuclear Chemistry, Articles, 161(2): 377-387

Reimer, G.M., and L.C.S. Gundersen, 1989, A direct correlation among indoor Rn, soil gas Rn and geology in the Reading Prong near Boyertown, Pennsylvania: Health Physics, 57(1): 155-160

Reimer, G.M., Linda C.S. Gundersen, S.L. Szarzi, and J.M. Been, 1991, Reconnaissance approach to using geology and soil-gas radon concentrations for making rapid and preliminary estimates of indoor radon potential, in Gundersen, Linda C.S., and Richard B. Wanty, eds., Field studies of radon in rocks, soils, and water: U.S. Geol. Survey Bulletin no. 1971, p. 177-181

Revzan, K.L., A.V. Nero, and R.G. Sextro, 1988, Mapping surficial radium content as a partial indicator of radon concentrations in US houses: Radiation Protection Dosimetry, 24(1/4): 174-184 
Rizzuto, Joseph E., 1988, New York State Energy Research and Development Authority radon program [abs.], in Radon in the Northeast: Perspectives and Geologic Research (conference), Troy and Albany, New York, May 31-June 2, 1988: Northeastern Environmental Science, 7(1): 9

Rogers, V.C., and K.K. Nielson, 1991, Correlations for predicting air permeabilities and ${ }^{222}$ Rn diffusion coefficients of soils: Health Physics, 61(2): 225-230

Rogers, Vern C., and Kirk K. Nielson, 1992, Data and models for radon transport through concrete, in The 1992 International Symposium on Radon and Radon Reduction Technology, Minneapolis, Minnesota, September 2225, 1992: U.S. Environmental Protection Agency, Preprints, v. 2, no. VI-3, 15 p.

Rogers, V.C., K.K. Nielson, and D.R. Kalkwarf, 1984, Radon attenuation handbook for uranium mill tailings cover design: Salt Lake City, Utah, Rogers and Associates Engineering Corporation, U.S. Nuclear Regulatory Commission Rept. NUREG/CR-3533, 85 p.

Roserens, G.-A., 1993, Radon program in Switzerland-Remedial actions [abs.], in First International Workshop on Indoor Radon Remedial Action, The Scientific Basis and Practical Applications, Rimini, Italy, 27 June-2 July 1993: Commission of the European Communities et al., Book of Abstracts, p. 23

Ross, B.C., M.R. Atkinson, and D.W. Dixon, 1993, Regional variations in occupational exposure to radon and the resulting regulatory enforcement procedures [abs.], in First International Workshop on Indoor Radon Remedial Action, The Scientific Basis and Practical Applications, Rimini, Italy, 27 June-2 July 1993: Commission of the European Communities et al., Book of Abstracts, p. 103

Sachs, H.M., T.L. Hernandez, and J.W. Ring, 1982, Regional geology and radon variability in buildings: Environment Internat., 8(1-6): 97-103

Samuelson, Alan C., David Ober, Thad Godish, David Govaer, and Alice Bennett, 1988, Air and water radon investigations in east-central Indiana [abs.]: Geol. Soc. America, Abstracts with Programs, 20(7): A338

Sanchez, David C., Richard Dixon, and Ashley D. Williamson, 1991, The Florida Radon Research Program: Systematic development of a basis for statewide standards, in The 1990 International Symposium on Radon and Radon Reduction Technology, Atlanta, Ga., 19-23 February 1990: Research Triangle Park, N.C., U.S. Environmental Protection Agency Rept. EPA600/9-91-026c, Proceedings, Vol. 3: Symposium Poster Papers, Paper No. A-I-3, p. 1-21-1-37 [NTIS Order No. PB91-234468/AS]

Schumann, R. Randall, ed., 1993a, Geologic radon potential of EPA Region 1, Connecticut, Maine, Massachusetts, New Hampshire, Rhode Island, and Vermont: U.S. Geol. Survey Open-file Rept. 93-292-A, ii + 245 p.

Schumann, R. Randall, ed., 1993b, Geologic radon potential of EPA Region 2, New Jersey and New York: U.S. Geol. Survey Open-file Rept. 93-292-B, ii + 131 p.

Schumann, R. Randall, ed., 1993c, Geologic radon potential of EPA Region 3, Delaware, Maryland, Pennsylvania, Virginia, and West Virginia: U.S. Geol. Survey Open-file Rept. 93-292-C, ii + 206 p.

Schumann, R. Randall, ed., 1993d, Geologic radon potential of EPA Region 4, Alabama, Florida, Georgia, Kentucky, Mississippi, North Carolina, South Carolina, and Tennessee: U.S. Geol. Survey Open-file Rept. 93-292-D, ii + 274 p.

Schumann, R. Randall, ed., 1993e, Geologic radon potential of EPA Region 5, Illinois, Indiana, Michigan, Minnesota, Ohio, and Wisconsin: U.S. Geol. Survey Open-file Rept. 93-292-E, ii + 194 p. 
Schumann, R. Randall, ed., 1993f, Geologic radon potential of EPA Region 6, Arkansas, Louisiana, New Mexico, Oklahoma, and Texas: U.S. Geol. Survey Open-file Rept. 93-292-F, ii + 160 p.

Schumann, R. Randall, ed., 1993g, Geologic radon potential of EPA Region 7, Iowa, Kansas, Missouri, and Nebraska: U.S. Geol. Survey Open-file Rept. 93-292-G, ii + 147 p.

Schumann, R. Randall, ed., 1993h, Geologic radon potential of EPA Region 8, Colorado, Montana, North Dakota, South Dakota, Utah, and Wyoming: U.S. Geol. Survey Open-file Rept. 93-292-H, ii + 184 p.

Schumann, R. Randall, ed., 1993i, Geologic radon potential of EPA Region 9, Arizona, California, Hawaii, and Nevada: U.S. Geol. Survey Open-file Rept. 93-292-I, ii + 142 p.

Schumann, R. Randall, ed., 1993j, Geologic radon potential of EPA Region 10, Alaska, Idaho, Oregon, and Washington: U.S. Geol. Survey Open-file Rept. 93-292-J, ii + 146 p.

Schumann, R. Randall, ed., 1994, Geologic radon potential of the District of Columbia, Guam, and Puerto Rico: U.S. Geol. Survey Open-file Rept. 93-292-K (in preparation)

Schumann, R.R., L.C.S. Gundersen, S. Asher-Bolinder, and D.E. Owen, 1989, Anomalous radon levels in crystalline rocks near Conifer, Colorado [abs.]: Geol. Soc. America, Abstracts with Programs, 21(6): A144-A145

Schumann, R. Randall, R. Thomas Peake, Kevin M. Schmidt, and Douglass E. Owen, 1991, Correlations of soilgas and indoor radon with geology in glacially derived soils of the northern Great Plains, in The 1990 International Symposium on Radon and Radon Reduction Technology, Atlanta, Ga., 19-23 February 1990: Research Triangle Park, N.C., U.S. Environmental Protection Agency Rept. EPA600/9-91-026b, Proceedings, Vol. 2: Symposium Oral Papers, Paper No. VI-3, p. 6-23-6-36 [NTIS Order No. PB91-234450/AS]

Schütz, M., and G. Keller, 1993, Diurnal and seasonal variation of radon concentration in the upper layer of the soil [abs.], in First International Workshop on Indoor Radon Remedial Action, The Scientific Basis and Practical Applications, Rimini, Italy, 27 June-2 July 1993: Commission of the European Communities et al., Book of Abstracts, p. 72

Scott, A.G., 1992, Site characterization for radon supply potential: A progress review: Health Physics, 62(5): $422-428$

Sextro, Richard G., 1987, Understanding the origin of radon indoors-Building a predictive capability [from Conference on Characterization of Contaminant Emissions from Indoor Sources, Chapel Hill, NC, May 13-15, 1985]: Atmospheric Environment, 21: 431-438 [Original Pub.: Lawrence Berkeley Laboratory Rept. LBL-20210, $21 \mathrm{p}$.

Sextro, Richard G., and Ashok J. Gadgil, 1993, Modeling radon entry into buildings: Insights for radon control [abs.], in First International Workshop on Indoor Radon Remedial Action, The Scientific Basis and Practical Applications, Rimini, Italy, 27 June-2 July 1993: Commission of the European Communities et al., Book of Abstracts, p. 45

Sextro, R.G., B.A. Moed, W.W. Nazaroff, K.L. Revzan, and A.V. Nero, 1987, Investigations of soil as a source of indoor radon, Chap. 2, in Hopke, Philip K., ed., Radon and Its Decay Products; Occurrence, Properties, and Health Effects: Washington, Am. Chem. Soc. Symposium Ser. 331, p. 10-29

Sextro, R.G., Nazaroff, W.W., and Turk, B.H., 1989, Spatial and temporal variation in factors governing the radon source potential of soil, in Osborne, M.C., and Jed Harrison, Symposium Cochairmen, The 1988 
Symposium on Radon and Radon Reduction Technology, Proc., Vol. 1, Symposium Oral Papers: Research Triangle Park, N.C., Radian Corp., U.S. Environmental Protection Agency Pub. EPA/600/9-89/006a [Springfield, Va., NTIS Order No. PB89-167480], p. 5-61--5-74.

Sherman, Max, 1993, Simplified modeling for infiltration and radon entry, in Proceedings: The 1992 International Symposium on Radon and Radon Reduction Technology, 4th, Minneapolis, Minn., Sept. 22-25, 1992. Vol. 1, Symposium Oral Papers, Opening Session and Technical Sessions I-VI: Research Triangle Park, N.C., U.S. Environmental Protection Agency Rept. EPA-600/R-93/083a, p. 6-57-6-78

Singler, C.R., E.C. Abram, and I.U. Khawaja, 1993, A predictive model for determining indoor radon levels in northeastern Ohio, in The 1993 International Radon Conference, Denver, Colo., Sept. 20-22, 1993: Denver, Colo., Am. Assoc. Radon Scientists and Technologists, Rocky Mountain Chapter, Preprints, p. IVP 12-IVP 13

Siniscalchi, Alan J., Lynne M. Rothney, Brian F. Toal, Margaret A. Thomas, David R. Brown, Maria C. van der Werff, and Carolyn J. Dupuy, 1991, Radon exposure in Connecticut: Analysis of three statewide surveys of nearly one percent of single family homes, in The 1990 International Symposium on Radon and Radon Reduction Technology, Atlanta, Ga., 19-23 February 1990: Research Triangle Park, N.C., U.S. Environmental Protection Agency Rept. EPA600/9-91-026a, Proceedings, Vol. 1: Symposium Oral Papers, Paper No. IV-1, p. 4-1-4-14 [NTIS Order No. PB91-234443/AS]

Slunga, E., 1988, Radon classification of building ground: Radiation Protection Dosimetry, 24(1/4): 39-42

Smith, Geoffrey W., Royal H. Mapes, Robert J. Hinkel, and Rick L. Darr, 1989, Radon hazards associated with glacial deposits in Ohio [abs.]: Geol. Soc. America, Abstracts with Programs, 21(6): A144

Solomon, Barry J., Bill D. Black, Dane L. Finerfrock, and John Hultquist, 1993, Geologic mapping of radonhazard potential in Utah, in The 1993 International Radon Conference, Denver, Colo., Sept. 20-22, 1993: Denver, Colo., Am. Assoc. Radon Scientists and Technologists, Rocky Mountain Chapter, Preprints, p. IVP 14-IVP 28

Speer, J. Alexander, Gregory T. Bertwell, Kevin W. Hoff, and Thomas J. Douglas, 1993, Using heat flow measurements to estimate and verify the total radon hazard potential of granites, southeastern United States, in The 1993 International Radon Conference, Denver, Colo., Sept. 20-22, 1993: Denver, Colo., Am. Assoc. Radon Scientists and Technologists, Rocky Mountain Chapter, Preprints, p. IV 10-IV 19

Sprinkel, Douglas A., 1988, Assessing the radon hazard in Utah: Utah Geological and Mineral Survey, Survey Notes, 22(4): 3-13

Steck, Daniel J., 1988, Geological variation of radon sources and indoor radon along the southwestern edge of the Canadian Shield, in Marikos, Mark A., and Robert H. Hansman, eds., Geologic Causes of Natural Radionuclide Anomalies, Proceedings of the GEORAD Conference, St. Louis, Mo., April 21-22, 1987: Rolla, Mo., Missouri Dept. Nat. Resources, Div. Geology and Land Survey Spec. Pub. No. 4, p. 17-23

Steck, DJ., and M.J. Bergmann, 1992, Indoor radon and the radon potential of soils, in The 1992 International Symposium on Radon and Radon Reduction Technology, Minneapolis, Minnesota, September 22-25, 1992: U.S. Environmental Protection Agency, Preprints, v. 3, no. VIII-1, 15 p.

Stieff, L.R., C.B. Stieff, and R.A. Nelson, 1987, Field measurements of in situ ${ }^{222} \mathrm{Rn}$ concentrations in soil based on the prompt decay of the ${ }^{214} \mathrm{Bi}$ counting rate: Nuclear Geophysics, 1(2): 183-195

Surbeck, H., and Piller, G., 1989, A closer look at the natural radioactivity in soils, in Osborne, M.C., and Jed Harrison, Symposium Cochairmen, The 1988 Symposium on Radon and Radon Reduction Technology, Proc., 
Vol. 1, Symposium Oral Papers: Research Triangle Park, N.C., Radian Corp., U.S. Environmental Protection Agency Pub. EPA/600/9-89/006a [Springfield, Va., NTIS Order No. PB89-167480], p. 5-13--5-26.

Surbeck, H., H. Völkle, and W. Zeller, 1991, Radon in Switzerland, in The 1991 International Symposium on Radon and Radon Reduction Technology, Philadelphia, Pa., 2-5 April 1991: Preprints, v. 3, no. VI-3, 16 p.

Swedish Radon Commission (Radonutredningen), 1983, Radon in dwellings. Report from the Radon Commission [in Swedish]: Stockholm, Ministry of Agriculture, SOU 1983:6, 145 p. [ISBN 91-38-07433-8]

Swedjemark, Gun Astri, 1982, Buildings with enhanced radioactivity in Sweden, in Vohra, K.G., U.C. Mishra, K.C. Pillai, and S. Sadasivan, eds., Natural Radiation Environment: New York, John Wiley and Sons, p. 535-542, disc., 542-543

Szarzi, S.L., G.M. Reimer, and J.M. Been, 1990, Soil-gas and indoor radon distribution related to geology in Frederick County, Maryland [poster abs.], in Indoor Radon and Lung Cancer: Reality or Myth?, Hanford Symposium on Health and the Environment, 29th, Richland, Washington, October 15-19, 1990: Richland, Wash., Battelle Pacific Northwest Laboratories, Final Program, p. 95-96

Tanner, Allan B., 1957, Physical behavior of radon, in U.S. Geological Survey, Geologic investigations of radioactive deposits, semiann. progress report, June 1 to November 30, 1957: U.S. Geol. Survey Rept. TEI-700: 243-246

Tanner, Allan B., 1986, Geological factors that influence radon availability, in Indoor Radon, Proceedings of the APCA International Specialty Conference, Philadelphia, Pa., February 24-26, 1986: Air Pollution Control Assoc., P.O. Box 2861, Pittsburgh, PA 15230, Pub. SP-54, p. 1-12

Tanner, Allan B., 1988a, Measurement of radon availability from soil, in Marikos, Mark A., and Robert H. Hansman, eds., Geologic Causes of Natural Radionuclide Anomalies, Proceedings of the GEORAD Conference, St. Louis, Mo., April 21-22, 1987: Rolla, Mo., Missouri Dept. Nat. Resources, Div. Geology and Land Survey Spec. Pub. No. 4, p. 139-146.

Tanner, A.B., 1988b, A tentative protocol for measurement of radon availability from the ground, in Natural Radioactivity, International Symposium on the Natural Radiation Environment, 4th, Lisbon, Portugal, December 7-11, 1987, Proceedings: Radiation Protection Dosimetry, 24(1/4): 79-83

Tanner, A.B., 1991a, Error in measuring radon in soil gas by means of passive detectors: Nuclear Geophysics, 5(1/2): $25-30$

Tanner, Allan B., 1991b, Methods of characterization of ground for assessment of indoor radon potential at a site, in Gundersen, Linda C.S., and Richard B. Wanty, eds., Field studies of radon in rocks, soils, and water: U.S. Geol. Survey Bulletin no. 1971, p. 1-18

Tanner, Allan B., 1991c, The role of diffusion in radon entry into houses, in The 1990 International Symposium on Radon and Radon Reduction Technology, Atlanta, Ga., 19-23 February 1990: Research Triangle Park, N.C., U.S. Environmental Protection Agency Rept. EPA600/9-91-026b, Proceedings, Vol. 2: Symposium Oral Papers, Paper No. V-2, p. 5-21-5-32 [NTIS Order No. PB91-234450/AS]

Terry, David B., and Robert D. Shumeyko, 1988, Geologic correlation with elevated indoor radon occurrence, Bergen County, New Jersey [abs.], in Radon in the Northeast: Perspectives and Geologic Research (conference), Troy and Albany, New York, May 31-June 2, 1988: Northeastern Environmental Science, 7(1): 10 
Thomas, D[onald] M., J[eff] M. Cotter, and D[iana] Holford, 1992, Experimental design for soil gas radon monitoring: Jour. Radioanalyt. Nuclear Chemistry, Articles, 161(2): 313-323

Thomas, M.A., and J.N. Hollis, 1988, Correlating radon distribution with geology and areal radioactivity in Connecticut [abs.], in Radon in the Northeast: Perspectives and Geologic Research (conference), Troy and Albany, New York, May 31-June 2, 1988: Northeastern Environmental Science, 7(1): 10

Turk, Bradley H., Jed Harrison, Richard J. Prill, and Richard G. Sextro, 1990, Developing soil gas and ${ }^{222} \mathrm{Rn}$ entry potentials for substructure surfaces and assessing ${ }^{222} \mathrm{Rn}$ control diagnostic techniques: Health Physics, $59(4)$ : 405-419

Turk, B.H., R.J. Prill, WJ. Fisk, D.T. Grimsrud, B.A. Moed, and R.G. Sextro, 1987, Radon and remedial action in Spokane River Valley houses: Vol. 1: Experimental design and data analysis: Berkeley, Calif., Univ. California Lawrence Berkeley Laboratory Rept. LBL-23430

Ulbak, K., B. Stenum, A[rne] Sørensen, B[enny] Majborn, L[ars] Bøtter-Jensen, and S[ven] P[oul] Nielsen, 1988, Results from the Danish indoor radiation survey: Radiation Protection Dosimetry, 24(1/4): 401-405

van Assendelft, A.C.E., and H.M. Sachs, 1982, Soil and regional uranium as controlling factors of indoor radon in eastern Pennsylvania: Princeton, NJ, Princeton Univ. Center for Energy and Environmental Studies Rept. PU/CEES-145, 68 p.

van den Boom, Günter, and Matthias Ort, 1991, Reconnaissance survey for determining radon and helium soil-air concentrations in the area of Ronneburg-Seelingstädt, Germany [abs.], in International Symposium on the Natural Radiation Environment, 5th, Salzburg, Austria, 22-28 September 1991, Abstracts: Salzburg, Univ. Salzburg, Inst. for General Biology, Biochemistry and Biophysics, abs. no. 168

Verger, P., Ph. Hubert, and S. Chéron, 1993, Use of field measurement in mapping [abs.], in First International Workshop on Indoor Radon Remedial Action, The Scientific Basis and Practical Applications, Rimini, Italy, 27 June-2 July 1993: Commission of the European Communities et al., Book of Abstracts, p. 79

Viljanen, Martti, Eero Slunga, Timo Lehtoviita, and Pekka Kanerva, 1987, Radon merkitys talonrakennustekniikassa. Radontekninen suunnittelu [Radon in building technology. Radontechnical design]: Espoo, Finland, Helsinki Univ. Technology, Dept. Civil Engineering, Div. Structural Engineering Rept. 88, 147 p.

Voutilainen, Anne, and Ilona Mäkeläinen, 1991, The use of indoor radon measurements and geological data in assessing the radon risk of soil and rock in construction sites in Tampere [SW Finland], in The 1991 International Symposium on Radon and Radon Reduction Technology, Philadelphia, Pa., 2-5 April 1991: Preprints, v. 2 , no. III-8, 13 p.

Vulcani, Julie, and James R. Wood, 1993, Soil gas radon potential of the Upper Peninsula of Michigan: Houghton and Marquette Counties, in The 1993 International Radon Conference, Denver, Colo., Sept. 20-22, 1993: Denver, Colo., Am. Assoc. Radon Scientists and Technologists, Rocky Mountain Chapter, Preprints, p. IVP 29-IVP 36

Wanty, R.B., L.C.S. Gundersen, and R.R. Schumann, 1990, Geological factors affecting radionuclide mobility [abs.], in Gough, L.P. (ed), Proceedings of the USGS Environmental Forum 1990: U.S. Geol. Survey Open-file Rept. $90-288$, p. $15-16$ 
Washington, Paul A., 1988, Proper scaling of radon surveys: A perspective based on natural radon sources in southern Vermont, in Radon in the Northeast: Perspectives and Geologic Research (conference), Troy and Albany, New York, May 31-June 2, 1988: Northeastern Environmental Science, 7(1): 40-44

Wilson, Carole, 1984, Mapping the radon risk of our environment, in International Conference on Indoor Air Quality and Climate, 3d, Stockholm, August 20-24, 1984; Vol. 2: Radon, Passive Smoking, Particulates and Housing Epidemiology, Birgitta Berglund, Thomas Lindvall, and Jan Sundell, eds.: Stockholm, Swedish Council for Building Research, Vol. 2, p. 85-92

Wilson, Carole, 1985-1986, Radon - Geological aspects of an environmental problem: [London Geol. Soc. \& Manchester Geol. Assoc.] The Amateur Geologist, Vol. XI, Pt. 2, p. 17-22, 27-33

Wollenberg, H.A., and K.L. Revzan, 1990, Radium regionalization in California: Geophys. Research Letters, 17(6): 805-808

Wollenberg, H.A., and A.R. Smith, 1984, Naturally occurring radioelements and terrestrial gamma-ray exposure rates: An assessment based on recent geochemical data: Berkeley, Calif., Univ. Calif. Lawrence Berkeley Lab. Rept. LBL-18714, 79 p. [Submitted to Environmental Geology and Water Resources]

Yokel, Felix Y., 1989, Site characterization for radon source potential: Gaithersburg, Md., Natl. Inst. Standards and Technology Rept. NISTIR 89-4106, 62 p.

Yokel, Felix Y., and Allan B. Tanner, 1992, Site exploration for radon source potential: U.S. Natl. Inst. of Standards and Technology Rept. NISTIR 5135, $61+$ xv p.

Zapalac, Geordie H., 1983, A time-dependent method for characterizing the diffusion of ${ }^{222} \mathrm{Rn}$ in concrete: Health Physics, 45(2): 377-383 

RADON SOURCE POTENTIAL

Note: Square brackets [] denote summaries, comments, or supplementary information by the compiler.

Agard, Sherry S., and Linda C.S. Gundersen, 1991

The geology and geochemistry of soils in Boyertown and Easton, Pennsylvania, in Gundersen, Linda C.S., and Richard B. Wanty, eds., Field studies of radon in rocks, soils, and water:

U.S. Geol. Survey Bulletin no. 1971, p. 51-63

Soils derived from a wide variety of metamorphic rocks in the Reading Prong, Pennsyivania, exhibit secular equilibrium between uranium and radium. Direct correlations between uranium, radium, radon in soil gas, and indoor radon indicate that radon in soil gas is attributable to the uranium content of the soils and can be used predictively to estimate levels of indoor radon. Permeability of the soils does not vary enough to affect the radon availability except where fractured and jointed bedrock is close to the surface, in which case convective flow, rather than diffusion, becomes the dominant radon transport mechanism. Radon emanation of soils, as measured in the laboratory, correlates well with radium, radon in soil gas, and indoor radon. Careful examination of the physical and chemical properties of the soil must be made in order for radon in soil gas to be used as an effective predictor of indoor radon levels. In addition, predictions of indoor radon levels based on radon in soil gas and geology are limited to ranges of values because of the inherent variability in soil makeup.

Åkerblom, Gustav, 1986

Investigation and mapping of radon risk areas:

Luleå, Sweden: Swedish Geological AB, Rept. IRAP 86036, 15 p.

It is estimated that in Sweden 400-800 lung cases of lung cancer per year are caused from the inhalation of radon and radon daughters. Extensive regional surveys of radon daughters in dwellings, together with investigations of geology and building construction have revealed that radon in soil air is the primary source of indoor radon pollution. Documentation of the natural radiation environment in a geological context is invaluable for tracing areas of high radon risk, for understanding the local causes of indoor radon problems, and for choosing suitable remedial measures, both for existing dwellings and for future building construction. Classification of areas into high, normal, or low radon risk must take into account not only the distribution of uranium and radium in the bedrock and soils, but also such parameters as soil permeability, water content, and thickness of individual soil layers. Radon in soil air in gravel in glacial eskers, for example, has proved in Sweden to give rise to a serious radon problem. On the other hand, clays, with approximately the same radium content, do not generally give rise to a radon problem in dwellings owing to their very low permeability to movement of soil air.

Åkerblom, Gustav, 1987

Investigations and mapping of radon risk areas, in Wolff, F.C., ed., Geology for Environmental Planning, Proceedings of the International Symposium on Geological Mapping in the Service of Environmental Planning, Trondheim, 6-9 May, 1986:

Trondheim, Norwegian Geological Survey, P.O. 3006, Trondheim, Norway, Special Papers, no. 2, p. 96-106 [See abstract from report above.]

Åkerblom, Gustav, 1991

Mapping and investigation of the risk for radon from the ground [abs.], in International Symposium on the Natural Radiation Environment, 5th, Salzburg, Austria, 22-28 September 1991, Abstracts:

Salzburg, Univ. Salzburg, Inst. for General Biology, Biochemistry and Biophysics, abs. no. 180

Geological mapping and investigations of the risk for radon from the ground have been made in Sweden since 1979. Parallel to these investigations research has continued on radon in soil air and transport of radon into houses. The investigations and research have resulted in a good knowledge of parameters that govern the 
radon concentration in soil air and indoors. Up to now radon risk maps at the scale of 1:50 000 or larger have been produced for more than half of Sweden. The maps give information to the local authorities on the radon situation in different parts of the municipalities. The main purpose of the maps is to use them in physical planning, but they also give valuable information in the search for "radon houses." The Swedish building regulations prescribe that the radon situation at a building site has to be investigated, and if there is a risk for radon gas, precautions have to be taken so that radon cannot come into the building. According to the risk for radon, the ground is classified into risk groups and the building has to be constructed to meet the risk. The following classification rules (here simplified) are used: High risk areas are expected on uranium-rich granites, pegmatites, and alum shale [dark marine shale], and in highly permeable soils, such as gravels and coarse sands, in which the radon concentration in soil air is $>50 \mathrm{kBq} / \mathrm{m}^{3}$; radon-safe construction such as thicker, reinforced concrete foundation or ventilation below the foundation is required. Normal risk areas are expected on rocks and soils with low or normal uranium content and average permeability, in which the radon concentration in soil gas is between 10 and $50 \mathrm{kBq} / \mathrm{m}^{3}$; radon protective construction with no open holes in the foundation is required. Low risk areas are expected on rocks with very low uranium content, for example, limestone, sandstone and basic igneous and volcanic rocks, and soils with very low permeability, for example, clay and silt or soils where the radon concentration in soil air is $<10 \mathrm{kBq} / \mathrm{m}^{3}$; no special building technical requirements apply. TOf the Swedish area approximately $10 \%$ consists of high risk areas, $70 \%$ of normal risk areas, and $20 \%$ of low risk areas. The classification of the radon risk is based on surveys of bedrock and soils, measurements of gamma radiation, in situ analyses of the radium concentration in bedrock and soils with portable gamma spectrometers, and measurements of radon in the soil air and ground waters. In the paper the methods used are described and results from the investigations and research are presented.

\section{Åkerblom, Gustav, 1993}

Ground radon-monitoring procedures in Sweden, manuscript of lecture given 12 February 1993 at the 'JAG' Discussion Meeting at "Radon Workshop-Geology, Environment, Techniques" at Royal Astronomical Society, Burlington House, London:

Stockholm, Swedish Radiation Protection Institute, 14 manuscript p. +31 illustrations

[This lecture gave a history of radon monitoring in Sweden from 1979 onward: GEO-radiation maps, based on $\boldsymbol{\gamma}$-radiation data; research on radon classification of land, employing additional measurements drill-hole logging, $\gamma$-spectrometric analysis of soil and bedrock samples, and soil-gas radon from depths $\geq 1 \mathrm{~m}$; radon risk mapping of districts or municipalities; and site classification. The Swedish airborne spectral $\boldsymbol{\gamma}$-ray surveys are conducted at $30-\mathrm{m}$ altitude and $200-\mathrm{m}$ flight-line spacing, which permits resolution of even small radioactive outcrops. At more critical places measurement of either soil-gas radon or concentration of ${ }^{226} \mathrm{Ra}$ in samples is recommended. Evaluation is particularly difficult for sites where a structure will be within $1 \mathrm{~m}$ of bedrock. There are no reports of new houses with high indoor radon levels that result from faulty evaluation of radon risk.]

Åkerblom, G., P. Andersson, and B. Clavensjö, 1984

Soil gas radon--a source for indoor radon daughters:

Radiation Protection Dosimetry, 7(1-4): 49-54

[The provisional limit in Sweden for the concentration of radon progeny in Swedish houses is $400 \mathrm{~Bq} / \mathrm{m}^{3}$ equilibrium equivalent ${ }^{222} \mathrm{Rn}(10.8 \mathrm{pCi} / \mathrm{L})$ at $\mathrm{f}=1$. Of 1.6 million Swedish houses, 30,000 to 40,000 may exceed the limit. An investigation was made (Clavensjö, Åkerblom, and Andersson, 1983) of 253 houses, sited on granite or rock waste in Lysekil or Strömstad, on alum-shale fragments in sand, gravel, or glacial clay of the Fjugesta and Vintrosa areas, and on till, eskers, or bedrock in the Stockholm area. Indoor measurements were made in each house for 3 months with 2 type $F \boldsymbol{\alpha}$-track detectors with filter membranes. For 110 of the houses, bedrock and soil mapping were done, including K-U-T $\gamma$-spectrometry in situ, soil-gas radon measurement with radon-on-activated-charcoal or $\alpha$-track detectors in $75-\mathrm{mm}$ diameter PVC pipes usually extending to 1-m depth, and some subslab air measurements with an $\alpha$-scintillation cell. At the 1-m depth, the soil-gas ${ }^{222} \mathrm{Rn}$ correlated with ${ }^{226} \mathrm{Ra}$. At Vintrosa, an indicated emanating power of $\geq 50 \%$ suggested an alternative explanation, that radon is being transported from an alum shale layer under $12 \mathrm{~m}$ of limestone and non-radioactive limestone till by methane produced in the alum shale. No other evidence of long-distance 
transport of radon was seen. The better a house is sealed, the greater the concentration of radon builds up where exhalation to the atmosphere is prevented. The detailed investigations showed that radon was drawn into houses through holes or cracks in the concrete slabs or the subsurface cellar walls by soil-gas flow driven by a higher atmospheric pressure in the soil than in the houses. For indoor radon levels to be enhanced or high, it was necessary that the ground beneath a house be permeable. The contribution $C_{\mathrm{m}}$ to the indoor radon of a house was calculated from the formula, $C_{\mathrm{m}}=\left(C_{\underline{\underline{t}}} L\right) /\{(n+\lambda) V\}$, where $C_{\mathrm{t}}$ is the radon concentration in the soil gas, $L$ is the soil-gas flow rate into the house, $n$ is the house ventilation rate, $V$ is the volume of indoor air, and $\lambda$ is the radon decay constant. Very large volumes of air can leak into houses from eskers; it is calculated that an indoor level of $10 \mathrm{kBq} / \mathrm{m}^{3}$ requires an intake of about $50 \mathrm{~m}^{3}$ of soil air per hour.]

Åkerblom, Gustav, Berndt Pettersson, and Bengt Rosén, 1990

Radon i bostäder. Markradon [Radon in the soil. Handbook of radon]:

Stockholm, National Council for Building Research Rept. R85:1988 [Revised 1990], 160 p.

Åkerblom, G.V., and Carole Wilson, 1981

Radon gas-A radiation hazard from radioactive bedrock and building materials:

Internat. Assoc. Engineering Geology Bull., 23: 51-61

Exposure to radioactive materials is not a problem solely connected with nuclear energy or nuclear weapons. The past year [1979] has witnessed real concern in Sweden regarding natural radiation hazards in the everyday environment, in particular exposure to high levels of radon gas and radon daughter products in dwellings. The source for the radon can be either building materials containing higher than normal amounts of radioactive elements, or bedrock and/or drift cover with relatively high concentrations of uranium. The bedrock contribution to the radiation hazard relates directly to the uranium-bearing alum shale formation of Cambrian age and to certain Precambrian uranium- and thorium-enriched granites. The Geological Survey of Sweden is preparing GEO-radiation maps which show the distribution of rocks and soils which are radioactive. Building materials incorporating these rock types, in particular alum shale, can also have high radium contents resulting in the release of radon gas to the indoor atmosphere. This paper summarizes the recommendations of the Swedish Government Commission set up to investigate the radon problem, and the role of the geologist in delimiting the extent of the problem of natural radiation from the ground. [The paper includes maps showing the national distribution of the alum shale, areas covered by aerial $\boldsymbol{\gamma}$-ray spectral survey as of 1979 , examples of the uranium-component aeroradiometric, geo-radiation, and soil-radon maps.]

Åkerblom, Gustav, and Carole Wilson, 1982

Radon-geological aspects of an environmental problem:

Uppsala, Sveriges Geologiska Undersökning [Swedish Geological Survey], Rapporter och meddelanden [Rept. \& commun.] No. 30, 47 p.

[This report comprises two papers, presented at the International Meeting on Radon-Radon Progeny Measurements, Montgomery, Alabama, August 27-28, 1981.] "Environmental radon investigations in Sweden," p. 3-21, by Gustav Åkerblom: In Sweden, radon daughter concentrations of $200-800 \mathrm{~Bq} / \mathrm{m}^{3}(0.05-0.2 \mathrm{WL})$ are known to occur in buildings constructed of aerated concrete which has been manufactured from alum shale, a Cambrian, uranium-rich black shale. As a result of these alarmingly high levels, the Swedish Government set up, in 1979, a Commission whose task is to initiate research around the problem of radon, and to recommend remedial measures against natural radiation in dwellings. Based on the recommendations of the Commission, the Government proposed the following measures: (1) The introduction of provisional limits permitted for radon daughter concentrations in dwellings. These limits are $400 \mathrm{~Bq} / \mathrm{m}^{3}(0.11 \mathrm{WL})$ for existing buildings and $70 \mathrm{~Bq} / \mathrm{m}^{3}(0.02 \mathrm{WL})$ for new development. (2) The use of specific building techniques when developing areas with high soil-gas radon contents. (3) An immediate search for all buildings constructed of alum-shale-based aerated concrete. TAbout 300,000 houses in Sweden are constructed entirely or partially of aerated concrete containing alum shale. During 1980, radon daughter levels were measured in 20,000 of these houses by local health authorities. The first results show that about $14 \%$ of the measured houses have radondaughter levels exceeding $400 \mathrm{~Bq} / \mathrm{m}^{3}$. In about $2 \%$ of the investigated houses the value exceeded $1,000 \mathrm{~Bq} / \mathrm{m}^{3}$ 
(0.27 WL), and maximum values of 4,000 to $9,000 \mathrm{~Bq} / \mathrm{m}^{3}(1.1-2.4 \mathrm{WL})$ have been measured in some houses. IRadon daughter levels exceeding $800 \mathrm{~Bq} / \mathrm{m}^{3}$ are not caused entirely by radon emanating from building materials. A contribution of radon from the ground is necessary. Most of the houses with values exceeding $800 \mathrm{~Bq} / \mathrm{m}^{3}$ have proved to be sited on ground containing alum shale, uranium-rich granite, uranium-rich pegmatite, or on eskers. Many thousands of houses in Sweden are built in such situations. IThe measurements obtained so far indicate that radon penetrating into buildings is a far greater problem than that of radon emanating from building materials. Geological and geophysical investigations of risk areas are of the utmost importance if all new development is to comply with the provisional limits for radon daughter levels proposed by the Radon Commission. [This report includes discussion of soil investigations by means of $\gamma$ spectrometers, emanometer probes, $\alpha$-track detectors, and radon-on-active-charcoal detectors, and includes a figure showing such traverses and the corresponding surficial geology profile from a Swedish-language report by Hesselbom, Israelsson, and Tovedal (1981). The traverses were in agreement, the radon emanometer traverse showing the highest contrast (with differences between two separate measurements), and the $\boldsymbol{\gamma}$-ray traverse showing the least contrast.] "Regional environmental documentation of natural radiation in Sweden," p. 22-47, by Carole Wilson: In 1979, when the problem of high radon daughter levels in Swedish houses became widely publicized, the need for information on variations in the natural radiation environment became very apparent. The radon problem was at first attributed to radon emanation from alum-shale-based aerated concrete, but it was soon obvious that ground with an abnormally high uranium content constitutes an even greater risk for high radon daughter levels in houses. The Geological Survey of Sweden was commissioned to produce documentation in map form of all areas and rock types with gamma-ray levels exceeding $30 \mu \mathrm{R} / \mathrm{hr}$, with the intention of delimiting risk areas for high soil-gas radon contents. The maps, known as GEO-radiation maps, are produced at a scale of 1:50,000. They are based primarily on airborne radiometric surveys, ground measurements of $\boldsymbol{\gamma}$ radiation, and geological mapping. To date, some 450 map sheets have been published, covering approximately $55 \%$ of the country. The maps provide primary information to local planning, health, and building authorities as to variations in the natural radiation environment. Within the socalled risk areas marked on the maps, local authorities are recommended to investigate the soil-gas radon content prior to any new development. Geological environments known in Sweden to be associated with radon daughter problems in dwellings are alum shale, a Cambrian, uranium-rich black shale, uranium-rich granites, and uranium-rich pegmatites. Both alum shale and uranium-rich granites constitute extensive areas of bedrock. More recently it has been established that high soil-gas radon concentrations are also associated with glacial eskers. [Maps show the country-wide distributions of alum shale and of known radioactive granites; largerscale maps of ${ }^{214} \mathrm{Bi} \gamma$ radiation and bedrock geology near Västerås, central Sweden; geological and GEOradiation maps Linköping, southeastern Sweden; ${ }^{214} \mathrm{Bi} \gamma$ radiation over Fornåsa, Östergötland, and Svennevad, southeastern Sweden; ${ }^{214} \mathrm{Bi} \gamma$ radiation, geology, and GEO-radiation over Mölndal, Gothenberg; geology and ${ }^{214} \mathrm{Bi} \gamma$ radiation of the Bohus granite complex, western Sweden; and ${ }^{214} \mathrm{Bi}$ and geology of the Fjugesta, central Sweden. A profile illustrates the distribution of fragments of alum shale in glacial drift cover, which may also illustrate the origin of regionally elevated indoor radon levels in central Ohio, USA.]

Aldenkamp, F.J., L.W. Put, and R.J. de Meijer, 1988

Investigations of the properties of an instrument for in situ exhalation measurements:

Radiation Protection Dosimetry, 24(1/4): 339-342

Arvela, Hannu, 1990

Radon study in 250 Finnish houses with different ventilation systems, in Proceedings of the Fifth International Conference on Indoor Air Quality and Climate, Toronto, 1990:

Proceedings, p. 3-8

[Radon measurements were made by means of polycarbonate $\alpha$-track films in 162 detached and semi-detached homes and 89 apartments randomly selected in metropolitan Helsinki. Natural ventilation, mechanical exhaust, and balanced ventilation systems were represented. Linear least-squares regression and analysis of variance techniques were applied to the radon data and ventilation rates measured by PFT tracers during two-week tests during the heating season. Summer measurements were made of radon only. Radon sources from the soil 
and soil permeability were not investigated directly, but house construction, building material, and air-exchange factors could explain only $<30 \%$ of the observed variations in radon concentration; soil radon concentrations and permeability were assumed to be the more important factors. Where winter indoor radon concentrations were low, the winter-summer ratio was near unity or lower, and diffusion was inferred to be important. Where winter indoor radon concentrations were high, the winter-summer ratios were normally $1.5-2.5$, and the contribution of radon by pressure-driven soil-gas flow was inferred to be dominant. Ventilation alone was concluded to be generally inadequate to cause radon reduction by a factor of $>2$.]

Arvela, H., I. Mäkeläinen, and O. Castrén, 1993

Residential radon survey in Finland:

Helsinki, Säteilyturvakeskus (STUK) Strålsakerhetscentralen [Finnish Centre for Radiation and Nuclear Safety, Rept. STUK-A108, 34 p. + app. 15 p.

This study measured the indoor radon concentration in the dwellings of 3074 persons, selected randomly from the central population register of Finland. Alpha-track detectors were used for two consecutive half-year measurement periods. The national mean values of indoor radon concentration for persons living in low-rise residential buildings and blocks of flats were 145 and $82 \mathrm{~Bq} / \mathrm{m}^{3}$, respectively. The mean for the total population was $123 \mathrm{~Bq} / \mathrm{m}^{3}$. Based on the decision of the Ministry of Social Affairs and Health in 1992, the indoor radon concentration should not exceed $400 \mathrm{~Bq} / \mathrm{m}^{3}$. According to this study, the percentages of the Finnish population living in houses with indoor radon concentrations exceeding 200,400 , and $800 \mathrm{~Bq} / \mathrm{m}^{3}$ were $12.3 \%, 3.6 \%$, and $1.0 \%$, respectively. The corresponding numbers of dwellings involved were $200,000,70,000$, and 20,000 . The average concentration in low-rise residential buildings exceeds $200 \mathrm{~Bq} / \mathrm{m}^{3}$ in a contiguous area with 1 million inhabitants, covering about $30,000 \mathrm{~km}^{2}$. In this area the percentages of residents living in dwellings exceeding levels of 200,400 , and $800 \mathrm{~Bq} / \mathrm{m}^{3}$ were $26 \%, 10 \%$, and $3 \%$. For persons in low-rise residential buildings built in 1980-1990 the percentages were, surprisingly, more than twice the above. The average concentration in low-rise residential buildings built in 1980-1990 was $60 \mathrm{~Bq} / \mathrm{m}^{3}$ higher than in houses built before 1980. Porous, lightweight concrete blocks in foundation construction and the reduced use of crawl spaces contributed to this increase. Open stairwells between the basement and first floor also increased radon concentrations.

Arvela, H., A. Voutilainen, I. Mäkeläinen, O. Castrén, and K. Winqvist, 1988

Comparison of predicted and measured variations of indoor radon concentration:

Radiation Protection Dosimetry, 24(1/4): 231-235

Arvela, H., and K. Winqvist, 1989

A model for indoor radon variations:

Environment Internat., 15: 239-246

[The authors have developed a model relating indoor radon concentration to variations in source strength, air exchange rate, and meteorological factors (indoor-outdoor temperature difference and wind). The Lawrence Berkeley Laboratory (analytical) air infiltration model (Sherman and Modera, 1984) was used to model the air exchange rate. The model was tested against winter-summer (February-October) differences in indoor ${ }^{222} \mathrm{Rn}$ concentration as determined by $\alpha$-track detector measurements of 1-2 months in 100 Finnish houses, supplementing data taken earlier in 250 houses. Using the model, they calculated winter-summer concentration ratios for different strengths of diffusion sources in building materials and soil, and varying soil-gas flow driven by the "stack effect" resulting from a difference between indoor and outdoor temperature. Best matches of the calculated and measured concentration ratios indicated that houses in which diffusion sources dominated would show decreasing radon concentration with increasing air exchange rates, and that houses in which soilgas inflow was dominant would show increasing radon concentration with increasing air exchange rates. Diffusion sources, if strong, were significant mainly in houses with large, porous concrete walls in ground contact. For houses with slabs in ground contact, the ratios were often in agreement with those predicted by nearly pure pressure-driven flow.] 
Asher-Bolinder, Sigrid, D.E. Owen, and R.R. Schumann, 1989

Soil-characteristic and meteorologic controls on radon in soil gas in the semiarid western United States [abs.]: Eos, Am. Geophys. Union Trans., 70(15): 497

The interaction between soil characteristics and meteorologic events affects soil structure and soil moisture. In turn, soil structure and moisture interact to influence both radon transport and emanation within the soil. Unirrigated smectitic clay-loam soil on a terrace deposit in Lakewood, Colorado, was monitored daily for soil-gas radon at depths of 50,75 , and $100 \mathrm{~cm}$. Radon data were integrated with hourly weather data, and tensiometers measured soil moisture at study depths. Soil moisture during spring, summer, and fall ranged from 10 to 30 weight percent. Radon concentrations varied by an order of magnitude throughout the year; day-to-day variations of 100-200 percent were controlled mainly by barometric pressure changes. Transitory soil-moisture caps blocked soil-gas exchange with the atmosphere and also raised radon content. Larger seasonal radon variations were controlled primarily by interaction between soil cracks when present, and radon emanation, both of which were controlled mainly by soil moisture. Grain-to-grain permeability is limited in this smectitic soil. Insolation and evaporation due to wind both control soil-crack development. In summer to early fall soil cracks (as deep as $90 \mathrm{~cm}$ and as wide as $2 \mathrm{~cm}$ at the surface and $0.1-03 \mathrm{~cm}$ at depth) developed in the soil. Crack polygons $15-25 \mathrm{~cm}$ across persisted through summer and fall except when precipitation temporarily healed cracks at the surface. Radon concentrations at $100-\mathrm{cm}$ depth in soil with surface cracks $>2 \mathrm{~mm}$ wide were nearly half the concentrations noted when no cracks were present. Thus, atmospheric air diluted soil gas at depth in deeply cracked soil. Emanated radon from the six soil horizons varied by an order of magnitude, depending on water content. Soil horizons contained $74 \mathrm{~Bq} / \mathrm{kg}(2.0-2.8$ $\mathrm{pCi} / \mathrm{g}$ ) radium and emanated $<3.7$ to $>37 \mathrm{kBq} / \mathrm{m}^{3}(<100$ to $>1000 \mathrm{pCi} / \mathrm{L}$ ) of radon per $\mathrm{kg}$ of soil in a laboratory study. Radon emanation was maximized when water was 9-17 weight percent of the sample. Temperature effects were not discernible at $5,20,36^{\circ} \mathrm{C}$, characteristic of much of the yearly weather range. Samples at $-18^{\circ} \mathrm{C}$, the low temperature extreme, showed lessened apparent emanation because ice within soil pores blocked transport from the soil.

Asher-Bolinder, Sigrid, Douglass E. Owen, and R. Randall Schumann, 1990

Pedologic and climatic controls on Rn-222 concentrations in soil gas, Denver, Colorado:

Geophys. Research Letters, 17(6): 825-828

Soil-gas radon concentrations are controlled seasonally by factors of climate and pedology [soil character]. In a swelling soil of the semiarid western United States, soil-gas radon concentrations at $100-\mathrm{cm}$ depth increase in winter and spring due to increased emanation with higher soil moisture and the capping effect of surface water or ice. Increased soil moisture results from a combination of higher winter and spring precipitation and decreased insolation [solar heating] in fall and winter, lowering soil temperatures so that water infiltrates deeper and evaporates more slowly. Radon concentrations in soil drop markedly through the summer and fall. The increased insolation of spring and summer warms and dries the soil, limiting the amount of water that reaches $100 \mathrm{~cm}$. As the soil dries, radon emanation decreases and deep soil cracks develop. These cracks aid convective transport of soil gas, increase radon's flux into the atmosphere, and lower its concentration in soil gas. Probable controls on the distribution of uranium within the soil column include its downward leaching, its precipitation or adsorption onto B-horizon clays, concretions, or cement, and the uranium content and mineralogy of the soil's granitic and gneissic precursors.

Asher-Bolinder, Sigrid, Douglass E. Owen, and R. Randall Schumann, 1991

A preliminary evaluation of environmental factors influencing day-to-day and seasonal soil-gas radon concentrations, in Gundersen, Linda C.S., and Richard B. Wanty, eds., Field studies of radon in rocks, soils, and water:

U.S. Geol. Survey Bulletin no. 1971, p. 23-31

A long-term study of radon concentrations in a smectitic soil of the semiarid Colorado Piedmont reveals that interaction of meteorologic, climatic, and pedologic factors affects radon concentrations on both a daily and seasonal time scale. Seasonal variations are generally of greater magnitude than day-to-day fluctuations. Dayto-day radon fluctuations in this soil are controlled largely by changes in barometric pressure and by shallow 
capping effects resulting from precipitation. Change in gas permeability due to variations in soil moisture is the major control on seasonal soil-gas radon variation. Radon concentrations correlate with wind speed, relative humidity, air and soil temperatures, and the difference between those temperatures. Because these factors are interrelated, it is difficult to determine the magnitudes of their individual influences. Therefore, the nature of a soil and its response to climate must be understood if short-term measurements are to be used to predict long-term ranges of soil-gas radon concentrations.

Azimi-Garakani, D., B. Flores, S. Piermattei, A.F. Susanna, J.L. Seidel, L. Tommasino, and G. Torri, 1988 Radon gas sampler for indoor and soil measurements and its applications:

Radiation Protection Dosimetry, 24(1/4): 269-272

Ball, T. K[eith], D.G. Cameron, T.B. Colman, and P.D. Roberts, 1991

Aspects of radon potential mapping in Britain, [abs.], in International Symposium on the Natural Radiation Environment, 5th, Salzburg, Austria, 22-28 September 1991, Abstracts:

Salzburg, Univ. Salzburg, Inst. for General Biology, Biochemistry and Biophysics, abs. no. 58

The factors controlling the emanation of radon from rocks and soils are discussed briefly. The use of existing data sets for the identification of zones of high radon production are described. For relatively impermeable rocks, stream sediment geochemical distribution maps for uranium provide a useful first indication, but the actual emanation coefficients depend upon mineralogical and permeability controls. For highly permeable rocks, for example in karstic terrains, stream sediments are relatively ineffective and greater weight must be placed on airborne, ground, and borehole radiometric procedures. Confirmation must make use of soil gas radon measurement techniques.

Barnet, I[van], ed., 1991

Radon investigations in Czechoslovakia II:

Prague, Czech Geological Survey, 51 p.

Barnet, Ivan, 1991

Radon risk mapping of the Czech Republic-results, in Barnet, I., ed., Radon investigations in Czechoslovakia II:

Prague, Czech Geological Survey, p. 13-19

In 1990 the radon risk mapping of the Czech Republic $\left(78800 \mathrm{~km}^{2}\right)$ was finished. The joint project of the Geological Survey (Prague), Uranium Exploration (Rynoltice, Prúrbram, and Nové Město na Moravě), Geophysics (Prague), and Faculty of Science, Charles University (Prague) resulted in the publication of radon risk maps at the scale of 1:200 000 for 7 administrative regions of the Czech Republic. The mapping was based on ${ }^{222} \mathrm{Rn}$ soil measurements carried out on 148 test sites representing different geological units (total sum of measured points $=3700$ ). Additional geological, airborne geophysical, pedological, and hydrogeological data were derived from maps produced by the Geological Survey and Geophysics and the catalogue of radiometric anomalies was provided by Uranium Exploration. The radon risk maps are used by the state institutions (Ministry of Health and Environment, Building, and Hygienic Service) and municipal authorities for organizing the distribution of soil and indoor radon measurements in detail as well as for urban planning. The SAN method, carried out by Uranium Exploration, was used for the soil radon measurements. The volume activity of ${ }^{222} \mathrm{Rn}$ was determined in $0.6-0.7$-m-deep soil drill[holes] using plastic foils exposed for 24 hours. Immediately after removing the foils from the tightened [sealed?] drillhole, the alpha activity of radon daughter products was measured by RP-103 D alphameter [spectrometer?]. Up to 5 gamma-spectrometric points were measured at each test site and grain-size analysis was carried out at each test site. [Soil-gas radon concentrations, in $\mathrm{kBq} / \mathrm{m}^{3}$, are used as follows for radon risk evaluation: the low risk class is applied if soil permeability and radon are respectively low and $<30$, medium and $<20$, or high and $<10$; the medium risk class is applied if permeability and radon are respectively low and 30-100, medium and 20-70, and high and 10-30; the high risk category is applied if permeability and radon are respectively low and $>100$, medium and $>70$, or high and $>30$. Graphs are shown for the following relations: Fig. 1, mean values of soil-gas radon 
in 14 rock types of the Bohemian Massif, showing durbachites (syenites), granites, diorites, and orthogneisses to have the highest associated soil-gas radon; Fig. 2, mean and maximum soil-gas radon in the same rock types; Fig. 3, scatter diagram of soil-gas radon $v$ s. soil uranium, showing no statistically significant relation; Fig. 4, mean soil-gas radon $v$ s. soil uranium for each of the 14 rock types, showing a better correspondence between soil-gas radon and soil uranium, except for metasediments (phyllites, crystalline carbonates, etc.), which had low soil-gas radon; Fig. 5, histograms of soil-gas radon for each of 7 rock types; Fig. 6, soil-gas radon and mean percentage of fine fraction $v$ s. rock type, showing generally smaller fine fractions for rock types having higher soil-gas radon; Fig. 7, soil-gas radon and mean percentage of gravel vs. rock type, showing a rough direct correlation between soil-gas radon and gravel fraction; and Fig. 8, pie charts of estimated abundances of high-, medium-, and low-risk among the 7 administrative regions of the Czech Republic. Since March 1991 the Ministry of Health has imposed limits as follows: $<120 \mathrm{~Bq}^{226} \mathrm{Ra} / \mathrm{kg}$ for building materials, $<100 \mathrm{~Bq}{ }^{222} \mathrm{Rn} / \mathrm{m}^{3}$ air in new and mitigated houses, $<200 \mathrm{~Bq}{ }^{222} \mathrm{Rn} / \mathrm{m}^{3}$ air in existing houses, and $50 \mathrm{~Bq} / \mathrm{L}(1350 \mathrm{pCi} / \mathrm{L})$ in drinking water.]

Barnet, Ivan, and Milan Matolin, 1991

Radon risk mapping in Czechoslovakia [abs.], in International Symposium on the Natural Radiation Environment, 5th, Salzburg, Austria, 22-28 September 1991, Abstracts:

Salzburg, Univ. Salzburg, Inst. for General Biology, Biochemistry and Biophysics, abs. no. 179

Radon risk mapping of the Czech Republic on the scale of 1:200 000 was completed in 1990. The joint project was prepared and realized by the Geological Survey, Prague, Uranium Survey (Rynoltice, Přibram and Nové Město na Moravě), Geophysics, Prague, and Faculty of Science, Charles University, Prague. TThe following data were used for radon risk compilation: (1) Field measurements of ${ }^{222} \mathrm{Rn}$ volume activity in soil air were carried out by the Uranium Survey on 148 test sites ( 25 points each), representing various rock types of the Bohemian Massif. Radon was determined in shallow soil drill[hole]s $\left(0.6-0.7 \mathrm{~m}\right.$ deep) using ${ }^{222} \mathrm{Rn}$ daughter product plastic collectors. The radon measurements were accompanied by gamma-spectrometric measurements and soil grain size analyses at each test site. All observed data are stored in a radon data base (HewlettPackard 86). (2) Additional data from airborne radiometric maps, geological, pedological, and hydrogeological maps, archived radiometric data, and results of monitoring of the seasonal variability of soil-gas radon. (3) Radon risk categories (low, medium, high) of geological and lithological units were classified according to fixed rules suggested by the team of the above-mentioned institutions. These rules were accepted by the Ministry of Environment of the Czech Republic. The resultant radon risk maps are the basis for planning radon protection activities and detailed measurements in individual regions. The cost of the protection against radon will be paid from the state budget. ISome data on ${ }^{222} \mathrm{Rn}$ volume activity in different rock types in the area of the Bohemian Massif are given in the following overview (mean value and range, in $\mathrm{kBq} / \mathrm{m}^{3}$ ): syenites and durbachites [dark biotite-hornblende syenites], 98 (4-435); granites and granitoid rocks, 52 (2-332); diorites, 40 (3-126); river terraces, 20 (1-183); sandstones, 11 (1-73); claystones, 9 (1-55). The radon risk maps have been compiled for seven regions of the Czech Republic. Two to eight percent of the measured radon values fall within the radon high risk category.

Been, J.M., G.M. Reimer, and S.L. Szarzi, 1989

Soil-gas radon distribution in Frederick County, Maryland [abs.]:

Eos, Am. Geophys. Union Trans., 70(5): 500

Soil-gas radon concentrations in Frederick County, Maryland correlate with lithology and geologic structure. Highest concentrations are found in phyllites and schists; lower concentrations are found in the carbonates of Frederick Valley; lowest concentrations correlate with quartzite ridges and mountains. Ground spectral gamma-ray measurements correlate well with the radon in the extremes but the correlation becomes unclear in the middle range of radon concentrations between 20 and $70 \mathrm{kBq} / \mathrm{m}^{3}(0.5$ and $2.0 \mathrm{nCi} / \mathrm{L})$. In some areas of the county, several populations of radon data are evident within a single geological formation. Such is the case for the rhyolites of the Catoctin Mountain region suggesting inhomogeneities within the volcanics. IThe study was conducted in two phases in 1988. Seasonal variations influence soil-gas radon so that concentrations were 30 percent higher in a dry period in late July than during an extended wet period in May. Despite 
seasonal differences, the average concentrations in some areas exceed $70 \mathrm{kBq} / \mathrm{m}^{3}(2.0 \mathrm{nCi} / \mathrm{L})$ and are great enough to indicate that there is a strong potential for indoor radon concentrations to exceed the $148-\mathrm{Bq} / \mathrm{m}^{3}$ (4-pCi/L) action level recommended by the U.S. Environmental Protection Agency. A radon potential map of rocks and soils could be derived from this data base that would be useful for land planning and establishing construction practices to minimize the problem.

Been, Josh M., S.L. Szarzi, and G.M. Reimer, 1989

Radon as a geologic mapping tool [abs.]:

Geol. Soc. America, Abstracts with Programs, 21(6): A143

Although the current interest in radon is a public health issue, most previous geologic studies that involved radon have been to evaluate its use for predicting volcanic eruptions, forecasting earthquakes, or locating uranium deposits. The wide range of soil- gas concentrations found in areal surveys, often several orders of magnitude, suggests that radon might be useful in mapping differences in rock type or geologic structure. A soil-gas reconnaissance survey of Frederick County, Maryland, has shown that the radon concentrations exhibit characteristic distributions for soils derived from various lithologies. The survey also indicates a contrast in radon concentration across major structural contacts or facies changes. While these concentration differences are not always unique, some are very distinctive. For example, quartzites, which form the core of ridges and mountains of the southern and western part of the county, have a mean radon concentration of $<18 \mathrm{kBq} / \mathrm{m}^{3}$ $(<500 \mathrm{pCi} / \mathrm{L})$, whereas phyllites, which occur in the Piedmont of the eastern part of the county, have a mean radon concentration of $>56 \mathrm{kBq} / \mathrm{m}^{3}(>1500 \mathrm{pCi} / \mathrm{L})$. The Catoctin rhyolites exhibit three populations of radon concentrations, with means of about 26,48 , and $85 \mathrm{kBq} / \mathrm{m}^{3}(700,1300$, and $2300 \mathrm{pCi} / \mathrm{L})$, suggesting subtle chemical variations within the parent material. Radon concentration differences from $18 \mathrm{kBq} / \mathrm{m}^{3}$ to over $0.15 \mathrm{MBq} / \mathrm{m}^{3}$ (500 to over $4000 \mathrm{pCi} / \mathrm{L}$ ) occur within a few meters across the Martic Line, a contact separating the Cambro-Ordovician limestones of the Frederick Valley from the pelitic schists to the east. Traverses across the Triassic border fault, which roughly defines the western side of the Frederick Valley, exhibit similar strong contrasts in soil-gas radon concentrations. Although rock type and structural contacts are well defined in the areas of Frederick County included in this study, it may be possible to use radon soil-gas concentrations for mapping hidden lithologies and structural contacts.

Blue, T.E., and M.S. Jarzemba, 1992

Determination and measurement of soil parameters for characterizing radon hazard of soils, in Cross, Fredrick T., ed., Indoor Radon and Lung Cancer: Reality or Myth? Twenty-ninth Hanford Symposium on Health and the Environment, Richland, Wash., October 15-19, 1990, Proceedings:

Columbus, Ohio, Battelle Press, Part 1, p. 373-382; discussion, p. 382-383 [NTIS]

There is little correlation between radon concentrations in soil and radon concentrations in homes. One explanation is that the soil radon concentration does not fully characterize the soil as a radon hazard. We have identified important soil properties by mathematically modeling ventilated air enclosed in basement walls of thickness $T$ (through which radon convects) and surrounded by soil of infinite extent (through which radon diffuses). The radon instantaneously mixes uniformly with the basement air by ventilation $\left(\lambda_{v}\right)$ and decay $(\lambda)$. The steady-state solution for the radon concentration in the basement is equal to:

$\mathrm{C}=\left\{\left(\mathrm{C}_{\mathrm{s}} \mathrm{K} \Delta \mathrm{P}\right) /\left[\left(\lambda+\lambda_{\mathrm{v}}\right) \mu \mathrm{T}\right]\right\}\{\mathrm{A} / \mathrm{V}\}\left\{\left[\epsilon_{3} \mathrm{~L}_{3}\right] /\left[\epsilon_{3} \mathrm{~L}_{3}+(\mathrm{K} \Delta \mathrm{P}) /(\mu \mathrm{T} \lambda)\right]\right\}\left\{\exp \left[\left(-\lambda \mu \epsilon_{2} \mathrm{~T}^{2}\right) /(\mathrm{K} \Delta \mathrm{P})\right]\right\}$, where $\mathrm{C}_{s}, \mathrm{~L}_{3}$, and $\epsilon_{3}$ are the soil's radon concentration, radon diffusion length, and porosity; $\epsilon_{2}$ and $K$ are the wall's porosity and permeability; $\mu$ and $\Delta \mathrm{P}$ are the air's viscosity and pressure difference across the basement wall; and $V$ and $A$ are the basement's volume and wall surface area. For a tight home, i.e., $\left[(K \triangle P) /(\mu T \lambda)<<\epsilon_{3} L_{3}\right]$, it is sufficient to measure $C_{s}$ to characterize the radon hazard of the soil. If a home is very leaky, i.e., $\left[(\mathrm{K} \triangle \mathrm{P}) /(\mu \mathrm{T} \lambda)>>\epsilon_{3} \mathrm{~L}_{3}\right.$ ], then $\mathrm{C}_{5} \epsilon_{3} \mathrm{~L}_{3}$ is a more appropriate parameter for assessing the radon hazard. [From preprint.]

Blue, T.E., J.A. Mervis, W.E. Carey, and M.S. Jarzemba, 1990

Characterization of soils as radon hazards [abs. WPM-A5], in Health Physics Society Ann. Mtg., 35th:

Health Physics, 58(Suppl. 1): S32 
Borak, T.B., D.C. Ward, and M.S. Gadd, 1992

Characterization of ${ }^{222} \mathrm{Rn}$ entry into a basement structure surrounded by low permeability soil, in The 1992 International Symposium on Radon and Radon Reduction Technology, Minneapolis, Minnesota, September 22-25, 1992:

U.S. Environmental Protection Agency, Preprints, v. 2, no. VI-1, 20 p.

An experimental facility has been developed to monitor the entry rate and concentration of ${ }^{222} \mathrm{Rn}$ in a basement type structure surrounded by soil having a permeability on the order of $10^{-11} \mathrm{~m}^{2}$. A data acquisition system recorded environmental conditions outside and inside the structures, plus basement air exchange rate information, every $15 \mathrm{~min}$. Indoor ${ }^{222} \mathrm{Rn}$ concentrations ranged from 400 to $1400 \mathrm{~Bq} / \mathrm{m}^{3}$. The observed ${ }^{222} \mathrm{Rn}$ entry rate is highly variable and has two primary components; a constant input rate caused by diffusion of ${ }^{222} \mathrm{Rn}$ through the concrete walls and floor, and a variable rate that depends upon indoor soil pressure differentials of only a few pascals. Pressure differentials are dependent upon wind speed and wind direction. Stack effect was not significant. During a 2-week period, with relatively calm winds, diffusion through the concrete walls and floor plus the floor-wall joint accounted for more than $80 \%$ of the total ${ }^{222} \mathrm{Rn}$ entry.

Braman, Robert S., and Robert L. Sutton, 1990

Development and application of a soil-air radon analysis technique in Florida:

Florida Scientist, 53(2): 130-137

[A soil probe of $2.2-\mathrm{cm}$ inside diameter, driven to depths of $20-25 \mathrm{~cm}$, was used in conjunction with evacuated $\alpha$ scintillation cells after a purging of more than twice the internal volume of the probe by means of a hand vacuum pump. Indoor alpha-track measurements in four houses showed a direct qualitative correlation with radon in soil gas measured by the probe technique.]

Brookins, Douglas G., 1986

Indoor and soil $\mathrm{Rn}$ measurements in the Albuquerque, New Mexico, area:

Health Physics, 51(4): 529-533

Brooks, J.R., 1989

Maryland geology and indoor radon [abs.]:

Eos, Am. Geophys. Union Trans., 70(15): 500

The first suggestion that Maryland could have a potential radon problem came from a report by Moschandreas and Rector [q.v.] during 1982. This study of 60 homes in and around Mount Airy indicated 30\% of the homes surveyed contained radon in excess of $148 \mathrm{~Bq} / \mathrm{m}^{3}(4 \mathrm{pCi} / \mathrm{L})$. Aeroradioactivity maps of the State indicated that geology might be important factor in determining where radon might be a problem. These maps together with the Naticnal Uranium Resource Evaluation Program data show a broad area of elevated radioactivity extending northeast from the Virginia [State boundary] line through Mount Airy and Westminster to the Pennsylvania border. This corresponds to a belt of phyllitic rocks which include the Ijamsville, Marburg, and Urbana formations. Other anomalies can be attributed to granitic rocks, faults, and Triassic sediments. Early in 1988 the Maryland Survey obtained several hundred indoor radon readings from the Maryland Department of Health and Mental Hygiene to see if elevated readings could be attributed to any particular geologic formation. These readings were then plotted on County Geologic Maps at a scale of 1:62500 and the geologic information along with the values and coordinates were entered into a computer database. The database showed that certain rock units or groups of rock units have recognizable indoor radon signatures. These signatures are influenced by rock and soil permeability as well as uranium content.

Buchli, R., and W. Burkart, 1989

Influence of subsoil geology and construction technique on indoor air ${ }^{222} \mathrm{Rn}$ levels in 80 houses of the central Swiss Alps:

Health Physics, 56(4): 423-429 
[Subsoil geology, cellar floor permeability, cellar ventilation, air tightness, ventilation practices of the occupants, and alpha-track indoor radon levels at cellar and first-floor living-room levels were compiled for 80 houses. Houses on granitic, ortho-gneissic, or verrucano subsoil had cellar radon concentrations averaging 4.4 times greater than those on a gray schistose or sedimentary subsoil; for houses not having a full concrete slab cellar floor the average was 5.4 times greater. Tight, energy-efficient houses had living-room levels averaging 1.8 times greater than did normally insulated houses.]

Burnett, Bill, Jim Cowart, Dave Clark, Renata van der Weijden, and Peter Cable, 1989

Radon in shallow groundwater in Florida - A possible relationship to soil flux? [abs.]:

Eos, Am. Geophys. Union Trans., 70(15): 500

The measurement by Florida of indoor radon in over 6000 homes and soil gas concentrations at approximately 3000 sites during 1986-1987 has resulted in a much better understanding of the distribution of radon in the state than was previously possible. Using these results as a guide, we selected three small $\left(\leq 400 \mathrm{~m}^{2}\right)$, undeveloped study areas to test in some detail the concept that the flux from the soil to the atmosphere may bear a relationship to radon in the associated shallow groundwater. The three sites represent areas of high, intermediate, and low indoor radon. Well fields were established and we have been making regular measurements of radon in water, soil-gas radon, and radon soil fluxes for approximately one year. Our results show that, in general, the area with the highest indoor radon also displays the highest radon in shallow groundwater (occasionally in excess of $2 \mathrm{MBq} / \mathrm{m}^{3}, 60,000 \mathrm{pCi} / \mathrm{L}$ ), and is characterized by the highest soil radon and soil fluxes. The area with low indoor radon had average water values two orders of magnitude lower than our high site, while the soil concentration and flux measurements were about one order of magnitude lower. These results suggest that groundwater, in a water-table aquifer, may be a useful indicator of radon potential of undeveloped land.

Carlisle, Donald, and Haydar Azzouz, 1991

Geological parameters in radon risk assessment-A case history of deliberate exploration, in The 1991 International Symposium on Radon and Radon Reduction Technology, Philadelphia, Pa., April 2-5, 1991, Proc., Volume 2, Symposium Oral Papers, Technical Sessions 6 through 10:

U.S. Environmental Protection Agency Rept. EPA/600/9-91/037B, p. 9-59-9-73

McLean, Va., Cohen (S.) and Associates, Inc. [Springfield, Va., NTIS Order No. PB92-115369]

[Preprints, v. 5, no. IX-6]

Geological exploration has identified an unsuspected radon-prone belt in southern California. Detailed analysis of aeroradiometric (NARR)[the National Airborne Radiometric Reconnaissance component of the National Uranium Resource Evaluation program] data in relation to geological units, soil-gas radon, soil permeability, and finally indoor radon has identified the Rincon shale and soils derived predominantly from the Rincon shale in Santa Barbara County as anomalous in uranium and radon. Roughly $76 \%$ of our screening tests to date from homes on the Rincon shale exceed $148 \mathrm{~Bq} / \mathrm{m}^{3}(4 \mathrm{pCi} / \mathrm{L})$ and $26 \%$ exceed $740 \mathrm{~Bq} / \mathrm{m}^{3}(20 \mathrm{pCi} / \mathrm{L})$. Measurements under "normal" living conditions show $42 \%$ exceeding $148 \mathrm{~Bq} / \mathrm{m}^{3}(4 \mathrm{pCi} / \mathrm{L})$. An estimated $>4000$ homes are at this level of risk; extensive new construction on the Rincon shale is limited only by domestic water availability. TUnusually good correlations between aeroradiometry, soil-gas radon at $75-\mathrm{cm}$ depth adjusted for soil-gas permeability, geology, and indoor radon concentrations reflect the unmetamorphosed character of sedimentary host rocks and the tendency for anomalous uranium concentrations to be disseminated throughout a geological unit rather than in erratic mineralized zones. Under these circumstances, deliberate geological exploration can be a more efficient approach to radon risk identification than simple random sampling or non-random testing of homes, and by the same token geological parameters can facilitate radon risk assessment on undeveloped lands.

Carlisle, Donald, and Haydar Azzouz, 1993

Discovery of radon potential in the Rincon Shale, California-a case history of deliberate exploration:

Indoor Air, 3: 131-142

[See abstract above.] 
Castrén, O., 1987

Dealing with radon in dwellings: The Finnish experience, in Indoor Radon II, Proceedings of the Second APCA International Specialty Conference, Cherry Hill, New Jersey, April 6-10, 1987:

Pittsburgh, Pa., Air Pollution Control Association Pub. SP-60, p. 45-56

[A main objective of the Finnish Centre for Radiation and Nuclear Safety (STUK) has been to locate and define the high radon concentration areas and dwellings. The geographical distribution of high radon concentrations is due to both uranium content and permeability of the ground. The highest indoor concentrations are caused by a combination of elevated uranium concentration, location on an esker, and a great temperature difference between indoor and outdoor air. There is usually a large seasonal variation, with a maximum in winter. Whereas in the 1970s Finnish researchers attributed high radon in water from bored wells to be the radiation protection problem (see above abstract), in late 1980 they changed their view in favor of the inhaled progeny from radon entering the indoor air from the soil. From the earliest surveys, the clustering of high indoor radon concentrations in certain geographical areas and in houses with ground contact suggested a connection with geology and indicated a need for maintaining a map of the occurrences. The map, in revised editions, is used in STUK's seeking strategy. It is considered most cost effective to concentrate measurement surveys in the geographical clusters. The map editions of 1983, 1985, 1986, and 1987 are shown, and comparison maps are shown for bedrock and ground-water uranium occurrences, external $\boldsymbol{\gamma}$-ray dose rate, uranium in glacial till, indoor radon concentrations, lung-cancer rates for males (1953-62 and 1973-82), and lung cancer rates for rural females. Everywhere in Finland, the houses built on eskers (long, sinuous ridges of stratified glacial sediments, usually of sorted sand and gravel of very high gas permeability) have the highest mean indoor radon concentrations and the highest percentages of houses with $>800 \mathrm{~Bq} / \mathrm{m}^{3}$.]

Castrén, Olli, 1990

Radon in Finland:

Finnish Features, November 1990, Classification 6.3.7.4., 4 p.

Helsinki, Finnish Government Printing Office

[This concise fact sheet, published by the Ministry of Foreign Affairs, summarizes research from 1955 onward on the indoor radon problem. Maps are shown of indoor radon occurrence. The 1983 edition was based on measurements in 2154 houses in 108 municipalities. The 1990 edition shows the arithmetic means in six concentration classifications for $10 \times 10 \mathrm{~km}$ squares and is based on measurements in about 20,000 detached houses. A map of the municipality of Tampere, Pispilan esker, shows the prevalence of houses of elevated radon concentration on an esker, a long ridge of sand deposited by glacial action. In most cases, the apparent primary cause of elevated indoor radon is high permeability to air of the soil on which a house has been built.]

Castrén, O., H. Arvela, I. Mäkeläinen, and A. Voutilainen, 1991

Indoor radon survey in Finland: Methodology and applications, [abs.], in International Symposium on the Natural Radiation Environment, 5th, Salzburg, Austria, 22-28 September 1991, Abstracts:

Salzburg, Univ. Salzburg, Inst. for General Biology, Biochemistry and Biophysics, abs. no. 130

Since 1980, the Finnish Centre for Radiation and Nuclear Safety (STUK) has performed indoor radon measurements with integrating alpha track dosemeters in about 35,000 homes. The position of the house marked on a map and relevant construction and other data have also been collected. A mapping system makes it easy to determine the coordinates from the local map and the type of bedrock and soil from geological maps. These data, together with the annual average radon concentration of the dwelling, form the basic radon database, a SAS dataset of about 23,000 houses, the coordinates of which are known. New results are continuously added. The basic radon database, the mapping system, and various auxiliary registers form together an indoor radon information system which is extensively used for planning and information puposes and for research. ISTUK helps the municipal health authorities by devising radon measurement plans and radon prognosis maps. The former helps the local health authorities to find the areas where more measurements should be performed. The radon prognosis map helps the municipalities to take radon-prone areas into account in their physical planning. Both the measurement plans and the prognosis maps are based on the use of the mapping system, which also makes it possible to draw maps of the results in any scale and 
form. TThe method of measurement, the seasonal correction, the collection, processing, and retrieval of data and the construction and use of the mapping system are briefly described. Examples of the principal applications are presented.

Castrén, O., I. Mäkeläinen, K. Winqvist, and A. Voutilainen, 1987

Indoor radon measurements in Finland: A status report, Chap. 8, in Hopke, Philip K., ed., Radon and Its Decay Products; Occurrence, Properties, and Health Effects:

Washington, Am. Chem. Soc. Symposium Ser. 331, p. 97-103

[The main factors that determine the indoor radon concentration are the product of the radium concentration in the ground and its emanating power, and the permeability of the ground. In Finland, the soil is mostly glacial till. Figure 3, showing a map of Finland with geometric means of indoor radon concentrations of 183 localities, shows fairly good correlation with figure 4 , the distribution of external gamma-ray dose rates measured from Finnish roads, as does the distribution of uranium concentration in glacial till. Higher wintertime indoor radon concentrations are attributed to stack effects, rather than to lower ventilation rates.]

Castrén, O., A. Voutilainen, and I. Makelainen, 1987

A seeking strategy for high indoor radon concentrations, in Indoor Air '87. Proceedings of the Fourth International Conference on Indoor Air Quality and Climate, Berlin, 17-21 October 1987:

Berlin, Inst. for Water, Soil and Air Hygiene, v. 2, p. 285-289

[The Finnish objective, based on a cost-benefit analysis, is to find dwellings in which the annual average ${ }^{222} \mathrm{Rn}$ concentration exceeds $800 \mathrm{~Bq} / \mathrm{m}^{3}(\approx 20 \mathrm{pCi} / \mathrm{L})$ and areas in which a significant fraction of houses exceed 200 $\mathrm{Bq} / \mathrm{m}^{3}$. Initial surveys indicated that the type of building site (soil character) and geographical location were the main determinants of indoor radon.]

Castrén, O., A. Voutilainen, K. Winqvist, and I. Makelainen, 1985

Studies of high indoor radon areas in Finland:

The Science of the Total Environment, 45: 311-318

Cattafe, Joseph S., Colleen A. Ranney, Keith E. Miller, and Robert H. Andolsek, 1989

Regional NURE, geology and soils data as predictors for indoor radon, in Osborne, M.C., and Jed Harrison, Symposium Cochairmen, The 1988 Symposium on Radon and Radon Reduction Technology, Proc., Vol. 2, Symposium Poster Papers:

Research Triangle Park, N.C., Radian Corp., U.S. Environmental Protection Agency Pub. EPA/600/9-89/006b [Springfield, Va., NTIS Order No. PB89-167498], p. 3-25--3-39.

For the New Jersey Statewide Scientific Study of Radon, environmental data were input into a geographical information system (GIS) to perform spatial analysis on geographic predictors of indoor radon. Geologic units were input at the 1:63,360 scale, and soil association units were input at the 1:250,000 scale. A radon source potential map was developed by classifying geologic units as high, medium, or low radon potential, based upon average radium concentrations assigned to the units from aerial radiometric data obtained from the National Uranium Resource Evaluation (NURE). A radon transport potential map was similarly developed by classifying soil association units according to soil-gas transport characteristics extrapolated from more detailed county soil surveys. A combined radon potential map was developed by intersecting [sic] these two maps, and was compared with indoor radon concentrations measured in 6,000 homes in New Jersey. A positive correlation was found between indoor radon and radon potential as defined in this study. [Table 1 lists geologic formations or rock types ranked as having high radon source potential. Within that category, from the lowest to highest potential, they are: Brunswick Formation (Triassic); gneisses, amphibolites, and granites (Precambrian); Lockatong Formation (Triassic); Pocono Island Inferred (Silurian); Jacksonburg Formation (Ordovician); Kittatinny Limestone(Cambro-Ordovician), including Ontelaunee, Epler, Rickenback, Allentown, and Leithsville Members; rocks similar to Lockatong; Hardyston Formation (Cambrian); and undifferentiated Cambrian and Ordovician rocks.] 
Chadima, Sarah A., 1989

Generalized potential for radon emission based on estimated uranium content in geologic rock units, South Dakota:

Vermillion, S.D., Univ. South Dakota Science Center, South Dakota Division of Geological Survey Circ. 44, 23 p.

[This report, based primarily on the estimated uranium content of bedrock units, includes a plate showing estimated radon potential in five tiers.]

Clavensjö, B., Åkerblom, G.V., and Andersson, P., 1983

Radon in dwellings. The effect of the ground on radon levels and gamma radiation indoors [in Swedish]:

Stockholm, Statens rad for byggnadsforskning, Rept. R9: 1983, 442 p. [ISBN 91-540-3866-9]

[Referenced in Wilson, 1985-1986.]

Cliff, K.D., A.D. Wrixon, B.M.R. Green, and J.C.H. Miles, 1987

Concentrations in dwellings in the United Kingdom, Chap. 9 in Hopke, Philip K., ed., Radon and Its Decay

Products; Occurrence, Properties, and Health Effects:

Washington, Am. Chem. Soc. Symposium Ser. 331, p. 104-112

[Certain regions, identified from geological data as having above average concentrations of natural radionuclides, received detailed local surveys of radon in dwellings. The local surveys in southwest England (Devon and Cornwall) showed average exposures 15 times greater than the national mean, in qualitative agreement with the greater uranium mineralization of their soils.]

Coleman, K.A., 1993

Washington's radon construction standards: The building code process, in The 1993 International Radon Conference, Denver, Colo., Sept. 20-22, 1993:

Denver, Colo., Am. Assoc. Radon Scientists and Technologists, Rocky Mountain Chapter, Preprints, 7 p.

Washington's radon prescriptive construction standards went into effect on an interim basis on July 1, 1991, as part of the State's Ventilation and Indoor Air Quality (VIAQ) Code adopted by the State Building Code Council. The code requires some State-wide radon-resistive construction measures and the provision of a three-month $\alpha$-track detector to all single-family homes and to all first-floor units of multi-family dwellings. The homeowner's use of the monitor is voluntary. An additional requirement is for a passive stack system and sub-slab aggregate to be installed in new slab-on-grade and basement homes located in eight counties designated as having higher radon potential. The final VIAQ Code was implemented on July 1, 1993.

Coleman, K.A., G.C. Hughes. nd EJ. Scherieble, 1993

Where's the radon? The Geagraphic Information in Washington State [abs.], in First International Workshop on Indoor Radon Remedial Action, The Scientific Basis and Practical Applications, Rimini, Italy, 27 June-2 July 1993:

Commission of the European Communities et al., Book of Abstracts, p. 75

As Washington State's lead agency for radon issues, the Department of Health (DOH) is developing the analytical basis for establishing a public-health policy regarding radon. The Geographic Information System (GIS) is a fundamental st in this analytical process to develop a map of the potential for radon occurrence. The GIS will take into account geology, geography, topography, soil permeability, indoor radon test results, population density and distribution; and housing type and volume contributing to our understanding of indoor radon. In addition, $\mathrm{DOH}$ is working to aid policy makers and residents by establishing the lowest exposure range at which lung cancers are observed, a departure from the commonly used risk assessments that extrapolate from high to low exposure, to determine how many Washington residents are at risk. In conclusion there is an examination of Washington's radon prescriptive construction standards for residences.

Coleman, K.A., and E.J. Scherisble, 1993

Radon and the Geographic Iruormation System, in The 1993 International Radon Conference, Denver, Colo., Sept. 20-22, 1993: 
Denver, Colo., Am. Assoc. Radon Scientists and Technologists, Rocky Mountain Chapter, Preprints, 7 p.

As Washington State's lead agency for radon issues, the Department of Health is developing the analytical basis for establishing a public health policy regarding radon. A fundamental step in this analytical process is the development of a map of the geologic potential for radon occurrence. This map will serve as the base map for a series of data overlays. Through the application of a geographic information system, the Department of Health will perform an integrated analysis of the various elements contributing to our understanding of indoor radon. These elements include geology, geography, topography, and soil permeability; indoor radon test results; population density and distribution; and housing type and number.

Collé, R., R.J. Rubin, L.I. Knab, and J.M.R. Hutchinson, 1981

Radon Transport Through and Exhalation from Building Materials; A Review and Assessment:

U.S. National Bur. Standards Tech. Note 1139, 101 p. [Washington, GPO]

The report 1) considers the routes of entry of radon into buildings, describes the basic models for radon transport through building materials, critically reviews the small number of existing values for the necessary transport coefficients, and summarizes the solutions of both steady-state and time-dependent transport cases; 2) reviews and considers how the microstructural properties and internal characteristics of building materials may affect the transport and exhalation of radon; 3) considers the exhalation process from a more macroscopic, phenomenological viewpoint, and summarizes selected experimental data on radium concentrations in building materials, radon flux and exhalation from soils and building materials, and the effects of meteorological variables on radon exhalation; and 4) reviews and assesses various measurement methodologies that are used for laboratory and in situ studies of radon transport and exhalation. Needs for further research in each area are also recommended.

Cotter, Jeff M., 1990

Simulated transport of radon in soil gas [M.S. Thesis]:

Honolulu, Univ. Hawaii at Manoa, Dept. Geology \& Geophysics, xiv + 155 p.

A field monitoring study was undertaken to characterize the interaction between environmental factors such as rainfall, atmospheric pressure changes, wind-driven pressure changes, and soil-gas radon mobility. Two identical test and control arrays containing radon, soil moisture, and differential pressure monitoring instruments were installed in central Oahu, Hawaii. Radon activities in soil gas were monitored using passive, electronic alpha-particle detectors at depths of $0.8,1.3$, and $2.3 \mathrm{~m}$; soil moisture and differential soil gas pressures were monitored at equivalent depths. After an evaluation period to confirm that the test and control arrays showed similar radon responses, the test array was covered with a plastic barrier to determine the significance of advective exchange of soil gas with atmospheric air. TThe field results show radon concentrations in soil gas were found to be strongly dependent on depth in the soil profile: at $0.8 \mathrm{~m}$ the average soil-gas radon concentration was $22,000 \mathrm{~Bq} / \mathrm{m}^{3}$; at $1.3 \mathrm{~m}$ it was $37,000 \mathrm{~Bq} / \mathrm{m}^{3}$; and at $2.3 \mathrm{~m}$ it averaged $48,000 \mathrm{~Bq} / \mathrm{m}^{3}$. Significant radon activity increases (30 to $120 \%$ ) at 0.8 - and $1.3-\mathrm{m}$ depth were found to follow moderate-to-intense rainfall events. The activity changes are attributed to reduced advective and diffusive pathways for radon loss to the atmosphere and partitioning of radon into a smaller volume of soil gas due to increased soil saturation. Rainfall events show little effect on radon concentrations at $2.3 \mathrm{~m}$. Radon concentrations at the shallow depths also exhibit a slow decline during extended dry periods due to increased advective and diffusive loss of radon through the drier soil; the deepest probe showed only minor changes in radon activity during the dry periods. TRadon activities also responded to synoptic and semi-diurnal atmospheric pressure changes at $0.8-\mathrm{m}$ depth throughout the study. A similar response was observed at $1.3-\mathrm{m}$ depth only when the soil was at its driest, but no pressure response was observed at 2.3-m depth at any time. Effects due to wind-driven pressure changes are inconclusive at present. Results from the advective-barrier experiment strongly suggest that mixing of soil gas with atmospheric air causes a significant reduction in soilgas radon concentrations at depth of 0.8 and $1.3 \mathrm{~m}$, but little effect at 2.3-m depth. $\pi$ Computer simulation of the measured and observed data was performed using [the numerical modeling] RN3D, a finite-element radon transport code. Simulated radon transport is by advection and diffusion in the gas phase and diffusion only in the liquid phase. The modeling effort was intended to calibrate RN3D, as well as to reveal the relative 
sensitivity of radon behavior to soil physical properties. IRN3D was calibrated by conducting steady-state simulations and adjusting soil diffusion coefficients to simulate the observed radon concentration profile. Transient, one-dimensional model runs were then used to further adjust the diffusion coefficients and determine soil air permeabilities. Using field-measured air permeabilities, RN3D was initially unable to simulate the observed variations in the radon time series; however, if air permeabilities were raised by a factor of 1000 above field values, RN3D was able to simulate the observed radon variations with respect to synoptic and diurnal pressure changes, as well as radon activity increases due to rainfall events. This suggests that the technique used in this study to measure soil air permeability does not adequately account for the preferential flow and large-scale soil features which contribute to the true soil air permeability or that the transport equations used in RN3D do not realistically characterize the subsurface air flow in a highly saturated, lowpermeability soil. A sensitivity analysis performed with RN3D showed that soil diffusion is the most important parameter in determining radon concentrations in soil gas and radon flux from the soil, followed by soil crack geometry, and then by soil-air permeability.

Cotter, J., and D.M. Thomas, 1989

Ground gas radon response to meteorological perturbations [abs.]:

Eos, Am. Geophys. Union Trans., 70(15): 497

Soil gas radon activities have been monitored at depths ranging from one-half to two meters for a period of several months using recently developed passive electronic alpha particle counters. The devices continuously integrate slpha particle decays and record the decay rates at fifteen minute intervals for later retrieval. The results of this monitoring effort have shown that semi-diurnal barometric pressure changes as small as four millibars $[\approx 400 \mathrm{~Pa}$ ] produce a detectable variation in radon activity at depths of at least two meters and that larger synoptic pressure changes can increase or decrease radon concentrations by as much as $20 \%$. Soil moisture has been found to have a substantial impact on the average radon activity at relatively low soil moisture levels but, after soil water content exceeds $50 \%$ saturation, the variations are much smaller even when intense rainfalls bring soil moisture to saturation levels. Characterization of seasonal rainfall effects on radon transport to the surface are currently underway. We have also found that subtle differences in deployment protocol can have substantial impacts on the radon response to barometric and rainfall perturbations. These differences have suggested that even small discontinuities in soil permeability (eg. cracks or root cavities) may have a substantial effect on near-surface radon degassing. The results of our ongoing radon monitoring investigation will be presented along with our initial efforts at modelling radon mobility in response to meteorological effects.

Cowart, J.B. and W.C. Burnett, 1989

Elevated radon generated in terra rossa in south Florida [abs.]:

Geol. Soc. America, Abstracts with Programs, 21(6): A144

An elevated radon anomaly located just south of Miami, Florida, was discovered by a state-wide radon survey completed in 1987. The anomaly seems to coincide with an area known as "The Redlands", an area of terra rossa underlain by the Miami limestone, which was deposited about 120,000 years ago, as determined by Useries methods. Terra rossa is generally considered to be a residual soil although in the case of south Florida and the Caribbean islands, an airborne source for some constituents has been proposed by others. Be that as it may, the terra rossa samples from south Florida have developed unusual activity ratios for the uranium series nuclides. Using acid-leached samples, gamma spectroscopy indicates the Ra-226 is greatly in excess of U-234 with $\mathrm{Pb}-210$ being intermediate in activity; by alpha spectroscopy Th-230 is greatly in excess of U-234. These results indicate that the processes operative in the formation of terra rossa retain Th-230 and Ra-226 while permitting loss of the parent uranium. The significant difference in activity between $\mathrm{Ra}-226$ and $\mathrm{Pb}-21 \mathrm{O}$ suggests that such soils may be powerful radon-emitting sources.

Cui, L[in]-P[ei], 1990

Radiometric methods in regional radon hazard mapping:

Nuclear Geophysics, 4(3): 353-364 
[Mechanisms of radon emanation and migration and procedures for radon potential mapping are discussed. Aeroradiometric data from the NURE program were processed for the Salt Lake City, Utah, area. A Precambrian gneiss was found to have associated soil-gas radon concentrations significantly greater than a Tertiary granite of greater equivalent uranium, as evaluated from the aeroradiometric data.]

Cullen, T. L., 1946

On the exhalation of radon from the earth:

Terrestrial Magnetism and Atmospheric Electricity, 51(1): 37-44

[Good historical review of rate of exhalation of radon from the earth.]

Culot, Michel V.J., Hilding G. Olson, and Keith J. Schiager, 1976

Effective diffusion coefficient of radon in concrete, theory and method for field measurements:

Health Physics, 30(3): 263-270

A linear diffusion model serves as the basis for determination of an effective radon diffusion coefficient in concrete. The coefficient was needed to later allow quantitative prediction of radon accumulation within and behind concrete walls after application of an impervious radon barrier. A resolution of certain discrepancies noted in the literature in the use of an effective diffusion coefficient to model diffusion of a radioactive gas through a porous medium is suggested. An outline of factors expected to affect the concrete physical structure and the effective diffusion coefficient of radon through it is also presented. Finally, a field method for evaluating effective radon diffusion coefficients in concrete is proposed and results of measurements performed on a concrete foundation wall are compared with similar published values of gas diffusion coefficients in concrete.

Czarwinski, R., R. Lehmann, and W. Röhnsch, 1993

Radon in Eastern German houses-Surveys and outcomes [abs.], in First International Workshop on Indoor Radon Remedial Action, The Scientific Basis and Practical Applications, Rimini, Italy, 27 June-2 July 1993: Commission of the European Communities et al., Book of Abstracts, p. 102

Comprehensive, systematic investigations of the problem of "Radon in Eastern German Houses" were launched, by the Federal Office for Radiation Protection after the German unification: 1. to study in the framework of the Federal Project, "Radiological registration, investigation and evaluation of mining relics," the influence of old and recent mining activity, especially of uranium ore mining and milling, on the radon concentration in houses; 2. to identify location and extent of areas with high radon potential from geogenic reasons, and find out communities and buildings especially afflicted; 3 . to solve specific problems of public, economic, or basic concern by investigating existing buildings or building ground upon request of territorial authorities, enterprises or citizens; and 4. to complete the country-wide, representative survey of the FRG with the respective values of the new Federal Lands. Under items 1 and 2, short-term measurements in 30,000 buildings of 250 communities were made in the interest of quick evaluation required, whereas under items 3 and 4 long-term measurements provide for the accurate conclusions needed. Results obtained so far show the dominant contribution of the underground to enhanced radon concentrations in buildings. Granitic formations near the surface give rise to extended high median values of the frequency distribution. Extremely high concentrations are observed where direct connections of buildings exist to mining relics in the ground, e.g., uranium-bearing waste rock or near-surface workings. Outside the geologically or mining-determined areas, the frequency distribution of radon in Eastern German houses is expected to be similar to that in Western Germany.

Damkjær, A[nders], and U. Korsbech, 1985

Measurement of the emanation of radon-222 from Danish soils:

The Science of the Total Environment, 45: 343-350

Damkjær, A., and U. Korsbech, 1988

A search for correlation between local geology and indoor radon concentrations:

Radiation Protection Dosimetry, 24(1-4): 51-54 
[Houses situated on limestone in the southern part of the island of Mors, in the northern part of Jutland, Denmark, had about twofold greater indoor ${ }^{222} \mathrm{Rn}$ concentrations than houses situated on moraine clay in the northern part of the island, despite an order-of-magnitude greater "radon emanation" of the clay. The permeabilities of the soils are not given.]

\section{Damkjær, A., and U. Korsbech, 1992}

A small-diameter probe for in-situ measurements of gas permeability of soils, in Janssens, A., W. Lowder, M. Olast, J. Sinnaeve, and F. Steinhäusler, eds., The Natural Radiation Environment, Proceedings of the Fifth International Symposium on the Natural Radiation Environment, Salzburg, Austria, September 22-28, 1991: Radiation Protection Dosimetry, 45(1-4), Supplement: 85-89

[From Book of Abstracts, no. 22] The gas permeability of the soil is one of the major factors determining the radon source potential of a local site. In situ measurements of the permeability are therefore needed to estimate the radon risk for a specific site. More detailed measurements of the permeability are also needed as input data for the mathematical models which describe the transport of radon through soil. A permeability probe for in-situ measurements has been designed and tested. A small-diameter probe was chosen in order to minimize the labor involved in the drilling operation prior to the measurement. The associated drilling equipment and the field instrumentation are described. The borehole is $20 \mathrm{~mm}$ in diameter and cased with a plastic tube. The probe, which is $16 \mathrm{~mm}$ in diameter [and $150 \mathrm{~mm}$ long] is led through the casing to the measurement position. A packing procedure designed to prevent gas leakage along the casing has been tested. The calibration procedure for the probe is described, and a protocol for in situ measurements is proposed. A site mapping of the permeability to depths of a few meters has been performed. The measurements are compared with a geological description of the strata and with measurements of the water content of the soil. The variation of permeability with time is considered. [The permeability probe operates in the injection mode, i.e., air is pumped into the formation under constant pressure. This paper summarizes the theoretical framework for the permeability measurement and gives the shape factor for the probe. A laboratory calibration facility has been designed and tested. The measured shape factor for the probe in the calibration facility was found to agree well with the calculated value. A possible correlation between the measured permeability and the applied pressure difference has been investigated.]

Dron, Elizabeth M., 1993

UK Radon Programme: Policy and progress [abs.], in First International Workshop on Indoor Radon Remedial Action, The Scientific Basis and Practical Applications, Ririni, Italy, 27 June-2 July 1993:

Commission of the European Communities et al., Book of A suracts, p. 110

The United Kingdom is pursuing a substantial and evolving program towards minimizing the problem of high radon levels in homes. Work focuses on those areas of the country which early surveys have shown to have a significant proportion of affected homes, and involves cooperation between central and local government, research institutions, and private companies. Elements of the program include: radon measurements on demand from householders in areas of potentially high radon, and systematic surveys to refine knowledge of these areas; research into geological, epidemiological, psychological, and financial aspects of the problem; the development and dissemination of advice on remedial and preventive measures; and a comprehensive approach to communication with all parties involved in issues of domestic exposure to radon. This paper contains a general description of the progr $2 m$, setting its objectives in the context of public policy on housing and health in the UK. An account of progress is given, and future options are outlined towards fulfilling the government's intention that substantial progress towards dealing with the impact of radon should be made by the close of the century.

DSMA Atcon, Ltd., 1983

Review of existing instrumentation and evaluation of possibilities for research and development of instrumentation to determine future levels of radon at a proposed building sit:

Ottawa, Atomic Energy Control Board Research Rept. INFO-0096. p. 
[This report carried Arthur Scott's soil probe for measuring radon concentration in soil gas and permeability, later used with slight modifications by C.O. Kunz, by EPA-ORP contractors in the House Evaluation Program, by Rogers and Associates Engineering Corp., and by contractors for the Florida Radon Research Program.]

Dulaney, Richard A., 1992

Analysis of indoor radon in New Mexico using geographic information systems (GIS) [abs.], in The 1992 International Symposium on Radon and Radon Reduction Technology, Minneapolis, Minnesota, September 22-25, 1992:

U.S. Environmental Protection Agency, Preprints [poster papers], v. 5, no. VIIIP-4

Geographic Information Systems (GIS) are a powerful computer based information management tool for spatial or geographic data. This technology, which blends traditional computer cartography with state-of-the-art database management, is being employed to analyze indoor radon in New Mexico. The project, being undertaken in support of EPA Region 6, looks at both state-wide and local patterns of indoor radon. The geographic distribution and spatial relationships of over 1000 indoor radon samples, taken from the EPA/State random survey conducted in 1989, are examined. The correlation of these radon samples with geology, soils, aerial radiometric, and population data is explored using GIS spatial overlay techniques.

Duval, J.S., 1989

Indoor radon prediction using gamma-ray spectrometric data [abs.]:

Eos, Am. Geophys. Union Trans., 70(15): 496

Because radium-226 is measured directly by gamma-ray techniques and because it is the progenitor of radon-222, spectral gamma-ray data can be used to estimate the amount of radon in soil gas, which then can be used to estimate relative indoor radon levels. The positive correlation between measurements of radon in soil gas and surface concentrations of radium confirms that the gamma-ray data can be used to estimate the radon in soil gas. Because such soil properties as emanation power and location of the radium affect the radon concentration at depth, the relationship between the surface radium and the radon in the soil gas can vary from place to place. Comparisons of aerial gamma-ray data to average indoor radon levels in homes in New Jersey and in the Pacific Northwest show that the aerial gamma-ray data also can be used to estimate the relative indoor radon levels. However, the data from the Pacific Northwest indicate that soil permeability is a very important factor that significantly increases the average indoor radon for a given amount of radium in the soil. Although aerial and ground gamma-ray data provide useful tools for radon hazard assessment, geologic properties of the soils must be considered also; soil permeability is particularly important.

Duval, Joseph S., 1991

Use of aerial gamma-ray data to estimate relative amounts of radon in soil gas, in Gundersen, Linda C.S., and Richard B. Wanty, eds., Field studies of radon in rocks, soils, and water:

U.S. Geol. Survey Bulletin no. 1971, p. 155-162

Because aerial gamma-ray measurements of equivalent uranium are an indirect measure of radium-226 and a direct measure of bismuth-214, which is a daughter isotope separated from radon-222 by short-lived isotopes of polonium and lead, gamma-ray data can be used to estimate the relative amounts of radon in soil gas. Theoretical calculations are available that enable an interpreter to define the limitations on the coverage provided by an aerial survey. Aerial survey data for the State of New Jersey are compared to indoor radon measurements. The results of this comparison support the use of aerial gamma-ray data to estimate the relative concentrations of radon in soil gas, and published data comparing radon concentrations in soil gas to surface gamma-ray measurements provide corroborating evidence. The application of Swedish criteria for assessing radon hazards to the data for New Jersey suggests that hazard-assessment criteria from one area may not be correct for other, geologically different areas.

Duval, Joseph S., and William J. Jones, 1988 
Regional aerial gamma-ray maps for Illinois and parts of Wisconsin, Iowa, Michigan, Indiana, Missouri, and Kentucky, in Marikos, Mark A., and Robert H. Hansman, eds., Geologic Causes of Natural Radionuclide Anomalies, Proceedings of the GEORAD Conference, St. Louis, Mo., April 21-22, 1987:

Rolla, Mo., Missouri Dept. Nat. Resources Spec. Pub. No. 4, p. 157-165.

Duval, J.S., WJ. Jones, and J.K. Otton, 1989

Radium distribution map and radon potential in northwestern United States, in Osborne, M.C., and Harrison, Jed, Symposium Cochairmen, The 1988 Symposium on Radon and Radon Reduction Technology, Proc., Vol. 2, Symposium Poster Papers:

Research Triangle Park, N.C., Radian Corp., U.S. Environmental Protection Agency Pub. EPA/600/9- 89/006b [Springfield, Va., NTIS Order No. PB89-167498], p. 3-41--3-49.

Duval, Joseph S., William J. Jones, Frederick R. Riggle, and James A. Pitkin, 1989 Equivalent uranium map of conterminous United States:

U.S. Geological Survey Open-file Rept. 89-478, 12 p. + two-part plate and color slide

[This map was also shown on the cover of Geophysical Research Letters, 17(6), 1990.]

Duval, Joseph S., and James K. Otton, 1990

Radium distribution and indoor radon in the Pacific Northwest:

Geophys. Research Letters, 17(6): 801-804

Aerial gamma-ray data were compiled to produce a map showing the distribution of radium $\left({ }^{226} \mathrm{Ra}\right)$ in nearsurface materials in the Pacific Northwest (Washington, Oregon, and Idaho, and parts of Montana, Wyoming, California, Nevada, and Utah). A comparison of measurements of indoor concentration levels of radon $\left({ }^{222} \mathrm{Rn}\right)$ in homes with the apparent surface concentration of radium shows that aerial gamma-ray data provide a first-order estimate of the relative amounts of indoor radon for township-sized areas $\left[\approx 93 \mathrm{~km}^{2}\right]$ where soils have low to moderate permeability. Townships with average indoor radon levels above the trend of the data are almost all characterized by soils that have higher intrinsic permeabilities.

Duval, Joseph S., James K. Otton, and William J. Jones, 1989

Radium distribution map and radon potential in the Bonneville Power Administration service area:

U. S. Geological Survey Open-file Report 89-340, 126 p.

Duval, J.S., J.K. Otton, and W.J. Jones, 1989

Estimation of radon potential in the Pacific Northwest using geological data:

U.S. Department of Energy, Bonneville Power Administration Report DOE/BP-1234, 146 p.

Duval, Joseph S., G. Michael Reimer, R. Randall Schumann, Douglass E. Owen, and James K. Otton, 1990

Soil gas radon compared to aerial and ground gamma-ray measurements at study sites near Greeley and Fort Collins, Colorado:

U.S. Geol. Survey Open-file Rept. 90-648, 42 p.

Dziuban, Jacolyn A., S.B. White, Jane W. Bergsten, and Barbara V. Alexander, 1989

Residential radon survey of fourteen States, in Osborne, M.C., and Jed Harrison, Symposium Cochairmen, The 1988 Symposium on Radon and Radon Reduction Technology, Proc., Vol. 1, Symposium Oral Papers:

Research Triangle Park, N.C., Radian Corp., U.S. Environmental Protection Agency Pub. EPA/600/9-89/006a [S field, Va., NTIS Order No. PB89-167480], p. 3-21-3-35

This er describes the cumulative results from 14 States that conducted surveys with the assistance of the E. amental Protection Agency during the 1986-1987 and 1987-1988 heating seasons....[North Dakota and Mussesota had higher percentages of houses $>148 \mathrm{~Bq} / \mathrm{m}^{3}(>4 \mathrm{pCi} / \mathrm{L})(60.7 \%$ and $45.4 \%$, respectively) than other States that participated in the surveys. The results in North Dakota and Minnesota are attributed to a 
combination of factors, including typical soil ${ }^{226} \mathrm{Ra}$ concentrations of $37 \mathrm{~Bq} / \mathrm{m}^{3}$ (1 pCi/L), high soil permeability, and a high percentage of homes having basements.]

Eaton, R.S., and A.G. Scott, 1984

Understanding radon transport into houses:

Radiation Protection Dosimetry, 7(1-4):251-253

The major cause of elevated radon levels is the entry of soil generated $\mathrm{Rn}$ as part of a larger flow of soil gas. A theoretical evaluation of the pressure differences causing these flows, and the resistance of different soil types and house foundations to the movement of soil gas suggested that the rate of radon entry could be predicted as a simple function of soil radon concentration and permeability. A new concept, the Radon Index Number, based on simple field measurements, is proposed as a guide to estimation of the annual average radon concentration in a standard house as a function of site soil parameters. [The primary determinants of the average radon concentration are the average pressure difference $(\Delta p)$ between the soil and the house interior, the resistance (R) of the soil and foundation to soil gas movement at such $\Delta \mathrm{p}$, the radon emanation rate (E) per unit volume of soil in the vicinity of the building, and the average ventilation period (h) of the house. These factors yield the average radon concentration, $C$, by $C=Q \Delta p E h / R$, where $Q$ is a constant. In Canada, $\Delta \mathrm{p}$ ranges up to $20 \mathrm{~Pa}$ and can be considered a constant for a given area. Experience at Elliott Lake indicates that foundation joints and other openings presented a total opening area of $\approx 300 \mathrm{~cm}^{2}$, and that radon resistance required an opening area $<1 \mathrm{~cm}^{2}$. The migration distances for radon in soil range from 2 to $3 \mathrm{~m}$ in soils of high permeability to 2 to $3 \mu \mathrm{m}$ in dense clays. The emanation rate can be estimated by (K-U-T) scintillation spectrometry with the reasonable assumption of an emanating power of $35-40 \%$. Numerical modeling by the finite-element method indicated that the radon supply rate increases as a fractional power of soil permeability. The radon index number $(\mathrm{Bq} / \mathrm{m})$ is defined as $\mathrm{RIN}=\mathrm{hE} / \mathrm{K}^{-\mathrm{n}}$ or as $\mathrm{RIN}=\mathrm{hE} /\left(-\log _{10} \mathrm{~K}\right)$, where $\mathrm{K}$ is the reciprocal of permeability. From field data it is estimated that the Canadian criterion for mining communities will be exceeded if the RIN by the latter formula is more than 0.5 to 1.0]

Ettlinger, Lester A., Dash Sayala, and Brant E. Smith, 1987

Predicting high radon areas: A study in Northern Virgina, in Indoor Radon II, Proceedings of the Second APCA International Specialty Conference, Cherry Hill, New Jersey, April, 1987:

Pittsburgh, Pa., Air Pollution Control Association Pub. SP-60, p. 4-15

[The indoor radon potential of locations in an area of $\approx 1800 \mathrm{~km}^{2}$ of Northern Virginia $\left(77^{\circ} 30^{\prime}\right.$ to $78^{\circ} 00^{\prime} \mathrm{W}$; $38^{\circ} 45^{\prime}$ to $39^{\circ} 00^{\prime} \mathrm{N}$ ) was assessed by examining the spectral $\gamma$-ray surveys of the National Aerial Radiometric Reconnaissance component and the stream-sediment uranium surveys of the National Uranium Resource Evaluation Program. Zones of anomalously high uranium-equivalent ${ }^{214} \mathrm{Bi}$ and thorium-equivalent ${ }^{208} \mathrm{~T} \ell$ were found only above Precambrian ( $>600 \mathrm{Ma}$ ) granitic bedrock units. Four of five uranium-equivalent anomalies were above granodiorite and biotite granite gneisses; two of the four were also located along fault zones. The other uranium-equivalent anomaly was found on the Catoctin metabasalt, containing tuffaceous phyllite and veins of quartz and epidote. Equivalent-thorium anomalies along three flight lines were more extensive than the equivalent-uranium anomalies and, along one flight line, extended over a metamorphosed sedimentary unit. Nine $\alpha$-track detectors, buried at $38-\mathrm{cm}$ depth in weathered, saprolitic soils formed on the area rocks, yielded the highest soil-gas ${ }^{222} \mathrm{Rn}, 23$ and $38 \mathrm{kBq} / \mathrm{m}^{3}(611$ and $1030 \mathrm{pCi} / \mathrm{L})$, on granitic material near a fault. No anomalies were seen over the Precambrian Virginia Blue Ridge Complex, Triassic redbeds, or Triassic diabase sills and dikes. (However, indoor radon concentrations as great as $11 \mathrm{kBq} / \mathrm{m}^{3}(300 \mathrm{pCi} / \mathrm{L})$ are known to have been associated with Triassic redbeds about $30 \mathrm{~km}$ to the east of the study area.-ABT)]

Fakundiny, Robert H., Philip R. Whitney, and John M. Matuszek, 1988

Inappropriateness of bedrock maps for predicting radon in soil [abs.], in Radon in the Northeast: Perspectives and Geologic Research (conference), Troy and Albany, New York, May 31-June 2, 1988:

Northeastern Environmental Science, 7(1): 5 
[Bedrock geological maps, especially of small scale $(1: \geq 100,000)$, are not appropriate for predicting areas of high radon potential in New York State. Besides great variability of the distribution of radon's parent nuclides within single map units, the criteria for the delineation of stratigraphic boundaries have no necessary relationship to the quantities that are known to be the principal controls on radon availability (such as radium content of the ground, emanating power, radon diffusivity, soil permeability, drainage, and soil fracturing) or the confusion added by glacial redistribution of the radionuclides and changes in permeability.]

Fang, H.Y., 1990

Environmental geotechnology approach for evaluation of radon gas, in Air \& Waste Management Association Annual Meeting, 83rd, Pittsburgh, Pa., June 24-29, 1990:

Preprint $90-153.10$

[This report is a very unconventional attempt to relate radon behavior to its attachment to particles by Van der Waals forces.]

Finch, W.I., I.S. Parrish, and G.W. Walker, 1959

Epigenetic uranium deposits in the United States:

U.S. Geol. Survey Misc. Geol. Inv. Map I-299, 3 sheets

[Sheet 2, "Distribution of epigenetic uranium deposits and igneous and metamorphic rocks of pre-Late Cretaceous age", shows some correlation with known areas of high indoor radon.]

Fisher, D.R., 1978

Risk evaluation and dosimetry for indoor radon progeny on reclaimed Florida phosphate lands [Ph.D. thesis]: Gainesville, Fla., Univ. Florida: 140 p.

Fitzpatrick-Lins, Katherine, Tom L. Johnson, and James K. Otton, 1990

Radon potential defined by exploratory data analysis and geographic information systems, in Wiltshire, $\mathrm{D}$ [enise] A., ed., Selected Papers in the Applied Computer Sciences 1990, Chapter E:

U.S. Geological Survey Bulletin 1908, p. E1-E10.

Through the use of exploratory data analysis and a geographic information system, indoor radon values located by zip code were analyzed statistically and related spatially to geology and soil data for Fairfax County, Virginia. A geographic information system overlay of geology on [postal] zip-code areas that have high upper quartile levels (25\% or more of the samples exceed the U.S. Environmental Protection Agency guideline for radon in air, $148 \mathrm{~Bq} / \mathrm{m}^{3}(4 \mathrm{pCi} / \mathrm{L})$ ) revealed that the majority of such areas are on Paleozoic metamorphic rock. In areas where the upper $25 \%$ of the radon values from Paleozoic metamorphic rock are lower than $148 \mathrm{~Bq} / \mathrm{m}^{3}$ (4 $\left.\mathrm{pCi} / \mathrm{L}\right)$, soil seems to provide a mitigating effect. Four levels of radon potential, low, moderate, moderate to high, and high, are defined for the study area. [See also Otton, Schumann, Owen, Thurman, and Duval, 1988, which ranked the same county in five tiers of radon potential. Maximum values measured in the four physiographic provinces represented in the county, Triassic basin, Piedmont Upland, Eastern Piedmont, and Coastal Plain, were $12.8,5.7,0.79$, and $0.21 \mathrm{kBq} / \mathrm{m}^{3}$, respectively; the corresponding medians were 70.3 , $77.7,59.2$, and $40.7 \mathrm{~Bq} / \mathrm{m}^{3}$; and the radon potential rankings for the respective areas were moderately high, high, moderate, and low. Several different statistical measures were used. Maps show the zip-code boundaries, mean and median radon values for each zip-code, a log-normal plot of the values, box (-and whisker) plots of log-transformed radon concentration values along a transect across the county, zip-code areas by quartile, bedrock units, soil series, and the evaluated radon potential.]

Fleischer, R.L., 1980

Radon flux from the Earth: Methods of measurement by the nuclear track technique:

Jour. Geophys. Research, 85(C12): 7553-7556

The nuclear track technique, which can be used to measure concentrations of radon directly, can also be employed to determine radon flux by means of gradients in concentration in the ground, at its surface, or above the surface. Diffusional properties or emanation properties need to be assessed, but often can also be 
measured by track counting. Measurements at Thoreau, New Mexico, give a flux of 1.4 atoms $/ \mathrm{cm}^{2}-\mathrm{s}$ over an area of $60,000 \mathrm{~m}^{2}$. At Scotia, New York, 1.1-1.2 atoms $/ \mathrm{cm}^{2}-\mathrm{s}$ are measured over an area of $100 \mathrm{~m}^{2}$.

Fleischer, Robert L., and Antonio Mogro-Campero, 1978

Mapping of integrated radon emanation for detection of long-distance migration of gases within the Earth: Jour. Geophys. Research, 83(B7): 3539-3549

[In connection with measurements of radon isotopes in soil, two types of detector are considered for registering the average $\alpha$-particle radiation incident on the detector surface over periods of about 30 days: a semiconductor (surface-barrier) detector produced by Alpha Nuclear, and the etchable cellulose-nitrate film detector ("TrackEtch $\left.{ }^{\otimes 1}\right)$ produced by Terradex Corporation. The influence of $\alpha$-particle energies of ${ }^{222} \mathrm{Rn},{ }^{218} \mathrm{Po}$, and ${ }^{214} \mathrm{Po}$ (from the uranium series) and ${ }^{220} \mathrm{Rn},{ }^{216} \mathrm{Po},{ }^{212} \mathrm{Bi}$, and ${ }^{212} \mathrm{Po}$ (from the thorium series), their distribution in the measuring cup, and the geometry of the cup are treated quantitatively to yield the theoretical efficiencies for the two types of detector. The rest of the paper deals with calibration and use of the detectors (almost exclusively $\alpha$-track) for measurement of radon in soil, and exclusion of the signals from the thorium-series nuclides. Calibration is done by sealing an inverted cup, with the detector film stuck to the inside flat surface, on a dish or jar containing a soil sample, and correcting the measured $\alpha$-track production rate, which is less than that equivalent to the soil gas undiluted by the non-radon-producing volume of air above the sample, by multiplying by $\left\{1+\left(1 /\right.\right.$ soil porosity) $\left(V_{\text {Volume }}\right.$ air space $/$ Volume $\left.\left._{\text {soil }}\right)\right\}$. (It is implicitly assumed that the soil in the calibration dish is packed to the same porosity as it is in situ, and that the moisture content of the sample also is sufficiently similar to yield the same emanating power. Dried soil should have significantly lower emanating power than soil in the moisture range that is typical in many areas, resulting in an underestimate of the radon generation in the soil in situ.-ABT) Plots of (track production rate) $)^{-1} v s$. (Volume air space $_{\text {Volume }} /$ soil $_{\text {) for }}$ measurements made with different soil volumes can be extrapolated to zero volume ratio, eliminating the need to measure the porosity of the soil sample. Interference from ${ }^{220} \mathrm{Rn}$ can be suppressed by covering the sample with several different thicknesses of high-purity sand; by saturating the sample with water; by using several different sample thicknesses; or by interposing a membrane barrier that delays ${ }^{220} \mathrm{Rn}$ passage long enough for it to decay (see Ward, Fleischer, and Mogro-Campero, 1977). Passage of radon through a distance greater than several times its $\approx 1-\mathrm{m}$ diffusion length in the ground is termed a "distant signal" by the authors, who cite $\alpha$-track measurements that exceed those that would be expected by diffusion from local sources as evidence for long-distance radon migration. The method has applications to uranium prospecting and earthquake prediction. The effects of lateral diffusion, high moisture saturation, and radon loss to the air space in the sampling hole above the detector cup are not discussed.]

Fleischer, Robert L., and Antonio Mogro-Campero, 1982

Track detectors for environmental radon studies: variation in concentrations in the ground, in Vohra, K.G., U.C. Mishra, K.C. Pillai, and S. Sadasivan, eds., Natural Radiation Environment:

New York, John Wiley and Sons, p. 317-323

Flood, James R., Tom B. Thomas, Neil H. Suneson, and Kenneth V. Luza, 1990

Radon potential map of Oklahoma:

Oklahoma Geol. Survey Map GM-32, Scale 1:750,000

[This map is essentially a reconnaissance map, based on the National Aerial Radiometric Reconnaissance of the National Uranium Resource Evaluation (NURE) Program and on the measured or estimated uranium concentrations of bedrock units. Only the sources of radon were considered; the mobility of radon in the various units was not considered. The geologic units were ranked in five tiers: generally very low, generally low, locally low to moderate, locally moderate, and locally moderate to high.]

Freeman, H.D., and J.N. Hartley, 1986

Radon flux measurement technology, in Indoor Radon, Proceedings of the APCA International Specialty Conference, Philadelphia, Pa., February 24-26, 1986:

Air Pollution Control Assoc., P.O. Box 2861, Pittsburgh, PA 15230, Pub. SP-54, p. 167-181 
[This paper describes instrumentation and interpretation procedures for flux (density) measurements by means of accumulator cans, small- and large-area activated charcoal canisters, a flow-through tent system, and flowthrough continuous flux systems. The methods were applied to flux density measurements from uranium mill tailings, phosphogypsum piles, and industrial waste water treatment sludge.]

\section{Friedmann, Harry, 1993}

The Austrian Radon Project [abs.], in First International Workshop on Indoor Radon Remedial Action, The Scientific Basis and Practical Applications, Rimini, Italy, 27 June-2 July 1993:

Commission of the European Communities et al., Book of Abstracts, p. 107

In 1991 the Austrian Radon Project was started with the global aim of investigating the radon concentration in Austrian homes. The Project is divided into several stages. The first stage (ÖRAP-1) was devoted to the collection of already existing data which may have relevance to indoor radon concentrations. These data include radon measurements in houses, radium and radon concentrations in ground and spring water, gamma dose, uranium and thorium concentration in the ground, and airborne gamma spectrometric measurement. This part of the project was finished at the end of 1991. The next stage (ÖRAP-2) started in mid 1992 and was planned as a pilot project for a country-wide survey on indoor radon concentration. In this pilot project the best way for measuring the radon concentration in homes should be found. The selected area has about 400,000 inhabitants and includes one large city, several smaller cities, and rural areas. First, a number of measurement methods (track-etch, electret, charcoal/liquid scintillation counting, charcoal/gamma spectrometry, ionization chamber) and several methods for the distribution of the measuring devices were extensively discussed and then tested (mailing, interviewer). Finally, the best way of organizing the whole project must be found. The latter includes also an estimation of the financial needs for the whole project. There are two main aims of the project: first, the actual radon exposure of the Austrian people should be investigated (radon exposure map), and second, a map for estimating the radon exposure in houses to be built in the future should be elaborated (radon potential map). So it must be established, if it is possible to extract from the available data, the "radon potential" of the ground which in the future will be used when planning new buildings. For this reason it is necessary to get more information from the houses and apartments to understand which parameters mainly influence the radon concentration in the homes. Therefore a questionnaire was distributed with the detectors and several special measurements (soil-gas measurements, continuous radon measurements, etc.) were made in specially selected houses. Finally in the last stage of the project, which will last several years, the whole country should be investigated with the methods which prove to be the most adequate for the task.

Frishman, David, W.C. Day, P.F. Folger, R.B. Wanty, P.H. Briggs, and Eileen Poeter, 1993

Bedrock geologic controls on radon abundance in domestic well water, Conifer, Colorado, in The 1993 International Radon Conference, Denver, Colo., Sept. 20-22, 1993:

Denver, Colo., Am. Assoc. Radon Scientists and Technologists, Rocky Mountain Chapter, Preprints, p. IV 20-IV 30

Radon in ground water used for domestic supply can contribute significantly to radon concentrations in indoor air. Our integrated studies of bedrock geology, bedrock and well-water chemistry, geohydrology, and downhole geophysics have delimited some of the features that can exert regional as well as local control on radon abundance in well water from crystalline rock aquifers. Local, small-scale features such as inhomogeneities in the distribution and mineralogical residence of uranium in the bedrock and on fracture surfaces exert the strongest control on partitioning of radon between the bedrock aquifer and its entrained ground water. Detailed geologic mapping (meter-scale) has outlined zones in the granite bedrock that are enriched in uranium by an order of magnitude. Alpha-track mapping of thin sections (millimeter-scale) demonstrates that iron-oxide coatings on fracture surfaces are enriched in alpha-emitting elements that may be contributing radon to the well water. Although bedrock composition determines the general abundance of radon in ground water, the local features control radon concentration in any given well.

Frohlich, Reinhard K, and Carl A. Pearson, 1988 
Potential radon hazard in Rhode Island estimated from geophysical and geological surveys:

Northeastern Environmental Science, 7(1): 30-34

[In Rhode Island, correlations have been observed between aeroradioactivity and ground and aeromagnetic maps over metamorphic granite, the greatest anomalies being found at intersections of new with old fracture zones. (Associations of uranium with magnetite are also common in the Reading Prong.)]

Fukui, M., 1987

Soil water effects on concentration profiles and variations of ${ }^{222} \mathrm{Rn}$ in a vadose zone:

Health Physics, 53(2): 181-186

Concentration profiles of ${ }^{222} \mathrm{Rn}$ and their variations were studied to understand the vertical motion in the ground caused by fluctuations of meteorological parameters, such as precipitation, ground-water level and atmospheric pressure. A method of trapping ${ }^{222} \mathrm{Rn}$ was developed to measure the concentration profiles by circulating and bubbling soil gas in porous cups into toluene. For locations where the water table is close to the surface, observations showed a peak concentration in the vertical profile of ${ }^{222} \mathrm{Rn}$ at about a $40-\mathrm{cm}$ depth and revealed that the concentration in soil gas decreases as soil moisture increases near the water table. Soil gas in a buried vessel also was circulated continuously to monitor ${ }^{222} \mathrm{Rn}$ in the ground air near the surface using an ionization chamber. A rising of the water table following precipitation causes a burst of ${ }^{222} \mathrm{Rn}$ concentration by upflow in the ground, though the concentration in the soil gas soon decreases with the intake of air above the surface due to increasing atmospheric pressure following precipitation. The concentration in soil gas again increases via the phenomenon accompanying the recovery of equilibrium in soil water between ${ }^{222} \mathrm{Rn}$ and ${ }^{226} \mathrm{Ra}$.

Garbesi, Karina, 1993

Toward resolving model-measurement discrepancies of radon entry into homes [Ph.D. Thesis]:

Berkeley, Calif., Univ. California, Energy and Resources Group, and Lawrence Berkeley Laboratories, Energy and Environment Div. Rept. LBL-34244, 169 p.

[The author observed that numerical modeling of radon entry underestimated measured entry rates by factors of $\approx$ 3-10 in several studies (Nazaroff, Lewis, Doyle, Moed, and Nero, 1987; Revzan, Fisk, and Gadgil, 1991; Garbesi and Sextro, 1989; Fisk, Flexser, Gadgil et al., 1989; Fisk, Modera, Sextro et al., 1992; Garbesi, Sextro, Fisk, Modera, and Revzan, 1993), and hypothesized that the discrepancies resulted from using low values of permeability, which had been based on measurements by single probes and yielded permeability information about soil volumes much smaller than those of building lots. A "dual-probe dynamic pressure technique" was developed in order to yield permeability over distances of several meters, thus averaging the effects of permeability variations due to shrinkage cracks, soil layering, root channels, etc.]

Garbesi, K., R.G. Sextro, W.J. Fisk, M.P. Modera, and K.L. Revzan, 1993

Soil-gas entry into an experimental basement: Model measurement comparisons and seasonal effects:

Environmental Science and Technology, 27(3): 466-473

[From original publication, Lawrence Berkeley Laboratory Rept. LBL-31873, 26 p.]:

Previous field studies of soil-gas entry into existing houses have found large discrepancies between modeled and measured values of soil-gas entry rate and pressure coupling between house substructures and the soil that could have been explained by inherently poor understanding of complex field sites. This paper reports the results of detailed investigation of soil-gas entry into an extensively instrumented and controlled experimental basement designed for the verification of existing numerical models of soil-gas and radon entry into houses. The experimental design provides greatly reduced uncertainty regarding structure and soil characteristics. Estimates of soil-gas entry based on radon mass-balance in the structure are compared with predictions of a 3-dimensional steady-state numerical model. This study corroborates the earlier findings of significant model underprediction of soil-gas entry and far-field pressure coupling. Observed soil-gas entry at 21-Pa structure depressurization was 8 times greater than predicted by the model and far-field pressure coupling was as much as 6 times greater than predicted. This suggests that field conditions at the site, and possibly at real houses, are inconsistent with model assumptions, or that typical methods of assessing bulk soil permeability are misleading. A number of hypotheses are raised to explain the discrepancy that will be tested in the future at 
the experimental facility. The effect of seasonal changes in soil conditions on soil-gas entry is also examined. Despite large seasonal changes in near-surface soil moisture content and air permeability, there is no observable effect on soil-gas entry because critical soil conditions near the soil-gas entry location in the structure floor remain relatively constant.

\section{Gates, A.E, L.C.S. Gundersen, and L. Malizzi, 1989}

Case studies of anomalous radon in soil over shear zones in VA and NJ [abs.]:

Eos, Am. Geophys. Union Trans., 70(15): 499

The concentration of radon ( $\mathrm{Rn}-222)$ in soil gas over shear zones is controlled by the composition of the bedrock, amount of strain in the shear zone and the nature of the soil cover. In the Brookneal mylonite zone, southwestern Virginia Piedmont, uranium content of the bedrock varies as a function of shear strain. The zone lies within the homogeneous Melrose granite and therefore the effect of variable composition of the protolith is eliminated. Radon in overlying saprolite also varies as a function of strain and is $\mathbf{1 0}$ times higher over the most deformed part of the zone than the undeformed granite. The Hylas mylonite zone in the eastern Virginia Piedmont shears several rock units with highly variable compositions. The composition of each protolith is also a dominant factor in the radon concentraton of the overlying saprolite. Soils above the intermediate to mafic gneisses contain up to 9 times less radon than those above pegmatites. Radon in soils above mylonites were up to 11 times higher than over undeformed counterparts. The Reservoir fault zone, New Jersey Highlands is a cataclastic shear zone and contains pegmatites with anomalous uranium concentrations. It also separates Grenville gneisses of the Reading Prong that exhibit elevated gamma radiation from Silurian/Devonian sediments with low gamma radiation. Unlike the other shear zones, soils above this area are glacial tills of a terminal moraine. Radon in these soils is highly variable and does not correlate with uranium concentration of the underlying bedrock. It appears to more closely reflect the composition of the glacial till.

Gates, Alexander E., Linda C.S. Gundersen, and Lawrence D. Malizzi, 1990

Comparison of radon in soil over faulted crystalline terranes: Glaciated versus unglaciated:

Geophys. Research Le ", 17(6): 813-816

[Uranium concentratio : a bedrock and radon concentrations in soil gas in the overlying soils were studied in the unglaciated Hylas shear zone area of Virginia and in the glaciated Reservoir fault area of the New Jersey Highlands. Radon concentrations in soil gas and uranium concentrations in bedrock correlated directly where the overlying soils are not a product of glaciation.]

Gates, Alexander E., Lawrence Malizzi, and John Driscoll III, 1992

Soil radon distribution in glaciated areas: Ar example from the New Jersey Highlands, in Gates, Alexander E., and Linda C.S. Gundersen, eds., Geologic Controls on Radon:

Boulder, Colo., Geological Soc. America Special Paper 271, p. 45-52

In contrast to results of regional soil radon studies in unglaciated areas, bedrock geology shows no correlation with radon concentrations in glacial soils overlying the Green Pond outlier and Reservoir fault zone, New Jersey Highlands. Total gamma radiation and uranium concentrations in the Paleozoic sedimentary rocks of the Green Pond outlier are generally lower than in the Precambrian gneisses of the Reading Prong to the west. The sedimentary bedrock shows average gamma radiation or 220 counts/s (136 to $323 \mathrm{c} / \mathrm{s}$ ) and uranium concentrations of 0.5 to $0.6 \mathrm{ppm}$, whereas gamma radiation fiv the Grenville gneisses averages $284 \mathrm{c} / \mathrm{s}$ ( 240 to $576 \mathrm{c} / \mathrm{s}$ ) and average uranium concentrations are 1.2 to $2.2 \mathrm{ppm}$. Rare pegmatites that occur along the Reservoir fault zone yield anomalously high average gamma radiation of $2,018 \mathrm{c} / \mathrm{s}(1,949$ to $3,495 \mathrm{c} / \mathrm{s})$ and average uranium concentrations of $28.5 \mathrm{ppm}$. Radon concentrations in the glacial soil cover exhibited similar averages with wide ranges regardless of underlying bedrock geology. No appreciable difference was found between soil radon concentrations over Paleozoic sedimentary units, the pegmatites, fault zone, or Precambrian gneisses. Radon from soil over the Paleozoic sedimentary bedrock averaged $19.1 \mathrm{kBq} / \mathrm{m}^{3}$ or $518 \mathrm{pCi} / \mathrm{L}(8.8$ $100 \mathrm{kBq} / \mathrm{m}^{3}$ or $\left.237-2,695 \mathrm{pCi} / \mathrm{L}\right)$, whereas it averaged $19.4 \mathrm{kBq} / \mathrm{m}^{3}$ or $527 \mathrm{pCi} / \mathrm{L}\left(7.4-69.3 \mathrm{kBq} / \mathrm{m}^{3}\right.$ or 200 $1,872 \mathrm{pCi} / \mathrm{L}$ ) in soil over the Grenville gneisses. The Green Pond outlier and the Reservoir fault zone are 
blanketed by the Wisconsin-age glacial cover and contain recessional deposits that are proximal to the terminal moraine. All soil radon was sampled in the glacial rover. The glacial sediments contain erratics primarily composed of lithologies in the area but also of exotic rock types. Because uranium concentrations in the erratics and matrix are highly variable, soil radon of individual samples is governed by the local uranium concentrations. Other possible reasons for the lack of correlation between bedrock and soil radon are the high permeability of the glacial soil that permits radon diffusion, atmospheric dilution, and variations in cover thickness.

Ghahremani, D.T., 1989

Radon hot spots caused by bed rock fracturing or proximity to shallow uranium mineralization in Ohio, in Osborne, M.C., and Harrison, Jed, Symposium Cochairmen, The 1988 Symposium on Radon and Radon Reduction Technology, Proc., Vol. 2, Symposium Poster Papers:

Research Triangle Park, N.C., Radian Corp., U.S. Environmental Protection Agency Pub. EPA/600/9-89/006b [Springfield, Va., NTIS Order No. PB89-167498], p. 3-55--3-68.

Ghahremani. Darioush T., 1991

Comparison of long term radon detectors and their correlations with bedrock sources and fracturing, in The 1991

International Symposium on Radon and Radon Reduction Technology, Philadelphia, Pa., 2-5 April 1991:

Preprints, v. 5, no. IXP-3, 12 p.

Ghomshei, M.M., and W.F. Slawson, 1991

Secular variations of radon in metropolitan Vancouver, British Columbia, Canada, in The 1990 International Symposium on Radon and Radon Reduction Technology, Atlanta, Ga., 19-23 February 1990:

Research Triangle Park, N.C., U.S. Environmental Protection Agency Rept. EPA600/9-91-026c, Proceedings, Vol. 3: Symposium Poster Papers, Paper No. C-VI-2, p. 2-1-2-11 [NTIS Order No. PB91-234468/AS]

Goodknight, Craig S., and R. Thomas Peake, 1988

Preliminary estimation of high radon potential areas in EPA Regions 3 and 4 as indicated by geologic factors [abs.]:

Geol. Soc. America, Abstracts with Programs, 20(7): A337

Indoor radon concentrations result from a combination of geologic, environmental, and anthropogenic factors.

To gain an understanding of the geologic component, maps of geologic factors related to radon have been prepared for the U.S. Environmental Protection Agency Regions 3 and 4 (generally, the southeastern and midAtlantic States) in support of EPA's Indoor Radon Program. Individual maps were prepared for the following factors: (1) uranium occurrence s and rock formations elevated in uranium content, (2) rock formations and other areas that have equivalent uranium concentrations of approximately $3 \mathrm{ppm}$ or greater from aerial radiometric survey data, (3) fault systems and Triassic-Jurassic dikes, and (4) carbonate rock formations. Indoor radon data and soil and house foundation characteristics were also examined. The principal source of uranium data for the first two factors listed above was the U.S. Department of Energy National Uranium Resource Evaluation Program. The areas most likely to contain high indoor radon concentrations were identified using a combination of the listed geologic factors. The principal high radon potential areas identified include most of the Inner Piedmont from southern Virginia to western Georgia, the Piedmont of southeastern Pennsylvania, the Inner Coastal Plain underlain by Cretaceous chalks, and the northern Kentucky Devonian and Ordovician black shales. Areas of low indoor radon potential include most of the Coastal Plain and the Cumberland Plateau.

Grace, John D., 1989

Radon anomalies in southern Michigan [abs.]:

Geol. Soc. America, Abstracts with Programs, 21(6): A144

Recent radon surveys in ten states by the U.S. Environmental Protection Agency have produced vast data on the geographic distribution and variability of indoor radon. Analysis of over 2000 screening measurements in 
Michigan indicates the presence of two major anomalies or "hot spots", one in the Northern Peninsula and the other in southeastern Michigan. The anomaly in the Northern Peninsula is reasonably well understood as it corresponds to uraniferous Precambrian bedrock. The anomaly in southeastern Michigan, where over $40 \%$ of the homes tested had readings above the $148 \mathrm{~Bq} / \mathrm{m}^{3}(4 \mathrm{pCi} / \mathrm{L})$ recommended limit, is centered on Hillsdale, Lenawee, and Washtenaw Counties. The causes for this southern anomaly are not immediately apparent as there is no direct correlation of high radon readings with soil type, glacial deposit thickness, bedrock geology, structure, or aeroradiometric surveys. A detailed analysis of the E.P.A. data suggests, however, that the highest radon readings are associated with the Defiance, Fort Wayne, and Wabash moraines produced by the Lake Erie Lobe of the Wisconsin glacial stage. We have conducted a series of supplementary soil-gas radon measurements in the southern Michigan area which confirms the E.P.A. data. The results are interpreted with respect to the type, mineralogical character, and permeability of these deposits.

\section{Grafton, H.E., and D.R. West, 1992}

Elevated indoor radon levels and elevated incidence of lung cancer in Columbus and Franklin County, Ohio: Cause or coincidence?, in Cross, Fredrick T., ed., Indoor Radon and Lung Cancer: Reality or Myth? Twentyninth Hanford Symposium on Health and the Environment, Richland, Wash., October 15-19, 1990, Proceedings: Columbus, Ohio, Battelle Press, Part 2, p. 863-870 [NTIS]

[The area discussed is coincident with elevated ${ }^{214} \mathrm{Bi}$ in soil, as revealed by aeroradioactivity surveys done for the National Uranium Resource Evaluation program. Average screening measurements for the county ranged between $63 \%$ and $73 \%>148 \mathrm{~Bq} / \mathrm{m}^{3}, 23$ and $27 \%>370 \mathrm{~Bq} / \mathrm{m}^{3}$, and $1 \%>1850 \mathrm{~Bq} / \mathrm{m}^{3}(50 \mathrm{pCi} / \mathrm{L})$. The rates of cancer of the bronchi, lungs, and trachea for 1979-1986 were 62.8/100,000 for Franklin County and $49.3 / 100,000$ for the State of Ohio. The data are not considered sufficient to demonstrate a coincidental or causal relationship, but the county is suggested as a good site for an epidemiological study.]

Grasty, R.L., 1989

The relationship of geology and gamma-ray spectrometry to radon in homes [abs.]:

Eos, Am. Geophys. Union Trans., 70(15): 496

Studies in Scandinavia, Britain, and North America have shown that there are regional variations in radon concentrations in homes that can be attributed to differences in the underlying rocks and soils. Homes built on granites invariably have elevated radon levels due to their increased uranium concentration compared with other rock types. The uranium concentration of the ground as measured by airborne gamma-ray spectrometry is shown to be a useful parameter for predicting potential radon problem areas. However, in Canada, the cities of Winnipeg, Manitoba and Regina, Saskatchewan have the highest radon levels and are situated on glacial lake clays. A cross-Canada airborne gamma-ray survey could not explain these elevated levels. Subsequent laboratory analyses of the Lake Agassiz clays underlying Winnipeg showed relatively high radium concentrations compared with most surficial materials. The differences between the airborne and laboratory analyses were attributed to radon loss from the surface of the ground and consequent reduction of the airborne signal. Because of their small size, clay particles are extremely efficient in emanating radon. Fracturing of the clays is common for the Interior Plains, and is believed to be a significant contributing factor to the high radon levels in Winnipeg and Regina. These fractures provide an efficient plumbing system for the radon to move through the ground. In addition, the Lake Agassiz clays are high in the mineral montmorillonite, which shrinks substantially on drying, not only enlarging the fractures but also making the clay itself more permeable to radon. The fracturing of the montmorillonite-rich clays, their radium content, and emanation efficiency are all factors which together with the dry conditions of the Interior Plains could contribute to the high radon levels found in Winnipeg and Regina and the adjacent states of North Dakota and Minnesota in the United States.

Graustein, William C., and Karl K. Turekian, 1990

Radon fluxes from soils to the atmosphere measured by ${ }^{210} \mathrm{~Pb}-{ }^{226} \mathrm{Ra}$ disequilibrium in soils:

Geophys. Research Letters, 17(6): 841-844 
[The ${ }^{226} \mathrm{Ra}$ parent and the ${ }^{210} \mathrm{Po}$ decay product of radon were measured in 119 cores of North American soils. It was inferred that the mean fraction of radon escaping from the uppermost $50 \mathrm{~cm}$ soil layer was $\geq 25 \%$, equivalent to a radon flux density of 0.48 atoms $/ \mathrm{cm}^{2}-\mathrm{s}\left(10 \mathrm{mBq} / \mathrm{m}^{2}-\mathrm{s}\right)$.]

Greeman, Daniel Jacob, 1992

The geochemistry of uranium, thorium, and radium in soils of the eastern United States [Ph.D. thesis]: University Park, Pa., Pennsylvania State Univ., Dept. Geosciences, 232 p.

A detailed study of the content, form, and behavior of ${ }^{238} \mathrm{U},{ }^{232} \mathrm{Th}$, and ${ }^{226} \mathrm{Ra}$ has been conducted on 12 undisturbed soil profiles developed on carbonates, shales, sandstones, granites, tills, and alluvial materials in the eastern U.S. in order to gain understanding relevant to radon hazard, nuclear waste isolation, and geochemistry. Data on parent rocks, vegetation, selective soil extraction, and soil chemistry have also been obtained. Soil concentrations are 2 to $7 \mathrm{ppm}{ }^{238} \mathrm{U}, 3$ to $20 \mathrm{ppm}{ }^{232} \mathrm{Th}$, and 19 to $100 \mathrm{mBq} / \mathrm{g}{ }^{226} \mathrm{Ra}$. ${ }^{238} \mathrm{U}$, ${ }^{232} \mathrm{Th}$, and ${ }^{226} \mathrm{Ra}$ content of these soils is always greater than bedrock values, with carbonate soils being enriched in ${ }^{238} \mathrm{U}$ and ${ }^{226} \mathrm{R}$ a up to 15 -fold and ${ }^{232} \mathrm{Th}$ up to 27 -fold over bedrock values. Shale soils are typically enriched 4-fold over bedrock values. Variation in ${ }^{238} \mathrm{U},{ }^{232} \mathrm{Th}$, and ${ }^{226} \mathrm{Ra}$ content with depth averages $20-25 \%$ about the mean for the twelve sites, and is chiefly the result of depletion in ${ }^{238} \mathrm{U}$ and ${ }^{232} \mathrm{Th}$ (up to $65 \%$ of average profile values) in surface soil horizons because of lessivage of fine radionuclide-bearing Fe-oxides, clays, and organic matter (pedogenic phases). Pedogenic ${ }^{238} \mathrm{U},{ }^{232} \mathrm{Th}$, and ${ }^{226} \mathrm{Ra}$ increase with depth up to 5-fold in granite- and carbonate-derived soils, but apparent mobility is much less for shale- and glacially derived soils. Mobility of ${ }^{226} \mathrm{Ra}$ in lower horizons is low; adjacent horizons have 2-fold differences in ${ }^{226} \mathrm{Ra} /{ }^{238} \mathrm{U}$ ratios and $25 \%$ differences in unsupported ${ }^{226} \mathrm{Ra}$. Because of the variable and depleted nature of upper soil horizons, the concentrations of Ra-daughters in the top $30 \mathrm{~cm}$ of soil determined by radiometric surveys are not necessarily representative of soil at depth. $U$ content in the surface horizons relative to the average profile value correlates well with analogous Th values in all twelve sites. This relation could be used in the identification of error in other surveys. Soil profile-averaged ${ }^{226} \mathrm{Ra}$ is in secular equilibrium with ${ }^{238} \mathrm{U}$; ${ }^{226} \mathrm{Ra} /{ }^{238} \mathrm{U}$ ranges 0.94 to 1.11 for ten of twelve sites. Average ${ }^{226} \mathrm{Ra} /{ }^{238} \mathrm{U}$ never deviates more than \pm 0.20 from equilibrium. Rocks and float from these sites show ${ }^{226} \mathrm{Ra} /{ }^{238} \mathrm{U}$ equilibrium values (av. 0.95 ). Organic-rich A-horizons with ${ }^{226} \mathrm{Ra} /{ }^{238} \mathrm{U}$ up to 1.80 can be explained by the rapid (0.70-1.0 ka) turnover of plant- incorporated ${ }^{226} \mathrm{Ra}\left({ }^{226} \mathrm{Ra} /{ }^{238} \mathrm{U}\right.$ up to 65 in vegetation). Cycling by vegetation also explains the content of pedogenic $\mathrm{U}, \mathrm{Th}, \mathrm{Ca}, \mathrm{Mg}$, and $\mathrm{K}$ in the A-horizon of a carbonate-derived soil. Some lower $\mathrm{C}$-horizons have high ${ }^{226} \mathrm{Ra} /{ }^{238} \mathrm{U}$ values, up to 1.5 , with an appreciable proportion of ${ }^{226} \mathrm{Ra}$ in exchangeable sites, up to $35 \%$ of the total ${ }^{226} \mathrm{Ra}$. Adsorption of ${ }^{226} \mathrm{Ra}$ to surfaces from soil water with a typical dissolved ${ }^{226} \mathrm{Ra}$ content, 37 $\mathrm{mBq} / \mathrm{L}$, over a period of $1.2 \mathrm{ka}$ explains the abundance and form of excess ${ }^{226} \mathrm{Ra}$ in C-horizons. Models of ${ }^{238} \mathrm{U}$ and ${ }^{232} \mathrm{Th}$ uptake by vegetation show that their mean residence times, relative to cycling by vegetation, are short, $6-120 \mathrm{ka}$, compared with the mean lives of ${ }^{230} \mathrm{Th}$ and ${ }^{234} \mathrm{U}$. Radiometric age-dating of vegetated soils using ${ }^{230} \mathrm{Th} /{ }^{234} \mathrm{U}$ disequilibium should not use closed-system assumptions since, by analogy, ${ }^{230} \mathrm{Th}$ and ${ }^{234} \mathrm{U}$ behave similarly to common $\mathrm{U}$ and $\mathrm{Th}$, and $\mathrm{U}$ - and Th-cycling rates are probably different. Based on selective extractions, ${ }^{226} \mathrm{Ra}$ is significantly cation-exchangeable in soils (up to $35 \%$ of the total ${ }^{226} \mathrm{Ra}$ ), while ${ }^{238} \mathrm{U}$ and ${ }^{232} \mathrm{Th}$ are not cation-exchangeable in soils, averaging $<1.5 \%$ and $<1.1 \%$, of their total occurrence, respectively. A large proportion of the ${ }^{226} \mathrm{Ra}$, averaging $26 \%$ of the total, is associated with soil organic matter at all depths. By contrast, less than $1.5 \%$ of the total ${ }^{238} \mathrm{U}$ and ${ }^{232} \mathrm{Th}$ is associated with organic matter and the maxiumum occurrence, $8 \%$ and $6 \%$, respectively, is generally restricted to the surface horizons. On average $15 \%$ of the total ${ }^{238} \mathrm{U}, 31 \%$ of the ${ }^{232} \mathrm{Th}$, and $10 \%$ of the ${ }^{226} \mathrm{Ra}$ in soils are asssociated with Fe-oxides (up to $38 \%, 68 \%$, and $21 \%$ of their total content, respectively). Approximate ${ }^{226} \mathrm{Ra}$ equilibrium with ${ }^{238} \mathrm{U}$ $\left({ }^{226} \mathrm{Ra} /{ }^{238} \mathrm{U}=0.94\right)$, the relatively low abundance of $\mathrm{Ra}$ in Fe-oxides, and previous studies of ${ }^{226} \mathrm{Ra}$ adsorption indicate no appreciable ${ }^{226} \mathrm{Ra}$ adsorption to Fe-oxides in these acidic (pH 3.5 to 6) soils. In all samples, ${ }^{226} \mathrm{Ra}$ in soil organic matter is largely unsupported by ${ }^{238} \mathrm{U}$ (and probably by ${ }^{230} \mathrm{Th}$ ). In contrast, minerals show ${ }^{226} \mathrm{Ra}$ loss, with ${ }^{226} \mathrm{Ra} /{ }^{238} \mathrm{U}$ ranging from 0.73 to 0.91 . Models of ${ }^{226} \mathrm{Ra}$ transfer show that ${ }^{226} \mathrm{Ra}$ cycled by plants may be insufficient to compensate for radioactive decay of unsupported ${ }^{226} \mathrm{Ra}$ in organic matter. The ${ }^{222} \mathrm{R}$. emanation coefficients of 17 Pennsylvania soils (range: 7 to $27 \%$ ) correlate well with the proportion of ${ }^{226} \mathrm{Ra}$ associated with organic matter. This relation could be useful in the prediction of soil-gas radon at a 
given site. Uranium loss from soils was estimated by comparing the ${ }^{232} \mathrm{Th} /{ }^{238} \mathrm{U}$ ratio in soil parent versus soil. The rate of $U$ - loss from soil was constrained by assuming rapid exchange of $U$ in soil organic matter with soil water and a $\mathrm{K}_{\mathrm{d}}$ of $10^{4}$ (organic phase/aqueous phase). Ages for two of three carbonate-derived soils, 610-670 $\mathrm{ka}$, estimated from U-loss rates, were similar to ages estimated by previous studies. Weathering of soil material results in separation of some $U$ - and Th-bearing resistates, followed by $U$ and $T h$ uptake by vegetation and/or chelation by organic matter produced by vegetation. Secondary, U- and Th-bearing fines are transported downward, and ultimately, $U$ and $T h$ are adsorbed to Fe-oxides and incorporated in pedogenic clays.

Greeman, Daniel J., and Arthur W. Rose, 1988

Abundance and occurrence of $\mathrm{U}, \mathrm{Th}$ and $\mathrm{Ra}$ in Pennsylvania and Georgia soils [abs.]:

Geol. Soc. America, Abstracts with Programs, 20(7): A337

The concentrations of uranium, thorium, and radium which are relevant in studies of radon and aerial radioactivity, have been measured in 5 soil profiles in Georgia and 5 in Pennsylvania by delayed-neutron activation, gamma spectroscopy, and radon bubbler methods. In 1- to 1.5-m deep profiles on shale, sandstone, limestone, granite, and schist in Georgia, uranium is mostly between 2 and $5 \mathrm{ppm}$ with the A horizon depleted by 10 to $25 \%$ relative to the B [horizon]; thorium is similarly depleted up to $50 \%$. Despite intense weathering, the uranium and thorium values suggest only slight mobilization from near-surface horizons. Radium is generally in approximate equilibrium with parent uranium. In three 1- to 2.5 -m-deep soil profiles developed on carbonate in Pennsylvania, uranium (3-8 ppm) and thorium (3-10 ppm) are enriched 2- to 10-fold over the parent carbonate (average $0.6 \mathrm{ppm} \mathrm{U,1.7} \mathrm{ppm} \mathrm{Th}$ ) and $\mathrm{Th} / \mathrm{U}$ averages $1.6 \mathrm{vs.} 3$ in the parent. Both uranium and thorium increase with depth. In two profiles on sandstone, uranium and thorium contents are mostly 1.5$2.5 \mathrm{ppm}$ and 3-5.5 ppm, respectively. Uranium increases only slightly with depth but thorium is depleted in near-surface horizons and doubles in concentration in illuviated zones [containing colloids, salts, and small particles from an overlying horizon]. Both the Pennsylvania and Georgia soils suggest greater net mobility of thorium than uranium, possibly because of recycling of uranium through vegetation, plus leaching of thorium from surface horizons. Radium at 4 sites in Pennsylvania is enriched to as much as $180 \%$ of equilibrium relative to uranium in A horizons and is slightly depleted in $\mathbf{E}$ horizons. Lower $\mathrm{B}$ and $\mathrm{C}$ horizons show approximate equilibrium. Selective extractions for a carbonate soil show that almost half the radium occurs in mobile or poorly crystalline forms (exchangeable cations, organic matter, Fe-Mn oxides). Radium generally correlates with Ca content and witk high radon (up to $170 \mathrm{kBq} / \mathrm{m}^{3}$ or $4500 \mathrm{pCi} / \mathrm{L}$ ) in the soil air.

Greeman, Daniel J., and Arthur W. Rose, 1991

Geochemical controls on radon emanation in soils; importance of "organic: radium [abs.]:

Geol. Soc. America, Abstracts with Programs, 23: A202

...The production of soil radon is controlled by six soil chemical and physical parameters, the most variable of which is the radon emanation coefficient (Rn EC). The Rn EC is the fraction of radon escaping from mineral grains. The $\mathrm{Rn}$ EC of rocks and soils ranges from $2-50 \%$ and averages about $25 \%$. Based on the short $\mathrm{Rn}$-recoil range and observed $\mathrm{Rn} E C$, the emanating radium must occur in fine clays (particles $<0.1 \mu \mathrm{m}$ diameter) or as a thin shell (coating). As there is no correlation between the clay content and Rn EC's of $>60$ eastern U.S. soils, the radium must occur as a thin shell. The identity, mechanism, and importance of thin-shell radium in soils has not been described previously. Experiments show that on average 25\% of the radium in soil minerals occurs as organic coatings on soil minerals as a result of Ra-cycling by live vegetation and transfer of radium from minerals to dead organic matter. Multiple regression analysis

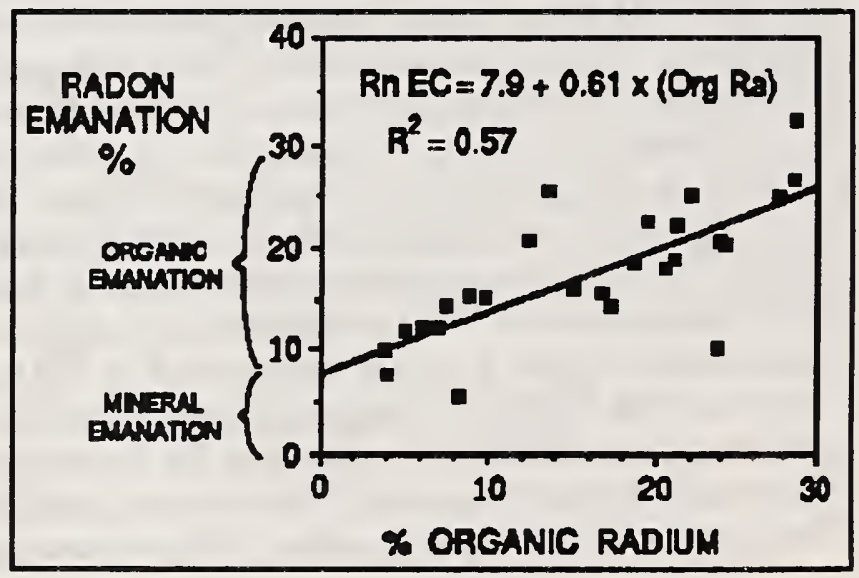


of Rn EC's from 17 soils from Illinois, New York, Pennsylvania, and North Carolina shows that $2 / 3$ of the soilgas radon results from radium in organic coatings with an emanation coefficient as high as $61 \%$. Experimentation on chemically amended soil samples confirmed that the remaining $1 / 3$ of soil radon results from volume-distributed $\mathrm{Ra}$ in silt-and clay-sized soil minerals with a $\mathrm{Rn} \mathrm{EC}$ of $22 \%$. The close relation of organic $\mathrm{Ra}$ and $\mathrm{Rn}$ production in soil suggests that mitigation of indoor radon hazard should include affecting soil organic matter. [See figure.]

Greeman, Daniel J., Arthur W. Rose, and William A. Jester, 1990

Form and behavior of radium, uranium, and thorium in central Pennsylvania soils derived from dolomite:

Geophys. Research Letters, 17(6): 833-836

[Well and poorly drained soils developed on Ordovician carbonate rocks in central Pennsylvania were analyzed for ${ }^{238} \mathrm{U},{ }^{232} \mathrm{Th}$, and ${ }^{226} \mathrm{Ra}$, and for other soil properties. In both soils radium in the surficial, "A" soil horizon was 165 to $180 \%$ of the equilibrium equivalent activity of uranium. Radium and uranium are enriched 10- to 12-fold, and thorium 20-fold, relative to their concentrations in bedrock. Half the radium occurred in pedogenic phases (exchangeable cations, organic matter, and $\mathrm{Fe}$ oxides), chiefly in the organic matter, which could account for nearly all the radon emanation from the soils.]

Greeman, Daniel J., Arthur W. Rose, and William A. Jester, 1990

Geochemical dynamics of radon precursors in eastern U.S. soils [abs.]:

Geol. Soc. America, Abstracts with Programs, 22(7): A247-A248

To study the effect of pedogenesis on the mobility of $\mathrm{U}$, Th, and $\mathrm{Ra}$ as soil-gas radon precursors, the concentration with depth and chemical form of $\mathrm{U}, \mathrm{Th}$, and $\mathrm{Ra}$ in soils, associated parent materials, and vegetation have been determined. The radiometric values have been compared with various soil properties. Soils ranged from incipiently weathered alluvial materials in Pennsylvania to deeply weathered carbonates in Tennessee. Other soil sites included those developed on granites, carbonates, sandstone, shale, gneiss, alluvium, and three in glacially derived materials. Unlike ten other soil profiles tested, all soils derived from glacial materials show considerable $\mathrm{Ra}$ excess (as much as twice the $\mathrm{U}$ activity in some horizons) with whole profiles where $\mathrm{Ra} / \mathrm{U}$ averages $150 \%-180 \%$. Surface horizons are depleted in $U$ and $\mathrm{Th}: 2 \times$ for profiles in glacial materials, and up to $5 \times$ for one profile. With respect to $U$ loss from the soil profile, glacial soils appear more rapidly weathered than older soils in similar climates because of translocation of $U$ and $T h$ from surface horizons and preferred enrichment of Th over $U$ in lower horizons. All vegetation contains abundant $U$, Th, and $\mathrm{Ra}$ with $\mathrm{Ra}$ similar to soil values and $\mathrm{Ra} / \mathrm{U}>>1$. Chemical extraction shows $\mathrm{Th}$ with nearly $3 x$ the adsorption affinity to pedogenic Fe-oxides than $\mathrm{U}$ at most depths in all profiles; similar techniques show $\mathrm{Ra}$ retention in organics. $\mathrm{Th} / \mathrm{U}$ in soils $>\mathrm{Th} / \mathrm{U}$ in parent materials up to $2 \times$ for some profiles. The excess $\mathrm{Ra} / \mathrm{U}$ can be accomplished by two mechanisms: 1) influx of Ra-rich vegetation with organic-Ra retention in near-surface horizons; 2) growth of excess Ra from excess ${ }^{230} \mathrm{Th}$ in deeper horizons. For mechanism 2), we assume equilibrium of ${ }^{234} \mathrm{U}$ with daughter ${ }^{230} \mathrm{Th}$ in parent materials. During soil formation continuous loss of $U>\mathrm{Th}$ could result in a dynamic, temporary excess of ${ }^{230} \mathrm{Th}$ if weathering is rapid enough. With an $80,000-$ year half life, excess ${ }^{230}$ Th will ingrow $\mathrm{Ra}>\mathrm{U}$ on a time scale that is long compared with glacially derived soils. Because of the above effects, and large surface depletions, care should be taken in using airborne radiometric surveys to assess soil radon in glacial terranes.

Greeman, D.J., A.W. Rose, and J.W. Washington, 1990

Evaluation of radon precursors and radon production in major soil types for the NE U.S. [abs.]:

Eos, Am. Geophys. Union Trans., 71(17): 649

The abundance and distribution with depth of ${ }^{238} \mathrm{U},{ }^{232} \mathrm{Th},{ }^{226} \mathrm{Ra}$, along with emanation of ${ }^{222} \mathrm{Rn}$ and ${ }^{220} \mathrm{Rn}$, and in situ radon have been determined for ten common soil types and the associated vegetation. The soils range from incipiently weathered materials in cool climates to deeply weathered materials in warm climates. The parent materials are limestone, dolostone, granite, granitic gneiss, granitic till, shale till, shale, alluvial sandstone/shale, organic-rich loess, and interbedded shale and sandstone. The locations range from the northern Adirondacks, New York, to central North Carolina and Tennessee to central Illinois and throughout 
Pennsylvania. Concentrations range from 2-10 ppm U and 4-25 ppm Th in the soils; $U$ and Th are commonly depleted in surface horizons, up to 5-fold for deeply weathered soil profiles. All soils are enriched in U, Th, and $\mathrm{Ra}$ in comparison with the parent materials, up to $22 \times$ for limestone soils. In general, $\mathrm{Ra}$ is in equilibrium with $U$ at depth; however, in many soils the A-horizon (surface) is Ra enriched (up to $180 \%$ ). Emanation coefficients range from $8-30 \%$ for ${ }^{222} \mathrm{Rn}$ (ave. $22 \%$ ) and $8-24 \%$ for ${ }^{220} \mathrm{Rn}$ (ave. $18 \%$ ). Based upon selective extraction experiments, ${ }^{222} \mathrm{Rn}$ probably emanates from ${ }^{226} \mathrm{Ra}$ in soil organics and the ${ }^{220} \mathrm{Rn}$ likely emanates from ${ }^{224} \mathrm{Ra}$ in free Fe-oxides. Plants contain abundant $\mathrm{U}, \mathrm{Th}$, and $\mathrm{Ra}$ in the ash, with $\mathrm{Ra}>\mathrm{U}$. Soilgas radon ranges from $19 \mathrm{kBq} / \mathrm{m}^{3}(500 \mathrm{pCi} / \mathrm{L})$ in a Pennsylvania granite soil to $310 \mathrm{kBq} / \mathrm{m}^{3}(8500 \mathrm{pCi} / \mathrm{L})$ in a North Carolina granite soil. Radon and thoron $\left({ }^{220} \mathrm{Rn}\right)$ are in subequal amounts and both vary in almost all soils seasonally with summer yielding the highest values. In these soils, the highest soil-gas radon is found in soils formed over limestone residuum and deeply weathered high- $U$ granite soils; soils formed in glacial materials have moderate radon and sandy soils have the lowest radon.

\section{Greeman, Daniel J., John W. Washington, and Arthur W. Rose, 1991}

Measurement and prediction of geologic radon: Some considerations [abs.]:

Geol. Soc. America, Abstracts with Progrants, 23(3): 15

Observations of radon, thoron, $\mathrm{Ra}, \mathrm{U}, \mathrm{Th}$, and some meteorological parameters at 13 sites in the eastern U.S. over the past five years allow some general conclusions and admonitions about the measurement and occurrence of environmental radon. Measurements of the above are more reproducible and relevant at depth ( $>0.7 \mathrm{~m}$ ) for the following reasons: 1) Radon variation in the near surface is most susceptible to short-term changes in meteorological conditions and entry of high-radon soil gas into the home is likely to occur at depth; 2) Because of transport during pedogenesis by both inorganic and organic processes (action of vegetation), surface radium values can be $20 \%$ lower than those at depth in northern sites and up to $40 \%$ lower for southern sites; in some midwestern soils, where cycling by vegetation is intense, $R$ a values at the surface are double the value at depth. Thus, airborne and surficial surveys can be inaccurate. Using volumetrically averaged $\mathrm{Ra}$ values, soil radon at depth can be reasonably approximated. In these moist eastern soils, radon concentrations even at $1.5 \mathrm{-m}$ depth are temporally variable, up to $10 \mathrm{x}$ during one year with high values generally in late summer and are variable from year to year (up to $4 x$ ). The seasonal variation is controlled by soil temperature and soil moisture. During wet, cool periods radon is forced into large soil pores with low radon production and enhanced radon partition in the aqueous phase. Further, moisture inhibits diffusion so that significant radon decay occurs in transport from small high-radon pores to macro-pores and cracks where radon is believed to be sampled. Also, radon can back-diffuse into low-radon bedrock underlying high-radon soils, resulting in decreased radon values at depth For these reasons, radon measurements need to be collected with care over long periods of time if they are to be useful in the prediction of potential radon hazard by geologic terrain.

Gregg, L.T., and Gene Coker, 1991

Geologic controls on radon occurrence in Georgia, in The 1990 International Symposium on Radon and Radon Reduction Technology, Atlanta, Ga., 19-23 February 1990:

Research Triangle Park, N.C., U.S. Environmental Protection Agency Rept. EPA600/9-91-026b, Proceedings, Vol. 2: Symposium Oral Papers, Paper No. VI-2, p. 6-11-6-21 [NTIS Order No. PB91-234450/AS]

Through a combination of geologic models and field measurements, each of the four geologic provinces of Georgia can be characterized for radon concentration. The combinations of bedrock lithology and soil characteristics most likely to exhibit higher radon concentrations in Georgia are granites, granodiorites, granite gneisses, pegmatites, mylonites, carbonaceous shales, phosphates, and monazite/heavy mineral placers, coupled with high to medium permeability soils such as gravels, sands, and uniformly graded silts and sandy silts. Saprolite and surficial soil may either enhance or impede radon migration, as may hydrogeologic characteristics and rock structures such as faults and joint/fractures.

Gregg, L.T., and James J. Holmes, 1990 
Radon detection and measurement in soil and groundwater, in Ward, Stanley H., ed., Geotechnical and Environmental Geophysics, Vol. I: Review and Tutorial:

Tulsa, Okla., Soc. Exploration Geophysicists, p. 251-262

[This paper is a tutorial including sections entitled, Abstract, Introduction, History, Basic Physics of Radioactive Decay and the Production of Radon and Radon Daughter Products, Geological Considerations, Field Methods (The Alpha Scintillometer in Soil-gas Surveys, The Alpha Scintillometer in Water-gas Surveys, Etched-track Detection), Data Interpretation, Case Histories (Field Techniques and Instrumentation, Location/Geology, Data, Interpretation and Conclusions), and References (37). See also the preceding paper in this volume (Nielson, D.L., et al., 1990).]

Grodzins, L[ee], T. Bradstreet, and E. Moreau, 1991

The State of Maine schools radon project, in The 1991 International Symposium on Radon and Radon Reduction Technology, Philadelphia, Pa., April 2-5, 1991, Proc., Volume 2, Symposium Oral Papers, Technical Sessions 6 through 10:

U.S. Environmental Protection Agency Rept. EPA/600/9-91/037B, p. 6-71-6-85

McLean, Va., Cohen (S.) and Associates, Inc. [Springfield, Va., NTIS Order No. PB92-115369]

[Preprints, v. 3, no. VI-6]

A comprehensive study has been made of the radon concentrations in every frequently occupied room on or below grade in every public school in the State of Maine....The radon concentrations showed a strong correlation with geography. The median radon concentrations in the western counties--Oxford, York, Cumberland, and Adroscoggin-and the northernmost county, Aroostook, were more than twice the values in the coastal counties of Knox and Lincoln and the Maine woods counties of Franklin, Somerset, Piscataquis, and Penobscot....The strong correlation between radon levels in school rooms and homes in the same geographical area implies that the underlying geological factors are the determinants for the average or median radon concentrations in county-size areas.

Gross, S., and H.M. Sachs, 1982

Regional (location) and building factors as determinants of indoor radon concentrations in eastern Pennsylvania: Princeton, NJ, Princeton Univ. Center for Energy and Environmental Studies, PU/CEES Rept. 146, 117 p.

Gundersen, L.C.S., 1989

Anomalously high radon in shear zones, in Osborne, M.C., and Jed Harrison, Symposium Cochairmen, The 1988 Symposium on Radon and Radon Reduction Technology, Proc., Vol. 1, Symposium Oral Papers:

Research Triangle Park, N.C., Radian Corp., U.S. Environmental Protection Agency Pub. EPA/600/9-89/006a [Springfield, Va., NTIS Order No. PB89-167480], p. 5-27--5-44.

Sheared fault zones throughout the Appalachian region of the eastern United States have the potential for creating anomalously high indoor radon. They are often characterized by high aeroradioactivity and/or have uranium occurrences. Shear zones are known to be the cause of severe indoor radon problems at Boyertown, PA, and Clinton, NJ, among the worst recorded in the United States. Factors controlling the radon concentrations at these locations are bedrock uranium enrichment, high permeability, and high radon emanation [emanating power or emanation coefficient]. These factors may be directly attributed to the deformation process of ductile shear, known as mylonitization of the rock. During mylonitization, the uranium concentration is increased by the addition of new uranium into the shear zone or by volume loss, leaving uranium relatively enriched as a residuum. The deformation texture imparted to the rock during shear increases its permeability. Oxidation of iron during deformation and subsequent weathering results in the distinctive iron "staining" characteristic of many shear zones. These iron oxides scavenge radium, increase the emanation of the rocks and soils, and make radon readily available to local ground waters. Case studies of shear zones in Pennsylvania, Virginia, New Jersey, and Maryland show anomalously high radioactivity, uranium, indoor radon, and radon in soil gas that statistically sets them apart from their undeformed host rocks. Shear zones can be local as well as regional areas of high radon, especially in mountain belts such as the Appalachians. 
Gundersen, L.C.S., 1989

Geologic control on radon [abs.]:

Geol. Soc. America, Northeastern Section, Abstracts with Programs, 21(2): 19-20

Of the many factors affecting the amount of radon available to enter a home, geology and climate are the most important. These two parameters control the distribution of uranium and radium in rocks and soil, the rock and soil chemistry, the permeability and weathering profile of rocks and soil, and the emanation of radon. Rock types most likely to cause indoor radon problems include carbonaceous shales, glauconitic sandstones, phosphorites, chalk, some limestones, some glacial gravel deposits, uranium-bearing granites, and metamorphic rocks of granitic composition, and mylonite. Rock types least likely to cause radon problems include marine quartz sands, noncarbonaceous shales and siltstones, most clays and fluvial sediments, metamorphic and igneous rocks of mafic composition, and most volcanic rocks. Exceptions exist within these general lithologic groups because of the formation of localized uranium deposits such as hydrothermal vein deposits and sedimentary roll-front deposits. Geologic studies of radon conducted on metamorphic rocks of the northeastern United States during the past three years indicate that radon in soil gas, when used with geology, is an effective predictor of the severity of indoor radon problems in homes with basements. More than a thousand indoor radon and soil-gas radon measurements have been correlated with the underlying geology and indicate that on the average, the radon concentration measured in the home is one percent of the concentration measured in the soil. Thus, if the radon concentration of the soil is $74 \mathrm{kBq} / \mathrm{m}^{3}(2000 \mathrm{pCi} / \mathrm{L})$, the indoor radon concentration will be $\approx 740 \mathrm{~Bq} / \mathrm{m}^{3}(20 \mathrm{pC} / \mathrm{L})$. For indoor radon concentrations in the $148 \mathrm{~Bq} / \mathrm{m}^{3}(4 \mathrm{pCi} / \mathrm{L})$ or less range, the indoor radon-to-soil-gas radon concentration ratio is usually less than one percent and commonly 0.5 to 0.7 percent. For indoor radon greater than $\approx 740 \mathrm{~Bq} / \mathrm{m}^{3}(20 \mathrm{pC} / \mathrm{L})$, the concentration ratio may be greater than one percent. In severe situations, such as Boyertown, Pennsylvania, the radon concentration measured in homes is 10 percent or more of the concentration measured in the soil. Permeability is the major control on the variation of the concentration ratio from the average of one percent. In other climatic and geologic terrains one percent may not be the average. For example, in the southeastern United States, where slab-on-grade is the favored construction practice, the amount of soil-gas radon that enters a home is expected to be much less. Hopefully, regional models based on geology, climate, and construction will be developed for other parts of the United States.

Gundersen, Linda C.S., 1989

Predicting the occurrence of indoor radon: A geologic approach to a national problem [abs.]:

Eos, Am. Geophys. Union Trans., 70(15): 280

Indoor radon has been cited as a significant contributor to as many as 20,000 lung cancer deaths per year. This statistic from the Environmental Protection Agency has been challenged and supported by a number of studies in recent years and is a controversial subject among health physicists, State, and federal governments, the real estate industry, and homeowners. Equally controversial are the methods of testing for radon in the home and for assessing and predicting the severity of the indoor radon problem in the United States. Of the many factors affecting the amount of radon available to enter a home, geology and climate are the most important. These two parameters control the emanation of radon, the rock and soil chemistry, uranium and radium distribution and the permeability and weathering profile of rocks and soil. As geologists we have the task of understanding the processes involved with the distribution and migration of radon. An understanding of the processes will lead to assessment and prediction of its occurrence. However, the amount of radon available to a home and the amount actually occurring in the home can be very different. Another set of complex factors including architecture, construction materials, and heating systems must be considered. Can all these parameters be regionally assessed? Studies conducted in the northeastern and mid-Atlantic regions of the United States indicate that radon in soil gas, when used with geology, is an effective predictor of the severity of indoor radon problems in homes with basements. More than a thousand indoor and soil-gas radon measurements have been correlated with the underlying geology and show that, on the average, the radon concentration measured in the home is one percent of the concentration measured in the soil. In other climatic and geologic terrains, one percent may not be the average. For example, in the southeastern United States, where slab-on-grade is the favored construction practice, the amount of soil-gas radon that enters a 
home is expected to be much less. Regional models based on geology, climate, and construction can be developed for other parts of the United States. Aerial radioactivity is an effective predictor of regional radon anomalies and correlates well with geology. Other geologic methods currently being examined use radon emanation, permeability, and radium concentration in the soil.

Gundersen, Linda C.S., 1990

Grain size and emanation as controlling factors in soil radon [abs.], in The 1990 International Symposium on Radon and Radon Reduction Technology, Atlanta, Ga., 19-23 February 1990:

Preprints, Vol. III, no. C-VI-4

A comparison of two soil radon sampling techniques, the Reimer grab sampling technique (RG) and the EPA flow-through grab sampling technique (EFT), reveals a strong control of grain size and sorting on the soil radon measured. Moisture produces secondary effects on sampling, sometimes determining whether a sample can be obtained at all. Emanation [coefficient], however, is the ultimate control on the amount of radon sampled and it appears to be influenced most by the abundance of metal oxides and the siting of uranium and radium in and around grains. In well-sorted, medium-to-coarse grained sands, the two sampling techniques obtain similar radon concentrations, usually within $10 \%$ of each other. In poorly sorted sands, especially clayey sands, the RG obtains higher concentrations than the EFT. Under high moisture conditions, including saturated conditions, the EFT cannot obtain a radon sample, but the RG will obtain a sample approximately $50 \%$ of the time. Permeability measured at all these sites has no apparent correlation with the radon concentration. Equivalent uranium from gamma spectrometry at the suerface and uranium and radium measured chemically in the soil have been compared with the soil radon concentrations. Although a generally positive correlation exists, anomalous amounts of soil radon with respect to its parent radionuclides are found in a variety of geologic settings. The common factor causing these anomalous concentrations is the occurrence of metal oxides, particularly iron, and the sorption or coprecipitation of uranium and radium in association with the metal oxides, dramatically enhancing the emanation [coefficient] in the rocks and soils. [No paper was found in the proceedings.]

Gundersen, Linda, 1991

Geologic radon potential of the United States [abs.], in International Symposium on the Natural Radiation Environment, 5th, Salzburg, Austria, 22-28 September 1991, Abstracts:

Salzburg, Univ. Salzburg, Inst. for General Biology, Biochemistry and Biophysics, abs. no. 181

A geologic radon map depicting the major geologic provinces relevant to radon has been constructed for the United States. Indoor radon data from the State/EPA Indoor Radon Survey and from other sources were compared with bedrock and surficial geology, aerial radiometric data, soil properties, and soil and water radon studies to designate and rank the different provinces. The map depicts areas of the country that have the potential for indoor radon (1) less than the national average of $\approx 74 \mathrm{~Bq} / \mathrm{m}^{3}(2 \mathrm{pCi} / \mathrm{L}),(2)$ greater than the national average, and (3) greater than $148 \mathrm{~Bq} / \mathrm{m}^{3}(4 \mathrm{pCi} / \mathrm{L})$. The areas of the country with the highest radon potential are: (1) The Proterozoic rocks of the Appalachians and Rocky Mountains: These uraniferous metamorphosed sediments, volcanics, and granite intrusives and carbonates are highly deformed and often sheared. Shear zones in these rocks cause the highest indoor radon problems in the United States. (2) Glacial deposits of the northern Midwest, particularly those derived from uranium-bearing shales, and glacial lake deposits. The clay-rich tills and lake clays have high radon emanation coefficients, in part because of their high specific surface areas, and exhibit higher-than-expected permeabilities due to desiccation cracking when dry. (3) Devonian and Cretaceous black shales: The Chattanooga and New Albany Shales and their equivalents in Ohio, Tennessee, and Kentucky and some members of the Pierre Shale in the Great Plains are often moderately uraniferous and have high emanation coefficients and high fracture permeability. (4) Phosphorites: Natural and man-made accumulations of phosphorites in Florida, phosphatic clays in Georgia and Alabama, and the Permian Phosphoria Formation in Wyoming, Idaho, Utah, and Montana are typically associated with uniformly high concentrations of uranium or anomalously high concentrations of uranium caused by diagenesis [changes taking place in sedimentary materials between deposition and consolidation as rock]. 
Gundersen, Linda C.S., 1991

Radon in sheared metamorphic and igneous rocks, in Gundersen, Linda C.S., and Richard B. Wanty, eds., Field studies of radon in rocks, soils, and water:

U.S. Geol. Survey Bulletin no. 1971, p. 39-50

Sheared fault zones in the Appalachian region of the Eastern United States have the potential for creating anomalously high amounts of indoor radon. These fault zones, many of which have known uranium occurrences, are usually characterized by high aerial radioactivity. Factors controlling the radon concentrations at these locations are bedrock uranium concentration, high permeability, and high radon emanation. These factors may be directly attributed to the deformation process of ductile shear, known as mylonitization of the rock. During mylonitization, the uranium concentration is increased by (1) the introduction of uraniferous fluids into the shear zone or (2) volume loss, which leaves the rock relatively enriched in uranium. Grain-size reduction of uraniferous accessory minerals common to metamorphic and igneous rocks such as titanite, zircon, monazite, and apatite makes uranium available for redistribution into the foliation. This process increases the emanation of radon from the rock dramatically. The texture imparted to the rock during shear also increases its permeability. Oxidation of iron during deformation and subsequent weathering results in the distinctive iron "staining" characteristic of many shear zones. Iron oxides and other metal oxides scavenge uranium and radium available through the weathering processes, increase the radon emanation from the rocks and soils, and make radon readily available to local ground waters. Shear zones in Pennsylvania, Virginia, New Jersey, and Maryland show anomalously high radioactivity and uranium, indoor radon, and soil radon concentrations that set them apart statistically from their unsheared host rocks.

Gundersen, Linda C.S., 1993

The correlation between bedrock geology and indoor radon: Where it works and where it doesn't-Some examples from the eastern United States, in The 1993 International Radon Conference, Denver, Colo., Sept. 20-22, 1993:

Denver, Colo., Am. Assoc. Radon Scientists and Technologists, Rocky Mountain Chapter, Preprints, p. IV 1-IV 8

In the eastern half of the United States, below the limit of glaciation, bedrock geology accounts for a significant amount of the variation seen in indoor radon. Various geologic parameters as well as soil radon and surface gamma radiation have been compared with thousands of indoor radon measurements and regression analyses indicate high positive correlations ( $r>0.5$ to 0.9 ). In this part of the U.S., bedrock geologic models for indoor radon can be used successfully for prediction. Across the northern tier of states that have been subject to glaciation, the correlation of bedrock geology to indoor radon is obscured or is positive in only certain situations. In glaciated areas of the country, the type, composition, thickness, and permeability of glacial deposits play major roles in controlling radon sources in the soil. The contribution from water to indoor air and certain types of house architecture are also confounding factors in certain areas of the United States.

Gundersen, L.C.S., and A.E. Gates, 1988

Redistribution and enrichment of uranium in mylonite zones as a function of deformational processes [abs.]:

Geol. Soc. America, Abstracts with Programs, 20(7): A179-A180

In the Appalachian Region of the eastern USA, shear zones are often characterized by high aeroradioactivity and/or have documented uranium occurrences. Shear zones have also been identified as the major cause of some of the highest concentrations of indoor radon (a daughter product of uranium). Detailed geologic, structural and geochemical studies of two ductile shear zones reveal that deformational processes control the redistribution and enrichment of uranium. The deformational texture increases permeability and radon emanation, compounding the probability of increased radon production. In the southern Virginia Piedmont, the Melrose Granite has been deformed by a single late Paleozoic event to form the Brookneal Mylonite zone. Uranium, radon, and surface gamma radiation can be directly correlated with shear strain determined using the angle between $\mathrm{C}$ and $\mathrm{S}$ bands. Uranium is hosted in titanite and zircon in the undeformed granite. During deformation and grain size reduction, uranium is redistributed (on a thin section scale) by oxidizing fluids into the foliation of the rock. It is then associated with epidote, sericite, and hematite. On the hand sample scale, 
uranium and thorium remain in equilibrium with each other and increase in concentration directly with increasing strain. Thus, little uranium has been introduced into the system and the four-fold enrichment of both uranium and thorium may be attributed to volume loss with increasing strain. Similar results were found in the Boyertown Mylonite zone developed in Precambrian quartz-feldspar gneiss of the Reading Prong, PA. Uranium in undeformed gneiss is hosted in allanite, titanite, and monazite. In mylonite, uranium is redistributed into the foliation with hematite. Uranium increases from $25 \mathrm{ppm}$ to $50 \mathrm{ppm}$. Anomalously high radon indoors and in soil gas are also found on the mylonite.

Gundersen, L.C.S., and A.E. Gates, 1989

The concentration of uranium and radon in mylonite zones from Pennsylvania, Maryland and Virginia: A function of chemical and deformational processes [abs.]:

Eos, Am. Geophys. Union Trans., 70(15): 499

Mylonites formed in various rock types have consistently moderate- to-high radon and uranium concentrations. Geochemical and geologic studies of shear zones developed in metamorphic and igneous rocks found in PA, MD, and VA have been used to construct a model for radon concentration in mylonites. Several factors contribute to high radon in mylonites. First, uranium concentration increases relative to that of the parent rock. Uranium is removed from its crystalline source in minerals such as titanite and reacts with oxidizing fluids present in the developing mylonite. As shear strain increases, grain size reduction (the breaking down of the minerals) increases and more uranium is mobilized and concentrated in the foliation. Therefore, uranium concentrations increase by two processes: (1) new uranium is brought into the zone by fluids and/or (2) uranium is left in the zone as other elements leave the system, causing volume loss and relative enrichment of uranium. Second, emanation of radon from uranium increases in the foliation. Uranium is removed from a site of low radon emanation (the crystal) to a site of high radon emanation (the foliation). Weathering of mylonites occurs along foliations, exposing the source of uranium even further. Third, the foliation developed during mylonitization increases the permeability of the rock dramatically. This pervasive foliation is mimicked in the soil profile and provides preferred paths for water and air movement, increasing the concentration of radon in both. Shear zones are not the only cause of high indoor radon and some shear zones will not create radon problems. Shears developed in rocks with less than $1 \mathrm{ppm}$ uranium may not produce sufficient radon to cause a problem unless uranium is introduced from another source during deformation. However, shear zones developed in rocks with higher uranium concentrations, such as rocks of granitic composition, have a high probability of causing an indoor radon problem.

Gundersen, Linda C.S., R. Thomas Peake, Gary D. Latzke, Lisa M. Hauser, and Calvin R. Wiggs, 1991

A statistical summary of uranium and radon in soils from the Coastal Plain of Texas, Alabama, and New Jersey, in The 1990 International Symposium on Radon and Radon Reduction Technology, Atlanta, Ga., 19-23 February 1990:

Research Triangle Park, N.C., U.S. Environmental Protection Agency Rept. EPA600/9-91-026c, Proceedings, Vol. 3: Symposium Poster Papers, Paper No. C-IV-4, p. 6-35-6-47 [NTIS Order No. PB91-234468/AS]

The Atlantic and Gulf Coastal Plain appears to be an area of low radon potential based on recently available indoor radon surveys and aerial radiometric data. Measurements of radon in soil gas, uranium and radium analyses of soil samples, flow-through permeability of soils, and descriptions of soil profiles were performed to test this hypothesis and to determine the radon-producing potential of the Coastal Plain. Data from Texas, Alabama, and New Jersey indicate that Cretaceous and lower Tertiary glauconitic sands, Cretaceous and Tertiary chalks and carbonaceous shales, and phosphorites have the highest radon potential. Marine limestones and quartz sands have the lowest radon potential. In general, the Coastal Plain appears to be a region of low to moderate radon potential in the three states examined, especially when compared with other geologic terrains.

Gundersen, L.C.S., G.M. i. .er, and S.S. Agard, 1988 
Correlation between geology, radon in soil gas, and indoor radon in the Reading Prong, in Marikos, Mark A., and Robert H. Hansman, eds., Geologic Causes of Natural Radionuclide Anomalies, Proceedings of the GEORAD Conference, St. Louis, Mo., April 21-22, 1987:

Rolla, Mo., Missouri Dept. Nat. Resources, Div. Geology and Land Survey Spec. Pub. No. 4, p. 91-102

Detailed field studies of the Proterozoic metasedimentary rocks of Boyertown [Colebrookdale area] and Easton, Pennsylvania reveal a relationship between geology, radon in soil gas, and the potential for indoor radon accumulation. Fault zones and lithologies with high concentrations of uranium typically have high levels of radon associated with them. In contrast, lithologies with low uranium are not associated with high radon, even where soil permeability is high.... IThe Boyertown study area is underlain by hornblende gneiss and graphitic quartzite, which are low in uranium, and interlayered quartz-feldspar and biotite gneiss (QFB), which is high in uranium. Radon progeny in houses and radon in soil gas in soils over the hornblende gneiss and graphitic quartzite are low $\left(\triangle 0.42 \mu \mathrm{J} / \mathrm{m}^{3}\right.$ and $\leq 37 \mathrm{kBq} / \mathrm{m}^{3}$ or $\leq 0.02 \mathrm{WL}$ and $\leq 1000 \mathrm{pCi} / \mathrm{L}$, respectively), whereas homes and soils over the QFB generally have moderate radon $\left(>0.42\right.$ to $21 \mu \mathrm{J} / \mathrm{m}^{3}$ or $>0.02$ to $1 \mathrm{WL}$ and $<37$ to $74 \mathrm{kBq} / \mathrm{m}^{3}<1000$ to $2000 \mathrm{pCi} / \mathrm{L}$, respectively). Where the QFB has been mylonitized (by severe ductile shear deformation of the rock), the radon in houses and soils is high $\left(>21 \mu \mathrm{J} / \mathrm{m}^{3}\right.$ and $>7.4 \mathrm{kBq} / \mathrm{m}^{3}$ or $>1 \mathrm{WL}$ and $>2000 \mathrm{pCi} / \mathrm{L}$, respectively).... I[At Easton, as at Boyertown, quartz-feldspar gneiss and some biotite gneiss underlie houses and soil with moderate to high radon. Fault zones and local occurrences of exotic uraniumbearing minerals, which are mostly found along lithologic contacts and in local intrusions in marble, can also be correlated with high radon in soils and houses. IPhysical and chemical properties of soils at both study sites are controlled by the geology. Hornblende gneiss and biotite gneiss soils have higher clay content and less permeability than soils developed on the quartz-feldspar gneisses, which are sandier and more permeable. Comparisons of radium and radium content of soils indicate that these two elements are in secular equilibrium. Most radon measured in soil gas correlates positively with radium measured in the horizon from which the soil gas was taken, and thereby indicates that the soils are directly producing radon and that other sources or parameters are not affecting it.

Gundersen, L.C.S., Reimer, G.M., Wiggs, C.R., and Rice, C.A., 1988

Map showing radon potential of rocks and soils in Montgomery County, Maryland:

U.S. Geol. Survey Misc. Field Studies Map MF-2043.

Gundersen, Linda C.S., R. Randall Schumann, James K. Otton, Russell F. Dubiel, Douglass E. Owen, and Kendell A. Dickinson, 1992

Geology of radon in the United States, in Gates, Alexander E., and Linda C.S. Gundersen, eds., Geologic Controls on Radon:

Boulder, Colo., Geological Soc. America Special Paper 271, p. 1-16

More than one-third of the United States is estimated to have high geologic radon potential. A high radon potential area is defined as an area in which the average indoor radon screening measurement is expected to be $148 \mathrm{~Bq} / \mathrm{m}^{3}$ (4 $\mathrm{pCi} / \mathrm{L}$ ) or greater. Geologic terrains of the United States with high radon potential include: 1. Uraniferous metamorphosed sediments, volcanics, and granite intrusives that are highly deformed and often sheared. Shear zones in these rocks cause the highest indoor radon problems in the United States. 2. Glacial deposits derived from uranium-bearing rocks and sediments and glacial lake deposits. Clay-rich tills and lake clays have high radon emanation because of high specific surface area and high permeability due to desiccation cracking when dry. 3. Marine black shales. The majority of black shales are moderately uraniferous and have high emanation coefficients and high fracture permeability. 4. Soils derived from carbonate, especially in karstic terrain. Although most carbonates are low in uranium, the soils derived from them are very high in uranium and radium. 5. Uraniferous fluvial, deltaic, marine, and lacustrine deposits. Much of the nation's reserve uranium ores are contained within these sedimentary deposits, which dominate the stratigraphy of the western U.S.

Gundersen, Linda C.S., R. Randall Schumann, James K. Otton, Russel F. Dubiel, Douglass E. Owen, Kendell A. Dickinson, R. Thomas Peake, and Sharon J. Wirth, 1991 
Preliminary radon potential map of the United States, in The 1991 International Symposium on Radon and Radon Reduction Technology, Philadelphia, Pa., 2-5 April 1991:

Preprints, no. IX-4, 23 p.

...As part of an Interagency Agreement between the EPA and the U.S. Geological Survey (USGS), the USGS is preparing radon potential estimates for the United States in order to help identify and prioritize areas toward which states could target their resources and in which the different building code options would be most appropriate....Variations in geology, soil characteristics, climatic factors, and homeowner lifestyles can be quite large within any particular county; therefore these reports cannot be used to estimate or predict the indoor radon concentrations of individual homes or housing tracts. Indoor radon surveys used for the evaluations are also not consistently statistical at the county scale. TA geologic[ally based] radon potential map of the United States is also being produced, a preliminary version of which is presented in this paper (Figure 1). The final published version of this map will be presented at a 1:7.5 million scale and will include extensive text and annotation. This map illustrates the radon potential of the country by the major geologic provinces of relevance to the radon problem.... IThe assessment of geologic radon potential for the United States was made using five main types of data: (1) geologic (lithologic), (2) radiometric, (3) soil characteristics, including soil moisture, and permeability, (4) indoor radon data, and (5) building architecture (specifically, whether homes in each area are built slab-on-grade or have a crawl space versus homes with basements).... [Twenty-eight physiographic provinces of the 50 States are ranked as having high, moderate, or low radon potential, referring to average indoor concentrations, rather than to the probability of occurrence of severe indoor radon concentrations in some houses.]

Gundersen, Linda C.S., and Richard B. Wanty, eds., 1991

Field studies of radon in rocks, soils, and water:

U.S. Geol. Survey Bulletin no. 1971, 355 p.

Washington, U.S. Government Printing Office

Hall, Francis R., Eugene L. Boudette, and William J. Olszewski, Jr., 1987

Geologic controls and radon occurrence in New England, in Graves, Barbara, ed., Radon in Ground Water:

Chelsea, Mich., Lewis Publishers, p. 15-30

[This paper reviews the principal rock types and distributions in New England with respect to their typical uranium concentrations and expected radon production. Correlations of radon in ground water with rock type are also discussed, and some effects of pumping rates on the radon concentrations.]

Hall, Stephen T., 1991

Combining mitigation \& geology: Indoor radon reduction by accessing the source, in The 1991 International Symposium on Radon and Radon Reduction Technology, Philadelphia, Pa., 2-5 April 1991:

Preprints, v. 5, no. IX-1, 10 p.

Soil radon testing has shown that radon sources are concentrated in narrow linear areas congruent with local geology in the eastern Piedmont, which should also hold true in any folded mountain belt region with heterogeneous geology. IIn existing buildings, if micromanometer tests indicate poor communication in the sub-slab environment, soil radon concentration gradients can be mapped with instantaneous sub-slab radon measurements. By then orienting these difficult-to-mitigate homes on a geologic map, we have been able to predict the location of the radon source adjacent to foundation walls. Tapping these source areas with a multiduct sub-slab depressurization system has been shown to be effective in achieving optimum radon reductions....

Hall, Stephen T., 1991

Correlation of soil radon availability number with indoor radon and geology in Virginia and Maryland, in The 1991 International Symposium on Radon and Radon Reduction Technology, Philadelphia, Pa., 2-5 April 1991: Preprints, v. 4, no. VIIIP-3, 9 p.

[Soil radon availability measurements have yielded correlations with both indoor radon levels and various geologic units. The radon availability number is a function of the soil radon concentration, permeability, and 
diffusion rate. The equipment consists of a special probe and a radon monitor with an attached $\alpha$-scintillation cell. A plot of radon availability numbers against indoor radon levels revealed two distinct populations: buildings with basements and buildings without basements or with other construction factors. Soil tests are being used with success to predict the potential for elevated radon levels and to enable the design of of mitigation systems with the correct magnitude and location of ventilation points. (Modified author's abstract)]

\section{Hall, Stephen T., 1991}

Mitigation diagnostics: The need for understanding both HVAC and geologic effects in schools, in The 1991 International Symposium on Radon and Radon Reduction Technology, Philadelphia, Pa., 2-5 April 1991:

Preprints, v. 5, no. X-4, 16 p.

[Techniques described in the two papers above were applied to schools with success.]

Hall, Stephen T., 1991

Paleozoic granites in the southeastern United States as sources of indoor radon [posters], in The 1991 International Symposium on Radon and Radon Reduction Technology, Philadelphia, Pa., 2-5 April 1991:

Preprints, v. 5, no. IXP-2, 9 p.

Hand, Bryce M., 1988

Geologic factors affecting indoor radon in Onondaga County, N.Y. [abs.], in Radon in the Northeast: Perspectives and Geologic Research (conference), Troy and Albany, New York, May 31-June 2, 1988:

Northeastern Environmental Science, 7(1): 6

Haque, A.K.M.M., and C. Halls, 1993

Radon migration related to structure and plutonism in high heat production province [abs.], in First International Workshop on Indoor Radon Remedial Action, The Scientific Basis and Practical Applications, Rimini, Italy, 27 June-2 July 1993:

Commission of the European Communities et al., Book of Abstracts, p. 76

According to the [U.K] National Radiation Protection Board (Documents of NRPB, 3(4):19, 1992), 90,000 or so dwellings with radon levels exceeding $200 \mathrm{~Bq} / \mathrm{m}^{3}$, are still to be discovered, the majority of which are likely to be in Cornwall and Devon. Reimer and Gundersen (1989) have claimed a striking correlation between soilgas radon concentration, indoor radon level and the geology. All homes built over a mylonite area have indoor radon concentrations greater than $150 \mathrm{~Bq} / \mathrm{m}^{3}$ (US action level), and they are the only homes [in that immediate area] that have radon concentrations greater $7.4 \mathrm{kBq} / \mathrm{m}^{3}$. Sheared fault zones have been identified as the cause of many of the highest levels of indoor radon. It is believed that during ductile deformation of a homogeneous rock there is redistribution of $\mathrm{U} / \mathrm{Ra}$ in the shear bands of the fault zone. According to Scott (1992), the near-surface soil-gas radon concentration in the Reading Prong area was up to $222 \mathrm{kBq} / \mathrm{m}^{3}$, suggesting an effective air permeability as high as $10^{-10} \mathrm{~m}^{2}$, equivalent to sand and gravel. NRPB results (NRPB-R254, 1992) of radon measurement in Northamptonshire, Derbyshire, and Somerset contain some geological inputs. Varley and Flowers (1992) have recorded high levels of radon, up to several thousand $\mathrm{Bq} / \mathrm{m}^{3}$, over faults close to granite areas. Ball et al. (1991) and Heath (Quarterly Jour. Engineering Geology, $24: 169,1991)$ also related zones of high radon concentrations to fracture zones. The major objective of the proposed study is to gain greater insight into the factors that determine radon availability and accumulation in dwellings. The approach will be to assemble geological, soil, and radiological data, leading to the formulation of models that can identify areas and structures with a high radon potential. The intention of the paper is to invite thorough discussions which will lead to successful planning of experimental and theoretical studies.

Harrell, James A., and Ashok Kumar, 1988

Radon hazards associated with outcrops of the Devonian Ohio shale. Final report for a grant awarded by the Ohio Air Quality Development Authority:

Toledo, Ohio, Univ. Toledo, 163 p. 
The indoor radon concentrations in houses, and the uranium, organic carbon and radon contents of samples from the underlying Ohio shale were investigated in six $35-40 \mathrm{mi}^{2}\left[91-104 \mathrm{~km}^{2}\right]$ areas of Ashtabula, Cuyaghoga, Erie-Huron, Franklin, Pike, and Logan Counties. In addition, for each house, the thickness and texture of the sediment overburden above the Ohio shale were determined, as were also numerous parameters relating to the design, construction, and maintenance of the house. IBased on the survey results for the study areas, the following trends and relationships were found to exist. The amount of radon emanating from the Ohio shale is a direct function of the uranium concentration in this rock formation, and the uranium itself is ultimately controlled by the amount of organic matter. Organic matter (as measured by total organic carbon), uranium, and radon in the Ohio shale all increase in a westward direction across Ohio. Similarly, the indoor radon concentration in houses increases from east to west across the state. IIn the Ashtabula, Cuyaghoga, Erie-Huron, and Logan study areas, where the sediment overburden is, on average, less than 20 feet $(6 \mathrm{~m})$ thick, the indoor radon levels are probably directly attributable to the underlying Ohio shale. In the Franklin and Logan study areas, however, the sediment overburden (a silty glacial till) averages 90 and 125 feet [27 and $38 \mathrm{~m}$ ] thick, respectively. These great thicknesses combined with the generally fine-grained texture of the overburden probably greatly diminishes the amount of radon reaching the surface from the Ohio shale. The elevated indoor radon levels in these two areas must then be due, in part, to radon emanating from material within the overburden. IOf the several house parameters investigated, only two had a statistically significant effect on indoor radon levels in all study areas: the penetration factor (a measure of the prevalence of radon entry points in the house substructure; higher values indicate more entry points) and the air exchange factor (a measure of the "tightness" of a house; higher values indicate greater indoor-outdoor air exchange). Increasing indoor radon levels were found to be associated with increasing penetration factor and decreasing air exchange.

Hassler, Gerald L., 1940

Soil gas sampling device and method:

U.S. Patent no. 2,210,546, Aug. 6, 1940, 6 p.

[A soil-gas sampling probe having two inflated packers, one above the other near its lower end, creates two separate spaces in a sampling hole. The absolute pressure in the upper space is maintained less than that in the lower space, so that any atmospheric contamination, even that passing through the ground beyond the hole wall, is intercepted in the upper space. An undiluted, contamination-free soil-gas sample is practically guaranteed from the lower space. An analogous arrangement with the same advantages can be used for sampling soil gas rising through the surface of the ground: two concentric cylinders, open on the bottom side only, are pressed on the ground surface, and the pressure in the outer cylinder is maintained less than that in the inner cylinder, from which the soil-gas sample is withdrawn.]

Hawthorne, A.R., R.B. Gammage, and C.S. Dudney, 1984

Effects of local geology in indoor radon levels, in International Conference on Indoor Air Quality and Climate, 3d, Stockholm, August 20-24, 1984; Vol. 2,: Radon, Passive Smoking, Particulates and Housing Epidemiology, Birgitta Berglund, Thomas Lindvall, and Jan Sundell, eds.:

Stockholm, Swedish Council for Building Research, Vol. 2, p. 137-142

A monitoring study of 40 homes in eastern Tennessee found that about $30 \%$ had radon levels $>148 \mathrm{~Bq} / \mathrm{m}^{3}$ $(>4 \mathrm{pCi} / \mathrm{L})$ in the living space and that these elevated levels showed correlation with location on a porous dolomite ridge surrounding Oak Ridge.

Henry, Mitch E., Maggie Kaeding, and Don Monteverde, 1989

Radon in soil gas and gamma ray activity measurements at Mulligan's Quarry, Clinton, New Jersey [abs.]:

Geol. Soc. America, Northeastern Section, Abstracts with Programs, 21(2): 22

Mulligan's Quarry, Clinton, New Jersey, is located near an area in which elevated (greater than $148 \mathrm{~Bq} / \mathrm{m}^{3}$ or $4 \mathrm{pCi} / \mathrm{L}$ ) indoor radon concentrations have been measured. As part of a continuing study to evaluate the geologic controls on the distribution of radon in the environment, gamma- ray activities were measured with a hand-held scintillometer and a portable gamma spectrometer. These gamma measurements were compared 
with one another and with soil-gas radon measurements. Although throughout the quarry, gamma-ray activity (total counts average over 70 per second) is relatively high, large variations in these values (nearly an order of magnitude from 40 to 350 counts per second) occur over small distances (tens of feet). Variations of greater than an order of magnitude also exist in the soil-gas radon concentrations between sample sites about fifty feet apart. A positive correlation exists among the three data sets. Areas with anomalously high scintillometer counts are generally coincident with, although somewhat larger than, areas of anomalously high equivalent uranium (eU) determined with the gamma spectrometer. Such areas are also generally coincident with areas displaying anomalously high soil-gas radon concentrations. A few sample locations have a negative correlation between the $\mathrm{eU}$ and the soil-gas radon concentration. Data presented herein suggest that if a pre-construction evaluation of the radon hazard potential for a site is desired, a detailed survey should be conducted. Moreover, measurements of the equivalent uranium in the soil and rock and the concentration of soil-gas radon are both valuable measurements for a thorough site evaluation.

Henry, Mitchell E., Margret E. Kaeding, and Donald Monteverde, 1991

Radon in soil gas and gamma-ray activity of rocks and soils at the Mulligan Quarry, Clinton, New Jersey, in Gundersen, Linda C.S., and Richard B. Wanty, eds., Field studies of radon in rocks, soils, and water:

U.S. Geol. Survey Bulletin no. 1971, p. 65-75

Total-count gamma-ray data, gamma-ray spectrometer data, and soil-gas radon measurements were made at the Mulligan Quarry, Clinton, N.J. Although the entire area shows relatively high values of radioactivity, some areas within the quarry show radioactivity levels that are greater than twice background with all three measuring techniques used. Radon in soil-gas measurements generally shows high values in locations where gamma-ray activity is high, but this is not always the case. One area shows a high radon soil-gas value that corresponds to a relatively low equivalent uranium value, and another area shows a high equivalent uranium value that corresponds to a relatively low radon value. High gamma activity and high radon in soil-gas concentrations appear to be related to mineralization that occurs in a shear zone at the southern end of the quarry and may be related to fracture-filling material throughout the entire quarry. Soil development on top of the quarry prevents direct tracing of the fractures seen on the working face and may broaden any radon and (or) gamma-ray highs associated with these concealed fractures.

Hess, C.T., R.E. Casparius, S.A. Norton, and W.F. Brutsaert, 1980

Investigation of natural levels of radon-222 in groundwater in Maine for assessment of related health effects, in Natural Radiation Environment III, Gesell, Thomas F., and Wayne M. Lowder, eds.:

Springfield, Va., NTIS, U.S. Dept. Energy Rept. CONF-780422, Vol. 1, p. 529-546

We have used an inexpensive radon $\left({ }^{222} \mathrm{Rn}\right.$ ) measurement method using liquid scintillation counting (Gesell and Prichard, 1977; Prichard and Gesell, 1977).to remeasure potable wat:r from 10 sites near Raymond, Maine, to determine the accuracy and reproducibility of earlier measurements (Smith et al., 1961). Duplication or triplication of samples shows a high degree of reproducibility for the liquid scintillation method. Comparison with earlier measurements shows good agreement. We have also measured, in duplication, water from 150 new sites from several counties in Maine: York, Aroostook, Penobscot, Cumberland, Waldo, Lincoln, and Hancock. The sites were characterized in the field for rock and overburden types, well and casing depths, and water temperature; water samples were collected for water chemistry and ${ }^{222} \mathrm{Rn}$ measurement. A hypothesis emerged from analysis of the measured values of ${ }^{222} \mathrm{Rn}$ near Raymond, Maine, that high values (1.8 to $7.4 \mathrm{MBq} / \mathrm{m}^{3}$ or 50,000 to $200,000 \mathrm{pCi} / \mathrm{L}$ ) are associated with granite. This was shown to be correct for several large areas of granite such as the Sebago, Lucern, Waldo, and Waldoboro granites. The presence of high ${ }^{222} \mathrm{Rn}$ concentrations in granite areas hundreds of kilometers from the Raymond area shows that the high ${ }^{222} \mathrm{Rn}$ levels in water are a statewide and perhaps a regional problem rather than a western Maine problem. The groundwater with highest concentrations seems to be in the granites and adjacent metasedimentary rocks lying in the highest grade metamorphic terrain. Nongranitic areas with low-grade metamorphic rocks, as in most of Aroostook County, show low values of ${ }^{222} \mathrm{Rn}\left(7.4\right.$ to $74 \mathrm{kBq} / \mathrm{m}^{3}$ or 200 to $\left.2000 \mathrm{pCi} / \mathrm{L}\right)$.

Hesselbom, Åke, 1984 [Pub. 1985] 
Radon in soil gas: A study of methods and instruments for determining radon concentrations in the ground: Uppsala, Sveriges geologiska undersökning, ser. C., no. 803, p. 1-58

This is a study of some of the commercially available detectors for field measurements of radon concentrations in soil gas and of radon flux from the ground surface. Most of the methods for measuring radon are based on detection of alpha particles or gamma radiation which are produced during radioactive decay of radon and radon daughter isotopes. The methods used can be described as active or passive. The active methods involve pumping of soil gas into or through a detector whereas the passive methods register radon concentrations in the ground under natural conditions. TCalibrations were made experimentally by exposing detectors in a controlled radon/radon daughter environment at the National Institute of Radiation Protection in Stockholm, Sweden. TThe methods used have been compared with regard to ability to detect variations in radon concentration, reproducibility, depth effects, and meteorological effects. TThe results show that all methods and detectors used in the study have established the presence of radon in the soil gas. The accuracy of the results obtained, whatever the method or detector used and whatever purpose of the measurements, depends very much upon the physiographic and geological environment (e.g. types of soil and moisture content) in which the detectors are placed.

Hilpman, Paul L., Raymond M. Coveney, Jr., and Charles G. Spencer, 1988

Pennsylvanian black shales may be overrated as radon sources [abs.]:

Geol. Soc. America, Abstracts with Programs, 20(7): A338

Much current radon research is focused on mechanisms of migration from source material to the home, largely based on the assumption that rocks rich in uranium are likely to cause hazardous concentrations of radon whenever adequate pathways to overlying structures are present. In 1984, for example, within the infamous Reading Prong Index House located above gneisses containing 28-55 ppm uranium, radon concentrations of $74 \mathrm{kBq} / \mathrm{m}^{3}$ (>2000 pCi/L) of air were detected-far exceeding the U.S. EPA action level of $148 \mathrm{~Bq} / \mathrm{m}^{3}$ $(4.0 \mathrm{pCi} / \mathrm{L})$. In western Missouri and eastern Kansas, uranium concentrations of several black Pennsylvanian shales are nearly twice the levels (>50-100 ppm uranium) of gneisses below the Reading [Prong] Index House. Accordingly, it seemed appropriate in 1986 to identify the large region of the Midwest underlain by these shales as a potentially high radon risk area. However, more than 200 residences within the Kansas City [Missouri] area have subsequently been tested and radon concentrations above $3.7 \mathrm{kBq} / \mathrm{m}^{3}(100 \mathrm{pCi} / \mathrm{L})$ have yet to be detected in any structure. Of 48 homes tested exclusively during the winter season, all but seven had readings below the group average of $240 \mathrm{~Bq} / \mathrm{m}^{3}(6.4 \mathrm{pCi} / \mathrm{L})$. Even within limestone mines beneath the City, where commercial underground space is commonly floored by uraniferous black shales, readings average $<220 \mathrm{~Bq} / \mathrm{L}$ $(<6.0 \mathrm{pCi} / \mathrm{L})$ and none exceed $481 \mathrm{~Bq} / \mathrm{m}^{3}(13.0 \mathrm{pCi} / \mathrm{L})$. On the basis of results thus far, we conclude that shales may be more effective than crystalline rocks* in retarding radon emanation. Despite slightly elevated average values for radon in homes of Kansas City, it is inappropriate to project severe contamination levels for the area simply as a function of uranium concentrations in local bedrock. [" "Crystalline rocks" is an inexact term usually meaning igneous or metamorphic rock, as opposed to sedimentary, but sometimes including sedimentary rocks having contiguous crystals, such as marbles and quartzites.]

Holkko, J[ussi], and S[imo] Liukkonen, 1991

Radon diffusion in Finnish glacial till soil, [abs.], in International Symposium on the Natural Radiation Environment, 5th, Salzburg, Austria, 22-28 September 1991, Abstracts:

Salzburg, Univ. Salzburg, Inst. for General Biology, Biochemistry and Biophysics, abs. no. 66

Glacial till is the most common soil in Finland. In Scandinavia the term moraine is usually used to describe the glacial till. The structure of ground moraine is very dense and its permeability very low. Areas with a high ${ }^{222} \mathrm{Rn}$ content in the ground are concentrated, in general, in the moraine and esker regions in Finland. IGlacial sandy till was chosen for model tests to determine the diffusion behavior of the ${ }^{222} \mathrm{Rn}$ gas. Soil parameters like granulation, specific grain density, bulk density, water content, and porosity were measured and calculated for the original soil samples. Four radon vessels of about $11.5 \mathrm{dm}^{3}$ volume were filled with this material to the bulk density approaching that in the natural ground. The filling of the material was made under four different moisture conditions. The diffusion experiments were carried out both in steady-state and 
non-steady-state conditions with the opened vessels. In non-steady-state experiments the vessels were opened for four different time intervals. For steady state the vessels were left open for a longer period in order to reach the stationary conditions for the ${ }^{222} \mathrm{Rn}$ diffusion. The ${ }^{222} \mathrm{Rn}$ production was determined in closed vessels with an equilibrium time of about one month. The pressure in the vessels was controlled with mercury manometers against the atmospheric pressure. Lucas cells were applied to the measurements of ${ }^{222} \mathrm{Rn}$ concentrations by taking ${ }^{222} \mathrm{Rn}$ specimens from soil pores through a special filter plate. The diffusion coefficients were calculated in steady-state and non-steady-state conditions by using appropriate solutions of differential equations for diffusion in these two cases. TThe moisture content of the soil seems to have a clear influence on the exhalation rate and on the emanation of the ${ }^{222} \mathrm{Rn}$ gas in glacial till soil. The water content, i.e., the degree of saturation, in partly saturated soils, has a dominating effect on the diffusion behavior in the soil.

Holkko, J., and S. Liukkonen, 1993

Radon diffusion in model tests on Finnish esker and till soils:

Health Physics, 64(2): 132-140

[The most common soil in Finland is "moraine," known in North America as glacial till, which is generally of low permeability; radon movement in it is dominantly diffusive. In contrast, the long, sinuous ridges of stratified gravel and coarse sand known as eskers, are highly permeable, and although their radon is more easily leaked to the atmosphere, they permit very easy infiltration of radon-bearing soil gas into houses and are the most dangerous sites for construction in Finland (see papers by Castrén and by Voutilainen). A building-site radon classification scheme proposed by Slunga (1988) is reviewed. Field investigations in southern Finland were made at two locations on dense glacial till and one location on an esker, and were followed up by laboratory measurements to characterize the soils. Steady-state formulas were obtained in order to determine radon diffusion coefficients in two of the soils in a cylindrical test chamber with suitable inlet and outlet controls and the ends and test ports at several levels in the chamber. Non-steady-state formulas were obtained for transient tests with soil packed in open-top cylindrical chambers with lids in place or removed while samples of air in the soil were removed from a specific level in the soil volume. An effective porosity equal to the air-filled porosity plus $1 / 3$ of the water-filled porosity was used. Glacial till of the in situ characteristics (porosity, 0.201 ; water, $6 \%$ on a dry mass basis; saturation, 0.42 ) yielded diffusion lengths of $0.41,0.51$ and $0.63 \mathrm{~m}$ and interstitial diffusion coefficients of $3.5 \times 10^{-7}, 5.5 \times 10^{-7}$, and $8.3 \times 10^{-7} \mathrm{~m}^{2} / \mathrm{s}$ in different steady-state tests. From the trat sint tests, interstitial diffusion coefficients of $2.7 \times 10^{-6}$ and $3.9 \times 10^{-6} \mathrm{~m}^{2} / \mathrm{s}$ were estimated for glacial till of $2.1 \%$ and $4.7 \%$ water on a dry mass basis. Dry esker sand of $39 \%$ porosity under steady-state conditions yielded a diffusion length of $1.54 \mathrm{~m}$ and an interstitial diffusion coefficient of $5.0 \times 10^{-6} \mathrm{~m}^{2} / \mathrm{s}$. Soil-gas ${ }^{222} \mathrm{Rn}$ concentrations measured in the field were $(0.15-2.6$, mean 0.77$)$ and $0.105 \mathrm{MBq} / \mathrm{m}^{3}$ for dense glacial till at two sites and (28-97, mean 63$) \mathrm{kBq} / \mathrm{m}^{3}$ in esker sand; the corresponding ${ }^{226} \mathrm{Ra}$ concentrations for the dry soils were (176-216), 77.5, and $75 \mathrm{~Bq} / \mathrm{kg}$.]

Holub, R.F., R.F. Droullard, T.B. Borak, W.C. Inkret, J.G. Morse, and J.F. Baxter, 1985

Radon-222 and ${ }^{222} \mathrm{Rn}$ progeny concentrations measured in an energy-efficient house equipped with a heat exchanger:

Health Pt sics, 49(2): 267-277

$\left[{ }^{222} \mathrm{Rn}\right.$ ts progeny were measured in the basement of a recently constructed house in Denver, Colorado. The house had a poured concrete basement and was well sealed for energy efficiency. Indoor radon levels did not correlate well with the degree of depressurization of the basement or with the air exchange rate, and were attributed mainly to diffusive radon entry. Assuming such entry, the diffusion length of radon in the concrete was calculated to be $43 \mathrm{~cm}$ ( $38 \pm 5 \mathrm{~cm}$ in a later response to correspondence in the journal).]

Hutter, Adam R., and Arthur W. Rose, 1987

Radon variability in soil gases over fracture traces in limestones, central Pennsylvania [abs.]:

Geol. Soc. America, Abstracts with Programs, 19: 90 
Significant $\mathrm{Rn}$ anomalies ( 2 to $6 \times$ background of $3.7-37 \mathrm{kBq} / \mathrm{m}^{3}$ or $100-1000 \mathrm{pCi} / \mathrm{L}$, depending on the season and method) occur in soil gases over two photogeologic fracture traces near the Pennsylvania State University Campus. The anomalies were detected using both a field radon detector (EDA Inst. Model RD-200) and Track Etch detectors during most but not all seasons. The anomaly is missing over one fracture trace in data collected by Track Etch in early summer 1986, suggesting that soil moisture or other seasonal effects may have been operative. However, the anomaly is present in the data collected by the RD-200 in early May. Contents of $\mathrm{U}$, Th, and ${ }^{214} \mathrm{Bi}\left({ }^{226} \mathrm{Ra}\right)$ are enriched by $20-30 \%$ in soil along one fracture trace, possibly indicating accumulation of residual clay relative to adjacent areas. Emanation coefficients (proportion of radon lost to the aqueous phase from disaggregated soil in lab measurements) vary from 6 to $40 \%$, averaging $26 \%$, but show no correlation with the location of the fracture trace. Measurements of soil conductivity are still underway to determine soil depth, but it appears that soils are thicker along the fracture trace. Data to evaluate $\mathrm{Rn}$ enrichment by upward flow along the fracture trace have not yet been obtained. The results clearly indicate that $\mathrm{Rn}$ in soil gases varies considerably over short distances, as a result of a variety of phenomena involving soil properties. These local variations in soil $\mathrm{Rn}$ probably cause much of the large range of local variability in the $\mathrm{Rn}$ levels in houses.

Jacobs, P.M., M.G. Mudrey, Jr., C.V. Weiffenbach, and D.M. Mickelson, 1993

Comparison of soil profile characteristics and radon potential with soil gas radon along hillslope transects in southeastern Wisconsin [abs.], in The 1993 International Radon Conference, Denver, Colo., Sept. 20-22, 1993:

Denver, Colo., Am. Assoc. Radon Scientists and Technologists, Rocky Mountain Chapter, Preprints, p. IV 9

This continuing study evaluates the relationship of radon source potential of Quaternary units and soils to hillslope transects in southeastern Wisconsin. Analysis of soil profiles developed in the sandy-textured New Berlin and clayey-textured Oak Creek Formations disclosed elevated concentrations of $\mathbf{R n}$ precursors relative to the parent till. Accumulation of Rn precursors by weathering and biocycling with subsequent adsorption on humus, clay, and oxide fractions account for this phenomenon. However, the effect of a hillslope system (erosion and deposition) on the redistribution of radon precursors has not been investigated.[*] Two hillslope segments, one each in the New Berlin and Oak Creek Formation outcrop areas, were selected for detailed study. Integration of soil-profile attributes with related bulk-soil radon concentrations compares favorably with independently determined soil-gas radon. These relationships are supported by other empirical evidence for hillslope redistribution of radon precursors by sediment erosion and soil solution throughflow. The magnitude of redistribution appears to be a function of relief and permeability of the soil. This observation is compatible with other studies in the Midwest and suggests that radon potential studies must include not only geologic, but also pedologic and topographic factors. [* See Reesman, 1988.]

Jasinska, M., T. Niewiadomski, and J. Schwabenthan, 1982

Correlation between soil parameters and natural radioactivity, in Vohra, K.G., U.C. Mishra, K.C. Pillai, and S. Sadasivan, eds., Natural Radiation Environment:

New York, John Wiley and Sons, p. 206-211

In an earlier paper [Jasinska et al., Health Physics, 38:416-419, 1980], the authors suggested that a linear correlation exists between the concentration of the natural radionuclides U-238, Th-232, and $\mathrm{K}-40$ contained in the upper layer of the soil, and the weight fraction of particles of diameter less than $0.02 \mathrm{~mm}$, i.e., the soil's mechanical composition. The hypothesis has been verified on a larger and statistically significant sampling of soils frequently occurring in Poland: chernozem [highly organic black earth], podzolic [thin matted organic layer overlying gray leached layers and brown layers of organic material transported from above], muds, and anthropogenic, where, for a given soil type, samples were chosen to represent various mechanical compositions. They conclude that the radioactivity concentrations of the head radionuclides in the soil depend on its mechanical composition, rather than on the type of soil. Thus, in principle, one may estimate dose rates from terrestrial sources directly from soil maps, without the need for outdoor measurements.

Kearney, P.D., and D.A. Krueger, 1987

Radon-222 flux density measurements using an accumulator: an alternative technique: 
Keller, G., and M. Schütz, 1988

Radon exhalation from the soil:

Radiation Protection Dosimetry, 24(1/4): 43-46

[The exhalation of ${ }^{222} \mathrm{Rn}$ and ${ }^{220} \mathrm{Rn}$ from the soil in southwestern Germany was measured by covering the ground with an insulated hemispherical metal dome. The dome was charged to $8 \mathrm{kV}$. Beyond an aperture at the top of the dome was an insulated box containing a grounded surface-barrier $\alpha$ detector. Upon decay of a radon isotope, the product polonium isotope ion was attracted to the $\alpha$ detector to be spectrometrically identified and counted. The rate of exhalation was computed from the increases in polonium-isotope counting rates over a 2-hour period; for radon the lower limit of detection was $0.3 \mathrm{mBq} / \mathrm{m}^{2}-\mathrm{s}$, with a median error of $\approx 10 \%$. Radon exhalation was found to be influenced chiefly by the effective porosity (the air-filled porosity), and was also correlated with the difference between the soil temperature and the temperature of the nearsurface air. Soils over Lower and Middle Permian sandstone, coal, and shell limestone showed average exhalation rates of $1-2 \mathrm{mBq} / \mathrm{m}^{2}-\mathrm{s}$; soils over Tertiary volcanic rocks near the village of Döttingen exhalation averaged 5-10 times greater. Older houses with bare dirt cellar floors had significantly greater indoor radon concentrations, up to $\approx 500 \mathrm{~Bq} / \mathrm{m}^{3}$, than more modern houses with concrete slabs. (Wilkening, Clements, and Stanley, 1975, estimated a worldwide average ${ }^{222} \mathrm{Rn}$ exhalation for continental areas of $0.75 \mathrm{atom} / \mathrm{cm}^{2}-\mathrm{s}$, equivalent to $16 \mathrm{mBq} / \mathrm{m}^{2}-\mathrm{s}$.)]

Kirichenko, L.V., 1970

Radon exhalation from vast areas according to vertical distribution of its short-lived decay products: Jour. Geophys. Research, 75(18): 3639-3649

Geophys. Abs. 288-386

The use of natural radioactivity in the investigation of mixing and transport processes in the atmosphere is impossible without allowing for radon influx from vast surfaces on the Earth. An estimate of the effective radon flux from areas with nonuniform emanation is considered. The technique consists of calculating the total amount of natural radioactive products through the entire atmosphere per unit of ground surface. A vertical profile of the alpha-active short-lived products of radon has been determined by sounding the atmosphere with equipment installed in aircraft. The possiblities of the technique are analyzed. Characteristics of emanation of a number of regions in the Soviet Union are given.

Kline, S.W., and D.G. Mose, 1989

Causes of elevated indoor radon during winter seasons [abs.]:

Eos, Am. Geophys. Union Trans., 70(15): 500

Indoor radon values have been shown to depend on the season of measurement, with winter values generally being highest. Long-term alpha-track basement measurements from 347 metropolitan Washington, DC homes during the winter of 1986/87 and 655 homes during the winter of 1987/88 indicate that radon levels can also vary from winter to winter. The colder $1986 / 87$ winter produced significantly higher median indoor radon in surveyed homes. Most models for explaining seasonal variations deal principally with air exchange between buildings and the out-of-doors. Homes are thought to have more radon in the winter because they are more often closed to conserve heat. Also, soil-to-building flow rates are increased by heated indoor air escaping from the upper part of homes and creating a pressure difference between the building and its substrate. Preliminary data from alpha-track soil radon monitors, indoor radon monitors, and surface gamma-ray spectrometry indicate that indoor radon values in winter are also influenced by intervals of elevated soil-gas radon in the subsurface. Freezing of the upper layer of soil creates a capping effect that reduces the escape of soil-gas radon to the atmosphere, so soil radon concentrations build up to higher-than-normal levels. Thus, periods of frozen ground cause higher concentrations of indoor radon. Since actual radon concentrat in soil gas are apparently higher during such periods, attempts to simulate winter conditions during other seasons through closed-home procedures will probably be less successful in northern latitudes.

Kline, Stephen W., Douglas G. Mose, and Isidore Zietz, 1988 
Use of aeroradioactivity maps in indoor radon prediction: A case study from Fairfax County, Virginia and Montgomery County, Maryland [abs.]:

Geol. Soc. America, Abstracts with Programs, 20(7): A337-A338

An indoor radon survey in northern Virginia and southern Maryland in 1987-1988 has accumulated $\approx 5000$ alpha-track (3-month exposure interval) radon measurements. The study area, which contains a diversity of sedimentary, igneous, and metamorphic rocks, is being used to evaluate measurement methods, remediation methods, and methods for radon prediction for communities. Good bedrock, soil, and aeroradioactivity maps are available for the study area. A land-based spectral gamma-ray survey of a number of sites in Fairfax County indicates that there is a general increase in calculated equivalent uranium with increasing total counts of gamma radiation. Analyses for uranium in some soil and rock materials of Fairfax County by neutron activation are in agreement with trends in total count aeroradioactivity averaged over various geologic units. These data indicate that there should be a relationship between total-count aeroradioactivity and soil radon, and hence indoor radon, in this area. Comparison of home locations and their indoor radon values with aeroradioactivity maps of Fairfax and Montgomery Counties shows that total-count aeroradioactivity is a very good discriminator of areas of high potential indoor radon. The results were even better than potential maps based on geology and soil characteristics. Subtle differences in the relationship between the percentage of homes over $148 \mathrm{~Bq} / \mathrm{m}^{3}(4 \mathrm{pCi} / \mathrm{L})$ and the aeroradioactivity signal are present between different rock types. The differences are likely a consequence of using total gamma-ray aeroradioactivity (includes signal components of $\mathrm{K}$ as well as daughters of $\mathrm{U}$ and $\mathrm{Th}$ decay) and to differences in the geology of the surface material. A spectral aeroradiometric survey is expected to produce the best results in regional indoor radon prediction.

Kothari, Brajesh K, 1983

Use of NURE data for natural radiation exposure: indoor radon and gamma-ray radiation [abs.], in Health Physics Soc. Ann. Mtg., 28th, no. P/246:

Health Physics, 45(1): 254

Radionuclide data obtained in the National Uranium Resource Evaluation (NURE) survey of the U.S. Department of Energy were used to correlate equivalent uranium with indoor radon concentrations and to calculate natural outdoor exposure rates. In the NURE survey, distributions of equivalent uranium and thorium (eU and $\mathrm{eTh}$ ) and $\mathrm{K}$ concentrations of "surface soil" were obtained by flying $\mathrm{NaI}$ crystals generally at flight spacings of three or six miles. Indoor exposure to radioactive radon daughters is a potential health problem which varies with geographical location. The present difficulty in identifying problem areas might improve by the use of eU data from the NURE program. We have calculated equivalent uranium (eU) from NURE survey for areas where annual indoor radon concentrations have been measured by others. The respective eU and radon or radon daughter concentrations are: Middlesex, NJ, $1.5 \mathrm{ppm}, 12-29 \mathrm{~Bq} / \mathrm{m}^{3}(0.32-0.79 \mathrm{pCi} / \mathrm{L})(15 \mathrm{homes})$; Lewiston, NY, 1.5 ppm, 13-29 Bq/m $\mathrm{m}^{3}$ (0.34-0.79 pCi/L) (10 homes); Cannonsburg, PA $2.2 \mathrm{ppm}, 17-167 \mathrm{~Bq} / \mathrm{m}^{3}$ $(0.45-4.50 \mathrm{pCi} / \mathrm{L})$ (8 homes); Butte, MT, $7 \mathrm{ppm}, 0.040-5.03 \mu \mathrm{J} / \mathrm{m}^{3}$ (0.0019-0.242 WL) (56 homes); Anaconda, MT, $3.3 \mathrm{ppm}, 0.087-0.69 \mu \mathrm{J} / \mathrm{m}^{3}$ (0.0042-0.033 WL) (16 homes); Florida, phosphate region, $6.7 \mathrm{ppm}, 0.06-$ $2.16 \mu \mathrm{J} / \mathrm{m}^{3}$ (0.003-0.104 WL) (107 homes); Florida, background for phosphate region, $1.5 \mathrm{ppm}, 0.02-0.23 \mu \mathrm{J} / \mathrm{m}^{3}$ (0.001-0.011 WL) ( 26 homes). A significant correlation between $\mathrm{eU}$ and indoor radon concentration, obtained by using weighted regression analysis, implies that for these locations, ground underneath the home is a major source of radon. Since almost all of the USA has been surveyed, NURE data can be used to identify areas, where ground could be a major source of indoor radon, for further studies. Using appropriate factors for the various radionuclides, contour maps of outdoor exposure rates from gamma-rays were prepared from the NURE data for some areas in New York State in cooperation with the Bendix Field Engineering Corporation. Results from exposure rate maps and limitation of the NURE data will be discussed.

Kothari, B., C. Kunz, and W. Lilley, 1985

Identifying areas with potential for high indoor radon: results of surficial soil measurements [abs.], in Health Physics Soc. Ann. Mtg., 30th, Chicago, Ill., May 26-31, 1985, Abstracts of Papers, no. TPM-D7:

Health Physics, 49(1): 158 
Kovach, Edward Michael, 1944

An experimental study of the radon-content of soil-gas:

Am. Geophys. Union Trans., 25(4): 563-571

Geophys. Abs. 8256:

All the solid constituents of the earth have minute admixtures of radioactive substances and give off emanation.

Accordingly, the soil gases the fill the capillaries of the earth must contain radon and thoron. The present study at Fordham, N.Y., seeks to establish a connection between the fluctuations of the soil's radon content and the variations of penetrating radiation from the ground studied by V.F. Hess. Three pipes were lowered into bored holes in the ground to depths of 25,75 , and $150 \mathrm{~cm}$ respectively and sealed at the surface by cement. For 69 days the radon content of the soil gas was measured in these pipes simultaneously by means of an ionization apparatus. The following conclusions are drawn at this phase of the experiment: (1) Radon content in soil gas increases with freezing and decreases with water soaking of the ground; (2) dry ground produces stability within the three layers studied; radon is found to increase with depth; and (3) atmospheric influences are secondary to the ground conditions of the soil.

Kovach, Edward M., 1945

Meteorological influence upon the radon-content of soil gas:

Am. Geophys. Union Trans., 26(2): 241-248

[This paper continues the work reported above. Soil gas was drawn from pipes bottoming at $25,75,150$, and $200 \mathrm{~cm}$ over the course of 177 days of actual investigation during the period May 17, 1944-March 25, 1945, and included 642 individual measurements using ionization chambers connected to a Wulf bifilar electrometer. It was inferred that (1) Dry ground produces constant values of radon content at each depth and shows an increase with depth; (2) A long period of snow-and-ice cover on the ground causes the radon content at all depths to approach the same value, which is the highest for the investigation period; (3) Within the depth range studied, increasing barometric pressure causes a decrease in radon content, and contrariwise, the effect being most pronounced at the shallower depths; (4) a high wind velocity over a period of hours noticeably reduces the radon content in the top layers of the ground; and (5) Soil temperature changes have no great effect on the radon content of soil gas.]

Kovach, Edward M., 1946

Diurnal variations of the radon-content of soil-gas:

Terrestrial Magnetism and Atmospheric Electricity, 51: 45-56

[Measurements similar to those reported above were conducted in a lawn-covered area at a site about $6 \mathrm{~km}$ from the previous one. Only $25-$ and $75-\mathrm{cm}$ depths were investigated, because short-term changes were to be expected most at the shallow depths, but as many as five $25-\mathrm{cm}$ pipes were emplaced in the $15 \times 38-\mathrm{m}$ lawn. It was inferred that (1) Constant atmospheric pressure is accompanied by rather stable values of the radon content of soil gas; (2) Variations in pressure had only a slight influence, although in general decreasing pressure tended to increase the radon content at both depths, and contrariwise; (3) The radon content of the air in the soil capillaries increased linearly with depth to $75 \mathrm{~cm}$; (4) If several 4-L samples were taken from the same pipe at intervals of a few hours, the values of radon conent did not diminish; (5) Samples taken from $25-\mathrm{cm}$ depth at the different locations on the lawn differed a great deal; (6) The radon content at 75- $\mathrm{cm}$ depth was somewhat periodic, with afternoon values generally lower than morning values (but no consistent periodicity was noted at $25-\mathrm{cm}$ depth); and (7) The radon content in the upper layers of the ground was markedly reduced by winds that were strong and continuous over a period of several hours. The strong winds reported ranged from 5.2 to $23 \mathrm{~m} / \mathrm{s}$, most $>11 \mathrm{~m} / \mathrm{s}$; the location and height of the anemometer were not reported. No data on radium content or emanating power of the soil at the sampling points were reported.]

Kullman, Frej, 1993

Radonrisk mapping-a method of predicting problem areas on geological grounds [abs.], in First International Workshop on Indoor Radon Remedial Action, The Scientific Basis and Practical Applications, Rimini, Italy, 27 June-2 July 1993: 
Commission of the European Communities et al., Book of Abstracts, p. 78

Swedish authorities have stipulated a maximum radon level of $200 \mathrm{~Bq} / \mathrm{m}^{3}$ for permanently inhabited buildings. For buildings built later than 1981 the limit is $70 \mathrm{~Bq} / \mathrm{m}^{3}$. In order to trace buildings with elevated radon levels and to avoid building new ones the radon risk for different areas needs to be evaluated. Radon risk mapping is done both at regional scale (normally 1:50,000) and in detailed scale $(1: 1000-1: 10,000)$. For the mapping the ground is classified into high-, normal- and low-risk areas. The classification work is started by an interpretation of all available geological material from the investigated area, such as bedrock maps, Quaternary geological, results from airborne radiometric surveys, earlier geotechnical investigations, results from uranium prospecting, and so on. This is followed by field investigations including radon measurements in possible risk areas, and control of radium content by gamma spectrometry in typical rock types and soil types of the area. The results are compiled on a map and into a report, with recommendations about building technical requirements within different parts of the investigated area, and recommendations for the future tracing of high radon buildings. Experience from Swedish radon measurements shows a tenfold increase of high-radon houses within high-risk areas classified according to the above model, if compared with randomly distributed measurements.

Kunz, Charles O., 1988

Indoor radon: Source characterization:

Environmental Progress, 7(4): 236-240

[Measurements of soil radium concentrations, soil-gas radon concentrations, and permeability of soil to gas flow in six areas of New York State correlated with indoor radon measurements by a "Radon Index Number," RIN = (source term) (permeability) ${ }^{1 / 2}$ (depth factor), where the source term can be the soil radium concentration, emanating radium, or soil-gas radon concentration, and the depth factor, $\leq 1$, is the depth of soil to the water table, bedrock, or to a soil layer of much lower permeability, divided by $3 \mathrm{~m}$ for homes with basements. This RIN is different from that introduced by Eaton and Scott (1984).]

Kunz, C.O., 1988

Field measurements to characterize the availability of radon in soil-gas for transport into homes [abs.], in Radon in the Northeast: Perspectives and Geologic Research (conference), Troy and Albany, New York, May 31-June 2, 1988:

Northeastern Environmental Science, 7(1): 7

[See abstracts above and below.]

Kunz, C., C.A. Laymon, and C. Parker, 1989

Empirical relationship between soil parameters and indoor radon [abs.]:

Eos, Am. Geophys. Union Trans., 70(15): 497

Soil measurements were compared with indoor radon concentrations for several areas in New York State and based on these results the following empirical relationship was developed:

(Indoor radon) $\propto$ (source strength)(depth factor)(permeability) ${ }^{1 / 2}$

To characterize surficial soil and bedrock regarding the amount of radon likely to enter homes it is necessary to have a measure of the concentration of radon in the soil gas entering the homes (source strength) and a measure of the amount of soil gas that can flow into the homes (permeability). The source strength can be either the soil-gas radon concentration, the total soil radium concentration, or the emanating fraction of radium. The depth factor is the depth of soil to the water table, bedrock, or other low-permeability feature. The distribution of indoor radon concentrations within areas of similar soil types had geometric standard deviations ranging from about 1.5 to 3.0. This limits the ability to predict the indoor level for a particular house. However, it appears that useful estimates of mean indoor concentrations can be made based on soil and bedrock parameters.

Kunz, C., C.A. Laymon, and C. Parker, 1989 
Gravelly soils and indoor radon, in M.C. Osborne, and Jed Harrison, Symposium Cochairmen, The 1988 Symposium on Radon and Radon Reduction Technology, Proc., Vol. 1, Symposium Oral Papers:

Research Triangle Park, N.C., Radian Corp., U.S. Environmental Protection Agency Pub. EPA/600/9-89/006a [Springfield, Va., NTIS Order No. PB89-167480], p. 5-75--5-86.

Many homes in New York State with above-average concentrations of indoor radon are built on deep, well-drained, gravelly soils. Gravelly soils were studied in three areas where the geometric mean for basement ${ }^{222} \mathrm{Rn}$ concentration ranges from 370 to $740 \mathrm{~Bq} / \mathrm{m}^{3}(10$ to $20 \mathrm{pCi} / \mathrm{L})$, and at 12 additional State-wide homes with basement ${ }^{222} \mathrm{Rn}$ concentrations greater than $740 \mathrm{~Bq} / \mathrm{m}^{3}(20 \mathrm{pCi} / \mathrm{L})$. The gravelly soils examined in this study contain average to slightly above average concentrations of soil ${ }^{226} \mathrm{Ra}(\approx 37 \mathrm{~Bq} / \mathrm{kg}$ or $1.0 \mathrm{pCi} / \mathrm{g})$ and the concentration of soil-gas ${ }^{222} \mathrm{Rn}$ is within the range of average values for soils $\left(\approx 26 \mathrm{kBq} / \mathrm{m}^{3}\right.$ or $700 \mathrm{pCi} / \mathrm{L}$ at $120 \mathrm{~cm}$ ). The permeability of these soils is high with a geometric mean of approximately $6 \times 10^{-10} \mathrm{~m}^{2}$ at a depth of $120 \mathrm{~cm}$. Tests conducted in one study area showed increases in permeability between depths of 30 and $120 \mathrm{~cm}$. The product of a source term (soil ${ }^{226} \mathrm{Ra}$ concentration, emanating ${ }^{226} \mathrm{Ra}$, or soil-gas ${ }^{222} \mathrm{Ra}$ concentration) and the square root of the permeability yields a Radon Index Number (RIN) which is used to predict mean indoor ${ }^{222} \mathrm{Rn}$ concentrations. The RIN, which is based on soil parameters agrees well with measured indoor ${ }^{222} \mathrm{Rn}$ concentrations. [This RIN is different from that introduced by Eaton and Scott (1984).]

Laymon, Charles, and Charles Kunz, 1991

Geologic factors and house construction practices affecting indoor radon in Onondaga County, New York, in The 1990 International Symposium on Radon and Radon Reduction Technology, Atlanta, Ga., 19-23 February 1990:

Research Triangle Park, N.C., U.S. Environmental Protection Agency Rept. EPA600/9-91-026b, Proceedings, Vol. 2: Symposium Oral Papers, Paper No. VI-4, p. 6-37-6-50 [NTIS Order No. PB91-234450/AS]

Indoor radon in Onondaga County, New York is largely controlled by bedrock and surficial geology. At more local scales, these alone are insufficient to characterize radon potential. A detailed study of the concentration of indoor radon, soil radium, soil-gas radon, soil and bedrock type, permeability, and home construction practices indicates that above-average indoor radon concentrations are associated with gravelly moraine and glaciofluvial deposits, the radium-bearing Marcellus shale, and high-permeability zones around the substructure of houses built into limestone bedrock.

Laymon, Charles, Charles Kunz, and Lawrence Keefe, 1990

Indoor radon in New York State: Distribution, sources and controls:

Albany, N.Y., State of New York Dept. Health Tech. Rept. [unnumbered], 49 p.

[Short-term basement screening measurements in New York State, totalling 26,477 , wer listributed log-normally with a geometric mean of $93 \mathrm{~Bq} / \mathrm{m}^{3}(2.5 \mathrm{pCi} / \mathrm{L})$. Cortland, Chemung, and Steuber counties had geometric means $>222 \mathrm{~Bq} / \mathrm{m}^{3}(>6 \mathrm{pCi} / \mathrm{L})$, one-third exceeded $148 \mathrm{~Bq} / \mathrm{m}^{3}(4 \mathrm{pCi} / \mathrm{L})$, and 58 homes in 22 counties exceeded $3.7 \mathrm{kBq} / \mathrm{m}^{3}(100 \mathrm{pCi} / \mathrm{L})$. Onondaga and Erie Counties had more homes with the extreme radon levels, attributable to geologic conditions. The levels tended to be greater than the geometric mean from August through February and equal to or less than the geometric mean from March through July. Indoor radon potential, although necessarily variable within each physiographic province, was evaluated as generally low for the Adirondack Mountains ( $<\approx 56 \mathrm{~Bq} / \mathrm{kg}$ or $\approx 3.5 \mathrm{pg}^{226} \mathrm{Ra} / \mathrm{g}$ ), mostly sandy soils with moderate-to-low permeability); variable for the several lowlands (some very permeable gravels, with some occurrences of radium enrichment); moderately elevated for the Allegheny Plateau (highly permeable glacial deposits in valleys); elevated in Onondaga County (derived from uranium originally deposited in the black marine Marcellus shale); probably somewhat elevated for the Taconic Mountains (intermediate-grade metamorphic bedrock with some elevation of ${ }^{226} \mathrm{Ra}$ content and gravelly soils on valley bottoms); elevated in places in the Hudson Highlands (occurrences of uranium with iron minerals in high-grade metamorphic rocks); low in the Manhattan Prong (based on existing indoor data); and low for Long Island (low ${ }^{226} \mathrm{Ra}$ content and generally moderate-to-low permeability of soils, although coarse moraines are found along the northern coast and along the middle; some boulders of high $\gamma$ radiation are known and could be local sources of radon).] 
LeGrand, Harry E., 1987

A predictive model for indoor radon occurrences--A first approximation, in Graves, Barbara, ed., Radon, Radium, and Other Radioactivity in Ground Water. Hydrogeologic Impact and Application to Indoor Airborne Contamination. National Well Water Association Conference, Somerset, N.J., April 7-9, 1987, Proceedings: Chelsea, Mich., Lewis Publishers, Inc., p. $477-487$

[This paper presents a method of evaluating four major factors for assessing indoor radon potentialof a building site: Rock type (uranium concentration); topographic slope and vertical emplacement of building; hydrogeologic setting and average water-table position; and water-table behavior and characteristics. The method is designed mainly for the eastern U.S., and is an outgrowth of the paper below. After scale-of-ten evaluation of each of the major factors, the scores are combined by an algorithm, adjusted for anticipated construction characteristics, and the final numerical answer is compared with a five-tiered "hazard potential scale," of "likelihood of worrisome concentrations of radon" (probability of $\geq 148 \mathrm{~Bq} / \mathrm{m}^{3}$ at least $30 \%$ ).]

\section{LeGrand, Harry E., 1987}

Radon and radium emanations from fractured crystalline rocks--a conceptual hydrogeological model:

Ground Water, 25(1): 59-69

Subsurface air is a refuge for radon escaping from rock and soil surfaces and from subsurface water. Where the subsurface air is confined in a zone by overlying poorly permeable material or by downward-moving water, the radon can accrete and become mobile. The crystalline [non-sedimentary] rocks of the eastern U.S. contain granites and associated rocks that have moderate to low amounts of uranium source material; the amounts are sufficient for radon to emanate significantly from both the soil-saprolite zone and the part of the underlying fractured rock above the water table. Both the soil-saprolite confined air system and the fracture air system are nondescript and are erratic in size and shape from place to place and from time to time. They tend to have a gross horizontality because of blanket infiltration of precipitation and in some cases by crude layering of soil horizons or tension fracturing of bedrock. The pressure in the air systems increases chiefly as infiltrated water moves downward and as the water table rises. The radon-laden air moves toward two types of low-pressure chamber. One type of chamber is a house on sloping topography niched into the soil-saprolite zone and perhaps into bedrock fractures. The other type is the unwatered fracture zone of a pumping cone of depression where overlying clays are less permeable. These two types of low-pressure chamber have characteristics of vacuum cleaners, sucking in radon-laden air. Conditions leading to high indoor radon concentrations are: (1) granites and associated rocks with normal or above normal amounts of uranium, (2) normal interconnecting fracture pattern, (3) a thin mantle of relatively impermeable clay soil, (4) repeated cycles of recharge and of a fluctuating water table in the fracture zone or in the overlying regolith, (5) indentation of buildings into soil and rock materials, and (6) building construction allowing relatively easy inflow of air from the subsoil and rock. Promoting the continual accretion of radon and radium in well water is the alternating action of air and water in the tortuous fractures in the cone of pumping depression. Radon accretes in well water more readily than does radium, chiefly because it is able to diffuse out of the pores and small fractures to become then mixed with the churned well water; radium tends to be absorbed on the rock materials, but the resurging ground water may desorb or dislodge radium and bring it into the well in some cases....

Lehtoviita, Timo, Jussi Holkko, Martti Viljanen, and Eero Slunga, 1985

Radonin merkitys talonrakennustekniikassa. Tutkimuskohteiden rakennustekninen tarkastelu [Radon in building technology. Structural comparison on the research sites]:

Espoo, Finland, Helsinki Univ. Technology, Dept. Civil Engineering, Div. Structural Engineering Rept. 73, 145 p. Indoor radon concentrations in 45 small houses are compared with their structural characteristics. Measured radon concentrations ranged from 9 to $3541 \mathrm{~Bq} / \mathrm{m}^{3}$. Radon concentrations in soil gas from 13 of the sites ranged from 1 to $241 \mathrm{kBq} / \mathrm{m}^{3}$. The highest radon levels were measured in houses where the foundation slab was not continuous, and were higher in houses with cellars. In most cases indoor radon levels were high if the radon content of the soil was high.

Lehtoriita, Timo, Jussi Holkko, Martti Viljanen, and Eero Slunga, 1986 
Radonin merkitys talonrakennustekniikassa. Maaperan ja rakenteiden radontuotto ja-lapaisevyys [Radon in building technology. Radon exhalation and radon permeability of soil and structures]:

Espoo, Finland, Helsinki Univ. Technology, Dept. Civil Engineering, Div. Structural Engineering Rept. 82, 130 p. The effects of soil and building structural characteristics on radon entry through basements are given in this treatment of the theoretical bases of radon transfer, laboratory and field experiments, and calculation examples. The main transfer mechanism in clays is duffusion and in coarse sands and gravels is convection. The exhalation of soil and other radon-technical parameters can be defined by the experimental methods developed in this research. Convection is the main radon transfer mechanism into structures. In some cases diffusion must be taken into account. Some building materials can yield radon to indoor air. Theoretical calculations are required when experimental results are analyzed and in radon-technical design.

\section{Lehtoviita, Timo, and Martti Viljanen, 1986}

Radonin merkitys talonrakennustekniikassa. Radonin siirtymisen laskenta maanvastaisen rakenteiden lapi [Radon in building technology. The computation of radon transfer through ground based structures]:

Espoo, Finland, Helsinki Univ. Technology, Dept. Civil Engineering, Div. Structural Engineering Rept. 81, 138 p. This report presents the basic theory of radon transfer from the soil to indoor air. Some calculation methods are presented. Mainly convection and partly diffusion are the transfer mechanisms of radon entry in basement structures, caused by pressure and concentration gradients. The radon transfer can be solved by both analytical and numerical methods. The analytical methods require simple boundary conditions and the material where the transfer occurs must be homogeneous. With numerical methods nonlinear problems can also be solved. A 2-dimensional finite element computer program was developed from a transient heat transfer program for the solution of analogous problems in radon transfer by convection and diffusion. Various examples of radon entry into structures have been computed by both numerical and analytical methods.

Liinamaa, Paula, and Martti Viljanen, 1984

Radonin merkitys talonrakennustekniikassa. Kirjallisuusselvitys [Radon in building technology. Literature survey]:

Espoo, Finland, Helsinki Univ. Technology, Dept. Civil Engineering, Div. Structural Engineering Rept. 66, 65 p. This is a review of factors that cause high indoor radon concentrations. The major source of radon is the soil under buildings. Finnish building materials do not contain high radioactive concentrations. The use of radonrich water may in some individual cases be the major source of indoor radon. Alpha-film measurements of Finnish indoor air have shown that there are great regional and seasonal variations of radon content. The highest concentrations have been measured in houses built on ridges and rough bedrock. The radon problem can be solved by construction and ventilation techniques developed in the U.S.A., Canada, and Sweden, where air-tightening the floor and ventilation of the foundation are thought to be the most efficient solution to the problem. In Finland this type of remedial action is done in only very few cases.

Lilley, William D., Charles Kunz, and B. Kothari, 1988

Geologic factors in predicting indoor radon in New York [abs.], in Radon in the Northeast: Perspectives and Geologic Research (conference), Troy and Albany, New York, May 31-June 2, 1988:

Northeastern Environmental Science, 7(1): 7

Lindmark, Alf, and Bengt Rosén, 1984

Radon i jord. Exhalation-vattenkvot, årstidsvariationer, permeabilitet. [Radon in the ground. Exhalation water ratio, seasonal variations, permeability.]:

Lonköping, Sweden, Statens geotekniska institut [Swedish Geotechnical Institute] Rept. No. 24, 85 p.

[English summary] Radon in soil gas beneath buildings can enter houses through cracks or holes in the foundations. Alpha radiation given off during the formation and decomposition of radon implies a risk of lung cancer. The main purpose of this project has been to gain greater knowledge of the behavior of radon in natural ground. Three different aspects have been studied: radon exhalation, soil permeability with respect to gas flow, and seasonal variations in radon-222 concentrations. Experience gained from the project has also 
given us better insight into the advantages and disadvantages of the methods of measurement used today. Exhalation [The preferred term, because no advective flow is implied, would be "emanation".] Exhalation can, in a simplified way, be explained as the soil's own radon production capacity. Exhalation tests have been carried out using soil samples enclosed in glass jars for about 100 hours. The exhalation (E) has been calculated using the measured concentrations of radon $R n(t)$ in the glass jars as a function of time. Each soil sample was investigated at a number of different water contents. The temperature was kept constant during the tests. Radon dissolved in the water and variations in the volume of air in the glass jar due to variations in water content were taken into consideration in the calculations. The radon exhalation is dependent on the water ratio of the soil samples, as shown in Figure 1. [Figure 1 is a plot of exhalation $\left(\mathrm{Bq} \mathrm{kg}^{-1} \mathrm{~h}^{-1}\right)$ vs. "water ratio" (ratio of water to dry mass, \%). The radon concentration was measured by drawing air from the glass jar into the measuring instrument. From a minimum exhalation at dryness, maximum exhalation was reached at some water ratio between $\approx 5 \%$ and $\approx 13 \%$; at greater water ratios the exhalation decreased. From figures 3 \& 4 and table 3, for various soils the ratios of maximum/dry and maximum/wet, respectively, were: clay \#1, 3.7, 8.6; clay \#3, 10.8, 3.4; sand \#2, 2.6, 2.3; sand \#4, 3.9, 3.1; gravel \#5, 3.8, 3.3; gravel \#6, 4.1, 3.4; and gravelly moraine (till), 31.2, 1.7.] The exhalation was calculated by means of the formula, $E=R n(t) \cdot\left(\lambda_{\text {eff }} / M\right)\left[1-\exp \left(\lambda_{\text {eff }} \cdot t\right)\right]^{-1}\left[V_{L}+\left(V_{V} / 3\right)\right]$, where $E$ is exhalation $\left(\mathrm{Bq} \mathrm{kg}{ }^{-1} \mathrm{~h}^{-1}\right), \lambda_{\text {eff }}$ is the "effective decay" (constant $=0.0392 \mathrm{~h}^{-1}$ )[includes loss by air exchange], $\mathrm{M}$ is the mass of the soil sample, and $V_{L}$ and $V_{V}$ are the volumes of water and air in the glass jars $\left(\mathrm{m}^{3}\right)$. The largest change in exhalation was obtained for a highly radioactive soil. The exhalation of the soil with a water ratio of $10 \%$ was 30 times that of the soil with a water ratio of $0 \%$. At water ratios above approximately $10 \%$, the exhalation decreased by one-third of the maximum value. The effects of meteorological events are dependent on the current water content of the soil because of the dependence of the exhalation on the water ratio. Rain, for example, which will raise the water ratio, may increase or reduce the exhalation. The result will depend on the water ratio of the ground before the rain. Meteorological events not only have an impact on the exhalation of radon, but also influence the rate of its removal. Seasonal variations To study the influence of meteorological events, the time dependency of radon concentrations was measured at six test sites during a period of 19 months. The radon content of the soil was measured [by passive detectors; note that measurement errors can result (Tanner, 1991, "Errors...")] at depths of $0.3,0.5$, and $0.9 \mathrm{~m}$ below the surface at 14 day intervals. The [apparent] concentrations $\left(\mathrm{Bq} / \mathrm{m}^{3}\right)$ measured at a depth of $0.5 \mathrm{~m}$ [for a period of 19 months] are shown in Figure 2 . [Figure 2 is a bar graph showing the ranges and median values for soils on granitic bedrock and on radioactive alum shale bedrock. On granitic bedrock, they were: clays, 0 to $\approx 62$, two medians, at $\approx 5$ and $\approx 45 ;$ sands, $\approx 3$ to $\approx 16$, median at $\approx 6 ;$ gravels, $\approx 5$ to 30 , median at $\approx 10$. On the radioactive alum shale, they were: clays, $\approx 4$ to $\approx 165$, median at $\approx 35$; sands, $\approx 4$ to 30 , median at $\approx 11$; gravels, $\approx 16$ to $\approx 100$, median at $\approx 25$. In situ, the clays ranged from 19 to $31 \%$ water ratio and from 44 to $47 \%$ porosity; the sands from 7 to $14 \%$ water ratio and 40 to $41 \%$ porosity, and the gravels from 12 to $15 \%$ water ratio and 37 to $59 \%$ porosity.] Pronounced changes in radon concentration can be linked to meteorological events. Snow and frozen ground effectively prevent radon flow by a "capping effect," which results in increased radon concentrations. Changes in water content have an impact on the radon concentration of both impermeable and permeable soils. When permeable soils, such as sand, dry up, exhalation decreases while the ventilation increases. The combined effect of these changes reduces radon concentrations noticeably during the summer. But the clays investigated exhibited very large increases in radon concentration when the water ratio decreased by only a few percent. Radon measurements in very dry or very wet soils give a misleading picture of the radon risks. We propose that radon measurements be discontinued when the soil is extremely wet or dry. Permeability The investigation of radon permeability of soils comprised analysis of different types of soil using special equipment. The measurements were carried out by the principle of drawing air from the soil, through an inverted box pressed [into an excavation] $0.3 \mathrm{~m}$ into the soil. Flow, pressure, and radon concentrations were measured while air was being drawn from the soil. The radon concentrations were also measured using conventional long-term and direct methods. The results of the permeability tests showed that: (1) Many types of soil liberate large amounts of soil gas even at low pressures; 2-5 Pa below atmospheric pressure. (2) If impermeable types of soil with a high radium content dry up and crack, they can assume the "nature of a gravel" in both radon content and permeability. (3) Two types of soil with a radon content of the same magnitude can give a 
difference in radon-daughter content indoors of more than $600 \%$, because of differences in permeability. (4) The exhalation of radon in the cases analyzed has been large, so that the volume of the soil producing radon does not have to be large. (5) Radon concentrations and permeability give an idea of the radon risk of a soil. Assessments based on the radon content alone can be completely misleading. The permeability can be estimated with reasonable accuracy on the basis of the soil type only. IA considerably better method of exhalation measurement probably can be developed. The advantages of working with the radon exhalation [radon availability] of the soil instead of radon concentrations are that: (1) The influence of many meteorological factors that are difficult to assess is eliminated. (2) The exhalation values permit calculation of radon contents in the soil, under buildings, and indoors. [A sample calculation assumes radon production from a soil layer $1.5-\mathrm{m}$ thick under a $100-\mathrm{m}^{2}$ house foundation, the soil having a dry density of $1800 \mathrm{~kg} / \mathrm{m}^{3}$, totaling $270,000 \mathrm{~kg}$. Four soil types were considered, each at two water ratios (\%), with corresponding exhalation fluxes $\left(\mathrm{kBq} \mathrm{kg}^{-1} \mathrm{~h}^{-1}\right)$ : clay, $10 \%, 1.534,35 \%, 0.179$; sand, $10 \%, 0.153,20 \%, 0.068$; gravel, $10 \%$, $0.725,20 \%, 0.408$; gravelly till, $10 \%, 8.711,20 \%, 7.226$. The radon concentration in the subslab region was then calculated for each of these exhalation fluxes as a function of the percentage of the ventilation air drawn from the soil. For $10 \%$ soil-gas intake, the respective concentrations $\left(\mathrm{kBq} / \mathrm{m}^{3}\right)$ were: $35,1,3,1,15,2,187$, and 83 ; for $1 \%, 238,9,26,16,120,21,1474$, and 755 ; for $0.1 \%, 539,57,83,88,439,163,4740$, and 4157 . The corresponding indoor radon progeny concentrations also were calculated.]

Lindmark, A[lf], and B[engt] Rosén, 1985

Radon in soil gas--exhalation tests and in situ measurements:

The Science of the Total Environment, 45: 397-404

[Radon entry into dwellings is principally influenced by the concentration of radon in the pore gas in the soil, the air permeability of the soil, leakage points in the foundation, and indoor ventilation. The foundations of new dwellings should provide radon resistance in proportion to the risk associated with the soil at the site, which can be estimated by measurements of the radon concentration and air permeability of the soil. On the basis of the radon concentration (in $\mathrm{kBq} / \mathrm{m}^{3}$ ) at $0.5-\mathrm{m}$ depth, high-risk areas are those $>25$ in gravel or sand, $>35$ in silt, or $>50$ in clay; low-risk areas are those $<6$ in gravel or sand, $<10$ in silt, or $<15$ in clay. Radon concentrations in soil gas were measured during a 19-month period in soils overlying granite bedrock (2-10 $\mathrm{ppm} \mathrm{U)} \mathrm{and} \mathrm{overlying} \mathrm{alum} \mathrm{shale} \mathrm{bedrock} \mathrm{(20-265} \mathrm{ppm} \mathrm{U).} \mathrm{Radon} \mathrm{concentrations} \mathrm{(in} \mathrm{kBq} / \mathrm{m}^{3}$ ) at $0.5-\mathrm{m}$ depth in soils over the granite ranged up to about 60 for clay, about 3 to 17 for sand, and about 5 to 32 for gravel. Soils over the alum shale ranged from about 4 to 166 for clay, about 5 to 31 for sand, and about 16 to 100 for gravel. Because the water content of the soil strongly influences the permeability and the radon exhalation of the soil, it is important to make measurements when the water content is typical.]

Lively, Richard, and Daniel Steck, 1991

A site study of soil characteristics and soil gas radon, in The 1991 International Symposium on Radon and Radon Reduction Technology, Philadelphia, Pa., April 2-5, 1991, Proc., Volume 2, Symposium Oral Papers, Technical Sessions 6 through 10:

U.S. Environmental Protection Agency Rept. EPA/600/9-91/037B, p. 9-43-9-57

McLean, Va., Cohen (S.) and Associates, Inc. [Springfield, Va., NTIS Order No. PB92-115369]

[Preprints, v. 5, no. IX-5]

In regional surveys, indoor radon is usually the parameter of interest, but occasionally soil gas radon at depths of $1 \mathrm{~m}$ or less is also measured. At statewide scales, even limited data sets can be used to infer relationships between geology and soil gas or indoor radon. However, predicting the radon potential of a single house or even an area the size of a neighborhood is more difficult. As the size of a surveyed area decreases, site-specific variables become more significant. TWe recently completed a study of two residential neighborhoods within $7 \mathrm{~km}$ of each other near Rochester, Minnesota. Eight holes were augured into glacial sediments to maximum depths of $4.5 \mathrm{~m}$ and the samples collected for grain-size analysis, measurement of radon parent/daughter nuclides and radon emanation. A total of 65 homes in the areas were provided with two alpha-track registration detectors for 1 year of indoor monitoring. Positive correlations were observed between the average soil radon, the average indoor radon, and the precursor/daughter radionuclides. The study area with the most 
topographic relief also had the highest radionuclide contents, the most variability with depth, and some variation with time and soil moisture; these results were not observed at the low-relief site. The type of study described would best be applied to site-specific pre-construction screening, rather than to predicting radon in existing structures.

LKB Resources, Inc., 1977

NURE Aerial Gamma Ray and Magnetic Reconnaissance Survey, Thorpe Area, Newark NK 18-11 Quadrangle: Huntingdon Valley, PA 19006, LKB Resources, Inc., 55 Buck Road, U.S. Dept. Energy Rept. GJBX-16(78) [This survey includes an area having the largest density of houses exceeding $7.4 \mathrm{kBq} / \mathrm{m}^{3}(200 \mathrm{pCi} / \mathrm{L})$ of indoor radon known as of 1988.]

LKB Resources, Inc., 1980

Aerial Gamma and Magnetic Detail Survey of the Reading Prong Area:

Huntingdon Valley, PA 19006, LKB Resources, Inc., U.S. Dept. Energy Rept. GJBX-90(80), 6 vols.

[This survey includes a substantial area containing houses found to have indoor radon exceeding $7.4 \mathrm{kBq} / \mathrm{m}^{3}$ $(200 \mathrm{pCi} / \mathrm{L})$.

Llewellyn, Ralph A., 1991

Radon in large buildings: Pre-construction soil radon surveys, in The 1991 International Symposium on Radon and Radon Reduction Technology, Philadelphia, Pa., April 2-5, 1991, Proc., Volume 4, Symposium Poster Papers, Technical Sessions 6 through 10:

U.S. Environmental Protection Agency Rept. EPA/600/9-91/037D, p. P10-15-P10-25

McLean, Va., Cohen (S.) and Associates, Inc. [Springfield, Va., NTIS Order No. PB92-115385]

[Preprints, v. 5, no. XP-2]

Attempts to correlate individual soil radon and/or radium concentrations with the subsequent concentrations of radon measured in structures constructed on the sites of the tests have had only occasional, or perhaps only coincidental success. High concentrations in the soil may or may not result in elevated levels in buildings, and vice versa. Over the past two years the University of Central Florida Radon Project has been conducting an intensive radon screening of all buildings $(>40)$ on the campus, a relatively compact concentration occupying about 300 acres [ $1.2 \mathrm{~km}^{2}$ ] of a 1200 -acre site. Analysis of these data suggest that perhaps the earlier difficulties in obtaining correlations between soil radon/radium measurements and radon concentrations in structures has been simply a failure to measure at a sufficient number of locations for a long enough duration. A contour "map" of average radon concentrations in the campus buildings was used as a guide for measuring soil radon for periods of several months in the areas where the construction of three large new buildings was planned. The results were used to predict the levels that were to be expected on completion and to suggest appropriate radon-resistant construction measures. Two of the structures incorporating such suggestions are now under construction.

Lloyd, Larry L., 1983

Evaluation of Radon Sources and Phosphate Slag in Butte, Montana:

U.S. Environmental Protection Agency Rept. EPA 520/6-83-026, 75 p.

In 1978 the Montana Department of Health and Environmental Services (DHES) began investigating the potential sources of radon which contribute to elevated ambient and indoor concentrations of radon and its decay products in Butte, Montana. During the early stages of the investigation, effort were directed toward the evaluation of phosphate slag that has been used extensively for paving and graveling and building materials in the Butte area. The phosphate slag proved not to be a significant source of radon.... TThe northern part of Butte is located on a hill interlaced with geological fractures and richly mineralized veins.... The most prevalent rock type in the area, commonly known as "Butte granite," is quatrz monzonite. Aplite and alaskite [very light colored igneous rock composed mainly of potassium feldspar and silica] dikes are prevalent in the quartz monzonite. Rhyolite, which is of volcanic origin [and chemically similar to granite] is found in the most northwestern part of the city. Alluvium is the prevalent geology in the southern parts of the city. The alluvium 
is predominantly sand and gravel that resulted from erosion of the surrounding hills, so that in gross composition it is nearly the same as the quartz monzonite, rhyolite, and aplite.... TRadon exhalation [emanation] tests were performed on samples of quartz monzonite, aplite, alluvium, and mineralized vein samples from 25$\mathrm{cm}$ depths. The highest radon exhalation rates were from mineralized vein material, which averaged $1.32 \mathrm{~Bq} / \mathrm{m}^{2}-\mathrm{s}\left(2139 \mathrm{pCi} / \mathrm{m}^{2}-\mathrm{min}\right)$. Aplite samples showed exhalation rates $\left(0.44 \mathrm{~Bq} / \mathrm{m}^{2}-\mathrm{s}\right)$ that were about three times the exhalation rates from quartz monzonite $\left(0.15 \mathrm{~Bq} / \mathrm{m}^{2}-\mathrm{s}\right.$ average), and alluvium $\left(0.14 \mathrm{~Bq} / \mathrm{m}^{2}-\mathrm{s}\right.$ average).... TThe Butte areaa is subject to severe atmospheric thermal inversions that often trap...radon in the Butte Basin during certain periods of the day in a diurnal pattern ...with the highest concentrations occurring at approximately $6 \mathrm{a} . \mathrm{m}$. and the lowest at 6 p.m. [Continuous radon monitoring at $1.8 \mathrm{~m}$ at one location showed about 3-fold increases from a baseline of $\approx 56 \mathrm{bq} / \mathrm{m}^{3}$ in the maximum month of September 1980. Baselines were more erratic and as low as $\approx 9 \mathrm{~Bq} / \mathrm{m}^{3}$ during months when the ground had high soil moisture or was frozen.] The pattern...occurs throughout the year, but is frequently interrupted by winds and storms... [About 400 measurements of radon in soil gas were made by emplacing a $10-\mathrm{cm}$ diameter by $66-\mathrm{cm}$ long PVC open tube with the bottom at 76- $\mathrm{cm}$ depth, lowering an inverted $\alpha$-track cup with thoron filter to the bottom of the tube, covering the tube, and filling the remaining $10-\mathrm{cm}$ deep hole with soil. The apparent radon concentrations in the alluvium were $69 \%$ higher in the winter months than in the summer months. Some of the highest soil-gas radon results were near mineralized veins, but the sparseness of sampling sites, the summer-winter contrasts in levels, and the site-to-site variations away from veins, particularly at the Yellow Jacket vein, detract from a robust correlation. The concentration of radon dissolved in four ground waters sampled ranged from 18 to $151 \mathrm{kBq} / \mathrm{m}^{3}$; in underground sewers it ranged from $\approx 0$ to $\approx 15 \mathrm{kBq} / \mathrm{m}^{3}$.]

Lombardi, S., and G. Etiope, 1993

222-Rn soil-gas in sedimentary basin in Central Italy: its implications in the radioprotection zoning [abs.], in First International Workshop on Indoor Radon Remedial Action, The Scientific Basis and Practical Applications, Rimini, Italy, 27 June-2 July 1993:

Commission of the European Communities et al., Book of Abstracts, p. 70

Many studies of radon in soil gas confirmed that the presence of endogenous fluid reservoirs, uranium deposits, and tectonic discontinuities are the primary parameters for determining the radon potential of the soil and that indoor radon strictly depends on soil-gas radon levels. Nevertheless most world radon data refer to geothermal-volcanic or uraniferous environments, where the high level of near-surface radon activity, due to the abundance of uranium minerals in the rocks, is well known. Both studies of radon in petroleum research and recent CEC work on radioactive waste disposal suggest that high radon emissions occur not only in "hot areas" but also in relatively cool and non-uraniferous sedimentary basins. High values of radon were found in central Italy, in two sedimentary basins, without (likely) hydrocarbon reservoirs or uranium deposits in the underground, i.e., in the Siena Basin, over very thick argillaceous [clayey] sediments (the mean $R n$ value is $14171 \mathrm{~Bq} / \mathrm{m}^{3}$ ) and in the San Vittorino Valley, with Apenninic limestones overlain by sandy-clayey deposits (the mean $\mathrm{Rn}$ value is $38147 \mathrm{~Bq} / \mathrm{m}^{3}$ ). Rn values in such areas have the same ranges as are found in the Phlegraean Fields and Western Volsini Volcanoes where Rn levels have mean values, respectively, of 8473 $\mathrm{Bq} / \mathrm{m}^{3}$ and $171283 \mathrm{~Bq} / \mathrm{m}^{3}$. Both Siena Basin and San Vittorino radon anomalies are distributed along linear zones, according to local tectonic discontinuities (fault and fracture systems). A shallow-origin component for the near-surface $\mathrm{Rn}$, as uranium or radium concentration induced by groundwater flow, cannot be excluded. Nevertheless, the rectilinear geometry of anomalies and their coincidence with both deep-origin helium anomalies and the local fracture systems suggest that, in spite of the thickness and low permeability of the clayey rocks, gas rises toward the surface through fracture networks as preferential routes for a rapid and subvertical advective geogas migration. Briefly stated, the leading conclusion is that natural radioactivity at the earth surface is not exclusive to volcanic or geothermal areas, and this should give rise to new implications in environmental safety and radioprotection. All these results suggest the utilization of $\mathbf{R n}$ soil-gas prospecting as a tool for mapping radon potential in the ground, not only in volcanic areas but anywhere. Therefore a preliminary investigation of near-surface $\mathrm{Rn}$ content and distribution, based on soil-gas surveys, can greatly contribu: to radioprotection zoning. In this case, indoor $\mathrm{Rn}$ measurements can be performed only in the 
areas where high $\mathrm{Rn}$ levels in soil gas occur. Besides providing a rapid (and economic) Rn zoning; such an approach can also contribute to better knowledge of links between indoor and soil-gas radioactivity.

Lombardi, S., and G.M. Reimer, 1990

Radon and helium in soil gases in the Phlegraean Fields, central Italy:

Geophys. Research Letters, 17(6): 849-852

[Radon and helium in soil gases were measured in the volcanic Phlegarean Fields, which are seismically active and have fracture systems and other tectonic features. Although radon and helium concentrations in soil gas were not in proportion at each sampling point, they had similar areal distributions, suggesting that the distribution is controlled mainly by the fracture system and movement of geothermal fluids.]

Mäkeläinen, I., A. Voutilainen, and O. Castrén, 1992

Prediction of indoor radon concentration based on residence location and construction, in Cross, Fredrick $T$., ed., Indoor Radon and Lung Cancer: Reality or Myth? Twenty-ninth Hanford Symposium on Health and the Environment, Richland, Wash., October 15-19, 1990, Proceedings:

Columbus, Ohio, Battelle Press, Part 1, p. 55-63 [NTIS]

We have constructed a model for assessing indoor radon concentrations in houses where measurements cannot be performed. It has been used in an epidemiological study and to determine the radon potential of new building sites. The model is based on data from about 10,000 buildings. Integrated radon measurements were made during the cold season in all the houses; their geographic coordinates were also known. The 2-month measurement results were corrected to annual average concentrations. Construction data were collected from questionnaires completed by residents; geological data were determined from geological maps. Data were classified according to geographical, geological, and construction factors. In order to describe different radon production levels, the country was divided into four zones. We assumed that the factors were multiplicative, and a linear concentration prediction model was used. The most significant factor in determining radon concentration was the geographical region, followed by soil type, year of construction, and type of foundation. The predicted indoor radon concentrations given by the model varied from 50 to $440 \mathrm{~Bq} / \mathrm{m}^{3}$. The lower figure represents a house with a basement, built in the $1950 \mathrm{~s}$ on clay soil, in the region with the lowest radon concentration levels. The higher value represents a house with a concrete slab in contact with the ground, built in the 1980s, on gravel, in the region with the highest average radon concentration. [The desired factors were considered to be the concentration of ${ }^{222} \mathrm{Rn}$ in soil gas, a leakage function of resistance of the soil and a house to soil-gas flow, the inverse of house volume, the reciprocal of the air exchange rate, and unnamed others. For practicality, surrogate factors were used, based on data from 13,975 houses: three geographic zones classified by uranium concentration of till samples, and the special zone of Tampere, because of its eskers; soil type (sand and gravel in eskers, sand and gravel in other deposits, till, rock, and clay); and foundation factors (type, construction year, ventilation type, heating system, number of stories, house type, and, in houses with basements, type of staircase).]

Malizzi, L.D., and A.E. Gates, 1989

Soil gas radon distribution in glacial moraines: an example from the New Jersey Highlands [abs.]:

Geol. Soc. America, Northeastern Section, Abstracts with Programs, 21(2): 30

Unlike regional radon studies from other areas, bedrock geology and gamma radiation show no correlation with radon from soils overlying the Green Pond outlier and the Reservoir fault zone of the N.J. Highlands. Gamma radiation in the Paleozoic sedimentary rocks of the outlier is lower than in the Precambrian gneisses. Sedimentary bedrock shows average gamma radiation of 220.4 counts/s (cps) with a range of 136.0 to 322.8 cps. Gamma radiation from the Precambrian gneisses averages $284.2 \mathrm{cps}$ and range from 240.4 to $575.8 \mathrm{cps}$. Rare pegmatites from within the Reservoir fault zone yield anomalously high average gamma radiation of 2017.5 cps with a range of 1948.6 to $3493.6 \mathrm{cps}$. Radon concentrations in soil cover yielded similar averages with wide ranges regardless of bedrock geology. Radon from soil over the sedimentary bedrock of the outlier averaged $19.2 \mathrm{kBq} / \mathrm{m}^{3}(517.9 \mathrm{pCi} / \mathrm{L})$ with a range of 8.77 to $99.7 \mathrm{kBq} / \mathrm{m}^{3}$ (236.9 to $\left.2695.3 \mathrm{pCi} / \mathrm{L}\right)$. Radon from soil over the gneisses averaged $19.5 \mathrm{kBq} / \mathrm{m}^{3}(527.0 \mathrm{pCi} / \mathrm{L})$ with a range of 8.89 to $69.3 \mathrm{kBq} / \mathrm{m}^{3}(240.4$ 
to $1872.3 \mathrm{pCi} / \mathrm{L})$. The Green Pond outlier and the Reservoir fault zone are covered by the terminal moraine deposits of northwestern N.J. All soil-gas radon samples were taken in glacial till which is poorly sorted, very porous, and in a sandy matrix. The moraine sediments contain erratics composed of all lithologies in the area as well as exotic rock types. Uranium concentrations in the erratics and matrix is highly variable. Radon is a daughter product of uranium and levels in soils are locally governed by the uranium concentrations of each erratic and the matrix. Because glacial till covers the area and is relatively homogeneous, average radon values are similar over all lithologies. Another reason for a lack of a correlation is that the soil is porous, causing radon diffusion and atmospheric dilution. This study shows that regional radiation surveys, such as NURE may not be useful in locating potentially high radon areas in moraine-covered terrains.

Markkanen, M., and H. Arvela, 1991

Radon emanation from Finnish soils [abs.], in International Symposium on the Natural Radiation Environment, 5th, Salzburg, Austria, 22-28 September 1991, Abstracts:

Salzburg, Univ. Salzburg, Inst. for General Biology, Biochemistry and Biophysics, abs. no. 77

The results of gamma-spectrometric sample measurement of ${ }^{222} \mathrm{Rn}$ emanation coefficient and radium concentration $\left({ }^{226} \mathrm{Ra}\right)$ from over 700 Finnish soil samples are presented. Also radon emanation rate was measured from over 200 soil samples by using radon-tight cans and Lucas cells. The effect of water content and temperature on radon emanation were investigated with various samples of different soil types. Radon emanation and the effect of water content on radon emanation were investigated with different grain sizes separately (samples of till). The results give information on radon emanation in different soil types and they relate emanation under laboratory conditions to conditions in nature. In routine measurements of radon emanation from soil samples the use of $5 \%$ water content [dry weight basis] was regarded advisable. The correction coefficients of radon emanation varied between 0.3 and 1.5 , depending on water content and soil type. With $5 \%$ water content there was hardly any difference between radon emanation at $20^{\circ} \mathrm{C}$ and at $1^{\circ} \mathrm{C}$ temperatures. Radon emanation was found to be a decreasing function of grain size for grain sizes greater than $0.5 \mathrm{~mm}$ diameter. A simple mathematical model for radon emanation from soil grains was developed, the results being consistent with the measurements.

Marvin, Richard K., 1989

Effects of water table fluctuation and meteorological parameters on radon-222 concentration and mobility in soil [M.S. thesis]:

University Park, Pa., Pennsylvania State Univ., Dept. Geosciences, 252 p.

This study was initiated to determine the influence of water level changes on radon in soil gas during and following the pumping of an unconfined aquifer. In addition, the effects of wind, barometric pressure change, precipitation, temperature, and seasonal water level change on radon concentration were investigated. From August 1987 to May 1988, soil gas radon concentrations were monitored in 4 gas sampling holes constructed in alluvia1 and terrace soils along Spring Creek near Houserville, Pennsylvania. Radon concentrations in the soil gas, which was extracted from depths of 0.55 to $5.97 \mathrm{~m}$, were measured using an EDA Instruments RD-200 portable radon meter. The maximum average radon concentrations of the soil gas within the holes ranged from 32.3 to $68.4 \mathrm{kBq} / \mathrm{m}^{3}$ (872 to $\left.1,848 \mathrm{pCi} / \mathrm{L}\right)$. Soil gas radon concentrations calculated from radium contents (range, $14-159 \mathrm{~Bq} / \mathrm{kg}(0.39-4.29 \mathrm{pCi} / \mathrm{g}$ ) and emanation coefficients (range, 0.01-0.68) of the soils collected fram the holes averaged $84.5 \mathrm{kBq} / \mathrm{m}^{3}(2,284 \mathrm{pCi} / \mathrm{L})$. The calculated radon concentrations correlate positively with the percentage of clay in the soils $(r=0.79)$ and negatively with the percentage of sand in the soils $(r=-0.68)$. These correlations are explainable by the much higher emanation coefficient of the clay-sized particles than the sand-sized particles due to their difference in diameter. The calculated radon concentrations of the soils tend to be greater than the radon values measured for the gas in the holes. The low measured values are concluded to result from 1) loss of radon by diffusion and 2) dilution of radon caused by leakage of less concentrated gas from shallower depths into deeper soil horizons during gas sampling. Radon concentrations in the holes were also found to be influenced by meteorological conditions. The radon values have a weak to moderate negative correlation with barometric pressure changes (average $r=-0.337$ ) and 24-hour wind movement (average $r=-0.447$ ). These meteorological factors probably produced pressure gradients between 
the atmosphere and the soil gas in the sampling holes, causing flow of radon-laden soil gas out of the holes and the flow of atmospheric air into them. Soil-gas radon concentration and daily liquid precipitation amount were found to have no significant correlation. Radon concentration has a moderate positive correlation with mean daily temperature (average $r=0.418$ ), but the reason for the relationship is not evident. The soil gas radon concentrations in three of the sampling holes were unaffected by small water table fluctuations $(<1 \mathrm{~m})$ caused by the pumping of two nearby wells. At the fourth sampling hole, radon concentrations increased from approximately 7.4 to $50 \mathrm{kBq} / \mathrm{m}^{3}$ (200 to $\left.1,350 \mathrm{pCi} / \mathrm{L}\right)$ during one of the pumping tests as the water table beneath the hole rose $3 \mathrm{~m}$. The concentration increase is attributed to the lateral flow of radon-laden soil gas that became trapped between ponded discharge water at the soil surface and the rising water table. The soil gas radon concentration in the hole decreased from approximately 33 to $1.1 \mathrm{kBq} / \mathrm{m}^{3}$ (900 to $30 \mathrm{pCi} / \mathrm{L}$ ) at the conclusion of the pumping test due to air that flowed into the soil as water drained from the soil pores and fractures at depth. The rate of water table change at the site during spring, 1955 averaged less than $0.1 \mathrm{~m} /$ day. Based on calculations, this rate was too slow to significantly influence the radon concentration in the soil.

Marvin, Richard K., Richard R. Parizek, and Arthur W. Rose, 1988

Effects of water table fluctuations on radon-222 concentration and mobility in overlying soil [abs.]:

Geol. Soc. America, Abstracts with Programs, 20(7): A354

In order to determine the effect of water table fluctuations on the concentration and potential transport of radon in overlying soil, four soil-gas monitoring stations were installed along a floodplain near State College, Pennsylvania. Each station consists of a nest of sampling tubes arranged in a backfilled borehole. Gas samples can be extracted at $1-\mathrm{m}$ intervals at depths $\leq 7 \mathrm{~m}$. During October 1987, an 11,000- $\mathrm{m}^{2}$ area near one of the gas sampling stations was flooded by water during a 72-hour pumping test. The well was tested at a rate of $4,000 \mathrm{~L} / \mathrm{min}$ and all the water was recycled to the water table during the test. This resulted in a 3-m watertable rise over 3 days. The rapid rise in the water table elevation produced an increase in radon concentration from 17 to $56 \mathrm{kBq} / \mathrm{m}^{3}$ (450 to $1500 \mathrm{pCi} / \mathrm{L}$ ) at depths from 1 to $4 \mathrm{~m}$. The subsequent decline of the water table resulted in a decrease in radon concentrations from 56 to $1.9 \mathrm{kBq} / \mathrm{m}^{3}$ (1500 to $\left.50 \mathrm{pCi} / \mathrm{L}\right)$. The concentration increase is due to radon-enriched soil gas from micro and macro pores migrating away [upwards] from the advancing wetting front. The corresponding [subsequent] decrease is produced by the flux of fresh air into the soil as the pores dewater. Both the increase and decrease in radon concentrations are significant at the $99 \%$ confidence level when compared with concentration changes over the data collection period from September 1987 to May 1988. Gradual seasonal water-table fluctuations ( $<0.1 \mathrm{~m} /$ day) do not appear to affect the radon soil-gas concentration profiles.

Matz, Barbara, 1993

Compilation of radon levels found in Albuquerque, New Mexico, in 1992 and 1993 [abs.], in The 1993 International Radon Conference, Denver, Colo., Sept. 20-22, 1993:

Denver, Colo., Am. Assoc. Radon Scientists and Technologists, Rocky Mountain Chapter, Preprints, p. IVP 1

Results are compiled from more than 100 short-term residential radon tests conducted in Albuquerque, New Mexico, and the surrounding area in 1992 and 1993. Contouring of mapped data points indicates a correlation of radon levels with lithology and geologic structures. The highest radon levels, 241 and $263 \mathrm{~Bq} / \mathrm{m}^{3}(6.5$ and $7.1 \mathrm{pCi} / \mathrm{L}$ ), were found in the extreme northeastern area of the city, which borders the highest point of the Sandia Mountains. The steep mountain slopes in this area provide a continuous supply of fresh granite and gneiss boulders and alluvium. A second zone of relatively high radon levels, 96 to $163 \mathrm{~Bq} / \mathrm{m}^{3}$ (2.6 to 4.4 $\mathrm{pCi} / \mathrm{L}$ ), located several miles west of the mountain front, may be related to an underlying basin-bounding fault. Results of tests west of the Rio Grande [River], where thick sand deposits overlie young volcanic rocks, had an average value of $33 \mathrm{~Bq} / \mathrm{m}^{3}(0.9 \mathrm{pCi} / \mathrm{L})$, and only one result over $74 \mathrm{~Bq} / \mathrm{m}^{3}(2 \mathrm{pCi} / \mathrm{L})$.

McFarland, David, 1991

A comparison of radon results to geologic formations for the State of Kentucky [abs.], in The 1991 International Symposium on Radon and Radon Reduction Technology, Philadelphia, Pa., 2-5 April 1991:

Preprints, v. 5, no. IX-2 
A large bank of radon results for the State of Kentucky are compared to the local geologic formation. These results are discussed in detail. Elevated radon levels from native building materials are also discussed.

McLaughlin, J[ames] P., 1987

An assessment of indoor radon exposure in Ireland, in Indoor Radon II, Proceedings of the Second APCA International Specialty Conference, Cherry Hill, New Jersey, April 6-10, 1987:

Pittsburgh, Pa., Air Pollution Control Association Pub. SP-60, p. 68-77

[A survey of 700 dwellings in the Republic of Ireland yielded a median value of $37 \mathrm{~Bq} / \mathrm{m}^{3}$ in an approximately log-normal distribution. Significantly higher mean and maximum concentrations were found in western Ireland (the Counties of Cork and Clare were noted), and were attributed to radon in soil gas primarily. In contrast with results in many other countries, no houses with indoor radon $>400 \mathrm{~Bq} / \mathrm{m}^{3}$ were found in granitic areas. (A later discussion with the author indicated some association of high indoor radon with karst terrain.)]

McLaughlin, J.P., 1987

Population doses in Ireland, Chap. 10, in Hopke, Philip K., ed., Radon and Its Decay Products; Occurrence, Properties, and Health Effects:

Washington, Am. Chem. Soc. Symposium Ser. 331, p. 113-123

[From early results of the indoor radon survey of Ireland, the radon exhalation characteristics of the soil or geological structure subjacent to houses were found to be more significant than house construction characteristics.]

McLemore, Virginia T., and John W. Hawley, 1988

Preliminary geologic evaluation of radon availability in New Mexico:

Socorro, New Mexico Bureau of Mines and Mineral Resources Open-file Rept. 345, 31 p.

The primary objective of this preliminary report is to identify and characterize areas in New Mexico where geologic factors may significantly influence indoor radon values. Areas which may have potential for generating elevated levels of indoor radon need to be identified so that a larger percentage of radon detectors can be allocated to these localities during a statewide survey conducted by the New Mexico Environmental Improvement Division in cooperation with the U.S. Environmental Protection Agency. The first step in this evaluation is to identify large areas where previous geologic studies indicate a probability of having elevated levels of indoor radon. Assessment of any health risks due to exposure of radon are beyond the scope of this study. Also, any potential exposure hazard may vary significantly from house to house. The only way to find out the extent of exposure due to indoor radon in a specific house is to test that house for radon. In this study rocks and soils in New Mexico were initially grouped into three radon-availability categories, which are relative to each other and specific to New Mexico based on geologic interpretations. Subsequently, each county and the major cities in the state were given a radon-availability rating based on the predominant availability category established for geologic units in that area. The health risks, if any, associated with these geologically ranked areas are not known until the survey of indoor radon levels is completed. Ten counties are assigned a high availability rating for radon based on interpretation of available geologic and soil data; they are Doña Ana, Hidalgo, Los Alamos, Luna, McKinley, Rio Arriba, Sandoval, Socorro, Santa Fe, and Taos. Seven of the most populated cities (1984 estimates) are rated high: Santa Fe, Las Cruces, Roswell, Carlsbad, Gallup, Deming, and Los Alamos-White Rock. Thirteen counties: Bernalillo, Catron, Cibola, Chavez, Colfax, Eddy, Grant, Lea, Lincoln, Quay, San Juan, Sierra, and Union; are assigned a moderate availability rating. Six of the most populated cities are rated moderate: Albuquerque, Rio Rancho, Clovis, Hobbs, Grants-Milan, and Lovington. The remaining ten counties in New Mexico: Curry, De Baca, Guadalupe, Harding, Mora, Otero, Roosevelt, San Miguel, Torrance, and Valencia, are assigned a low availability; although some homes in these areas may still have elevated levels of indoor radon. Six of the most populated cities are rated low: Farmington, Alamagordo, Las Vegas, Silver City, Portales, and Artesia. In addition it should be emphasized that even in counties with moderate and high availability many houses may have low levels of indoor radon. ["Radon availability," as used in this report, includes radon generation, emanation, and mobility in the ground, as introduced by Tanner (1986).] 
McLemore, Virginia T., John W. Hawley, and Ralph A. Manchego, 1991

Geologic evaluation of radon availability in New Mexico: A progress report, in The 1991 International Symposium on Radon and Radon Reduction Technology, Philadelphia, Pa., April 2-5, 1991, Proc., Volume 4, Symposium Poster Papers, Technical Sessions 6 through 10:

U.S. Environmental Protection Agency Rept. EPA/600/9-91/037D, p. P9-3—P9-22

McLean, Va., Cohen (S.) and Associates, Inc. [Springfield, Va., NTIS Order No. PB92-115385]

[Preprints, v. 5, no. IXP-1]

The New Mexico Bureau of Mines and Mineral Resources and the Radiation Licensing and Registration Section of the New Mexico Environmental Improvement Division in cooperation with the U.S. Environmental Protection Agency have been evaluating geologic and soil conditions that may contribute to elevated levels of indoor radon throughout New Mexico. During the first phase of this evaluation, New Mexico lands have been subdivided into three provisional radon-availability categories (high, moderate, and low). data sources include 1) aerial radiometric surveys; 2) uranium-resource evaluations; 3 ) reports on lithologic character and structure of major geologic units; 4) hydrologic and geochemical information; and 5) soil surveys (including data on particle size, clay minerals, moisture regimes, and permeability). This information was used in selection of private homes tested during an initial random survey of indoor radon in 1989. The New Mexico radon survey was unique in that it was the first in the nation to successfully use a decentralized strategy in the attempt to place charcoal canisters randomly across a State. Results of $\mathbf{1 7 7 5}$ homes tested throughout New Mexico during January to March 1989 indicated that $24 \%$ had indoor-radon screening results exceeding the recommended EPA guideline of $148 \mathrm{~Bq} / \mathrm{m}^{3}$ (4 pCi/L) of air. Visits were also made to about 50 home sites in north-central New Mexico where preliminary surveys (random and volunteer) indicated that geologic and soil conditions were the major factors contributing to elevated indoor-radon levels $\left(>370 \mathrm{~Bq} / \mathrm{m}^{3}\right.$ or $\left.>10 \mathrm{pCi} / \mathrm{L}\right)$. IStudies to date suggest that elevated radon levels are commonly associated with hillside building sites where floors and walls are contiguous to geologic units such as highly fractured bedrock of varying lithology, limestones with solution enlarged joints, or thick pumice deposits. Bedrock units, associated alluvial-colluvial deposits, and ground water that contain high concentrations of uranium and thorium locally make a significant contribution and need further study. Some homes built on clay-rich expansive soils also have elevated levels of radon. Areas that have been tested in the vicinity of uranium mines and mills have relatively low levels of indoor radon $\left(<370 \mathrm{~Bq} / \mathrm{m}^{3}\right.$ or $\left.<10 \mathrm{pCi} / \mathrm{L}\right)$. A better understanding of the natural factors that affect indoor radon concentrations in New Mexico will only be gained through integrated, site-specific investigations which combine more comprehensive indoor-radon measurements and home construction information with data on geology, hydrology, and soils.

Megumi, Kazuko, and Tetsuo Mamuro, 1972

A method for measuring radon and thoron exhalation from the ground:

Jour. Geophys. Research, 77(17): 3052-3056

[Radon and thoron exhalation from the ground were measured by adsorption on granular activated charcoal distributed on the ground surface and analysis of the ${ }^{214} \mathrm{Bi} 609-\mathrm{keV}$ and ${ }^{208} \mathrm{~T}$ e $2615-\mathrm{keV} \gamma$-ray photopeaks.]

Miles, J.C.H., 1993

Mapping the proportion of the housing stock exceeding a radon reference level [abs.], in First International Workshop on Indoor Radon Remedial Action, The Scientific Basis and Practical Applications, Rimini, Italy, 27 June-2 July 1993:

Commission of the European Communities et al., Book of Abstracts, p. 74

In order to identify homes with high radon levels as efficiently as possible, it is necessary to have accurate numerical information on radon-prone areas. Maps based on geological indicators are generally qualitative and sometimes contain misleading information. Maps based on radon measurements in homes are definitive if there are sufficient results in the area of interest, but if there are small numbers of measurements, none of which exceeds the reference level, it is difficult to estimate the fraction of the whole housing stock which exceeds it. Distributions of radon levels are usually log-normal, however, so mathematical modelling of the distribution allows the fraction of the housing stock exceeding any level to be calculated. A subset of the UK 
database of 120,000 radon results is used here to answer three questions: does the log-normal distribution fit the data well enough to allow reliable maps of radon-prone areas to be drawn? If so, how can the parameters of the log-normal distribution best be estimated for small areas with few results available? What is the minimum amount of data required for mapping radon-prone areas?

Milly, George H., and John T. MacWaters, 1981

Unique applications for environmental and area radon measurements, Chap. 87 in Gomez, Manuel, ed., Radiation Hazards in Mining: Control, Measurement, and Medical Aspects, International Conference, Golden, Colo., October 4-9, 1981:

New York, Am. Inst. Mining, Metallurgical, and Petroleum Engineers, Soc. Mining Engineers, p. 586-588

[This paper describes a two-step technique for locating radon sources, as in uranium exploration or in environmental monitoring. A reconnaissance is first made by means of measuring atmospheric concentrations of ${ }^{222} \mathrm{Rn}$ progeny under stable atmospheric conditions (temperature inversions) or neutral conditions, usually at night, by means of a membrane filter during a 5-min sampling period. The filter is immediately counted in two successive 5-min periods, from which the interval since the ${ }^{222} \mathrm{Rn}$ was exhaled from the ground may be determined. The equipment is mounted in a vehicle, and by mapping the intervals at different locations, the radon source may be located. The intervals ("ages of the radon clouds") are more important than the magnitudes of the radon-progeny concentrations. When the source area has been localized to $\approx 1 \mathrm{~km}^{2}$, the flux density of exhaled ${ }^{222} \mathrm{Rn}$ is measured at places within the area by collecting radon progeny on the surface of thin frosted adhesive plastic tape covering an electrode at $-3600 \mathrm{~V}$ for $15 \mathrm{~min}$ under a circular metal openbottom can $20 \mathrm{~cm}$ high and $30 \mathrm{~cm}$ in diameter, and counting the activity deposited on the tape in an $\alpha$-particle counter for $5 \mathrm{~min}$.]

Milly, George H., and Scott D. Thayer, 1981

Statistical evaluation and discussion of the significance of naturally-occurring radon exposures, Chap. 111 in Gomez, Manuel, ed., Radiation Hazards in Mining: Control, Measurement, and Medical Aspects, International Conference, Golden, Colo., October 4-9, 1981:

New York, Am. Inst. Mining, Metallurgical, and Petroleum Engineers, Soc. Mining Engineers, p. 746-750.

[Ambient atmospheric concentrations and flux densities of exhaled ${ }^{222} \mathrm{Rn}$ in the literature are cited and data obtained by the authors by means of their apparatus (preceding abstract) are reviewed. For the uranium areas of the western United States they summarized their data for generally mineralized areas, for which representative means were 22,28 , and $41 \mathrm{~Bq} / \mathrm{m}^{3}$; maxima were 104,110 , and $96 \mathrm{~Bq} / \mathrm{m}^{3}$; and minima were 1.9 , 4.1 , and $3.7 \mathrm{~Bq} / \mathrm{m}^{3}$. For areas with near-surface mineralization they obtained means ranging from 19 to $150 \mathrm{~Bq} / \mathrm{m}^{3}$. (The authors emphasize that the ambient atmospheric measurements underestimate those that would be made over the highest-flux areas because their practice is to discontinue the atmospheric measurements once the anomalous area has been confirmed.) Their flux-density measurements range from means of 20 to $40 \mathrm{mBq} \cdot \mathrm{m}^{-2} . \mathrm{s}^{-1}\left(0.5\right.$ to $\left.1.0 \mathrm{pCi} \cdot \mathrm{m}^{-2} . \mathrm{s}^{-1}\right)$, compared with the world-wide continental estimate of $\approx 16 \mathrm{mBq} \cdot \mathrm{m}^{-2} \cdot \mathrm{s}^{-1}$ by Wilkening, Clements, and Stanley, (1975), to means of 0.1 to $0.2 \mathrm{~Bq} \cdot \mathrm{m}^{-2} \cdot \mathrm{s}^{-1}$ ( 3 to 5 pCi. $\left.\mathrm{m}^{-2} . \mathrm{s}^{-1}\right)$ in areas with general uranium mineralization and greater over strong anomalies. The ambient outdoor atmospheric ${ }^{222} \mathbf{R n}$ levels in such areas likely exceed the U.S.E.P.A. action level for indoor radon. Their results are contrary to the generalizations made by several authors that radon exhalation is fairly uniform; they found significant temporal and spatial variation.]

Misquitta, Neale J., Richard W. Carlton, and Lindgren L. Chyi, 1989

Excessive radon level over abandoned underground coal mine [abs.]:

Geol. Soc. America, Abstracts with Programs, 21(6): A144

Anomalous high radon levels were found in areas with low surface uranium concentrations. Our previous study indicated that excessive radon levels occur over faults in the Serpent Mound area in southern Ohio [see Heirendt et al., 1988]. It is, therefore, suspected that the excessive radon levels in Summit County, Ohio, might be related to induced faults from abandoned underground coal mines. The induced fractures, which resulted from total withdrawal of the coal, might propagate to the surface and serve as conduits for the migration of 
underground radon to the surface. The hypothesis was tested with 133 passive alpha-track detector assemblies for soil-gas radon. They were buried for 21 days at a depth of 30 inches [1 m] in a series of five traverses over an abandoned coal mine in southern Summit County from directly over the mined-out area to areas adjacent to it. The results indicated that radon levels over the mined-out area are at least twice as high as those over adjacent undisturbed areas. The average radon level over mined-out areas was $4.14 \mathrm{kBq} / \mathrm{m}^{3}(112 \mathrm{pCi} / \mathrm{L})$, as compared with $1.9 \mathrm{kBq} / \mathrm{m}^{3}$ ( $\left.52 \mathrm{pCi} / \mathrm{L}\right)$ over the undisturbed areas. The latter is similar to the surface soil-gas radon level of the vicinity. Thus, the $2.2 \mathrm{kBq} / \mathrm{m}^{3}(60-\mathrm{pCi} / \mathrm{L})$ additional radon over the mined-out area must have come from underground sources, because radon is not expected to migrate a significant distance over its short half life. The phenomenon that excessive radon levels are found over abandoned coal mines is being explored for the mapping of undocumented abandoned coal mines. [Alternative or additional factors that may have affected the results could be the greater air reservoir volume's response to periodic barometric pressure changes, which have been shown to increase the effective exhalation of radon from greater depths, and a greater drying of the soils overlying the mine site as a result of movement of the mine and atmospheric air through the soil, leading to greater efficiency of the detectors; see Tanner, 1991 ("Error....")]

Moed, B.A., W.W. Nazaroff, A.V. Nero, M.B. Schwehr, and A. Van Heuvelen, 1984

Identifying Areas with Potential for High Indoor Radon Levels: Analysis of the National Airborne Radiometric Reconnaissance data for California and the Pacific Northwest:

Berkeley, CA, Univ. California Lawrence Berkeley Lab. Rept. LBL-16955, 70 p. [Also published with additional pages $i$ and ii by Bonneville Power Administration, 1985]

Radon-222 is an important indoor air pollutant which, through the inhalation of its radioactive decay products, accounts for nearly half of the effective dose equivalent to the public from natural ionizing radiation. Indoor radon concentrations vary widely, largely because of local and regional differences in the rate of entry from sources. The major sources of indoor radon are soil and rock near building foundations, earth-based building materials, and domestic water; of these, soil and rock are thought to be predominant in many buildings with higher-than-average concentrations. Thus, one key factor in determining radon source potential is the concentration of radium, the progenitor of radon, in surficial rocks and soils. We have analyzed aerial radiometric data, collected for the National Uranium Resource Evaluation Program, for seven Western states with a view towards 1) providing information on the spatial distribution of radium contents in surficial geologic materials for those states, and 2) investigating approaches for using the aerial data,which have been collected throughout the contiguous United States and Alaska, to identify areas where high indoor radon levels may be common. The results showed a range of mean radium concentrations averaged over geologic map units of 3.7$133 \mathrm{~Bq} / \mathrm{kg}(0.1-3.6 \mathrm{pCi} / \mathrm{g})$, with an overall mean for the study area of $26 \mathrm{~Bq} / \mathrm{kg}(0.7 \mathrm{pCi} / \mathrm{g})$. Radium concentrations were found to be relatively low in central and western portions of Washington, Oregon, and northern California; they were found to be relatively high in central and southern California. A field validation study, conducted along two flight-line segments near Spokane, Washington, showed close correspondence between the aerial data, in situ measurements of both radium content and radon flux from soil, and laboratory measurements of both radium content of and radon emanation rate from soil samples.

Monette, Frederick A[lcide], 1990

Variations of ${ }^{222} \mathrm{Rn}$ concentrations in soil gas at a site in the semiarid western U.S. [M.S. Thesis]:

Fort Collins, Colo., Colorado State Univ., Dept. Radiology and Radiation Biology, 63 p.

Soil-gas ${ }^{222} \mathrm{Rn}$ concentration [by soil-gas extraction and measurement in $\alpha$-scintillation cells], soil moisture content [by fiberglass blocks, time-domain reflectometry, and neutron-neutron moisture probe], and soil temperature [by resistance temperature detectors] were monitored at depths of 30,100 , and $180 \mathrm{~cm}$ for a period of 10 months at a radon research facility at Colorado State University, Fort Collins, Colorado. The greatest amount of variation in radon concentration was observed at $30 \mathrm{~cm}$ and the least at $180 \mathrm{~cm}$. Stepwise multiple regression suggests that soil moisture content accounted for $57 \%$ of the total radon variance at $30 \mathrm{~cm}$. $79 \%$ of the variance at $100 \mathrm{~cm}$, and $91 \%$ of the variance at $180 \mathrm{~cm}$. The influence of soil temperature on soilgas radon concentration is small compared with moisture effects. Increased soil moisture content affects radon concentration in two ways: First, increased moisture reduces the volume of the gas filled by pore space, 
effectively increasing the soil-gas radon concentration. Second, increased moisture changes the transport characteristics of the soil, reducing leakage from a given volume, a phenomenon referred to as "capping." Analysis suggests that capping may be more important near the soil surface than at greater depths [because the barometric pumping causes greater radon depletion in the shallow soil layers]. The radon concentration profile as a function of depth is shown to be consistent with a simple one-dimensional diffusion model under certain conditions. In one case [for the drier period, November-March], this model was used to estimate the interstitial diffusion coefficient of radon in the soil as $3 \times 10^{-6} \mathrm{~m}^{2} / \mathrm{s}$. Under different conditions [for the wetter period, May-August], the simple diffusion model yielded an estimate of $3 \times 10^{-5} \mathrm{~m}^{2} / \mathrm{s}$, a value greater than the radon diffusion coefficient in air. It is likely that violations of assumptions inherent in the simple diffusion model were responsible for the unreasonable second estimate. [The soil at the sites of investigation had been excavated, thoroughly mixed, characterized, and replaced in the excavations $>16$ months before the study.]

Morley, D.R., M.M. Ghomshei, C. Van Netten, and B.G. Phillips, 1991

Radon studies in British Columbia, Canada, in The 1991 International Symposium on Radon and Radon Reduction Technology, Philadelphia, Pa., April 2-5, 1991, Proc., Volume 2, Symposium Oral Papers, Technical Sessions 6 through 10:

U.S. Environmental Protection Agency Rept. EPA/600/9-91/037B, p. 6-61-6-70

McLean, Va., Cohen (S.) and Associates, Inc. [Springfield, Va., NTIS Order No. PB92-115369]

[Preprints, v. 3, no. VI-5]

Three radon studies, involving 150 background gamma measurements and long-term alpha-track tests in a total of $\mathbf{4 0 0}$ homes have been conducted in three geologically distinct areas of the province of British Columbia. A positive correlation between the background gamma radiation and the measured radon level can be depicted only at the regional scale. III the Coastal Area, where the terrestrial gamma radiation is low, no homes were found to exceed $148 \mathrm{~Bq} / \mathrm{m}^{3}(4 \mathrm{pCi} / \mathrm{L})$ on the main floor. In the Kootenays, where the background gamma is relatively high, considerably higher gamma and radon levels were encountered. The highest radon levels were found in the West Kootenay about $45 \%$ of the homes have radon levels $>148 \mathrm{~Bq} / \mathrm{m}^{3}(>4 \mathrm{pCi} / \mathrm{L})$ and $7 \%$ $>740 \mathrm{~Bq} / \mathrm{m}^{3}(>20 \mathrm{pCi} / \mathrm{L})$ on the main floor; more than $60 \%$ have levels $>148 \mathrm{~Bq} / \mathrm{m}^{3}(>4 \mathrm{pCi} / \mathrm{L})$ in the basement. Radon and gamma levels were lower in East Kootenay....

Morse, R.H., 1976

Radon counters in uranium exploration, in Exploration for uranium ore deposits, Proceedings of a Symposium on Exploration of Uranium Ore Deposits, Vienna, March 29-April 2, 1976:

Vienna, Internat. Atomic Energy Agency Rept. STI/PUB/434; 229-239

Rapid analytical techniques are available for uranium, radium and radon, each of which is characterized by a different geochemical behaviour and each of which is absolutely specific for uranium. An efficient geochemical exploration programme will be based on a judicious combination of these elements. The battery-operated digital alpha scintillometer combines portability with high sensitivity. Radon and radium can be determined in the field. Thoron is recognized by a rapid drop in count-rate owing to its 54.5 -s half-life. At the detailed level of exploration radon in soil gas provides a useful supplement to ground gamma scintillometry. Readings as low as 20 counts/min or lower are significant. High readings due to especially permeable soils are characterized by rapidly falling count-rates because of dilution by thoron. Uranium anomalies are characterized by steady or rising count-rates. Counting beyond the first minute and monitoring any changes is essential. Diurnal radon variations are not critical in Canada. An example is provided from the Bancroft area which compares radon in soil to ground gamma scintillometry. The radon survey shows more detail, in agreement with the geology, than the scintillometer.

Moschandreas, D.J., and H.E. Rector, 1982

Indoor radon concentrations:

Environment Internat., 8(1-6): 77-82

Mose, Douglas G., Charles E. Chrosniak, and George W. Mushrush, 1989 
State-size radon hazard maps based on zip-code compilations [abs.]:

Geol. Soc. America, Abstracts with Programs, 21(6): A143-A144

Indoor radon measurements are now available for many populated areas in the United States, particularly in the Appalachian Mountain system. A compilation of 1.3 million measurements, using activated charcoal and alphatrack indoor radon monitors, has been gathered from several radon testing companies and grouped according to zip codes. The hypothesis that charcoal monitor data yield zip code averages lower than alpha-track monitor data was found to be incorrect, using Maryland zip code zones. These two measurement methods tend to yield the same average for zip code zones, and the average charcoal measurement was found to be equally likely to be lower than, or higher than, the alpha-track average. A comparison between the geological provinces in Maryland and the zip-code-based radon hazard map of Maryland reveals the geological control on indoor radon. The Coastal Plain, composed of Cretaceous and younger poorly cemented sedimentary strata, has the lowest average indoor radon. Of intermediate concern for indoor radon is the eastern side of the Piedmont (mainly Paleozoic high-grade metamorphic rocks and granitic rocks), the Blue Ridge (mainly $1 \mathrm{Ga}$-old highgrade metamorphic and plutonic rocks), and the Plateau Province (flat-lying mid-upper Paleozoic sedimentary rocks). The area that tends to have the most zip code zones with higher indoor radon levels includes the western side of the Piedmont (low-medium-grade metamorphic rocks) and the Valley and Ridge Province (mainly early Paleozoic limestones and shales that were folded in the middle-late Paleozoic, and now form a karst topography). Studies in Maryland and several other States have indicated that zip-code compilations of large numbers of charcoal and alpha-track indoor radon measurements are useful indicators of indoor radon problem areas. If these compilations are superimposed on a geological map, useful radon hazard maps can be quickly constructed for many States.

Mose, D.M., C.E. Chrosniak, G.W. Mushrush, and S.L. Davis, 1989

Relationships between radon in water, indoor radon and cancer : A case study in Virginia and Maryland [abs.]: Eos, Am. Geophys. Union Trans., 70(15): 500

Year-long indoor radon measurements have been made in the homes of $\approx 1500 \mathrm{VA}$ and $\mathrm{MD}$ residents from which radon was also measured in drinking water. About $85 \%$ of the homes have municipal water, and these had no detectable radon (lower limit of detection is $\approx 370 \mathrm{~Bq} / \mathrm{m}^{3}$ or $\approx 100 \mathrm{pCi} / \mathrm{L}$ ). Almost all of the water samples from private wells had detectable radon (range up to $0.37 \mathrm{MBq} / \mathrm{m}^{3}$ or $\approx 10 \mathrm{nCi} / \mathrm{L}$; median $\approx 74 \mathrm{kBq} / \mathrm{m}^{3}$ or $\approx 2 \mathrm{nCi} / \mathrm{L}$ ). A correlation cannot be demonstrated between drinking water radon and indoor radon, indicating that other factors (e.g., home construction and use) are important. Based on a questionnaire (time in home, cancer if any and when found, etc.), there is a positive correlation between the percentage of people who develop cancer (all types except lung cancer in long-term smokers) and the radon concentration in the drinking water, and the correlation is more pronounced with increasing length of exposure. In the study area, $\approx 15 \%$ of the homes use private water wells; a simple population study shows that the incidence of cancer related to drinking water may exceed the incidence of cancer from inhalation of airborne radon. We recommend that increased attention be given to radon in water, and to associated radionuclides ( $\mathrm{Ra}$ and $\mathrm{Po}$ ). We also recommend that $37 \mathrm{kBq} / \mathrm{m}^{3}(1000 \mathrm{pCi} / \mathrm{L})$ for radon in drinking water be used as a national "action level" even though data show there is some risk at the $3.7-37 \mathrm{kBq} / \mathrm{m}^{3}(100-1000 \mathrm{pCi} / \mathrm{L})$ level. We note that the large numbers of homes now in the $3.7-37 \mathrm{kBq} / \mathrm{m}^{3}(100-1000 \mathrm{pCi} / \mathrm{L})$ range, some of which are served by public water systems, makes a "no-risk" action level of $3.7 \mathrm{kBq} / \mathrm{m}^{3}(100 \mathrm{pCi} / \mathrm{L})$ unreachable.

Mose, Douglas G., George W. Mushrush, and Stephen W. Kline, 1988

The interaction of geology, weather, and home construction on indoor radon in northern Virginia and southern Maryland, in Radon in the Northeast: Perspectives and Geologic Research (conference), Troy and Albany, New York, May 31-June 2, 1988:

Northeastern Environmental Science, 7(1): 15-29

Mose, Douglas G., George W. Mushrush, David Saum, Mark Messing, Steven Hall, Nick Gromicko, and Robert Dunkle, 1988

Prediction of indoor radon and home remediation in Fairfax County, VA and Montgomery County, MD [abs.]: 
Geol. Soc. America, Abstracts with Programs, 20(7): A337

An important goal of the radon studies program in the Center of Applied Science is to develop site-specific criteria for the identification of (a) homesites with a potential indoor radon problem, (b) home construction features that tend to be associated with elevated indoor radon, and (c) the application a particular remediation method, sub-slab ventilation, to reduce indoor radon in different soil types. Out of a study group of $\approx 1500$ homes in which radon gas was measured during an entire year using four seasonal intervals in each home, a set of 150 homes was studied to determine the relationship between homesite soil radon, soil permeability, and indoor radon. Another set of 150 homes was used to test the effectiveness of sub-slab ventilation. Our study shows that in more than $80 \%$ of the homes, the pre-remediation indoor radon could be estimated by measuring the soil radon (Terradex soil monitors, buried at $1 \mathrm{~m}$ within $\approx 5 \mathrm{~m}$ of the home for $1-3$ months) and the soil permeability (simplified water percolation test). We found that basement wall construction, home heating system, and other factors show a correlation with indoor radon. Finally, we found that a simple sub-slab ventilation system reduced indoor radon to less than $74 \mathrm{~Bq} / \mathrm{m}^{3}(2 \mathrm{pCi} / \mathrm{L})$ in most homes, in spite of differences in pre-remediation indoor radon, soil radon potential, or home construction factors. It thus appears that while indoor radon is often predictable by homesite (or regional) criteria and home construction criteria, all homes (at least in the northern Virginia and central Maryland study area) can be adequately remediated by simple sub-slab ventilation to effectively eliminate the home health risk due to radon.

Mosley, Ronald B., 1991

Model calculations of the interaction of a soil depressurization system with the radon entry process, in The 1991 International Symposium on Radon and Radon Reduction Technology, Philadelphia, Pa., April 2-5, 1991, Proc., Volume 3, Symposium Panel and Poster Papers, Technical Sessions 1 through 5:

U.S. Environmental Protection Agency Rept. EPA/600/9-91/037C, p. P5-3-P5-21

McLean, Va., Cohen (S.) and Associates, Inc. [Springfield, Va., NTIS Order No. PB92-115377]

[A simple model for describing radon migration and entry into houses: Preprints, v. 3, no. VP-1]

An approximate analytical solution to describe radon transport in soil having uniform properties is applied to the interaction of a soil depressurization system with radon emission to the atmosphere. The study addresses the question of whether soil depressurization systems are likely to significantly increase the local ambient radon levels by increasing the emission rate from the soil. While the model predicts that the operation of a soil depressurization system usually increases the total emission rate, this increase does not appear to be significant except for soils with high permeabilties. This is true because the decrease in emission rate from the soil surface tends to compensate for the increase in emission rate by the mitigation system unless the soil permeability is quite high. For permeabilities below $2 \times 10^{-11} \mathrm{~m}^{2}$, the increase in total emission rate of a single mitigation system and its sphere of influence is less than $1 \%$. Even for permeabilities greater than $4 \times 10^{-10} \mathrm{~m}^{2}$, the increase in total emission rate associated with a single house and its sphere of influence is probably not greater than $50 \%$. A $50 \%$ increase in the emission rate from a single mitigation system does not translate into a $50 \%$ increase in the ambient radon level. If only $10 \%$ of the soil surface in a community with permeability greater than $4 \times 10^{-10} \mathrm{~m}^{2}$ is associated with operating mitigation systems, the local ambient level might be expected to increase by about $5 \%$.

Muessig, Karl W., 1989

Uranium cycling in the crust and its relationship to radon hazards in New Jersey [abs.]:

Geol. Soc. America, Northeastern Section, Abstracts with Programs, 21(2): 53

Information accumusted from uranium resource occurrences and more recently on indoor radon problems indicate that anomalous concentrations of uranium and associated elevated radon occur in all of the New Jersey geological provinces. A model of uranium cycling in the crust, involving partial melting, hydrothermal activity, deformation and later fluid movement, is proposed to explain the varied mineralization styles throughout the lithologic column. It also explains the more pervasive uranium enrichment in the western parts of the provinces. The oldest recognizable concentrations of uranium occur in the Precambrian metamorphosed granites and volcanic-sedimentary rocks of the Reading Prong. Widespread enrichment of uranium is characteristic of the granites. Other smaller but more concentrated uranium occurrences are found in the 
metavolcanics and sediments. Metamorphism, partial melting, hydrothermal activity and deformation were important in recycling and concentrating uranium. Cambro-Ordovician cover rocks in the Valley and Ridge and Reading Prong host equally varied uranium mineralization. Residual uranium-rich minerals are found in the basal Cambrian quartzite. Hydrothermal deposits of uranium cause severe radon problems in some Cambro-Ordovician dolomites. Uranium was also incorporated into the marine shales of the Martinsburg and Jutland Formations during sedimentation and was reconcentrated during diagenesis and hydrothermal activity. The dominant repository for uranium in the Triassic rocks of the Piedmont Province is the lacustrine black shales of the Lockatong Formation. Diagenesis induced the secondary migration of uranium and small secondary deposits are associated with severe radon problems in the arkosic sandstones of the Stockton Formation. These appear to be related to structures and later fluid movements.

Muessig, Karl, and Christy Bell, 1988

Use of airborne radiometric data to direct testing for elevated indoor radon, in Radon in the Northeast:

Perspectives and Geologic Research (conference), Troy and Albany, New York, May 31-June 2, 1988:

Northeastern Environmental Science, 7(1): 45-51

Murane, David M., 1993

Model standards and techniques for control of radon in new buildings [abs.], in First International Workshop on Indoor Radon Remedial Action, The Scientific Basis and Practical Applications, Rimini, Italy, 27 June-2 July 1993:

Commission of the European Communities et al., Book of Abstracts, p. 3

In response to a requirement in the Indoor Radon Abatement Act of 1988, the U.S. Environmental Protection Agency (EPA) has been developing "Model Standards and Techniques for Control of Radon in New Buildings." A draft of the Model Standards was developed in close cooperation with the building industry and disseminated for public comment in early 1993. This paper describes the recommended construction techniques and implementation procedures contained in the draft. Use of the recommended standards and techniques is linked to the potential for elevated radon levels that is predicted for different geographical areas of the United States. The paper emphasizes the cost-effectiveness of building-in radon-resistance in new homes, and highlights the use of construction techniques that many builders already use as standard building practice.

Murane, David M., and John Spears, 1987

Radon reduction in new construction, in Indoor Radon II, Proceedings of the Second APCA International Specialty Conference, Cherry Hill, New Jersey, April 6-10, 1987:

Pittsburgh, Pa., Air Pollution Control Association Pub. SP-60, p. 183-197

[The Swedish criteria (see Åkerblom, 1987) are recognized for risk classification. In building radon-resistant construction, one needs to answer questions concerning indoor radon concentrations in houses built on the same rock and soil characteristics, whether the soil is derived from an underlying rock that normally contains above average concentrations of uranium/radium, whether the permeability of the soil is conducive to soil-gas flow, and whether the domestic water source, if at the site, is likely to contain such high levels of radon as to contribute significant levels of radon to the indoor air.]

Mushrush, George W., and Douglas G. Mose, 1988

Regional variation of indoor radon over three seasons:

Environmental Toxicology and Chemistry, 7: 879-887

[Radon levels in homes in the metropolitan Washington, D.C. area were measured by $\alpha$-track detectors. Average levels were highest in winter, intermediate in spring, and lowest in summer, and were related to geological material under the homes and to construction characteristics.]

Narasimhan, T.N., Y.W. Tsang, and H.Y. Holman, 1990

On the potential importance of transient air flow in advective radon entry into buildings:

Geophys. Research Letters, 17(6): 821-824 
[Numerical modeling by an integral finite difference method was used to model the temporal variations of air flux within homogeneous soil surrounding a basement during periodic variations of barometric pressure and a persistent 5-Pa underpressure in the basement. The basement walls were assumed to be impermeable, the basement was assumed to be barren earth, and the water table was assumed to be $5 \mathrm{~m}$ below the basement floor. In the absence of barometric pumping, the air flow into the basement was computed to be proportional to the soil permeability over the range $0.153-15.3 \times 10^{-12} \mathrm{~m}^{2}$. Barometric pumping with a period of $0.5 \mathrm{hr}$ and peak-to-peak amplitude of $100 \mathrm{~Pa}$ amplified the air flow by a factor of $\approx 70$ for the lowest permeability and by a factor of $\approx 4$ for the highest permeability; flow into the basement during increasing barometric pressure slightly exceeded flow into the ground during decreasing pressure for the lowest permeability, but for the highest permeability flow into the basement was several times greater than flow into the ground; and air flow through the vertical plane below the basement wall changed direction for the lowest permeability but was always toward the basement for the highest permeability. Barometric pumping of 500-Pa peak-to-peak amplitude and $24 \mathrm{hr}$ period amplified the air flow into the basement by a factor of $\approx 29$ for the lowest permeability and a factor of $\approx 3$ for $1.53 \times 10^{-12}-\mathrm{m}^{2}$ permeability, but reduced air flow into the basement by a factor of $\approx 3$ for the highest permeability. The results show that with short-period barometric pumping, advective movement of soil air into a basement can be significant even if the soil's permeability is low enough to be negligible under steady-state conditions.]

Nason, Richard, and Bernard L. Cohen, 1987

Correlation between ${ }^{226} \mathrm{Ra}$ in soil, ${ }^{222} \mathrm{Rn}$ in soil gas, and ${ }^{222} \mathrm{Rn}$ inside adjacent houses:

Health Physics, 52(1): 73-77

Nazaroff, William W., 1992

Radon transport from soil to air:

Reviews of Geophysics, 30(2): 137-160

[This detailed exposition includes the following sections and subsections: (1) Introduction; (2) Overview: A radon entry paradigm; (3) Radon availability in soil: radium content of rocks and soils, emanation coefficient, radon partitioning in soil pores; (4) Radon migration through soil pores: diffusive transport, diffusive flux into the atmosphere, advective transport (Darcy's law, permeability-a strong function of soil grain size and soil moisture), general transport equation; (5) Building factors that affect radon concentrations: model representation, ventilation, substructure; (6) Radon entry into buildings: quantifying pressure-generating mechanisms (wind, temperature differences), accounting for radon entry from soil and building materials (diffusive entry, advective entry), reducing radon entry, refined paradigms for radon entry?; and (7) Concluding remarks. A list of symbols and 104 references are included. "Radon availability," as used here and in Nazaroff et al. (1988) refers only to the equilibrium concentration of radon in the soil pore fluids if not modified by transport; it differs from the term introduced by Tanner (1986) to characterize both radon production and radon migration characteristics of a soil.]

Nazaroff, William W., Barbara A. Moed, and Richard G. Sextro, 1988

Soil as a source of indoor radon: Generation, migration, and entry, in Nazaroff, W.W., and A.V. Nero, eds., Radon and Its Decay Products in Indoor Air:

New York, John Wiley and Sons, p. 57-112

Nazaroff, W.W., B.A. Moed, R.G. Sextro, K.L. Revzan, and A.V. Nero, 1989

Factors influencing soil as a source of indoor radon: Framework for assessing radon source potentials:

Berkeley, Calif., Lawrence Berkeley Laboratory Rept. LBL-20645, 114 p.

Nazaroff, William W., and Richard G. Sextro, 1989

Technique for measuring the indoor ${ }^{222} \mathrm{Rn}$ source potential of soil:

Environmental Science and Technology, 23(4): 451-458 
[A soil-probe technique is described for appraising the soil-related factors considered to be most important in contributing to high indoor radon levels. Because the initial period of adjustment to sudden depressurization of the soil-probe cavity is too brief in which to make measurements in soils of the assumed permeability range, and steady-state conditions are not established in a convenient period of time, the measurements are made during an intermediate interval during which the pressure and flow conditions are constant but the radon concentration in the soil pores may be changing. A "radon source potential" parameter, an estimate of the maximum sustainable rate of entry of ${ }^{222} \mathrm{Rn}$ from the soil into a building, is obtained by measuring factors that determine two key characteristics, the rate of release of ${ }^{222} \mathrm{Rn}$ atoms from soil grains into pore space and the volume of soil that can feed radon to a building. It is assumed that the soil is uniform and isotropic, that molecular diffusion of radon is negligible in comparison with transport by soil air flowing through the pores, that a constant negative pressure of $4 \mathrm{~Pa}$ exists in the building relative to atmospheric pressure, and that a hypothetical building at the site has a basement substructure with a radon entry opening of uniform width around the $40-\mathrm{m}$ perimeter of a basement slab located $2 \mathrm{~m}$ below the soil surface. Six dimensionless parameters, defined for measurement of the soil-probe cavity size, the pressure difference, the radon flux into a spherical cavity, the air flow into the cavity, radon flux into a cylindrical cavity, and air flow into the cavity, are used to compute numerically the streamline trajectories and travel times from the ground surface to the cavity or entry gap. Once the trajectories and travel times have been computed in terms of the dimensionless parameters, they may be obtained for other values of the real variables by scaling. The solutions for the spherical cavity are appropriate for the interpretation of the sample-probe data; for analysis of the radon entry into the hypothetical building, the solutions for the cylindrical cavity with horizontal axis along the perimeter gaps, are appropriate. At low air flow rates, the radon flux into a cavity is equal to the undepleted radon concentration in the soil pores times the flux of air into the cavity, but at high flow rates significant atmospheric air is drawn from the surface and upper soil, diluting the radon flux. The radon source potential, expressed in $\mathrm{Bq} / \mathrm{s}$, is obtained from the radon flux, the building perimeter length, and the assumed width of the entry gap. Because the basement walls shield a part the air flow, it is expected that the actual rate of radon entry would be reduced to $50-100 \%$ of the calculated value. If the interior air is well mixed, the indoor radon concentration can be predicted as a function of the ratio of radon source potential to building volume, the outdoor radon concentration, the rate of radon entry from sources such as building materials and potable water, the radon decay constant, and the ratio of outdoor air infiltration rate to building volume. Radon source potentials were obtained from measurements made at four houses in northern New Jersey. Although the radon source potentials calculated from individual measurement sites at each house varied significantly, their geometric means correlated well with measured indoor radon concentrations.]

Nero, Anthony V., Jr., 1993

Risk evaluation and control strategies for indoor radon [abs.], in First International Workshop on Indoor Radon Remedial Action, The Scientific Basis and Practical Applications, Rimini, Italy, 27 June-2 July 1993:

Commission of the European Communities et al., Book of Abstracts, p. 111

Exposures to radon decay products in homes entail significant estimated risks of lung cancer, but are amenable to control strategies of various kinds. The risks of death from radon and other indoor pollutant classes-estimated to average 0.1 to $1 \%$, depending on country and smoking status-are larger than the 0.0001 . to $\mathbf{0 . 0 1 \%}$ lifetime risks from many outdoor air or water pollutants, and similar to some risks occurring in industrial settings, as well as to accident risks in homes and automobiles. However, qualitative features of the indoor environment - in regard to cost, benefit, responsibility, and distribution of risk-differ significantly from the outdoor and occupational settings, where frameworks for setting risk-limiting objectives and strategies have already been developed. Past analyses of radon risks illustrate the dangers of examining them from points of view developed for other contexts, as do the differences in radon control strategies adopted in different countries. This experience indicates the need to develop a conceptual framework for evaluating risk in the indoor environment, in the context of which the objectives of a strategy for controlling indoor radon can sensibly the chosen. In the absence of this framework, the magnitude and distribution of estimated risks still suggest $\therefore$ icral near-term objectives of any national strategy for indoor radon, objectives that have not universisi: been adopted. These are: to provide accurate and useful information for the public, so that they 
can make effective choices; to provide suitable monitoring techniques and protocols, indicative of actual occupant exposures; and to identify areas of the country where the highest indoor levels tend to occur, so that monitoring and control efforts can be brought to bear rapidly. Concurrent development of a conceptual framework for evaluating indoor risks will permit the adoption of objectives relevant to more typical indoor exposure and to new housing, as well as to settings-such as schools or workplaces-where exposures tend to be lower than in houses.

Nero, A.V., A.J. Gadgil, W.W. Nazaroff, and K.L. Revzan, 1990

Indoor radon and decay products: Concentrations, causes, and control strategies:

Washington, GPO, U.S. Dept. Energy Tech. Rept. DOE/ER-0480P, 138 p.

...The purpose of this report is to provide an introduction to the behavior of ${ }^{222} \mathrm{Rn}$ and its decay products, based primarily on research of the last fifteen years, and to review certain aspects of the radon question about which there has been significant misunderstanding. We therefore include 1) an appraisal of the concentration distribution in U.S. homes, 2) an examination of the utility and limitations of popular monitoring techniques and protocols, and 3) a discussion of the key elements of strategies for controlling radon levels in homes. It is useful here to summarize the main results from this review of radon and decay-product behavior, as well as to provide some perspective on the three key issues just mentioned.... [Extract from authors' summary]

Nero, A.V., S.M. Leiden, D.A. Nolan, P.R. Price, S. Rein, K.L. Revzan, H.A. Wollenberg, and A.J. Gadgil, 1993 Statistically-based methodologies for mapping of radon "actual" concentrations: The case of Minnesota [abs.], in

First International Workshop on Indoor Radon Remedial Action, The Scientific Basis and Practical Applications, Rimini, Italy, 27 June-2 July 1993:

Commission of the European Communities et al., Book of Abstracts, p. 77

A number of approaches have been developed for mapping the radon "potential" of areas, using radiometric, soils, or geologic data, sometimes together with measured indoor concentrations and sometimes utilizing models of the radon generation or transport process. These, however, have typically yielded indicators only of transportable radon, of upper-bound radon entry rates, or of concentrations in a standard housing unit, without statistical optimization or normalization to actual indoor levels. We here describe an alternative approach, where measured indoor radon concentrations are used jointly with physical data (radiometric, soils, geological, meteorological, and structural) in a statistical framework to yield a correlation model that directly provides estimators of the actual indoor radon concentration distribution by area and of the uncertainties in those estimators. Applied over a large region, this approach would thus yield a topography of indoor radon concentrations. This could be used to focus efforts to identify existing homes having excessive indoor concentrations or to characterize the expected indoor levels for new structures. This approach has been applied in a preliminary way using data from the state of Minnesota, an area of the United States having higher-than-average indoor levels. We find the regression analysis to indicate geometric mean radon concentrations for Minnesota counties with an $R^{2}$ exceeding 0.5 , a very high level considering the noise introduced into the analysis by the relatively small number of actual measurements in most counties. In a joint project with the U.S. Geological Survey, we are investigating the use of more sophisticated statistical methodologies and more complete physical data, as a means to provide estimators at a finer geographic scale than the county level, and developing a comprehensive statistical, geographical, database system for processing and analysis of the data required and for suitable representation of the analysis results.

Nero, A.V., and W.W. Nazaroff, 1984

Characterising the source of radon indoors:

Radiation Protection Dosimetry, 7(1-4): 23-39; [orig. pub.: Lawrence Berkeley Laboratory Rept. LBL-16636, 1983]

Average indoor radon concentrations range over more than two orders of magnitude, largely because of variability in the rate at which radon enters from building materials, soil, and water supplies. Determining the indoor source magnitude requires knowledge of the generation of radon in source materials, its movement within materials by diffusion and convection, and the means of its entry into buildings. This paper reviews the 
state of understanding of indoor radon sources and transport. Our understanding of generation rates in and movement through building materials is relatively complete and indicates that, except for materials with unusually high radionuclide contents, these sources can account for observed indoor radon concentrations only at the low end of the range observed. Our understanding of how radon enters buildings from surrounding soil is poorer; however, recent experimental and theoretical studies suggest that soil may be the predominant source in many cases where the indoor radon concentration is high.

Nevissi, Ahmad E., and David Bodansky, 1987

Radon sources and levels in the outside environment, Chap. 4 in Bodansky, David, Maurice A. Robkin, and

David R. Stadler, eds., Indoor Radon and Its Hazards:

Seattle, Univ. Washington Press, p. $42-50$

Ney, E.P., and Lively, R.S., 1989

Boundary conditions affecting radon estimation based upon daughter deposition, in Osborne, M.C., and Harrison, Jed, Symposium Cochairmen, The 1988 Symposium on Radon and Radon Reduction Technology, Proc., Vol. 1, Symposium Oral Papers:

Research Triangle Park, N.C., Radian Corp., U.S. Environmental Protection Agency Pub. EPA/600/9-89/006a [Springfield, Va., NTIS Order No. PB89-167480], p. 4-65--4-68.

Nielson, Dennis L., Cui Linpei, and Stanley H. Ward, 1990

Gamma-ray spectrometry and radon emanometry in environmental geophysics, in Ward, Stanley $H_{\text {., ed., }}$ Geotechnical and Environmental Geophysics, Vol. I: Review and Tutorial:

Tulsa, Okla., Soc. Exploration Geophysicists, p. 219-250

[This tutorial review includes the following sections and subsections: Abstract; Introduction; Natural radioactive decay processes (elementary particles, concentration and distribution, equilibrium and disequilibrium, scattering and absorption, health effects of radioactivity); Operational considerations-gamma-ray spectrometry (background, meteorological effects, calibration, statistical errors in count rates, field of view of gamma-ray detectors, data analysis); Origin and migration of radon in the natural environment (introduction, radon emanation, migration processes, fluids, meteorological effects); Measurement of radon in soils (measurement methods); Examples of environmental geophysical surveys (case study-Vitro tailings site, Salt Lake City, Utah, fault and earthquake studies, indoor radon, landslides, caves and karst, groundwater detection, the search for Cosmos 954 [satellite], Chernobyl fallout); Summary; and 87 references. A related tutorial review on ground sources of indoor radon by Gregg and Holmes (1990) follows.]

Nielson, K.K., M.K. Bollenbacher, V.C. Rogers, and G. Woodruff, 1989

Users guide for the MK-II Radon/Permeability Sampler:

Salt Lake City, Utah, Rogers and Associates Engineering Corp. Rept. RAE-9000/9-2, 39 p.

[This guide describes the theory, implementation, set-up, operation, transportation, maintenance, and calibration of a hammer-driven probe and the associated pressure and soil-gas flow measuring instruments for a system for determining soil permeability while extracting a sample of the soil gas for radon analysis. The probe follows a general design introduced by DSMA Atcon, Ltd. (1983) and is a nominal 60-in. (1.5 m) heavy steel pipe of $\approx 2 \mathrm{~cm}$ diameter with a removable steel driving point and a 21/4-in. (57 mm) diameter steel driving head. The inlet consists of a recessed surface near the bottom end with small diametrically opposed holes in a vertical row 10 holes long. The outlet is a hose barb threaded into the driving head. The suction pump, a battery, and gauges are fitted to a lightweight metal suitcase that needs only to be opened to make the system available for operation. The probe has been calibrated within cylinders of semi-permeable foam whose permeabilities have been determined in a conventional one-dimensional flow system.]

Nielson, K.K., and V.C. Rogers, 1989

Radon generation, absorption and transport in porous media - the RAETRAN model [abs.]:

Eos, Am. Geophys. Union Trans., 70(15): 497 
A new mathematical model has been developed to describe the generation and transport of radon gas in soils. It is aimed at describing radon sources and their availability for entry into the indoor environment from substructure soils. The model is a multiregion, one-dimensional analytical model. It combines individual mathematical descriptions of radon emanation, diffusive transport, and advective transport in both gas- and liquid-filled pore space. It explicitly considers the equilibrium absorption of both radon and radium in the liquid phase and of radon adsorption on solid surfaces. The model is implemented in a Fortran code, RAETRAN, which computes radon fluxes and distributions for prescribed source concentrations, pressure gradients, concentration boundary conditions, moistures, and a variety of soil properties. The code uses defining properties for any number of regions. Defining properties may include the soil thickness, porosity, radium concentration, emanation coefficient, moisture, grain size distribution, diffusion coefficient, gas permeability, temperature, and applied pressure gradient. For cases in which suitable input values of soil gas permeability, diffusivity, or radon emanation coefficient are not known, the code computes appropriate values from empirical correlations with the soil particle size distribution, moisture content, and porosity. By unifying the theories of radon generation and transport, the model avoids previously required approximations and inconsistencies, and correctly describes radon source strengths and availabilities. It has been applied in describing experimental systems and sensitivity testing of the source parameters that affect indoor radon concentrations.

Nielson, Kirk K., and Vern C. Rogers, 1990

Correlation of Florida soil-gas permeabilities with grain size, moisture and porosity:

Salt Lake City, Utah, Rogers and Associates Engineering Corp. Rept. RAE-8945-1, 39 p.

U.S. Environmental Protection Agency Rept. EPA-600/8-91-039

Nielson, Kirk K., and Vern C. Rogers, 1991

Development of a prototype map of the soil radon potentials in Alachua County Florida:

Salt Lake City, Utah, Rogers \& Associates Engineering Corp., Rept. RAE-9127/3-1, 114 p.

A prototype map of the soil radon potentials in Alachua County, Florida has been developed. The map is designed to show from geological and soil features the areas associated with different potentials for accumulating elevated indoor radon concentrations that can pose health hazards. Radon potential maps have been proposed as a basis for implementing radon-protective building construction requirements in Florida. The map for Alachua County is a prototype to develop the necessary methods and to examine the feasibility and problems associated with a broader statewide radon mapping effort. ISoil radon potentials were characterized by modeling individual soil profiles at numerous locations throughout Alachua County with respect to their radon generation and transport properties. The RAETRAD model was used to compute the potential rates of radon entry into a hypothetical reference house that was modeled over each soil profile. The resulting radon entry rates, expressed in units of $\mathrm{mCi} / \mathrm{y}$, give a relative measure of radon potential for any building on the soil profile, and lead to estimates of indoor radon concentrations for the reference house. The radon potential calculations utilize multiphase modeling of radon emanation and 2-dimensional advective and diffusive transport into the house. The reference house approximates single-story slab-on-grade housing typical of central Florida. ISoil profiles were defined for each of 65 detailed soil map units from the existing data in the Alachua County soil survey. The profiles were associated with approximately 15,000 areas (polygons) on a digitized 1:24,000 Alachua County soil map. Each profile was defined in terms of approximately 5-9 soil horizons that represented soils to approximately 2-2.5 m depths. Soils in the deeper 2.5-5-m zone were characterized by a separate geological study by the U.S. Geological Survay. Individual properties of soils in each horizon of each profile were defined as far as possible from existiz soil survey data. These properties included horizon depths, soil densities, water drainage characteristics, soil textural properties, and high water table limits and durations. Related soil properties were computed from these measured characteristics as far as possible. These included soil porosity, water saturation fraction, annual water table depth distribution, mean particle size, soil air permeability, soil radon diffusion coefficient. Several properties, such as water contents, permeabilities, and radon diffusion coefficients varied in different parts of the year due to water table fluctuations. Up to three different water table depths were considered in defining these profile properties. 
ISoil radium concentrations and radon emanation coefficients were measured by a new, more sensitive method in 323 and 131 soil samples, respectively, that were mostly obtained from the archive of samples collected in the original Alachua County soil survey. Some additional samples also used in the radiological measurements were obtained from new borings in Alachua County by the U.S. Geological Survey and the Florida Geological Survey. Radium concentrations were log-normally distributed with a geometric mean of $30 \mathrm{~Bq} / \mathrm{kg}(0.8 \mathrm{pCi} / \mathrm{g})$ and a geometric standard deviation of 122 (3.3). They ranged from $<7.4$ to $1600 \mathrm{~Bq} / \mathrm{kg}(<0.2 \mathrm{pCi} / \mathrm{g}$ to $43 \mathrm{pCi} / \mathrm{g}$ ). Radon emanation coefficients were approximately normally distributed with a mean of 0.48 , a standard deviation of 0.16 , and a range of 0.05 to 0.85 . The emanation coefficients are significantly higher than most previously reported soil values, and exhibit an approximate correlation with radium concentrations in the low-radium range of $0-74 \mathrm{~Bq} / \mathrm{kg}(0-2 \mathrm{pCi} / \mathrm{g})$. TFor production of the draft radon potential map, measured radium and emanation characteristics were represented by three different radiological tiers for each of two general soil categories. Various combinations of the six radiological categories were attributed to each soil profile to accommodate different underlying geology that occurs in different locations. Radon potentials were computed for each soil profile with its defined radiological distribution and with up to three different soil water profiles to represent different seasonal conditions. The radon potentials were attributed to individual map units by overlaying the digitized map of surface soils with the geological map based on soil formations and origins. From this overlay, the appropriate calculated radon potential was assigned based on the combination of surface soil profile and geologic unit. The resulting annual-average radon potentials ranged from 0.37 to $>150 \mathrm{MBq} / \mathrm{a}$ $(0.01 \mathrm{mCi} / \mathrm{y}$ to $>4 \mathrm{mCi} / \mathrm{y}$. For the reference house, a radon potential of $111 \mathrm{MBq} / \mathrm{a}(3 \mathrm{mCi} / \mathrm{y})$ corresponds to an indoor radon concentration of $74 \mathrm{~Bq} / \mathrm{m}^{3}(2 \mathrm{pCi} / \mathrm{L})$. IBecause of the method used to average measured radium concentrations over broad soil regions, high values that might indicate particular problem areas are not indicated. However the broad range of calculated radon potentials is consistent with probabilistic interpretations even for the observed elevated radon levels in Alachua County. The present draft radon potential map appears to be most suitable for identifying areas that would not require special radon-protective building precautions, rather than identifying "hot" areas that need special attention. Using this approach, the areas with intermediate radon potential, which also are most likely to exhibit occasional "hot" areas, also would be included in the areas suggested for precautionary radon-protective building features.

Nielson, Kirk K., and Vern C. Rogers, 1991

Feasibility and approach for mapping radon potentials in Florida. Florida Radon Research Program:

Salt Lake City, Utah, Rogers \& Associates Engineering Corp., Rept. EPA-600/8-91-046, 45 p. [Springfield, Va., NTIS]

Statewide maps of radon potentials in Florida have been proposed as a means of assessing the need for radon-protective construction features for new housing. Suitable radon maps would reduce costs and increase benefits from radon-based building code requirements being promulgated by the Florida Department of Community Affairs (DCA) by defining local radon risks that could be keyed to the need for prescribed levels of radon protection. Radon potentials are dominated by concentrations of the naturally occurring radium-226 parent nuclide and by the gas-transport properties of soils in the top few meters beneath a house. The potentials thus correlate with regional geology, mineralogy, and physiographic features. An analysis was made of the feasibility of developing radon maps that would meet DCA programmatic needs and of the approach that would be required. The analysis included a review of previous radon mapping approaches and experience, as summarized in presentations and discussions at a DCA workshop or DCA workshop on radon mapping, and a subsequent critical review of pertinent scientific literature and mathematical approaches. Prior radon maps were aimed at identifying radon-prone areas for prioritizing testing programs and alerting the public to testing needs. They generally have used 3-5 tier classifications of state- or region-sized land areas on a scale of county or physiographic units. The classifications generally are qualitative or probabilistic, and represent broad correlations of indoor radon concentrations with surface geology, lithology, aeroradiometric data, soil permeability, and/or soil radium concentrations. A few have resolutions approaching a 10-acre parcel, but most show only broader trends. Several deterministic approaches have utilized radon indices based on simple correlations of indoor radon with two or three soil or house parameters. The parameters have included soil radium or uranium concentration, soil permeability, soil radon concentration, house ventilation rate, house 
foundation parameters, and other related parameters. More detailed calculations have utilized steady-state analytical calculations of advective or combined advective-diffusive radon entry rates into houses. To provide a basis for requiring radon-protective construction, a more precise, theoretically-based approach is needed to quantify radon potentials throughout Florida and to interpret them in terms of probable indoor radon concentrations. Greater precision can be achieved by partitioning radon variations into the three categories: source variations, house variations, and time variations. By using only long-term average or invariant parameters, the time component is minimized. Source and house variations are partitioned by computing radon entry rates (mCi/year) for a reference house, typical of Florida housing stock, located on layered soils representing the source variations throughout the state. From the resulting statewide distribution of radon source potentials, housing variability is assessed by statistical summaries of indoor radon variations for a constant or normalized source potential. Statistical analyses of Florida indoor radon data suggest relatively constant, house-dominated variations within similar geologic or physiographic units, but broader variations when areas are grouped by county or other institutional boundaries. Methods are described to obtain unbiased estimates of the variations, which are useful indicators of the presence of local "hot spots" within a region. These were shown to occur mainly in northern and central Florida, and to demonstrate the importance of localized, high-resolution analyses of source potentials from soils, geologic, and radiological data. The proposed mapping approach will generate two kinds of radon maps. A radon source map will display isopleths of the deterministic estimates of radon entry rates for the reference house. A radon probability map then will utilize the source information with probability distributions to display isopleths of the probabilities of exceeding prescribed indoor radon concentrations at each map location. A nominal statewide mapping scale of 1:100,000 to 1:250,000 is proposed for the main, initial mapping effort. For certain populated areas where radium anomalies and near-surface lithology (0-5 m) are non-uniform, higher resolution mapping to a 200-m scale will be needed for radon zoning purposes. Radon source maps can utilize present multi-region, multi-phase analytical equations for diffusive and advective radon transport. The reference house is defined from average Florida and U.S. parameters for slab-on-grade housing. Layered soil data are mostly available from existing borings, geology, lithology, and Soil Conservation Service (SCS) data. These will serve to define the required layer boundaries, densities and porosities. From SCS soil textural classifications and porosities, long-term average water contents will be estimated from soil matric potentials. The water contents in turn can be used with soil porosities and textures to estimate soil permeabilities and diffusion coefficients using existing empirical correlations. SCS water percolation data also may prove useful. The remaining radium and emanation parameters will use existing data where available, but will require supplementary measurements on samples archived at the University of Florida and the Florida Geological Survey. The measurements should characterize these radiological properties by geological formation and/or lithological unit. Precisions of the mapped radon source potentials are anticipated to approach a geometric standard deviation of about 2.5. The probability maps will utilize a simple indoor radon dilution model based on the radon entry rate, house volume, and ventilation rate. Log-normal radon distributions appear appropriate, and will be used to compute the probabilities of exceeding $148 \mathrm{~Bq} / \mathrm{m}^{3}(4 \mathrm{pCi} / \mathrm{L}$ ) or other criteria using log-normal distribution statistics.

\section{Nielson, Kirk. K., and Vern C. Rogers, 1991}

Proceedings of the Workshop on Radon Potential Mapping. Florida Radon Research Program:

Salt Lake City, Utah, Rogers \& Associates Engineering Corp., Rept. EPA-600/9-91-044, 71 p.

[The authors have summarized the presentations given at a workshop held in Gainesville, Florida, April 20, 1990, for guidance of the Florida Radon Research Program (see also Sanchez et al., 1991): (1) Introduction (Nielson and Rogers); (2) Overview of Florida Programmatic Goals (Rick Dixon, Florida Department of Community Affairs); (3) Meeting scope, objectives, and issues (Vern Rogers); (4) Review, use, and basis of existing radon maps (James Otton, USGS); (5) Technical basis for mapping radon potentials (Allan Tanner, USGS); (6) Rationale and level of detail for radon potential maps (Charles Laymon, New York State Dept. of Health); (7) Data available for Florida radon potential mapping (Walt Schmidt, Florida Geological Survey); (8) Radon mapping issues and priorities (Rick Dixon); Data, accuracy, and instrumentation (Task Group 1); Institutional issues, uses, and costs (Task Group 2); and appendices giving a list of participants and copies of slides and viewgraphs presented.] 
Nielson, Kirk K., and Vern C. Rogers, 1992

Radon transport properties of soil classes for estimating indoor radon entry, in Cross, Fredrick T., ed., Indoor Radon and Lung Cancer: Reality or Myth? Twenty-ninth Hanford Symposium on Health and the Environment, Richland, Wash., October 15-19, 1990, Proceedings:

Richland, Wash., Battelle Memorial Press, Part 1, p. 357-372 [NTIS]

Radon diffusion coefficients and air permeabilities of soils are required for modeling indoor radon entry, for interpreting data on soil radon sources, and for designing and evaluating potential radon mitigation or containment systems. Diffusion and permeability coefficients depend on soil moistures, particle sizes, and compactions. We present a systematic method for estimating these transport parameters for the 12 common Soil Conservation Service (SCS) soil textural classes for predicting radon entry. IDiffusion coefficients and air permeabilities are estimated from predictive correlations with soil particle-size distribution, porosity, and water content. The matric potential [the environmental tension or suction affecting a soil] and particle sizes are preferred for estimating soil moistures when site-specific data are unavailable because long-term average matric potentials near structures are relatively constant. They also provide a useful basis to compare radon transport properties of different soil textural classes in a given location. IPredicted diffusion coefficients range from about $10^{-9} \mathrm{~m}^{2} / \mathrm{s}$ for the silty clay class to $4 \times 10^{-6} \mathrm{~m}^{2} / \mathrm{s}$ for the sand class. Air permeabilities range from $8 \times 10^{-18} \mathrm{~m}^{2}$ for the silty clay class to $2 \times 10^{-11} \mathrm{~m}^{2}$ for the sand class. Comparison of measured diffusion and permeability coefficients with predicted values are within geometric standard deviations of 1.4 and 1.7 , respectively. TThe method provides generic diffusion and permeability coefficients as functions of soil textural class and matric potential. Because long-term average matric potentials near structures are relatively constant (10 to $30 \mathrm{kPa}$ ), specifying the soil textural class characterizes the soil radon transport properties sufficiently for estimating indoor radon entry. [From preprint. See Rogers and Nielson, 1991, "Correlations..." for the equations for diffusion coefficient as a function of porosity and fractional moisture saturation and permeability as function of porosity, fractional moisture saturation, and arithmetic mean soil particle diameter. Radon entry rates were computed by the two-dimensional, three-phase, multiregion radon transport model called RAETRAD described by Rogers and Nielson (1990, "Benchmark..."), for a slab-on-grade structure, using soil moistures for the various soil types at a matric potential of $-50 \mathrm{kPa}$.]

Nielson, Kirk K., Vern C. Rogers, Randall B. Brown, Willie G. Harris, and James K. Otton, 1991

Prototype mapping of radon potentials in Florida, in The 1991 Annual AARST National Fall Conference, Rockville, Md., October 9-12, 1991:

American Association of Radon Scientists and Technologists, Midatlantic Chapter, Preprints, Vol. I, p. 145-162

A prototype map of radon potentials in Alachua County, Florida is being developed to demonstrate the feasibility of defining geographic criteria for implementing radon-protective building construction standards. Because of regulatory needs and sensitivities, the map is being developed independent of institutional boundaries or of particular present radon limits. It defines the radon source potentials as the average rate at which radon would enter a reference house that is modeled on specific soil profiles that are defined in the existing county soil survey. Radon transport parameters (diffusion coefficients and air permeabilities) for each soil layer at each location are defined from soil densities, textures, and moisture properties in the soil survey data base. Parent radium concentrations and radon emanation coefficients were measured in 323 soil samples obtained from archived materials from the county survey reference pedon sites and from supplementary borings. Radium concentrations are mainly associated with clayey materials from the Hawthorne formation. Relatively high radon emanation coefficients were observed, averaging $0.48 \pm 0.16$. The high emanation coefficients are attributed to predominant radium mineralization in the Hawthorne-related surface coatings in sandy soils. Radon potentials of approximately $3 \mathrm{MBq} / \mathrm{a}$ per $\mathrm{Bq} / \mathrm{kg}\left(3 \mathrm{mCi} / \mathrm{y}\right.$ per $\left.\mathrm{pCi} / \mathrm{g}{ }^{226} \mathrm{Ra}\right)$ are estimated to correspond to uniform sandy soils to give an indoor radon concentration of $74 \mathrm{~Bq} / \mathrm{m}^{3}(2 \mathrm{pCi} / \mathrm{L})$.

Nielson, K.K., V.C. Rogers, R.B. Brown, W.G. Harris, and J.K. Otton, 1992

Soil radon potential mapping and validation for central Florida, in The 1992 International Symposium on Radon and Radon Reduction Technology, Minneapolis, Minnesota, September 22-25, 1992:

U.S. Environmental Protection Agency, Preprints [poster papers], v. 5, no. VIIIP-2, 19 p. 
Maps of soil radon potentials are being developed to provide a possible geographic basis for implementing radon-protective building construction standards in Florida. The maps are being developed from soil properties, independent of institutional boundaries or of particular present radon limits. The radon potentials are defined from the calculated rates of radon entry into a hypothetical house modeled over soil profiles for each map polygon. Two approaches are tested in prototype radon maps developed for Alachua County. The first approach defines soil profiles and associated transport properties (air permeability, radon diffusion, moisture) from county soil survey data for 65 map units occurring in 15,000 map polygons. Radon source strengths are based on 323 radium and radon emanation measurements, averaged by geologic unit, from archived samples collected at reference pedon sites in the soil survey. The second approach defines soil profiles and transport properties from the state-wide Statsgo soil maps and data, which include 30 map units occurring in approximately 200 polygons in Alachua County. The second approach uses NURE aeroradiometric data and geologic classifications to define individual radon source strengths for each map polygon. IThe two approaches were compared with ground-truth data that included surface radon fluxes, soil-gas radon concentrations, and indoor radon data. The mapped soil radon potentials were related most precisely to the radon fluxes, followed by the soil-gas radon concentrations. Indoor radon data exhibited more variation, as expected, due to house variability. A mapping precision of \pm 1 tier in a four-tier approach appears possible. The higher resolution of the first mapping approach did not demonstrate any advantage in mapping precision when comparing the maps with ground truth data. The second approach is proposed for mapping broader areas of the state because it utilizes data and samples that are already available throughout most of the state.

Nielson, Kirk K., Vern C. Rogers, and Rodger B. Holt, 1992

Development of soil radon potential maps for Alachua, Marion, and St. Johns Counties in Florida. Draft interim report.:

Salt Lake City, Utah, Rogers \& Associates Engineering Corp., Rept. RAE-9127/8-1, 127 p.

Soil radon potentials have been calculated for mapping geographic distributions of radon potentials in Alachua, Marion, and St. Johns Counties in Florida. The maps are designed to show from geological and soil features the areas that have different levels of radon potential. The soil radon potential maps have been proposed as a basis for implementing radon-protective building construction requirements in areas of greatest radon risk. Discrete areas (polygons) on the radon maps were defined from the digital intersection of STATSGO soil map units with digitized geological map units. The intersections to define radon map polygons were performed by the University of Florida GeoPlan Center using a geographic information system with ArcInfo format. They also partitioned National Uranium Resource Evaluation (NURE) aeroradiometric data for each polygon. Radon potentials of each map polygon were estimated from the radon source and transport properties of the soil profiles that compose the region represented by the polygon. Radon source properties were estimated from NURE aeroradiometric data for shallow horizons (0 to 2 or $2.5 \mathrm{~m}$ ), and from geological classifications of the soils for deep horizons (to 5-m depth). Radon emanation coefficients were based on several hundred emanation measurements on county-survey soil samples from Alachua, Marion, and St. Johns Counties. Radon transport properties were estimated from soil profile physical data compiled for the STATSGO soil maps from Soil Conservation Service (SCS) data bases by the University of Florida Soil Science Department. Summary soil data files characterized soil densities, particle size distributions, water drainage curves, high water table depths and durations, and other mechanical and hydrological data. Radon transport properties (water contents, radon diffusion coefficients, and air permeabilities) were calculated from these data. Soil radon potentials were computed by mathematically modeling a reference house typical of Florida slab-on-grade single-family housing as if it were located on each soil profile of each of the radon map polygons. The model calculations were based on the RAETRAD (RAdon Emanation and TRAnsport into Dwellings) model, but were conducted using a more specialized, benchmarked radon potential cartography algorithm named RnMAP. Both models calculated radon potentials as the rate of radon entry into the reference house. Annual units (mCi/y) were used to express the radon potentials to emphasize the long-term average nature of the radon potential estimates. Radon potentials were calculated and then averaged for each of several soil profiles in each polygon, at each of two or three seasonal water table depths. They also were also calculated for either "hot" or "cold" geology, and the applicable geologic classification was used afterward to select the appropriate values 
to use in representing each polygon. Separate radon potentials were calculated for the estimated median radium concentrations, and also for radium concentrations corresponding to the $75 \%, 90 \%, 95 \%$, and $99 \%$ confidence limits for areal radium distributions within each polygon. The confidence limits were calculated from the geometric means and geometric standard deviations of radium estimated from multiple NURE data points in many of the polygons that intersected NURE flight lines. Radium estimates for polygons not intersected by NURE flight lines were extrapolated from the overall data for the geologic unit in which the polygon was located. The resulting radon potentials were partitioned into seven tiers of similar numerical values for display on the radon potential maps. The tiers corresponded to the $<0.4,0.4-1,1-2,2-3,3-6,6-12$, and $>12 \mathrm{mCi} / \mathrm{y}$ levels of radon potential. This set of tiers provided suitable range for using a uniform tier scale on all of the radon potential maps. Map polygons finally were colored according to the appropriate tier classification for intuitive visual interpretation. Numerical values of the radon potentials computed for each map polygon are presented in this report for more quantitative interpretations of the maps. A radon potential of $\approx 111 \mathrm{MBq} / \mathrm{a}(3 \mathrm{mCi} / \mathrm{y})$ corresponded to approximately $148 \mathrm{~Bq} / \mathrm{m}^{3}(4 \mathrm{pCi} / \mathrm{L})$ in the reference house. Separate maps were plotted for the median, $75 \%, 90 \%, 95 \%$, and $99 \%$ confidence limits of radon potentials to give a better perspective of radon potentials in a given polygon region. Areas with low potentials on both the median and higher-confidence-limit maps exhibit reasonable assurance of having minimal indoor radon risk. Areas exhibiting high radon potentials on the median and higher-confidence-limit maps conversely have a relatively high probability of elevated indoor radon levels. Areas with low median radon potentials but high potentials for higher confidence limits suggest heterogeneous areas (low median; high geometric standard deviation) that may have generally low radon potentials but occasional to frequent anomalies of high radon potential. Special considerations may be needed to define radon-protective building needs in these areas.

Ogden, Albert E., William B. Welling, Robert D. Funderburg, and Larry C. Boschult, 1987

A preliminary assessment of factors affecting radon levels in Idaho, in Graves, Barbara, ed., Radon in Ground Water:

Chelsea, Mich., Lewis Publishers, p. 83-96

[The geology of Idaho was reviewed with particular attention toward formations that are likely to have aboveaverage concentrations of radium. Charcoal canisters were distributed throughout the state during the winter months of 1986-1987, with instructions to deploy them in the room most occupied for one week. The results from Ada County (containing the capital, Boise), and Kootenai County, in the northern panhandle, were examined in more detail than those from other counties. In the two counties there was a slight positive correlation between indoor radon and depth to the water table, which ranged as great as $180 \mathrm{~m}$ in Ada County and $135 \mathrm{~m}$ in Kootenai County. In Ada County, where most houses are sited on unconsolidated sediments, the median radon level was significantly high only on arkosic granitic sediments; houses sited on sandy soils underlain by clay layers in the subsoils of lacustrine foothills had the lowest median indoor radon. Sample sizes were small for both counties. The authors state that, "The greater the granitic composition of the alluvium and outwash on which the homes are built, the greater the possibility of higher radon levels. In general, homes built in counties where the Snake Plains basalt crops out have lower radon levels than homes built on granite or granitic-rich alluvium. Soils with high permeability appear to produce more radon than tighter soils. Finally, homes built in geothermal areas have higher radon levels...." In addition to this preliminary study, more extensive studies were done. See Moed et al., 1984; Otton and Duval, 1991; and Schumann, 1993j.]

Otton, James K, 1987

Indoor radon-Geologic controls in Pacific Northwest [abs.]:

Geol. Soc. America, Abstracts with Programs, 19(2): 122

Three-month, wintertime, indoor radon measurements of over 16,000 residences in selected areas of the northwest U.S. by the Bonneville Power Administration show higher radon values (more than 10 percent of homes $>185 \mathrm{~Bq} / \mathrm{m}^{3}(>5 \mathrm{pCi} / \mathrm{L})$ in townships in the Spokane and Rathdrum Prairie areas (SRP) of northeast Washington and northern Idaho, the Milton-Freewater area (MF) in eastern Oregon, several communities along the lower Columbia River (LCR), and several communities along the Willamette River Valley (WRV) in western Oregon. Maximum values approach $3.7 \mathrm{kBq} / \mathrm{m}^{3}(100 \mathrm{pCi} / \mathrm{L})$ near Spokane; of the 24 values 
exceeding $925 \mathrm{~Bq} / \mathrm{m}^{3}(25 \mathrm{pCi} / \mathrm{L})$ in the entire dataset more than half are from SRP. Throughout the SRP area, soils have relatively high soil uranium contents compared with the rest of the Northwest (2-3 ppm equivalent uranium estimated from aeroradiometric data), and the soils are typically rapidly to very rapidly permeable because they are developed on coarse glacio-fluvial outwash. Rapidly permeable soils permit more radon-bearing gas to enter into structures. Persistent low values occur in the Puget Lowland from Seattle northward to Everett (for example, in T27N, R4E, 1165 homes averaged $17 \mathrm{~Bq} / \mathrm{m}^{3}$ or $0.46 \mathrm{pCi} / \mathrm{L}$ radon with a maximum value of $105 \mathrm{~Bq} / \mathrm{m}^{3}$ or $2.84 \mathrm{pCi} / \mathrm{L}$ ); however the southern suburbs of Seattle show higher values in four townships (in T19N-R2 to $5 \mathrm{E}, 247$ homes averaged $55 \mathrm{~Bq} / \mathrm{m}^{3}$ or $1.48 \mathrm{pCi} / \mathrm{L}$ with a maximum of $655 \mathrm{~Bq} / \mathrm{m}^{3}$ or $17.71 \mathrm{pCi} / \mathrm{L}$ ). Although no significant differences can be seen in the permeability of the soils from north to south across this area, the average equivalent uranium value for soils increases systematically from about $0.5 \mathrm{ppm}$ at the latitude of $T 32 \mathrm{~N}$ to $1.5 \mathrm{ppm}$ at the latitude of T19N. In the other areas (LCR, WRV and MF), higher indoor radon values usually correspond to rapidly permeable soils and higher soil uranium contents. These data suggest that most higher indoor radon levels in the Pacific Northwest are associated with rapidly permeable soils and soil uranium concentrations about $1.5 \mathrm{ppm}$ and above. Overall, however, indoor radon levels in the Pacific Northwest are regionally low compared with other areas under examination in the U.S.

Otton, James K., 1987

Potential for indoor radon hazards: A first geologic estimate, in Radon and the Environment, Conference Proceedings, Mahwah, N.J., May 8-10, 1986, Makofske, William J., and Michael R. Edelstein, eds.:

Mahwah, N.J., Ramapo College of New Jersey, Inst. for Environmental Studies, p. 28-33

Otton, J.K., 1988

Radon potential of rocks and soils: a Fairfax County case history [abs.], in Proceedings of the 1988 Symposium on Radon and Radon Reduction Technology, Denver, Colorado, Oct. 19-22, 1988:

U.S. Environmental Protection Agency, Washington, D.C.

Otton, J.K., 1989

Mapping the radon potential of rocks and soils:

The Professional Geologist, 26(5): 8; also Virginia Minerals, 35(1): 2-3

Otton, J.K., 1989

Using geology to map and understand radon hazards in the United States:

U.S. Geol. Survey Yearbook, Fiscal Year 1988, p. $52-54$

Otton, James K., and Sigrid Asher-Bolinder, 1993

Elevated indoor radon associated with soils developed on Pleistocene limestones in tropical and subtropical latitudes, in The 1993 International Radon Conference, Denver, Colo., Sept. 20-22, 1993:

Denver, Colo., Am. Assoc. Radon Scientists and Technologists, Rocky Mountain Chapter, Preprints, p. IV 32-IV 39

Indoor radon data and geologic, geochemical, and radiochemical studies suggest that substantial quantities of radium have accumulated in soils formed on karstic limestones and related carbonate-rich sediments of various ages in Florida, Guam, and various islands in the Caribbean. These limestones are typically nearshore marine in origin and are elevated relative to sea level. In Florida, indoor radon levels exceeding $1.48 \mathrm{kBq} / \mathrm{m}^{3}$ $(40 \mathrm{pCi} / \mathrm{L})$ and, in Guam, indoor radon levels exceeding $7.4 \mathrm{kBq} / \mathrm{m}^{3}(200 \mathrm{pCi} / \mathrm{L})$ occur in homes built on these soils in spite of climatic, housing, and lifestyle factors that mitigate against high levels. In southeastern Florida, radium concentrations in soils of as much as $418 \mathrm{~Bq} / \mathrm{kg}(11.3 \mathrm{pCi} / \mathrm{g})$ have been measured in soils. The source of the radium in the Florida soils is uncertain; however, clayey, Fe-rich soils with high radium concen! ration ratios have been documented in many islands of the Caribbean and the Florida Keys. A primary component of these latter soils is Saharan airborne dust. We infer that the Florida soils have a similar origin. In Guam, aerosol dust from central Asia and other sources may be the parent material for the clayey, Fe-rich 
soils and inferred high radium concentrations. Elevated indoor radon levels may be expected in housing sited on these soil types on limestone terranes elsewhere at subtropical and tropical latitudes throughout the world where aerosol dust is a significant contributor to soil development.

Otton, James K., and Joseph S. Duval, 1991

Geologic controls on indoor radon in the Pacific Northwest, in The 1990 International Symposium on Radon and Radon Reduction Technology, Atlanta, Ga., 19-23 February 1990:

Research Triangle Park, N.C., U.S. Environmental Protection Agency Rept. EPA600/9-91-026b, Proceedings, Vol. 2: Symposium Oral Papers, Paper No. VI-5, p. 6-51-6-62 [NTIS Order No. PB91-234450/AS]

Comparisons of average indoor radon levels, soil radium content (derived from aerial gamma-ray data), and soil characteristics for selected townships in the Washington, Oregon, and Idaho show that: (1) soil radium content provides a first-order estimate of the relative amounts of indoor radon where soils are either of low to moderate intrinsic permeability or of permeability reduced by high moisture; (2) in drier parts of the study area (east of the Cascade Mountains), unusually high average indoor radon levels are almost all characterized by soils that have high effective permeabilities (greater than 20 inches per hour), based on available county soil descriptions; and (3) in the wetter parts of the study area (west of the Cascade Mountains), townships with unusually high indoor radon levels are characterized by steeply sloped soils.

Otton, James K., and Linda C.S. Gundersen, 1988

Geologic assessments of radon potential at county scales [abs.], in Radon in the Northeast: Perspectives and Geologic Research (conference), Troy and Albany, New York, May 31-June 2, 1988:

Northeastern Environmental Science, 7(1): 7-8

[Assessments of indoor radon potential have been made for Fairfax County, Va. (Otton and others, 1988) and for Montgomery County, Md. (Gundersen and others, 1988) using mainly indirect data, such as aeroradiometric surveys, geologic maps, and soil surveys, and supplementary measurements of radon in soil gas. Maps delineating areas of radon potential in five tiers or three tiers, respectively, have been published and show excellent correspondence between rock and soil types and indoor radon data in both counties.]

Otton, James K., R. Randall Schumann, Douglass E. Owen, and Alan F. Chleborad, 1988

Geological assessments of radon hazards: A Colorado case history [poster abstract], in Marikos, Mark A., and Robert H. Hansman, eds., Geologic Causes of Natural Radionuclide Anomalies, Proceedings of the GEORAD Conference, St. Louis, Mo., April 21-22, 1987:

Rolla, Mo., Missouri Dept. Nat. Resources, Div. Geology and Land Survey Spec. Pub. No. 4, p. 167

A preliminary geologic assessment of radon hazards must often rely on existing data to characterize those geologic features that are likely to influence indoor radon levels indirectly. The features believed to be the most important are the radium content and permeability of the soil and substrate (surficial materials, weathered and unweathered bedrock) at or near the ground surface. Because no databases exist that can provide direct information on the distribution of these features, interpretations of geological, geochemical, and geophysical data form the basis for assessment. These principles are illustrated in a recently compiled preliminary assessment of radon hazards in the State of Colorado. Key databases used include the NURE aeroradiometric flight-line data (most of the State was flown at a 3-mile [5-km] flight-line spacing; several areas were flown at a 1-mile spacing), uranium occurrence compilations (Colorado has been intensively explored for uranium), and soil permeability estimates from Soil Conservation Service mapping (less than half the State is covered but more than $90 \%$ of the State's population lives in the covered areas). IColorado has long been known to have high natural-background radioactivity. Uranium concentrations in soils across the State probably average just below $3 \mathrm{ppm}$, as estimated from examination of NURE flight-line data, so most soils across the State are expected to have $10-20 \mathrm{kBq} / \mathrm{m}^{3}$ (several hundred $\mathrm{pCi} / \mathrm{L}$ ) of radon in the soil gas. Thus, in virtually all areas of the State a significant percentage of homes $(10-30 \%)$ are expected to have elevated $\left(>148 \mathrm{~Bq} / \mathrm{m}^{3}\right.$ or $>4 \mathrm{pCi} / \mathrm{L}$ ) indoor radon levels. The area considered to have the highest risk includes all the Front Range of Colorado, from Pueblo north to the Colorado-Wyoming State line. This area is underlain by granitic, metamorphic, volcanic, and sedimentary rocks, including several moderately (3-6 ppm uranium) to 
highly ( $>6 \mathrm{ppm}$ uranium) uraniferous granites and many smaller uranium occurrences and deposits. Soils over the granites, many metamorphic rocks, and alluvium are typically bighly permeable, and the rocks are, in many areas, highly fractured.

Otton, J.K., R.R. Schumann, D.E. Owen, Nelson Thurman, and J.S. Duval, 1988

Map showing radon potential of rocks and soils in Fairfax County, Virginia:

U.S. Geol. Survey Misc. Field Studies Map MF-2047.

[In addition to the map itself, showing subareas of the county classified according to a five-tiered scale of indoor radon potential, the map sheet contains a detailed explanation of the criteria used and, for each of the subareas, a probability frequency distribution of indoor data obtained by the Fairfax County Health Department.]

Owczarski, P.C., D.J. Holford, H.D. Freeman, and G.W. Gee, 1989

Effect of soil porosity, permeability, and water content on radon flux from soil surfaces [abs.]:

Eos, Am. Geophys. Union Trans., 70(15): 500

A computer code, RN3D", was used to study the effects of varying the water content of five homogeneous soil types (gravel, sand, silt, clay, and loam) on the transport of radon from soil surfaces. Dry soil air permeabilities ranged from $10^{-3}$ to $10^{-9} \mathrm{~m} / \mathrm{s}$. Total porosities ranged from 0.27 to 0.54 . Temperature $\left(20^{\circ} \mathrm{C}\right)$ and radium content were assumed to be the same for all soils. Surface fluxes and concentrations were computed for zero (steady state), steadily increasing and decreasing, and sinusoidal (e.g., diurnal) changes in atmospheric pressure. These pressure changes drive the advective radon transport, which shows a net enhancement for sinusoidal changes. The magnitude of this enhancement for the five soil types was studied by varying the water content from dry to saturated. Water fills soil pores and affects the radon emanation coefficient, air-filled porosity, soil permeability, and ultimately the effective diffusion coefficient of radon. The effective radon diffusion coefficient in $\mathrm{m}^{2} / \mathrm{s}$ varies between $10^{-5}$ times the soil tortuosity at dryness to $10^{-9}$ times the soil tortuosity when water-saturated. Radon flux is affected as much by varying soil water content as it is by varying soil type (i.e., porosity and permeability). ("RN3D is a three-dimensional finite-element code that has been developed by D.J. Holford at New Mexico Tech and the Pacific Northwest Laboratory to simulate the transport of radon gas within and from unsaturated soils with or without parallel, partially penetrating cracks and other heterogeneities.)

Owen, Douglass E., 1989

Characterization of radon: Constraints of scale, Sec. O, in Duray, John R., et al., eds., Proceedings of the Technical Exchange Meeting on Assessing Indoor Radon Health Risks, Grand Junction, Colo., September 1819, 1989:

Grand Junction, Colo., U.S. Dept. Energy, Grand Junction Projects Office, Tech. Measurements Center, Rept. CONF-8909190, 2 p.

The size of the area to be assessed for radon determines the constraints on the techniques to be used and the data that are applicable. Studies of large land areas (small map scales) have by their very nature much less detail, and are therefore less constrained. At these scales many parameters can be generalized, averaged, or interpolated. Conversely, the smaller the land area, or the larger the map scale, the greater the constraints. The greater detail required to adequately characterize a small area necessitates collecting data that are more specific. As one investigates smaller areas or specific processes (even approaching the molecular level) the number and detail of parameters that must be taken into consideration increases, and the task of assessing radon becomes more complicated. TA radon assessment of several counties or a whole State can make used of generalized geologic and soils maps. A radon assessment of a single home site, however, may need new detailed geologic mapping and soils investigations. For example, Gundersen (1989 ["Anomalously high radon..."]) has shown that localized shearing in rocks can mobilize and concentrate uranium, producing elevated radon levels. Localization may be such that houses next to each other have order-of-magnitude differences in their indoor radon levels. Most areas the country do not have detailed enough geologic mapping to delineate such shear zones. IFor information on regional permeability, Soil Conservation Service (SCS) maps 
are adequate. However, there is too much variability in soils to reliably use SCS soil maps to characterize the soil at a single home site, and soil profiles and soil characteristics will need to be determined specifically for that site. TAerial radiometric data may or may not be suitable for use in radon assessments, depending upon the scale of the assessment. Most of the aerial radiometric surveys available for the U.S. were flown during the National Uranium Resource Evaluation (NURE) program. The NURE surveys were generally flown at a height of $125 \mathrm{~m}$ above the ground, with a spacing of 5 or $10 \mathrm{~km}$ between flight lines. The radius of investigation is two times the height, yielding actual ground coverages of $10 \%$ and $6 \%$, respectively. At a small map scale, e.g., 1:250 000, this is probably adequate, but for large map scale studies the chance is remote that a flight line passed directly over the site that is to be characterized. A limitation of both ground and aerial $\gamma$-ray surveys, in certain cases, is that approximately $90 \%$ of the measured $\gamma$-ray signal originates within $30 \mathrm{~cm}$ of the surface of the ground. Therefore, in areas where radionuclides in the soil may have been leached from near the surface and redeposited below $30 \mathrm{~cm}$, the $\gamma$-ray survey will give a low reading. The soil zone below $30 \mathrm{~cm}$, however, is still within radon migration range of a home [with a basement-ABT]. Gamma-ray surveys also assume secular equilibrium between uranium [or radium] and its various daughters in the soil, which is not always a valid assumption and could result in an over- or underestimate of actual near-surface uranium content in some cases. TThe following is a list of characterization scales (after Schumann) demonstrating the effect of scale on characterization methodology. Ideally, in order to properly characterize an area, something must also be known about the processes involved and the geologic and soil characteristics from two steps lower on the list. For example, in characterizing a State (1) for radon potential, information on a county scale (2) and small-scale bedrock and SCS soil maps (3) must be used. Characterization scales: (1) Region/State; (2) County(ies)/township(s); (3) Bedrock/soil units; (4) Single building site and (a) house construction characteristics; (5) Macroscopic soil properties, (a) soil profiles, (b) permeability, and (c) meteorologic effects; (6) Molecular-scale properties of soil particles and radon, (a) location of radium, and (b) radon emanation [emanating power].

Owen, Douglass E., Sigrid Asher-Bolinder, and R. Randall Schumann, 1988

Assessment of natural phenomena producing fluctuations and variations in soil-gas radon-222 concentrations [abs.]:

Geol. Soc. America, Abstracts with Programs, 20(7): A354

Although a correlation between soil-gas radon-222 concentrations and local geologic-pedologic setting has been identified and documented by several researchers, less is known quantitatively about the influence of climatic and meteorological phenomena on soil-gas radon concentrations. Assuming that over a year the geology and soil characteristics remained essentially constant, we selected and monitored a single site on the Denver Federal Center, Colorado, near a weather station from which hourly meteorological data were acquired. The site is little disturbed, unwatered [unirrigated], and mowed only twice a year, and thus favors the investigation of natural phenomena. Soil moisture conditions caused by precipitation and evaporation have a profound effect on soil-gas radon concentrations. Addition of soil moisture changes the effective gas permeability of the soil by occupying pore space and causing the swelling of expandable clays. Moisture-saturated layers also can produce capping effects. At the site, the larger seasonal variations in soil-gas radon concentrations are attributed mostly to changes in the soil moisture regime. The day-to-day smaller-scale fluctuations in soil-gas radon concentrations are attributed to changes in barometric pressure, soil and air temperature, soil moisture, and wind. Interrelation of these factors makes it difficult to determine the magnitude and individual influence of any one factor. Through an understanding of the geology and pedology of a site and of their interaction with climatic and meteorologic parameters, it may become possible to make predictions about ranges of radon222 concentrations that can be expected during the course of a year.

Padovani, Renato, and Maria Rosa Malisan, 1993

Assessment of radon exposure in kindergartens in north-east Italy [abs.], in First International Workshop on Indoor Radon Remedial Action, The Scientific Basis and Practical Applications, Rimini, Italy, 27 June-2 July 1993:

Commission of the European Communities et al., Book of Abstracts, p. 105 
A regional survey of indoor radon in family dwellings, conducted in the years 1989-1990 in the Region FriuliVenezia Giulia (NE Italy) as part of the Italian national survey, evidenced a mean annual radon concentration of $96 \mathrm{~Bq} / \mathrm{m}^{3}$, with $5 \%$ of houses having values $>400 \mathrm{~Bq} / \mathrm{m}^{3}$, the CEC reference level for consideration of remedial actions. In order to get a more complete picture of public exposure to natural radiation, the local laboratory of the national Environmental Radioactivity Monitoring Network promoted in 1992 a radon survey in kindergartens. One third of these schools were randomly selected and monitored, one classroom per school, for five months by means of radon alpha-track detectors. Preliminary results, concerning more than 160 classrooms, show that radon concentrations in kindergartens are generally higher than in family dwellings of the region, probably due to the prevailing building structure. Data on the building features and occupancy patterns are presented and discussed. The geographical distribution of measurements is analyzed and compared with soil characteristics of the region. Finally radon exposures for teachers and pupils are estimated.

Paschoa, A.S., M.E. Wrenn, and J.A. Torrey, 1984

A mathematical model of indoor radon and daughters:

Radiation Protection Dosimetry, 7(1-4): 139-142

A mathematical model associated with computer codes is useful for predicting indoor radon and its progeny concentrations at steady state as a function of ventilation rate, outdoor radon concentrations, and radon source strength associated with soils and building materials (i.e., wall, soil, and double-media source).

Peake, R. Thomas, 1988

An update on EPA radon geology activities [abs.], in Radon in the Northeast: Perspectives and Geologic Research (conference), Troy and Albany, New York, May 31-June 2, 1988:

Northeastern Environmental Science, 7(1): 8

[The U.S. Environmental Protection Agency's radon program includes characterization of soils at sites of indoor measurements in the State/EPA radon surveys of 1986-1987 and 1987-1988, a national radon potential map, radon potential maps of EPA Regions 3 and 4, a reprocessing of the NURE aeroradioactivity data (by U.S. Geological Survey), soil-gas radon and permeability measurements, and assessing the feasibility of land evaluation criteria.]

Peake, R.T., 1988

Radon and geology in the United States:

Radiation Protection Dosimetry, 24(1/4): 173-178

Peake, R. Thomas, 1988

Radon entry efficiency: A new look at radon entry into homes [abs.], in Radon in the Northeast: Perspectives and Geologic Research (conference), Troy and Albany, New York, May 31-June 2, 1988:

Northeastern Environmental Science, 7(1): 8

[A radon entry efficiency (REE) parameter is proposed; $R E E=100$ \{Closed-house, lowest-level, winter radon concentration $\} /\{$ Radon concentration in soil gas at $1 \mathrm{~m}$ depth, 3-5 $\mathrm{m}$ from house $\}$. Typical REEs for hones with basements are expected to be $\approx 0.3 \%-0.7 \%$; slab-on-grade houses are expected to have lower value : id houses with dirt basements or on very permeable soils or rocks are expected to have higher REEs.]

Peake, R. Thomas, 1990

Preiminary identification of high radon potential areas in twenty-five States [abs.], in The 1990 International Symposium on Radon and Radon Reduction Technology, Atlanta, Ga., 19-23 February 1990:

Preprints, Vol. III, no. C-VI-1

A preliminary radon potential map of 25 States has been prepared showing areas of high radon potential. The data used to create this map include: 1) National Uranium Resource Evaluation (NURE) aerial radiometric data. NURE data in glaciated and non-glaciated areas have to be interpreted differently because the properties of the surficial material can be as important as the radium concentration. 2) State/EPA Indoor Radon Survey data. Indoor radon data for 25 States have been analyzed by house construction by county and regionally. 
IBoth sets of data have been compared with geology to produce a county scale map. Areas of high radon potential include, but are not limited to, the Upper Midwest, the Rocky Mountain region, and parts of the Appalachian Mountains. This map will be used in EPA's efforts to identify and characterize high radon potential areas for school and workplace surveys, and for building code development.

Peake, R. Thomas, and L.C.S. Gundersen, 1989

An assessment of the radon potential of the U.S. Coastal Plain [abs.]:

Geol. Soc. America, Northeastern Section, Abstracts with Programs, 21(2): 58

Radon data collected during recent indoor radon surveys and data obtained from commercial radon measurement companies have produced indoor radon data which can be compared with geology in the U.S. Coastal Plain. Survey data are available for Tennessee, Alabama, New Jersey, and Florida. Indoor radon data from several radon testing companies for other Coastal Plain States are also available to the Environmental Protection Agency. We estimate that the screening indoor radon average in the Coastal Plain is approximately $0.9 \mathrm{pC} / \mathrm{L}$ and that less than $10 \%$ of the homes will have screening radon concentrations above $148 \mathrm{~Bq} / \mathrm{m}^{3}$ $(4 \mathrm{pCi} / \mathrm{L})$. These values may be higher in the Mid-Atlantic Coastal Plain, and slightly lower in the Southern Coastal Plain. Even though the Coastal Plain region may have low radon potential, there are areas in the Coastal Plain in which as many as $30 \%$ of the homes contain or may contain screening radon concentrations greater than $148 \mathrm{~Bq} / \mathrm{m}^{3}(4 \mathrm{pCi} / \mathrm{L})$. The homes with the highest indoor radon concentrations in the Coastal Plain are likely to be sited on phosphatic or glauconitic lithologies or on Cretaceous chalks and carbonaceous shales. House construction can influence radon screening measurements and is a critical component of our analysis. The concept of integrated radon potential (IRP) may be a useful method for factoring in the house construction component.

Peake, R. Thomas, Linda C.S. Gundersen, R. Randall Schumann, Julie James, and Melinda Ronca-Battista, 1991 Determination of radon-geologic provinces in the United States, in The 1990 International Symposium on Radon and Radon Reduction Technology, Atlanta, Ga., 19-23 February 1990:

Research Triangle Park, N.C., U.S. Environmental Protection Agency Rept. EPA600/9-91-026c, Proceedings, Vol. 3: Symposium Poster Papers, Paper No. C-VI-1, p. 6-1-6-12 [NTIS Order No. PB91-234468/AS]

A preliminary "radon-geologic province" map for the United States was prepared using indoor radon data from the 25 States surveyed with the assistance of EPA and available geologic data for the United States. This map will be used as a starting point for future assessment of high radon potential areas in the United States. Sixteen radon-geologic provinces have been identified and evaluated. The provinces with the highest radon potential in the country include the Northeast, Appalachian Mountains, northern and central Great Plains, and Colorado Plateau, but all provinces have the potential to generate indoor radon levels $\geq 148 \mathrm{~Bq} / \mathrm{m}^{3}(\geq 4 \mathrm{pCi} / \mathrm{L})$. This is a preliminary map, should be viewed as draft, and is subject to change. [See Gundersen et al., 1991, Preliminary radon potential map of the United States.]

Peake, R.T., L.C.S. Gundersen, and C.R. Wiggs, 1988

The Coastal Plain of the eastern and southern United States-An area of low radon potential [abs.]:

Geol. Soc. America, Abstracts with Programs, 20(7): A337

Six important parameters: geology, radon in soil gas, indoor radon, equivalent uranium, permeability, and housing construction all indicate that the Coastal Plain from New Jersey to Texas is an area of low radon potential. In general, the data suggest that the Inner Coastal Plain (mainly Cretaceous and Tertiary sediments) is slightly higher in radon potential than the Outer Coastal Plain (Eocene sediments). Grab samples of radon in soil gas measured at $1-\mathrm{m}$ depth averaged between $26-37 \mathrm{kBq} / \mathrm{m}^{3}(700-1000 \mathrm{pCi} / \mathrm{L})$. Data from the joint State/Environmental Protection Agency Indoor Radon Surveys (winter 1986-1987) show a median concentration for the Alabama Coastal Plain of 22 to 26 (average 33 ) $\mathrm{Bq} / \mathrm{m}^{3}$ or 0.6 to 0.7 (average 0.9 ) $\mathrm{pCi} / \mathrm{L}$. Other data sets for New Jersey, Tennessee, and Florida are similar. In Tennessee, the geometric mean (GM) for indoor radon is 30 (average 4) $\mathrm{Bq} / \mathrm{m}^{3}$ or 0.8 (average 1) $\mathrm{pCi} / \mathrm{L}$. The New Jersey Outer Coastal Plain has a GM for indoor radon of 44 (average 67 ) Bq/ $\mathrm{m}^{3}$ or 1.2 (average 1.8) pCi/L and the Inner Coastal Plain has a GM for indoor radon of 52 (average 93) or 1.4 (average 2.5 ) pCi/L. The GM for indoor radon in Florida 
is $44 \mathrm{~Bq} / \mathrm{m}^{3}(1.2 \mathrm{pCi} / \mathrm{L})$. Aeroradiometric data from the National Uranium Resource Evaluation Program show that equivalent uranium signatures for most of the Eocene sediments are typically $1.5 \mathrm{ppm}$. Higher values are found in Tertiary phosphorites (varying between 1 and $8 \mathrm{ppm}$ ) and Cretaceous chalk units (averaging $3 \mathrm{ppm})$. Soils overlying Cretaceous chalks yield radon concentrations up to $185 \mathrm{kBq} / \mathrm{m}^{3}(5000 \mathrm{pCi} / \mathrm{L})$, but their permeability is low. [Water] permeability of the Coastal Plain as a whole is in the 0.6-to-2 inches/hour range (considered moderate). A final and vital factor in the understanding of radon potential is the common construction practice of slab-on-grade buildings in the Coastal Plain. The absence of a basement significantly reduces the amount of radon that may enter a home and may be one of the most important factors to consider in radon potential assessments.

Peake, R. Thomas, and Susan M. Rush, 1988

An initial identification of areas with a potential for high indoor radon levels [poster abs.], in Marikos, Mark A., and Robert H. Hansman, eds., Geologic Causes of Natural Radionuclide Anomalies, Proceedings of the GEORAD Conference, St. Louis, Mo., April 21-22, 1987:

Rolla, Mo., Missouri Dept. Nat. Resources, Div. Geology and Land Survey Spec. Pub. No. 4, p. 173

To help assess the distribution of areas in the United States that might have elevated indoor radon levels, the Environmental Protection Agency (EPA) has prepared national maps delineating areas that appear to have the greatest potential to cause indoor radon problems. These maps are based on uranium concentrations in rock or soil in lieu of actual data on indoor radon levels, which are available for only certain areas of the country. ISwedish researchers have shown rough correlations of indoor radon concentrations with the uranium content of soils and rock around Swedish houses. In the United States, it appears that extremely elevated indoor radon levels are also associated with elevated uranium concentrations in the rock and soil near affected houses; therefore, a map based on rock and soil uranium content might approximate those areas that may have radon problems. Such a map would not be conclusive, however, because other factors such as soil permeability and building characteristics also influence radon concentrations in structures. In general, the rock types most likely to contain above-average concentrations of uranium, and which may suggest potential radon problems, include some granitic rocks, black shales, phosphatic rocks, and some sedimentary rocks adjacent to or derived from niferous source rocks. The EPA's composite map includes most of these rock types; it also includes uran 2 -resource information from the Nationai Uranium Resource Evaluation (NURE) database and adapted to be more applicable to indoor radon concerns. The EPA maps, however, cannot be used as the sole source for predicting elevated radon levels. Instead, it is necessary to use the information from these maps in conjunction with data on other factors (e.g., soil type, soil permeability, and housing characteristics) to predict local radon levels. Furthermore, the predictions on these maps have not yet been confirmed by actual measurements. The EPA plans to continue to develop and refine the maps as additional information becomes available.

Peake, R. Thomas, and R. Randall Schumann, 1991

Regional radon characterizations, in Gundersen, Linda C.S., and Richard B. Wanty, eds., Field studies of radon in rocks, soils, and water:

U.S. Geol. Survey Bulletin no. 1971, p. 163-175

Indoor radon is a potential health threat in a significant number of homes across the United States. Twenty-one percent of the homes tested in the 1986-87 Environmental Protection Agency/State Indoor Radon Survey of 10 States contained screening indoor radon levels greater than the Environmental Protection Agency's recommended action level of 4 picocuries per liter. However, the distribution of indoor radon screening levels, and, therefore, the potential health risk, is not uniform everywhere. These differences are related to geology and house construction. Characterizations of radon potential can be made by use of geologic, soil, and radiometric data. National Uranium Resource Evaluation equivalent uranium concentrations of 2.0 parts per million or greater indicate areas that have the potential to produce a substantial number of elevated indoor radon levels. Equivalent uranium concentrations less than 1 part per million may indicate low radon potential. Soil permeability greater than 6.0 inches per hour may increase the radon potential of an area, except in cases where soil radium concentrations are very low. 
Pearson, John E., and Gary E. Jones, 1976

Emanation of radon-222 from soils and its use as a tracer:

Jour. Geophys. Research, 70(20): 5279-5290

The temporal, geophysical, and geographical parameters related to the emanation of $\mathrm{Rn}-222$ at the earth-atmosphere interface have been studied. Such information is necessary in the evaluation of boundary conditions for an investigation of the vertical diffusivity of the atmosphere if natural $R n-222$ is to be used as a tracer. A system for collecting Rn-222 emanating at the surface of the earth with a minimum of disturbance to the site has been developed. It includes a stainless-steel collector, open on the bottom where it is in contact with the soil; a pump; water and carbon dioxide traps; and chilled traps in which the radon is adsorbed on activated coconut charcoal. Sampling patterns in east-central Illinois were selected using a randomized complete block design to permit statistical analysis of emanation data with respect to location, soil type, meteorological conditions, and other parameters. Although no statistically significant variation of $\mathrm{Rn}-222$ emanation with location or soil type was found, a variation with wind speed, gustiness, and soil moisture was observed. Criteria for the selection of locations suitable for vertical diffusivity studies using Rn-222 as a naturally occurring tracer should include, ideally, uniform emanation for tens of kilometers in all directions, substantially level topography, and uniform vegetative cover. The location chosen for these studies meets these criteria.

Pearson, John E., Donald H. Rimbey, and Gary E. Jones, 1965

A soil-gas emanation measurement system used for radon-222:

Jour. Appl. Meteorology, 4(3): 349-356

["Emanation" in this paper refers to the exhalation of ${ }^{222} \mathrm{Rn}$ from the earth to the atmosphere. The system comprised a separate motor-alternator, a separate collector (a metal box $2.5 \mathrm{~cm}$ high, presenting a rectangular opening $\approx 30.5 \times 7.6 \mathrm{~cm}$, pressed to the ground surface with a seal of caulking material), and a portable box containing the remaining pump, traps, and a flow meter. Air was pumped through a closed loop from the collector through water and $\mathrm{CO}_{2}$ absorbers; through the pump, controlled by a bypass valve; through tandem water traps cooled by solid $\mathrm{CO}_{2}$ shavings; through a valve that routed flow to one of two charcoal traps at solid $\mathrm{CO}_{2}$ temperature; through a flow meter; and thence back to the collector. One of the charcoal traps was used to trap radon until equilibrium was established in the system; the air stream was diverted to the other, "sample" trap during the sampling period (usually $300 \mathrm{~s}$ ) only. A series of experiments showed that the exhalation rate was directly proportional to the speed of the air stream through the collector in the range $\approx 0.8$ to $8 \mathrm{~m} / \mathrm{s}$. At the average height of the collector, $1.25 \mathrm{~cm}$, the normal range of wind speed at the study locality was only 0.03 to $0.08 \mathrm{~m} / \mathrm{s}$, and the mean exhalation rate at $0.045 \mathrm{~m} / \mathrm{s}$ was 7 times greater than that obtained by extrapolation of the linear relation found by experiment. The mean of 216 measurements of exhalation rate from 9 sites on agricultural soils in Champaign County, Illinois, was $52 \pm 27 \mathrm{mBq} / \mathrm{m}^{2}$. Measurements at the same site in Socorro, New Mexico, as reported by Wilkening and Hand (1960), were in good agreement at $\approx 38 \mathrm{mBq} / \mathrm{m}^{2}$. The mean of 8 measurements made on 26 August 1963 exceeded the mean of 8 measurements made at the same site on 21 November by a factor of nearly 3. During a 24 hour period measurements were made at $15-$ min intervals on a $3 \times 12 \mathrm{~m}$ grass-covered plot of well-drained loess (wind-deposited soil) $1 \mathrm{~m}$ deep on glacial till. Soil porosity, air void fraction, and moisture; wind speed and direction; air temperature and humidity; cloudiness; and barometric pressure were noted hourly. Exhalation was most stable and averaged lowest during the night hours.]

PEI Associates, Inc., and Rogers and Associates Engineering Corporation, 1986

Draft project report. Comparison of existing measurement methods for radon in soil gas:

Cincinnati, Ohio, PEI Associates, Inc., and Salt Lake City, Utah, Rogers and Associates Engineering Corp., 58 p.

Phillips, Jeffrey L., Jane Bergsten, and S.B. White, 1991

A cumulative examination of the State/EPA Radon Survey, in The 1991 International Symposium on Radon and Radon Reduction Technology, Philadelphia, Pa., 2-5 April 1991:

Preprints, unnumbered, $17 \mathrm{p}$. 
Podsednik, Mary L., 1991

Geologic assessment of radon-222 in McLennan County, Texas, in The 1991 International Symposium on Radon and Radon Reduction Technology, Philadelphia, Pa., April 2-5, 1991, Proc., Volume 4, Symposium Poster Papers, Technical Sessions 6 through 10:

U.S. Environmental Protection Agency Rept. EPA/600/9-91/037D, p. P9-45-P9-58

McLean, Va., Cohen (S.) and Associates, Inc. [Springfield, Va., NTIS Order No. PB92-115385]

[Preprints, v. 5, no. IXP-4]

Geologic parameters controlling the distribution and transport of radon were evaluated in McLennan County, Texas. Laboratory analysis of selected rock samples identified phosphate zones in the Austin formation and shales and bentonites in the Lake Waco formation as probable source rocks. Geophysical logging techniques utilizing gamma-ray logs were supplemental in identifying the Lake Waco formation as a source rock based on relative radioactivity among selected geologic formations. Emanation of radon from representative soil types was evaluated by using large area activated charcoal canisters. The Houston and Houston Black Clay soils had the greatest radon flux concentrations potentially resulting from increased surface area and more efficient transport of radon through desiccation cracks typical of these soils. Analysis of groundwater indicated that radon concentrations were greatest in the Austin formation, particularly when samples were collected after rainfall events. Radon concentrations were shown to be greatly increased in wells located near stream discharge points, owing to a flushing of the aquifer flow system, including the unsaturated zone, during periods of infiltration. Elevated indoor radon concentrations were found to be most commonly associated with homes overlying the Austin formation, which has been identified as a source rock and is characterized by high shrinkswell soils, abundant faulting and fracturing, and foundation failure caused by the high shrink-swell soils. These characteristics allow for the production of radon and efficient transport from the subsurface to the indoor environment.

Poffijn, A., G. Eggermont, S. Hallez, and P. Cohilis, 1993

Radon in Belgium: Mapping and mitigation in the affected area of Vise [abs.], in First International Workshop on Indoor Radon Remedial Action, The Scientific Basis and Practical Applications, Rimini, Italy, 27 June-2 July 1993:

Commission of the European Communities et al., Book of Abstracts, p. 31

The massif of Visé is well known by geologists for its special geological features, in particular the great abundance $(\mathrm{N}>30)$ of important uranium anomalies. The measuring campaigns conducted over the last years in several hundred houses resulted in a detailed radon map with clear indication of risk areas. Based upon the available information some 160 houses (2\% of the building stock) are expected to have real radon problems $\left(>400 \mathrm{~Bq} / \mathrm{m}^{3}\right)$. Up to now 24 of these problem houses have been localized. Three of the most contaminated houses ( $>3000 \mathrm{~Bq} / \mathrm{m}^{3}$ in the living areas) have been studied in detail for mitigation purposes. In two of them a subfloor ventilation has been installed. In this way the original high levels were reduced by more than a factor of ten.

Porstendörfer, J., 1987

Indoor radon exposure in the Federal Republic of Germany, in Indoor Radon II, Proceedings of the Second APCA International Specialty Conference, Cherry Hill, New Jersey, April 6-10, 1987:

Pittsburgh, Pa., Air Pollution Control Association Pub. SP-60, p. 57-67

[The nationwide survey of indoor radon in the Federal Republic of Germany comprised 20,000 measurements in 6,000 houses, and yielded a log-normal distribution with an arithmetic mean of $\approx 14 \mathrm{~Bq} / \mathrm{m}^{3}$, a median (geometric mean) of $\approx 40 \mathrm{~Bq} / \mathrm{m}^{3}$ and geometric standard deviation of 1.8. Significantly higher mean radon concentrations of 57 and $46 \mathrm{~Bq} / \mathrm{m}^{3}$ were associated with The Rheinland-Pfalz area and in Bavaria, respectively, and were attributed mainly to their geological characteristics.]

Raes, F., A. Poffijn, and G. Eggermont, 1988

The feasibility of using expert systems to cope with the complexity and extent of the indoor radon problem:

Radiation Protection Dosimetry, 24(1/4): 167-172 
[Radon potential methods based on maps are of too coarse a scale for indoor radon prediction at a single site. An alternative method for site characterization is proposed, based on a systematic interview with inhabitants of existing houses. The questions posed in the interview are designed to lead to an assessment of critical factors such as the mean indoor-outdoor temperature difference, quality of the foundation, water-table depth, air exchange rate, soil permeability, and underpressure due to mechanical ventilation.]

Ranger, L. Scott, 1993

Geologic control of radon in the greater Atlanta region, Georgia, in The 1993 International Radon Conference, Denver, Colo., Sept. 20-22, 1993:

Denver, Colo., Am. Assoc. Radon Scientists and Technologists, Rocky Mountain Chapter, Preprints, p. IVP 2-IVP 11

1,908 indoor radon screening tests are plotted by geologic formation. Each is presented with average, range and house construction type. For the region, $7.6 \%$ of homes measure $148 \mathrm{~Bq} / \mathrm{m}^{3}(4.0 \mathrm{pCi} / \mathrm{L})$ or greater with an average of $63 \mathrm{~Bq} / \mathrm{m}^{3}(1.7 \mathrm{pCi} / \mathrm{L})$ for all construction types and $81 \mathrm{~Bq} / \mathrm{m}^{3}(2.2 \mathrm{pCi} / \mathrm{L})$ for basement houses. The range is $0-940 \mathrm{~Bq} / \mathrm{m}^{3}(0.0-25.4) \mathrm{pCi} / \mathrm{L}$. Radon levels are lowest in the Upper Coastal Plain unconsolidated sands and the Piedmont metamorphic rock of basic (mafic) chemistry. Highest levels are found in acidic rock as granites, schists, and mylonites, particularly in areas of ductile shearing. This paper presents radon measurements in the most meaningful manner, by geologic formation. Radon does not recognize zip codes and political boundaries, yet many decisions use these criteria. Geologic precision allows for a greater understanding of radon potentia. This paper illuminates the possibility for more accurate potential maps based upon geology.

Rector, Harry E., 1991

Soil gas measurement technologies, in The 1991 International Symposium on Radon and Radon Reduction Technology, Philadelphia, Pa., April 2-5, 1991, Proc., Volume 1, Symposium Oral Papers, Opening Session and Technical Sessions 1 through 5:

U.S. Environmental Protection Agency Rept. EPA/600/9-91/037A, p. 3-13-3-28

McLean, Va., Cohen (S.) and Associates, Inc. [Springfield, Va., NTIS Order No. PB92-115351]

[Preprints, v. 2, no. III-3]

A wide range of methods for characterizing the radon potential of land areas has evolved over the last decade through research programs in the U.S.A. and abroad. Ideally, the methods should provide information on radon production in the soil, diffusivity, and permeability. This can be accomplished through various combinations of direct measurements and theoretical assumptions. Basic technologies concentrate on measuring: (1) radon in soil gas, (2) radon flux from the surface, or (3) radium content of the soil. Approaches may also include attendant measures of soil characteristics and other factors to support predefined indexes of radon potential. Basic measurement approaches for radon potential are reviewed in terms of the following technical issues: measurement parameters, field/laboratory methods, quality assurance, and model concepts applied to data to estimate radon potential. Theoretical aspects of these factors are also considered. Radiumbased measurements, for example, have the distinct advantage of being suited to testing water-saturated soils, but may take weeks to deliver results. Soil gas and flux measurements, on the other hand, generally fail to obtain samples from saturated soils because the gas volume is nearly zero, but approaches exist to deliver prompt results on site. If time is important, recognition factors to avoid generally saturated conditions are necessary to ensure sample validity.

\section{Reesman, A.L., 1988}

Geomorphic and geochemical enhancement of radon emission in middle Tennessee, in Marikos, Mark A., and Robert H. Hansman, eds., Geologic Causes of Natural Radionuclide Anomalies, Proceedings of the GEORAD Conference, St. Louis, Mo., April 21-22, 1987:

Rolla, Mo., Missouri Dept. Nat. Resources, Div. Geology and Land Survey Spec. Pub. No. 4, p. 119-130

A special stratigraphic sequence, involving the uranium-rich [30-40 ppm] Chattanooga shale and underlying phosphatic limestones..., combined with a sloping topography...provides a physical setting for subsequent 
chemical mobilization, reprecipitation, and enrichment of uranium and its alpha-emitting daughters as secondary phosphates, near the base of a relatively thin cover of residuum-colluvium. Secondary enrichment of uraniferous phosphate would occur on the surface of pre-existing grains. Subsequent daughter recoil from alpha decay would likely deposit the daughter near the surface and favor enrichment of the mineral surfaces with the daughter also, as both thorium-230 and radium-226 are compatible with phosphate minerals. Thus, radium-226 should become relatively enriched on mineral surfaces, and thereby increase the probability that its daughter, radon, will be emitted into the soil atmosphere. Although the Chattanooga shale contains higher concentrations of uranium than the phosphatic limestones, its asphaltic organic matter seals in the radon to produce a relatively closed system. During weathering, oxidation of pyrite in the shale produces acidic leachates that can dissolve $\mathrm{UO}_{2}$ and oxidize it to uranyl complexes, which can precipitate on residual phosphate grains accumulated form weathering of the underlying phosphatic limestones. Thus, uranium dissolved from either the Chattanooga or residual phosphate during weathering can be enriched downslope in the residuum. Mass movement aids downslope transport and tends to bring the uranium-enriched material toward the surface for renewed weathering. If uranium and its daughters, thorium[-230] and radium, follow phosphate through the weathering cycle, processes that enrich the phosphatic residuum to commercial-grade phosphate deposits would also enrich uranium and its daughters, thereby increasing the potential for radon emission. In cities where homes are confined to small lots, hilly topography favored foundations with piers that later evolved to partial basements when coal-fired, central heating developed. These older style homes should be especially vulnerable to radon capture.

Reimer, G.M., 1988

An integrated approach to assess potential radon content of soils using geologic, gamma-ray and soil-gas data [abs.]:

Geol. Soc. America, Abstracts with Programs, 20(7): A354

Various singular techniques of evaluating the radon potential of geographic areas have been used but data from field studies suggest that an integrated approach may give more reliable estimates. Many techniques are indirect in that they do not actually measure the in-situ radon concentration. For example, knowledge of geologic lithologies provides estimates of the uranium concentration; spectral gamma-ray measurements typically analyze for $\mathrm{Bi}-214$, a daughter of radon-222, in the upper portion of the surface. Even direct measurement of soil-gas radon has limitations because of diurnal, seasonal, and permeability effects. Gammaray and geologic data may be known for many areas, although their integration may be hampered by having different scales or degrees of resolution, but it is very unlikely that a soil-gas radon data base exists. Field studies must include the collection and analysis of soil-gas radon at a scale determined to be compatible with the overall resolution required. Results from Frederick County, Maryland show how data from different scales are combined and interpreted. Soil development in some areas created low uranium or radium concentrations in the upper soil horizon giving a lower gamma-ray reading than would be anticipated for the known lithology. Radon concentrations in regions that are structurally complex can be higher than from similar but undisturbed lithology. Interpretation of the combined data provides the most accurate estimates of radon potential and compares well with known indoor radon concentrations.

Reimer, G.M., 1988

Radon soil-gas survey in Prince Georges County, Maryland:

U.S. Geol. Survey Open-file Rept. 88-52, 10 p.

Soil-gas samples collected along a traverse in Prince Georges County, Maryland were analyzed for radon. The traverse included principal lithologies and areas for which aeroradiometric measurements showed various intensities. Although, in the past, this region in the Coastal Plain province had not been considered to possess the type of geologic setting or aeroradiometric signature that would contribute to significant indoor accumulations of radon, the measured soil-gas concentrations of up to $93 \mathrm{kBq} / \mathrm{m}^{3}(2500 \mathrm{pCi} / \mathrm{L})$ indicate that the potential exists for indoor accumulations in excess of the $148-\mathrm{Bq} / \mathrm{m}^{3}(4 \mathrm{pCi} / \mathrm{L})$ [action] level established by the U.S. Environmental Protection Agency. The higher levels of soil-gas radon were found in some of the Tertiary sediments with the lower concentrations in the Cretaceous and Quaternary sediments. Geologic 
relationships are thought to be the controlling factors for the radon soil-gas concentrations. Although very few indoor radon data are available for Prince Georges County, they, too, indicate levels exceeding the $148-\mathrm{Bq} / \mathrm{m}^{3}$ $(4-\mathrm{pCi} / \mathrm{L})$ guideline in areas underlain by some Tertiary formations but less for the Cretaceous and Quaternary formations.

Reimer, G.M., 1990

Reconnaissance techniques for determining soil-gas radon concentrations: An example from Prince Georges County, Maryland:

Geophys. Research Letters, 17(6): 809-812

Preliminary field measurements of soil-gas radon ( $R n)$ concentrations can provide an intitial assessment of the $\mathrm{Rn}$ potential in any location and aid in designing a larger or more detailed sampling program. Radon reconnaissance requires some special considerations because a large area must be covered in a short period of time and analyses must be made soon after collection because of Rn decay. A simple approach to collection and field analysis consists of a small-diameter probe pounded into the ground to a depth of at least $0.75 \mathrm{~m}$. Analysis is by an alpha scintillometer. Soil-gas samples collected along a traverse in Prince Georges County, Maryland, demonstrate the utility of the technique. Although this region in the Coastal Plain province might be considered to possess the type of geologic setting that would not contribute to significant Rn potential, the reconnaissance sampling revealed $\mathrm{Rn}$ soil-gas concentrations of up to $93 \mathrm{kBq} / \mathrm{m}^{3}(2500 \mathrm{pCi} / \mathrm{L})$, indicating that the potential exists for indoor accumulations in excess of $148 \mathrm{~Bq} / \mathrm{m}^{3}(4 \mathrm{pCi} / \mathrm{L})$.

Reimer, G.M., 1991

Derivation of radon migration rates in the surficial environment by use of helium injection experiments, in Gundersen, Linda C.S., and Richard B. Wanty, eds., Field studies of radon in rocks, soils, and water:

U.S. Geol. Survey Bulletin no. 1971, p. 33-38

Helium injection into the subsurface provides a means of determining the rate of radon migration in a particular area. The passage of a concentration front is monitored at outlying stations, and an effective diffusion coefficient can be determined. From experiments in a portion of the Reading Prong near Boyertown, Pa., it is possible to explain the observations with a model in which diffusion is the primary transport mechanism, and convective mass transport is influential. This technique permits determination of both horizontal and vertical migration components. The rate of migration is highly variable from area to area, but measurements can set realistic limits on models being developed for assessing the potential for radon accumulation in dwellings.

Reimer, G.M., 1991

Simple techniques for soil-gas and water sampling for radon analysis, in Gundersen, Linda C.S., and Richard B.

Wanty, eds., Field studies of radon in rocks, soils, and water:

U.S. Geol. Survey Bulletin no. 1971, p. 19-22

Various devices and techniques are available for sampling soil air and ground water for analysis of their gas content. A simple approach to collection is presented here and can be useful as a screening technique for radon when analyses are desired at the field location. For soil-gas samples, a small-diameter probe is pounded into the ground to a depth of at least 0.75 meter. For water, a plastic bottle containing the sample is shaken so headspace air purges the gases from the water. Once the gas samples are extracted from the soil or water, they can be analyzed with whatever field technique is desired.

\section{Reimer, G.M., 1992}

Methodology for rapid assessment of the radon potential of soils:

Jour. Radioanalyt. Nuclear Chemistry, Articles, 161(2): 377-387

A technique using a small-diameter probe and a portable alpha-particle scintillometer for sample collection and analysis has been developed. It is fast, efficient, cost effective, and can be modified to accommodate a wide spectrum of sampling conditions. When soil-gas sampling for radon is combined with geophysical gamma-ray measurements, pedological characteristics of surficial materials, and geologic knowledge of bedrock, the combination forms a powerful technological basis for estimating radon potential of soils. The method can help 
provide information on a short time frame so that local governments, land developers, and builders can take appropriate measures when planning new construction.

Reimer, G.M., J.M. Been, and S.L. Szarzi, 1989

Technique for rapid field assessment of radon soil-gas concentrations, in Osborne, M.C., and Jed Harrison, Symposium Cochairmen, The 1988 Symposium on Radon and Radon Reduction Technology, Proc., Vol. 2, Symposium Poster Papers:

Research Triangle Park, N.C., Radian Corp., U.S. Environmental Protection Agency Pub. EPA/600/9- 89/006b [Springfield, Va., NTIS Order No. PB89-167498], p. 3-51--3-54.

Reimer, G.M., and L.C.S. Gundersen, 1989

A direct correlation among indoor Rn, soil gas $\mathrm{Rn}$ and geology in the Reading Prong near Boyertown, Pennsylvania:

Health Physics, 57(1): 155-160

Reimer, G.M., Linda C.S. Gundersen, S.L. Szarzi, and J.M. Been, 1991

Reconnaissance approach to using geology and soil-gas radon concentrations for making rapid and preliminary estimates of indoor radon potential, in Gundersen, Linda C.S., and Richard B. Wanty, eds., Field studies of radon in rocks, soils, and water:

U.S. Geol. Survey Bulletin no. 1971, p. 177-181

Soil-gas samples collected along a traverse in Prince Georges County, Md., were analyzed for radon. The traverse included principal lithologies and areas for which total count aeroradiometric measurements showed various intensities. Although this region in the Atlantic Coastal Plaim might be considered to possess the type of geologic setting or aeroradiometric signature that would not contribute to significant radon potential, the measured soil-gas concentrations of up to 2,500 picocuries per liter indicate that the potential exists for indoor accumulations in excess of the level of 4 picocuries per liter established by the Environmental Protection Agency for remedial action. The higher levels of soil-gas radon were found in some of the Tertiary sediments, and lower concentrations occurred in Cretaceous and Quaternary sediments. Geologic relationships are thought to be the controlling factors for the radon soil-gas concentrations. The few data available from this survey suggest that a reconnaissance approach can be an effective screening method in the evaluation of areas for high radon potential.

Revzan, K.L., A.V. Nero, and R.G. Sextro, 1988

Mapping surficial radium content as a partial indicator of radon concentrations in US houses:

Radiation Protection Dosimetry, 24(1/4): 174-184

Ritchie, Ingrid, and Deanna English, 1987

A residential radon study: Marion County, Indiana, in Indoor Radon II, Proceedings of the Second APCA International Specialty Conference, Cherry Hill, New Jersey, April 6-10, 1987:

Pittsburgh, Pa., Air Pollution Control Association Pub. SP-60, p. 139-145

[Analysis of 3-month $\alpha$-track measurements of indoor radon in living areas of 118 houses in Marion County, Indiana, indicated that the type of soil beneath a house and the type of foundation were the important determinants of indoor levels. The soils beneath the houses with the lower indoor radon concentrations were characterized generally as well drained, and conversely.]

Rizzuto, Joseph E., 1988

New York State Energy Research and Development Authority radon program [abs.], in Radon in the Northeast:

Perspectives and Geologic Research (conference), Troy and Albany, New York, May 31-June 2, 1988:

Northeastern Environmental Science, 7(1): 9 
[Correlations were sought between indoor radon measurements made in the program and surficial and bedrock geology, including soil-gas radon concentrations and soil permeability to gas flow. See papers by B.J. Kothari or C.O. Kunz for results.]

Robayna, B., J[ose] H[ernan]dez-Armas, V. Soler, J.C. Carracedo, and A[ndre] Poffijn, 1991

Preliminary measurements of indoor radon in Canary Islands [abs.], in International Symposium on the Natural Radiation Environment, 5th, Salzburg, Austria, 22-28 September 1991, Abstracts:

Salzburg, Univ. Salzburg, Inst. for General Biology, Biochemistry and Biophysics, abs. no. 164

In two islands of the Canary Islands, 58 dwellings were selected as random sampling points for measuring indoor ${ }^{222} \mathrm{Rn}$ concentrations. Measurements in dwellings were all made with charcoal canisters following [U.S.] EPA's methodology. In addition, track-etch detectors were installed in 16 houses for a period of 3 months. A representative set of building materials used in these island, as well as some soil samples, were analyzed for their gamma activity with a high-purity $\mathrm{Ge}$ detector. The influence on the radon concentrations due to ventilation, altitude above sea level, meteorological parameters, geological substrate, and the building materials used were all analyzed. In all well-ventilated houses, the radon concentration values obtained by charcoal canisters were lower than $200 \mathrm{~Bq} / \mathrm{m}^{3}$. In dwellings not well ventilated, the values were systematically higher than $200 \mathrm{~Bq} / \mathrm{m}^{3}$. For all track-etch measurements the results were lower than $200 \mathrm{~Bq} / \mathrm{m}^{3}$, even for not-wellventilated houses. The discrepancy between short-term and integrated measurements will be analyzed in detail. No clear relation was found between the other factors considered and the ${ }^{222} \mathrm{Rn}$ concentration.

Roessler, C.E., R. Morato, D.L. Smith, and J. Wherett, 1991

Characteristics of Florida fill materials and soils. Florida Radon Research Program technical report:

Gainesville, Fla., Univ. Florida, 22 p.

This report transmits the results of laboratory work by the University of Florida in support of the Foundation Fill Data Base project of the Foundation Fill Materials Specifications Task Area of the Florida Radon Research Program (FRRP). Work included determination of radon concentrations in soil gas samples and physical and radiological characterization of soil/fill samples to provide data for further use in modeling radon production, transport, and entry. IThis work adds to the 35-site, 54-sample data base developed in an earlier study by the University of Florida under the State University Board of Regents Radon Research Program. The earlier study emphasized materials being used as fill at construction sites; only one-third of the samples were native surficial soil at construction or existing house sites. The study being reported here emphasized sites as prepared for construction. TThe field work was performed by another contractor. This included selection of field sites, performance of in-situ permeability, penetrometer, and density measurements, and deployment and retrieval of alpha-track soil gas radon detectors. The collaborating contractor also collected soil gas and soil samples for laboratory analysis at the University of Florida. TThe program involved 23 sampling sites. Two sites were selected in each of 11 regions designated to represent population centers covering a range of geographic, topographic, and geological features in Florida. Also included was a Brooksville school construction site being studied in another FRRP project. ISoil gas sampling at two or three stations per site, with collection at two depths at selected stations and duplicate sampling of a sub-set, generated over 90 soil gas samples for laboratory analysis for radon. Soil gas radon concentrations ranged from $\approx 0.1$ to $>370 \mathrm{kBq} / \mathrm{m}^{3}$ (a few $\mathrm{pCi} / \mathrm{L}$ to over $10,000 \mathrm{pCi} / \mathrm{L}$ ). The data were not submitted to statistical analysis; however, some observations can be made by inspection: (1) The two primary stations at a site generally had comparable levels. (2) In sampling 6 weeks later at a third station at 13 of the sites, about half the levels were noticeably different from those observed earlier at the primary stations. Since the two types of station were not sampled at the same visit, it is not possible to determine whether this is a time effect of a spatial effect. (3) In limited multi-depth sampling at 11 stations, concentrations generally increased with depth over the range of 0.30 to $0.75 \mathrm{~m}$ when the concentrations were greater than $3.7 \mathrm{kBq} / \mathrm{m}^{3}(100 \mathrm{pCi} / \mathrm{L})$. TCollection at a single depth at two sampling stations at each site generated 46 soil samples. All the regional soil samples were sand or sandy materials with loamy sand and clayey sand the most prevalent. In contrast, the Brookville school site samples were clay. Most of the sandy samples had moisture contents [dry weight basis] in the range of $2-10 \%$; the clay samples had moisture contents of about $30-40 \%$. Laboratory 
permeability measurements are reported for four combinations of compaction and moisture for each sample. Particle-size data are reported for the 46 samples. TRadium-226 concentrations were less than $37 \mathrm{~Bq} / \mathrm{kg}$ $(1 \mathrm{pCi} / \mathrm{g})$ in most samples and $74 \mathrm{~Bq} / \mathrm{kg}(2 \mathrm{pCi} / \mathrm{g})$ or less in $87 \%$. Exceptions included the Brookville clay samples and the samples from one Tallahassee site which had concentrations of $\approx 74-148 \mathrm{~Bq} / \mathrm{kg}(2-4 \mathrm{pCi} / \mathrm{g})$. The highest concentrations, $410-480 \mathrm{~Bq} / \mathrm{kg}(11-13 \mathrm{pCi} / \mathrm{g})$, were found in what appeared to be fill material at the Bartow site. The fact that soil gas radon concentrations at some of the $<37 \mathrm{~Bq} / \mathrm{kg}(<1 \mathrm{pCi} / \mathrm{g})$ sites approached or exceeded $37 \mathrm{kBq} / \mathrm{m}^{3}(1000 \mathrm{pCi} / \mathrm{L})$ suggests a radon source at greater depth than that from which the soil sample was taken. IResults of emanation coefficient measurements ranged from a few percent to about $40 \%$. Most of these samples had low radium concentrations; hence the associated emanation coefficient determinations have a high degree of uncertainty. [Executive summary]

Rogers, V.C., and Nielson, K.K., 1989

Radon emanation and transport in porous media, in Osborne, M.C., and Jed Harrison, Symposium Cochairmen, The 1988 Symposium on Radon and Radon Reduction Technology, Proc., Vol. 1, Symposium Oral Papers:

Research Triangle Park, N.C., Radian Corp., U.S. Environmental Protection Agency Pub. EPA/600/9-89/006a [Springfield, Va., NTIS Order No. PB89-167480], p. 5-45--5-58.

A unified model of radon emanation and transport has been developed that combines the RAECOM model for diffusive transport with new mathematical models of advective transport, moisture effects, and radon emanation. The model accounts for advective depletion in radon source regions, and for the effects of varying moistures on radon emanation, diffusion, and advective transport rates. Radon transport in gas- and water-filled pore space is characterized, and exchange between the phases is considered. Correlations are also given for diffusion and permeability coefficients. The model provides a comprehensive assessment of source potentials for indoor radon accumulation based on soil moistures, radium, emanation [coefficient], and advection of soil gas.

Rogers, V.C., and K.K. Nielson, 1991

Benchmark and application of the RAETRAD model, in The 1990 International Symposium on Radon and Radon Reduction Technology, Atlanta, Ga., 19-23 February 1990:

Research Triangle Park, N.C., U.S. Environmental Protection Agency Rept. EPA600/9-91-026b, Proceedings, Vol. 2: Symposium Oral Papers, Paper No. VI-1, p. 6-1-6-10 [NTIS Order No. PB91-234450/AS]

Field measurements were used to benchmark a simple new predictive correlation between soil gas permeability and soil grain size, moisture, and porosity. The correlation was incorporated with a previous diffusion correlation into the new RAETRAD code, that calculates radon generation and two-dimensional transport in soils, and radon entry into structures. RAETRAD generalizes the one-dimensional RAETRAN model, combining advective and diffusive radon transport with radon emanation, decay, absorption, and adsorption. RAETRAD calculations suggest $0.03 \%$ radon entry efficiency for slab-on-grade homes on low-permeability soils $\left(<10^{-12} \mathrm{~m}^{2}\right)$, increasing to $0.1 \%$ for sandy soils. Soil or fill properties in the first few feet dominate radon entry efficiency and limiting radium concentrations for prescribed indoor radon levels. For indoor radon concentrations of $74 \mathrm{~Bq} / \mathrm{m}^{3}(2 \mathrm{pCi} / \mathrm{L})$, sandy soils may contain only $74-110 \mathrm{~Bq} / \mathrm{kg}(2-3 \mathrm{pCi} / \mathrm{g}) \mathrm{radium}$ compared with $370-740 \mathrm{~Bq} / \mathrm{kg}(10-20 \mathrm{pCi} / \mathrm{g})$ for more clayey soils.

Rogers, V.C., and K.K. Nielson, 1991

Correlations for predicting air permeabilities and ${ }^{222} \mathrm{Rn}$ diffusion coefficients of soils:

Health Physics, 61(2): 225-230

Rogers, Vern C., and K.K. Nielson, 1991

Correlation of Florida soil-gas permeabilities with grain size, moisture, and porosity:

Salt Lake City, Utah, Rogers \& Associates Engineering Corp., Rept. EPA-600/8-91-039, 43 p. [Springfield, Va., NTIS]

This report augments existing soil gas permeability data using Florida soils, to produce a predictive correlation that is valid for Florida soils. The work was performed in connection with the broader Florida Department 
of Community Affairs (DCA) effort to define radon-protective standards for sub-slab fill materials. It also has applications in EPA and other agency efforts to assess radon potentials of soils and correlate indoor radon concentrations with source strengths. While it is preferred to have several in-situ measurements of soil gas permeability for the range of environmental conditions encountered, they are not usually available for many locations. The predictive correlation for soil gas permeability should be advantageous in making long-range average estimates that remove transient effects of moisture variations. They also will quantify the permeabilities of generic soil types for modeling and applications in which measurements are impractical. IMost previous studies of soil gas permeability have dealt with agricultural applications in the plant root zone, and thus tended to address near-surface tilled soils with low densities and large macropores. Permeabilities increase rapidly with soil air porosity and with macroporosity resulting from plowing. Air permeabilities also decrease with the moulding water content in laboratory tests, suggesting that the anisotropy of soil grains causes anisotropy in the gas permeability of compacted soil. Predictive correlations for soil-gas permeability: Predictions of soil gas permeability for estimating radon availability usually consider soils that are undisturbed or have been recompacted. The correlation proposed originally by Rogers and Nielson was based entirely on theoretical calculations from a random pore-combination model that considered tubular pores. The calculations used a pore-combination approach and modeled individual pore permeabilities by a simple function proportional to the cross-sectional area of each tubular pore fraction. A simpler correlation was developed later by the authors from empirical fits of field-measured soil gas permeabilities to several measured fundamental soil properties. The parameters correlating most strongly with measured gas permeabilities were the soil porosity and moisture saturation fraction, and the mass weighted arithmetic mean diameter of the soil grains. The resultant weighting of grain diameters toward larger sizes is consistent with previous studies that found air permeability to be dominated by the large pore mode, and by the generally better application of previous models and correlations to large-grained sandy soils than to clays. Florida data collection and analysis: The main Florida data collection effort consisted of field soil-gas permeability measurements and in-situ density sampling using procedures identical to those used in the earlier Utah measurements. The measurements and sampling included measurements at 16 locations throughout Florida. The measurements were made on open land areas that appeared undisturbed, at least throughout the past growing season. Primary measurements generally were at the $61-\mathrm{cm}$ depth unless non-uniform strata or shallow water tables were noted. In these cases, shallower depths were utilized to obtain uniform samples that were completely above any water table. Thirty-seven field permeabilities were measured, and soil samples were obtained and analyzed for each field measurement location. A quality control check was made on the permeability measurements for the Florida Radon Project using the MK-II permeameters. The RAE permeameter was calibrated immediately prior to the test. Then all three of the permeameters were compared at three locations in Gainesville, Florida, and were found to give statistically equivalent results at two of the three locations. A $21 \%$ relative standard deviation was observed at the third location. Permeabilities at the three locations ranged from $2 \times 10^{-10}$ to $2 \times 10^{-11} \mathrm{~m}^{2}$, and the average reproducibility of the MK-II permeameters was $11 \%$ relative standard deviation. Soil gas permeability correlation: The soil parameters were used in trial correlations with measured soil gas permeabilities. The general form of the correlation used terms of the moisture saturation fraction, the arithmetic mean grain size, and the total soil porosity. Since arithmetic mean grain sizes are strongly weighted toward the large particles, the possibility was investigated for computing arithmetic mean grain sizes solely from the coarse grain size fractions resulting from sieve analyses. Less than $5 \%$ error occurred in the sieve-only mean diameters for soils containing more than $50 \%$ passing the \#200 sieve. Furthermore, the errors were less than $10 \%$ for soils containing up to nearly $70 \%<\# 200$ mesh, and less than $15 \%$ for soils containing up to $90 \%<\# 200$ mesh. Based on these comparisons, a simple mechanical sieve analysis provides an adequate basis for estimating the arithmetic mean grain diameter for use in the soil gas permeability correlation. The proposed correlation for predicting soil gas permeability is thus defined as: $\mathbf{k}$ $=10^{-4}(\mathrm{p} / 110)^{2} \mathrm{~d}^{4 / 3} \exp \left(-12 \mathrm{~m}^{4}\right)$, where $\mathrm{k}=$ soil gas permeability $\left(\mathrm{m}^{2}\right) ; \mathrm{p}=$ total soil porosity (dimensionless); $\mathrm{d}=$ arithmetic mean grain diameter $(\mathrm{cm})$, excluding $>\# 4$ mesh material; and $\mathrm{m}=$ moisture saturation fraction (dimensionless). Comparisons with the 37 Florida soil gas permeability measurements have a geometric standard deviation (GSD) of 1.27, and a geometric mean bias (GMB) of 1.00. The Utah comparisons have a GSD of 1.52 and a GMB of 0.95 . Even though the correlation is applicable to a wide range of soils and soil 
conditions, it should not be used indiscriminately until additional data are obtained for validation. The overall comparison of all 37 Florida and 67 Utah soil gas permeabilities has a GSD of 1.44, and GMB of 0.97. This indicates that the correlation predicts $68 \%$ of the measured values within approximately $44 \%$, or $95 \%$ of the measured values within an approximate factor of $1.44^{2}$, or 2.07 . The bias term indicates that the correlation is about 3\% low, a negligible increment compared with the precision of its estimates. [This report includes a comprehensive literature review with approximately 65 references on soil permeability.]

Rogers, V.C., and K.K. Nielson, 1991

Multiphase radon generation and transport in porous materials:

Health Physics, 60(6): 807-815

\section{Rogers, Vern C., and Kirk K. Nielson, 1992}

Data and models for radon transport through concrete, in The 1992 International Symposium on Radon and Radon Reduction Technology, Minneapolis, Minnesota, September 22-25, 1992:

U.S. Environmental Protection Agency, Preprints, v. 2, no. VI-3, 15 p.

Radon generation and transport through Florida residential concretes are examined for their contribution to indoor radon concentrations. Radium concentrations in the 11 concretes tested are all $<93 \mathrm{~Bq} / \mathrm{kg}$ $(<2.5 \mathrm{pCi} / \mathrm{g})$, and radon emanation coefficients are all $<0.08$. Measurements on the constituents of four of the concretes reveal that when the radium concentrations are $>37 \mathrm{~Bq} / \mathrm{kg}$ ( $>1 \mathrm{pCi} / \mathrm{g}$ ), it is generally due to elevated radium in the aggregate, but may occasionally occur from radium in the cement. Because the aggregates tested generally have very low emanation coefficients, elevated radium in the aggregate has a lesser impact on indoor radon than elevated radium in the cement component. Diffusion coefficients for Florida concretes generally range from $10^{-8} \mathrm{~m}^{2} / \mathrm{s}$ to a few times $10^{-7} \mathrm{~m}^{2} / \mathrm{s}$, but air permeability coefficients are generally less than $10^{-15} \mathrm{~m}^{2}$. Thus advection through a concrete slab in negligible compared to diffusion. Finally, simple correlations are presented for diffusion and permeability coefficients and for radon generation in concrete and entry into dwellings.

Rogers, V.C., K.K. Nielson, and D.R. Kalkwarf, 1984

Radon attenuation handbook for uranium mill tailings cover design:

Salt Lake City, Utah, Rogers and Associates Engineering Corporation, U.S. Nuclear Regulatory Commission Rept. NUREG/CR-3533, 85 p.

Rose, A.W., 1988

Control of radon in soil gases by pedologic and geologic factors [abs.], in Radon in the Northeast: Perspectives and Geologic Research (conference), Troy and Albany, New York, May 31-June 2, 1988:

Northeastern Environmental Science, 7(1): 9

Rose, Arthur W., Edward J. Ciolkosz, John W. Washington, 1991

Effects regional and seasonal variations in soil moisture and temperature on soil gas radon, in The 1990 Interzational Symposium on Radon and Radon Reduction Technology, Atlanta, Ga., 19-23 February 1990:

Research Triangle Park, N.C., U.S. Environmental Protection Agency Rept. EPA600/9-91-026c, Proceedings, Vol. 3: Symposium Poster Papers, Paper No. C-VI-5, p. 6-49-6-60 [NTIS Order No. PB91-234468/AS]

Radon in houses depends partly on $\mathrm{Rn}$ concentration in soil gas, which is affected by water in a variety of ways. In this paper, temperature-dependent effects of $R \mathbf{n}$ partitioning between changing proportions of air and water in pore space are shown to be capable of causing variations in $\mathrm{Rn}$ concentration up to 5-fold. A map of regional soil moisture and temperature regimes, in combination with the moisture/temperature effects on $R n$, suggests that soil-gas $\mathrm{Rn}$ will be most elevated by moisture effects in eastern U.S. and other regions with the Udic soil moisture regime. Large seasonal differences are also predicted for soils of the Udic moisture regime, with soils of the Frigid temperature regime having higher $R \mathbf{n}$ in summer than winter. Aridic (dry) soils show negligible effects. Clay-rich soils will generally be most strongly affected by moisture variations. 
Rose, Arthur W., Adam R. Hutter, and John W. Washington, 1990

Sampling variability of radon in soil gases, in Kesler, S.E., ed., Soil and Rock Gas Geochemistry:

Jour. Geochem. Exploration, 38: 173-191

Little information is available on the long-term reproducibility of radon in soil gases, or on the vertical distribution of radon concentrations in soil gas. For five sites in central Pennsylvania, the radon activity in soil gas at depths exceeding about $70 \mathrm{~cm}$ varies by factors of 3 to 10 during the year, and shows even larger variability at shallow depths. At depths greater than about $70 \mathrm{~cm}$, values are lower in winter than in summer, apparently because radon is retained in the soil in some form other than the air phase, perhaps in soil moisture or sorbed on solids, as a result of increased moisture or decreased temperature during winter. The low radon values in winter are observed at depths below the frozen surface zone, so they do not result directly from freezing. Values at depths shallower than about $70 \mathrm{~cm}$ at one site studied in detail appear to average slightly higher in winter than in summer, but with erratic highs and lows defining a 3-fold annual range. At two other sites, the shallow values show patterns similar to the deep values with highs in summer. Vertical profiles show reversal and other features differing from previous models for simple diffusive transport. Sampling during the summer period at depths greater than $75 \mathrm{~cm}$ shows the best reproducibility for these soils. Several sets of soil-gas measurements along a traverse crossing a fracture trace indicate that elevated radon values tend to occur over the fracture zone, but anomalies also occur outside the fracture trace, and show appreciable variability with time and precise location. The literature indicates that 3- to 10 -fold seasonal variations are common. Most other studies show high radon in winter or in wet or frozen soils, attributed to capping by saturated or frozen soil, but clay-rich soils in Sweden have their highest radon in summer and fall. Soils that crack in dry weather can have low radon because of dilution by the atmosphere. These phenomena must be considered in comparing surveys performed during different seasons and interpreting surveys of soils with laterally differing texture or moisture content.

Rose, Arthur W., MacKenzie L. Keith, and Norman H. Suhr, 1976

Geochemical drainage surveys for uranium: Sampling and analytical methods based on trial surveys in Pennsylvania:

University Park, Pa., Pennsylvania State Univ., Dept. Geosciences, U.S. E.R.D.A. Rept. GJO-1645-1

Geochemical surveys near sandstone-type uranium prospects in northeastern and north-central Pennsylvania show that the deposits can be detected by carefully planned stream sediment surveys, but not by stream water surveys. Stream waters at single sites changed in U content by $\times 10-50$ during the 18 months of our studies, and even near known prospects, contain $<0.2 \mathrm{ppb} U$ most of the time. Uranium extractable from stream sediment by acetic acid- $\mathrm{H}_{2} \mathrm{O}_{2}$ provides useful contrast between mineralized and non-mineralized drainages of a square mile or less; total $U$ in sediment does not. High organic material results in increased $U$ content of sediments and must be corrected. Changes in $U$ content of sediment with time reach a maximum of $\times 3$ and appear to be of short duration. A sediment survey of about $200 \mathrm{mi}^{2}$ near Jim Thorpe detects anomalies extending over several square miles near known occurrences and a second anomaly about two miles northeast of Penn Haven Junction. A similar survey in Lycoming-Sullivan Counties shows anomalous zones near known prospects of the Beaver Lake area and northwest of Muncy Creek. As, $\mathrm{Mn}, \mathrm{Pb}$, and $\mathrm{V}$ are enriched in the mineralized zones, and perhaps in surrounding halo zones, but do not appear to be pathfinder elements useful for reconnaissance exploration.

Rose, Arthur W., and Lisa A. Korner, 1979

Radon in natural waters as a guide to uranium deposits in Pennsylvania, in Watterson, John R., and Theobald, Paul K., eds. Geochemical Exploration 1978, International Geochemical Exploration Symposium, 7th, Golden, Colo., April 17-19, 1978, Proc.:

Rexdale, Ont., Canada, Assoc. Exploration Geochemists: 65-76

The content of $R n$ in stream and ground waters of 2 areas of $U$ mineralization in Pennsylvania has been measured to test its use as a reconnaissance exploration technique. In addition, the causes for variations in the $R \mathbf{n}$ contents of natural waters have been evaluated. A physical model shows that the $R \mathbf{n}$ content of ground waters increases with increasing $U$ content of the host aquifer and with the proportion of $R n$ atoms which 
emanate from the solid phases into the pore water. Rn also increases with decreasing porosity, and with increasing time spent in the aquifer, up to a few weeks. Background values as well as anomalies are affected by these factors. An extension of the model indicates that Rn normally reflects the concentration of U. Many samples in areas of $U$ mineralization are anomalously high in $R n$. Some of these waters are also high in $U$. The Jim Thorpe area, where the best $U$ prospects occur, is indicated by strong $R \mathbf{n}$ anomalies but no $U$ anomalies. $R n$ measurement of ground water is a valuable addition to $U$ measurement as a reconnaissance exploration method.

Rose, Arthur W., and John W. Washington, 1989

Controls of seasonal variability in Rn content of soil gas [abs.]:

Geol. Soc. America, Northeastern Section, Abstracts with Programs, 21(2): 63

Measurements of soil gas radon over a one-year period at five sites in central Pennsylvania show a large seasonal variation. The radon $\left({ }^{222} \mathrm{Rn}\right)$ concentrations reach values of 56 to $150 \mathrm{kBq} / \mathrm{m}^{3}(1500$ to $4000 \mathrm{pCi} / \mathrm{L})$ in summer at depths of a meter or more. Winter values are only $1 / 3$ to $1 / 10$ of the summertime high values. The seasonal decrease is most pronounced in deep soils (greater than 1 meter). In summer the depth profiles approximate a diffusional-type pattern, but during other periods of the year the depth profiles are irregular, often showing peaks in the middle part of the profile. Thoron $\left({ }^{220} \mathrm{Rn}\right)$ shows patterns over time similar to ${ }^{222} \mathrm{Rn}$. Depth profiles of thoron are not clearly diffusionally controlled at any time of the year. Presumably the muting of the diffusion pattern for thoron is related to its short half-life. The radon variability both with time and depth correlates with soil moisture as determined by resistance blocks, tensiometers, neutron moisture gauge, and visual observation. In summer the soils are usually dry due to high evapotranspiration; in late fall the soils are relatively wet because of low evaporation and perhaps increased precipitation. The exact relationship between the low winter radon values and high moisture is not clear, but appears to involve inhibited diffusion through water-filled pores or adsorption-like effects. Several other researchers have reported similar seasonal effects in humid-region soils, but in semi-arid regions, high radon is reported in winter or early spring, apparently during periods of high moisture. Evidently several processes cause seasonal variability in soil-gas radon values.

Rose, Arthur W., John W. Washington, and Daniel J. Greeman, 1988

Variability of radon with depth and season in a central Pennsylvania soil developed on limestone:

Northeastern Environmental Science, 7(1): 35-39.

The concentrations of ${ }^{222} \mathrm{Rn}$ and ${ }^{220} \mathrm{Rn}$ have been measured with depth and time in a soil profile developed on limestone in central Pennsylvania, using both instantaneous measurements with a Lucas-cell type of radon detector and time-averaged measurements with alpha track detectors. Profiles of ${ }^{222} \mathrm{Rn}$ during summer grossly fit patterns expected for diffusion toward the surface, with values below $1 \mathrm{~m}$ leveling off at $74-111 \mathrm{kBq} / \mathrm{m}^{3}$ (2000-3000 $\mathrm{pCi} / \mathrm{L}$. These relatively high values are probably responsible for the high values reported in houses built on residual limestone-dolomite soil. Concentration of ${ }^{220} \mathrm{Rn}$ rises to a sharp peak of 31 to $52 \mathrm{kBq} / \mathrm{m}^{3}$ $(850-1400 \mathrm{pCi} / \mathrm{L})$ at 30 to $60 \mathrm{~cm}$, decreasing to 4.1 to $16 \mathrm{kBq} / \mathrm{m}^{3}(110-430 \mathrm{pCi} / \mathrm{L})$ at depth, suggesting higher emanation coefficients at shallow depth than in deeper soil or translocation of an ancestor isotope in the shallow soil. Values of ${ }^{222} \mathrm{Rn}$ decrease markedly during winter to only 10 to $20 \%$ of values in summer and early fall, for reasons that are presently unclear. An understanding of this effect may have important bearing on radon values in houses.

Rosén, Bengt, 1985

Utveckling av apparat för mätning av radonexhalation [Development of apparatus for measurement of radon exhalation]:

Linköping, Sweden, Statens geotekniska institut [Swedish Geotechnical Institute] Rept. SGI Varia 154, 20 p.

Rosen, R., 1957

Note on some observations of radon and thoron exhalation from the ground:

New Zealand Jour. Sci. Technology, sec. 5, 38(6): 644-654 
Geophys. Abs. 170-269

Measurements of radon exhalation from the ground have been made by a modified induction method, in which the decay of products on the collector wire is recorded by a gauze cylindrical ion chamber situated around the wire. Measurements from June to August 1955 (at a site in Wellington, New Zealand) showed an average exhalation rate of approximately $0.2 \mathrm{aCi} / \mathrm{cm}^{2}-\mathrm{s}$. During periods of decreasing atmospheric pressure, there was usually a slight increase in the exhalation rate. There was a marked decrease during rainfall. The results also indicated a diurnal variation in the exhalation rate. The radon thoron ratio was found to be about 1.5.

Roserens, G.-A., 1993

Radon program in Switzerland-Remedial actions [abs.], in First International Workshop on Indoor Radon Remedial Action, The Scientific Basis and Practical Applications, Rimini, Italy, 27 June-2 July 1993:

Commission of the European Communities et al., Book of Abstracts, p. 23

The results of the five-year radon research program RAPROS allow for scientifically valid statements on the origin of elevated levels of indoor radon in Switzerland. These results for a basis for recommendations and for actions to be taken. Indoor radon concentrations have been measured in more than 4000 living rooms and 2000 basements, a sampling density of about $0.2 \%$ of the Swiss housing stock. According to these measurements radon leads to an estimated average annual effective dose of $2 \mathrm{mSv}$, although in some regions the annual dose may be much higher. Extrapolation of the existing data shows that in about 10,000 Swiss houses radon may exceed $1000 \mathrm{~Bq} / \mathrm{m}^{3}$. For these houses remedial actions are recommended. High indoor radon concentrations in Switzerland are due to the soil beneath the buildings. Data from the study indicated that the most important soil characteristic influencing indoor radon concentrations was its gas permeability. Because natural ventilation in a heated house creates a slight underpressure in the lower levels with respect to surrounding soils, radon is driven into the building. Weatherization of the houses to reduce energy consumption had in most cases no effect on the indoor radon concentrations. Radon from tap water or from building materials does not contribute significantly to indoor radon levels in Switzerland. Several houses of different types now have been modified to reduce radon levels. The most successful mitigation technique combined forced-air ventilation with tightening of the basement to decrease or prevent air infiltration from the soil. The poster shows the most interesting cases of the successful remedial actions.

Ross, B.C., M.R. Atkinson, and D.W. Dixon, 1993

Regional variations in occupational exposure to radon and the resulting regulatory enforcement procedures [abs.], in First International Workshop on Indoor Radon Remedial Action, The Scientific Basis and Practical Applications, Rimini, Italy, 27 June-2 July 1993:

Commission of the European Communities et al., Book of Abstracts, p. 103

Measurements in over 3000 workplaces throughout Great Britain show that radon concentrations in about $10 \%$ of the premises exceed the action level at which the Ionising Radiations Regulations 1985 apply. Most of the measurements and high results are in Cornwall and Devon where $20 \%$ or more of the premises in some areas of these counties exceed the action level. High results have also been obtained in other counties, particularly Northhamptonshire, Somerset, and Derbyshire. The data for workplaces are supplemented by the results of measurements in about 100,000 homes suitably transposed to indicate the likely impact of the Regulations where workplace data are scarce. Results are presented in tables and maps for areas where the potential for high radon levels in workplaces has been identified. The HSE [Health and Safety Executive] has written to all registered employers in the worst affected areas informing them of the legal position and providing them with a leaflet and other publicly available advice on radon measurement and control. The employers who believe that their premises are not likely to be affected or who have already undertaken tests have been asked to return a completed proforma to the HSE. A follow up letter is sent to others asking for a progress report. Visits to selected premises are undertaken for enforcement purposes.

Sachs, Harvey M., 1986 
Notes on sources of radon in houses, in Radon and the Home Environment, Saturday Symposium, New Jersey Chapter, Health Physics Society and Delaware Valley Society for Radiation Safety, Princeton, N.J., March 22, 1986:

Unpublished outline, 2 p. +18 figs.

Until about 1980, most workers assumed that building materials, potable water supplies, and other "endogenous sources" were responsible for most radon in houses. Since then, on-site work in Canada and Sweden and mapping in Sweden and the USA has shown that most situations of large numbers of houses with high radon concentrations are correlated with specific geological formations. This finding is consistent with the log-normal distribution of radon in houses at scales from local to international. Although there is speculation about source rocks, at this time prudent research protocols assume that distribution studies should control for geology, but that a priori expectations are premature. However, interpretative mapping is likely to identify, on an ad hoc basis, those geological units strongly associated with anomalous frequencies of high radon concentrations. TOnsite work by many investigators has consistently shown that conventional housing construction techniques offer many routes for radon entry, and that some conditions strongly couple houses to their substrates. These include strong pressure gradients between soil gas and cellars, large cracks, sumps, and porous foundation walls. This knowledge is the basis for experiments in cost-effective mitigation.

Sachs, Harvey M., 1987:

Where is all the radon from?, in Radon and the Environment, Conference Proceedings, Mahwah, N.J., May 8-10, 1986, Makofske, William J., and Michael R. Edelstein, eds.:

Mahwah, N.J., Ramapo College of New Jersey, Inst. for Environmental Studies, p. 21-27

Sachs, H.M., T.L. Hernandez, and J.W. Ring, 1982

Regional geology and radon variability in buildings:

Environment Internat., 8(1-6): 97-103

Radon concentrations in dwellings vary by more than two orders of magnitude. Predicting where and when concentrations are likely to be high requires studying the variability of the contributors to radon in buildings. Among common sources, geological factors (water supply and substrate) are the most variable, whereas building materials are much less variable. Ventilation variation among houses is generally responsible for radon variations comparable to those introduced by building materials, but it is more significant at lower ventilation rates. In some regions with relatively high proportions of houses with elevated radon concentrations, mappable geological factors are associated with most cases of high radon concentrations. However, a priori identification of rock types likely to be implicated is likely to be successful in only a few cases.

Samuelson, Alan C., David Ober, Thad Godish, David Govaer, and Alice Bennett, 1988

Air and water radon investigations in east-central Indiana [abs.]:

Geol. Soc. America, Abstracts with Programs, 20(7): A338

The Radon Working Group at Ball State University [Muncie, Indiana] has initiated a study of radon levels in both air and groundwater in homes in east-central Indiana. The air data are collected for two-day periods in charcoal canisters placed in the center of the lower floor in private homes. The data are correlated with outside temperatures, house construction characteristics, and soil types on which the home is founded with the latter producing the most striking correlation. All of the highest radon levels (over $120 \mathrm{~Bq} / \mathrm{m}^{3}$ or $3.25 \mathrm{pCi} / \mathrm{L}$ ) are in homes founded on a subsoil consisting of glacial sand and gravels of high porosity, and including gravels of Precambrian granite pebbles. The water data are collected from groundwater wells and measured by scintillation techniques. The data are correlated with values for other elements, geographic location, well depth, and aquifer type with the latter two factors producing the most positive correlation. To data, most of the higher radon levels $\left(>11 \mathrm{kBq} / \mathrm{m}^{3}\right.$ or $\left.>300 \mathrm{pCi} / \mathrm{L}\right)$ are found in groundwaters coming from wells that are $>24 \mathrm{~m}$ deep that are in Silurian carbonates. Wells that are drawing from the glacial sand and gravels typically have lower radon levels. 
Sanchez, David C., Richard Dixon, and Ashley D. Williamson, 1991

The Florida Radon Research Program: Systematic development of a basis for statewide standards, in The 1990 International Symposium on Radon and Radon Reduction Technology, Atlanta, Ga., 19-23 February 1990:

Research Triangle Park, N.C., U.S. Environmental Protection Agency Rept. EPA600/9-91-026c, Proceedings, Vol. 3: Symposium Poster Papers, Paper No. A-I-3, p. 1-21-1-37 [NTIS Order No. PB91-234468/AS]

[In support of legislation requiring the use of radon-resistant building techniques for new construction in highrisk areas, a research program was authorized. Research needs identified included measurement and development of predictive techniques for sub-barrier radon concentrations based on soil characteristics, determination of the volume of soil or fill effectively contributing radon at the sub-barrier interface, definition of the extremes of environmental conditions affecting radon availability, and related information.]

Scarpitta, S.C., 1990

Measuring the exhalation of Rn-222 from soil in a closed system using activated charcoal [abs. WPM-A6], in Health Physics Society Ann. Mtg., 35th:

Health Physics, 58(Suppl. 1): S32

A method is described which uses $5 \mathrm{~g}$ of activated charcoal to directly measure the $\mathrm{Rn}$ exhalation rate from a $50 \mathrm{~g}$ soil sample in a sealed metal canister. The method, which combines the accumulation technique with the activated charcoal adsorption technique, minimizes back-diffusion of $\mathrm{Rn}$ into the soil gas. Calibration against conventional techniques is not required. Exhaled $\mathrm{Rn}$ is collected by a removable charcoal cartridge which is positioned on the inner lid of the canister. The charcoal can be directly gamma counted following exposure or extracted into a toluene based liquid scintillation cocktail. Desorptive losses associated with canister leakage and transferring are less than $5 \%$. IStudies using a dry sieved soil, spiked with ${ }^{226} \mathrm{Ra}$, demonstrated that a single exposure will yield a free $\mathrm{Rn}$ exhalation rate to within $10 \%$ of the true value if the sampling time is less than the half-life of $\mathrm{Rn}$. A minimum sampling time of $48 \mathrm{~h}$, followed by a 1-2 h gamma count, is required in order to determine the $\mathrm{Rn}$ exhalation rate from a dry sieved New Jersey topsoil containing $35 \mathrm{~Bq} / \mathrm{kg}{ }^{226} \mathrm{Ra}$. Multiple measurements over a $48-120 \mathrm{~h}$ period are required to determine the exhalation rate constant of diffusible $\mathrm{Rn}$ from the soil gas. TThe liquid scintillation counting (LSC) technique increases counting sensitivity by two orders of magnitude over gamma counting. A lower limit of detection at the $95 \%$ confidence level of $5.6 \mathrm{mBq}(0.15 \mathrm{pCi})$ is obtainable with a 30 -min count using the LSC technique.

Schery, S.D., D.H. Gaeddert, and M.H. Wilkening, 1984

Factors affecting exhalation of radon from a gravelly sandy loam:

Jour. Geophys. Research, 89(D5): 7299-7309.

Measurements of radon exhalation from a gravelly sandy loam have been made in a semi-arid climate by using a combination of closed accumulation, flow-through accumulation, and ${ }^{222} \mathrm{Rn}$ and ${ }^{210} \mathrm{~Pb}$ soil profiles. The meteorological factors that most affected the instantaneous value of exhalation of ${ }^{222} \mathrm{Rn}$ were atmospheric pressure and rain. Effects due to other parameters such as wind or temperature were either comparatively small or undetectable. No evidence was seen for migration of radon from distant ( $>>10 \mathrm{~m}$ ) sources or for an effect on exhalation due to limited nearby seismic activity. Measurements for ${ }^{220} \mathrm{Rn}$ indicated its exhalation was also sensitive to pressure variation but to a lesser extent than for ${ }^{222} \mathrm{Rn}$. While instantaneous exhalation of ${ }^{222} \mathrm{Rn}$ could easily vary by a factor of 2 or more, time-averaged exhalation was found to be close to that expected for pure diffusion. There is thus some indication that the time-averaged effect of cyclic environmental variables is small for this soil. Comparison with transport equations indicates that it is difficult to explain the observed variation in surface flux density solely in terms of the radon concentration gradient in the top few decimeters of soil. A contribution to transport from direct flow, perhaps through inhomogeneities such as cracks or channels, is one possible explanation.

Schultz, Art [Arthur P.], and Stephen D. Brower, 1991

Geologic and environmental implications of high radon soil-gas concentrations in carbonate rocks of the Appalachian Great Valley, West Virginia

Geol. Soc. America, Abstracts with Programs, 23(1): 125 
Radon soil-gas and ground radioactivity surveys across a portion of the Great Valley of West Virginia indicate that residuum and soils above some carbonate rocks have levels of radon soil-gas that exceed $148 \mathrm{kBq} / \mathrm{m}^{3}$ $(4,000 \mathrm{pCi} / \mathrm{L})$. Data indicate no correlation of anomalously high radon soil-gas concentrations with faults, cleavage, joints, or veins. Instead, radon anomalies are apparently related to thick, red, clay-rich residuum that may contain as much as 4 times the concentration of radium, 10 times the concentration of uranium, and 5 times the concentration of thorium as the underlying bedrock. The highest radon soil-gas concentrations are found in soils and residuum overlying argillaceous, cherty, silty, and sandy limestone and dolomite in the Elbrook and Conococheague Formations and in the Beekmantown Group. Within our sample population, uranium appears depleted and in disequilibrium with radium-226 in both bedrock and residuum. Uranium also is somewhat depleted from the upper layers of the residuum with respect to deeper layers. Our study has shown that existing geologic and radiometric data, soil surveys, and thickness of residuum data combined with field radon soil-gas data can be used to outline areas of potential indoor radon hazards.

Schultz, Arthur P., and Calvin Wiggs, 1989

Geol. Soc. America, Northeastern Section, Abstracts with Programs, 21(2): 65

Preliminary results of a radon study across the Great Valley of West Virginia [abs.]:

As part of the U.S. Geological Survey's radon program, a study of the distribution of radon in areas underlain by folded, faulted, and cleaved limestones, dolomites, and shales of the Great Valley of West Virginia was undertaken. Radon soil-gas measurements and scintillometer measurements of soil and bedrock were made on a $20-\mathrm{km}$ traverse approximately perpendicular to regional strike. Radon values generally vary with changes in rock type. Soil-gas values on the traverse are 19 to $56 \mathrm{kBq} / \mathrm{m}^{3}(500$ to $1,500 \mathrm{pCi} / \mathrm{L})$ for soils above the Cambrian through Middle Ordovician Tomstown dolomite, the Waynesboro Formation, the lower and middle parts of the Elbrook Formation, the Conococheague Formation, the Beekmantown Group and Middle Ordovician limestones and dolomites; 56 to $104 \mathrm{kBq} / \mathrm{m}^{3}$ (1500 to $2800 \mathrm{pCi} / \mathrm{L}$ ) for soils above the upper part of the Cambrian Elbrook Formation and the Middle Ordovician Martinsburg Formation; and 104 to $150 \mathrm{kBq} / \mathrm{m}^{3}$ (2800 to $\left.4000 \mathrm{pCi} / \mathrm{L}\right)$ for soils above a limited stratigraphic interval in the lower part of the Cambrian Conococheague Formation. In areas underlain by limestone and dolomite, where soil-gas values are high, scintillometer readings on outcropping bedrock were generally low. The high soil-gas readings may indicate concentration of uranium minerals during carbonate solution of adjacent bedrock and soil-forming processes. Outcrop scintillometer readings for shaly and sandy carbonate rocks were generally higher than those for adjacent limestones and dolomites. Except for high spot anomalies, the variation in soil-gas values is similar to the variation in aeroradioactivity values. Generally low radon soil-gas values were found above mapped faults. In one case, an area of high soil-gas values appears to be related to a zone of impermeable clay within a thick terra rossa developed on limestones.

Schultz, Art [Arthur P.], Calvin R. Wiggs, and Stephen D. Brower, 1992

Geologic and environmental implications of high soil-gas radon concentrations in the Great Valley, Jefferson and Berkeley counties, West Virginia, in Gates, Alexander E., and Linda C.S. Gundersen, eds., Geologic Controls on Radon:

Boulder, Colo., Geological Soc. America Special Paper 271, p. 29-44

Soil-gas radon and ground radioactivity surveys across a portion of the Great Valley of West Virginia indicate that residuum and soils formed above some carbonate rocks have sufficient levels of radon gas to cause high indoor radon values. Data indicate no correlation of soil-gas radon concentration with faults, cleavage, joints, or calcite veins. Instead, soil-gas radon distribution appears to be controlled by the solution of carbonate bedrock and the subsequent development of thick, red, clay-rich residuum, which may contain as much as 4 times the concentration of radium, 10 times the concentration of uranium, and 5 times the concentration of thorium as the underlying bedrock. Such residuum and associated soil develops over some parts of the Elbrook, Conococheague, and Beekmantown Forr: exceeding $150 \mathrm{kBq} / \mathrm{m}^{3}(4,000 \mathrm{pCi} / \mathrm{L})$. In area the Great Valley underlain by siltstone, fine-grained sandstone, and shale of the Martinsburg $F_{0}$ on, soil-gas radon values can exceed $150 \mathrm{kBq} / \mathrm{m}^{3}$ $(4,000 \mathrm{pCi} / \mathrm{L})$. In these areas, bedrock alone appears to have sufficient thorium, radium, and uranium 
concentrations to generate the soil-gas radon measured. Previous work by others and our own preliminary evaluations indicate that soil-gas radon levels are high enough to cause indoor air in homes to exceed $148 \mathrm{~Bq} / \mathrm{m}^{3}$ (4 pCi/L), the U.S. Environmental Protection Agency's (EPA) action level for radon. Aeroradiometric maps and National Uranium Resource Evaluation (NURE) Program data do indicate anomalously high radioactivity in some areas where radon soil-gas concentrations were high. These data, used with available geologic maps, soil maps, and maps showing thickness of residuum, are useful in predicting areas of radon soil-gas hazards.

Schumann, R. Randall, 1992

Radon potential of the glaciated upper Midwest: Geologic and climatic controls on spatial variation, in The 1992 International Symposium on Radon and Radon Reduction Technology, Minneapolis, Minnesota, September 22-25, 1992:

U.S. Environmental Protection Agency, Preprints, v. 3, no. VIII-3 [abs.], and separate paper, 17 p.

Many areas of the United States underlain by soils derived from continental glacial deposits generate elevated indoor radon levels $\left(\geq 148 \mathrm{~Bq} / \mathrm{m}^{3}\right.$ or $\left.\geq 4 \mathrm{pCi} / \mathrm{L}\right)$. For example, Iowa $(71 \%)$, North Dakota (63\%), and Minnesota (46\%) have some of the highest percentages of homes with elevated indoor radon levels in the State/EPA Indoor Radon Survey. Determining the radon potential of glaciated areas is complicated by several problems: 1) surface radioactivity is generally uncharacteristically low in glaciated areas and does not appear to correlate well with indoor radon values; 2) because glaciers redistribute the bedrock they override and entrain, the composition and physical properties of till soils do not necessarily reflect those of the underlying bedrock (transport distances were much farther for the continental glaciers of the Great Plains and Great Lakes regions than for glaciers in New England or for valley glaciers, however); and 3) where glacial cover is thin, the radon potential may be a complex product of the glacial cover and the underlying bedrock. Crushing and grinding of rocks by glaciers increases the mobility of uranium and radium in the resulting tills, allowing them to move readily downward through the soil profile with other mobile ions as the soils are leached. Clay-rich tills in North and South Dakota and Iowa generate significant numbers of elevated radon levels, whereas sandy tills in Michigan typically have low to moderate radon levels. Some of the highest indoor radon levels in North and South Dakota are associated with deposits of glacial Lake Agassiz and other glaciolacustrine deposits. In contrast, glacial lake deposits in Wisconsin, Michigan, Illinois, and Indiana are typically associated with low radon levels. Differences in source-rock composition, permeability, and soil moisture conditions of the glacially-derived soils are likely responsible for these dissimilarities.

Schumann, R. Randall, ed., 1993a

Geologic radon potential of EPA Region 1, Connecticut, Maine, Massachusetts, New Hampshire, Rhode Island, and Vermont:

U.S. Geol. Survey Open-file Rept. 93-292-A, ii + 245 p.

[This is one of 11 reports that assess the indoor radon potential of the states on the basis of geologic, aeroradiometric, soil characteristics, available indoor radon data, and dominant building construction type. The assessments were done by various U.S. Geological Survey geologists, in consultation with state geological surveys and other sources, and reviewed by state geological and health agencies and the U.S. Environmental Protection Agency. Boundaries of the assessed areas were adjusted from those dictated by the above factors to those dictated by political divisions (counties and states), so that each county is ranked as of high, moderate, or low radon potential according to the dominant ranking among the several differently assessed units within the county. The rankings indicate, qualitatively, the expectation that a significant, moderate, or small fraction of houses within a ranked area will contain indoor radon concentrations above certain levels; thus, "high" means a significant fraction $148 \mathrm{~Bq} / \mathrm{m}^{3}$ (>4 $\left.\mathrm{pCi} / \mathrm{L}\right)$, "moderate" means a significant fraction $74 \mathrm{~Bq} / \mathrm{m}^{3}(>2 \mathrm{pCi} / \mathrm{L})$, and low implies few houses $>74 \mathrm{~Bq} / \mathrm{m}^{3}(>2 \mathrm{pCi} / \mathrm{L})$. There is no implication in the rankings of the likelihood of very high indoor radon concentrations. These reports are not intended to be used as a substitute for indoor radon testing, and they cannot and should not be used to estimate or predict the indoor radon concentrations of individual homes, building sites, or housing tracts. Each report contains introductory material, including appendices for the geologic time scale, a glossary of terms, and lists of EPA Regional Offices, State radon 
contacts, and State geological surveys. The reports contain discussions of geological, soils, climatological, and radiometric data, indoor radon summaries, and references for the individual States covered.]

Schumann, R. Randall, ed., 1993b

Geologic radon potential of EPA Region 2, New Jersey and New York:

U.S. Geol. Survey Open-file Rept. 93-292-B, ii + 131 p.

[See above description.]

Schumann, R. Randall, ed., 1993c

Geologic radon potential of EPA Region 3, Delaware, Maryland, Pennsylvania, Virginia, and West Virginia:

U.S. Geol. Survey Open-file Rept. 93-292-C, ii + 206 p.

[See above description.]

Schumann, R. Randall, ed., 1993d

Geologic radon potential of EPA Region 4, Alabama, Florida, Georgia, Kentucky, Mississippi, North Carolina, South Carolina, and Tennessee:

U.S. Geol. Survey Open-file Rept. 93-292-D, ii + 274 p.

[See above description.]

Schumann, R. Randall, ed., 1993e

Geologic radon potential of EPA Region 5, Illinois, Indiana, Michigan, Minnesota, Ohio, and Wisconsin:

U.S. Geol. Survey Open-file Rept. 93-292-E, ii + 194 p.

[See above description.]

Schumann, R. Randall, ed., $1993 \mathrm{f}$

Geologic radon potential of EPA Region 6, Arkansas, Louisiana, New Mexico, Oklahoma, and Texas:

U.S. Geol. Survey Open-file Rept. 93-292-F, ii + 160 p.

[See above description.]

Schumann, R. Randall, ed., $1993 \mathrm{~g}$

Geologic radon potential of EPA Region 7, Iowa, Kansas, Missouri, and Nebraska:

U.S. Geol. Survey Open-file Rept. 93-292-G, ii + 147 p.

[See above description.]

Schumann, R. Randall, ed., 1993h

Geologic radon potential of EPA Region 8, Colorado, Montana, North Dakota, South Dakota, Utah, and Wyoming:

U.S. Geol. Survey Open-file Rept. 93-292-H, ii +184 p.

[See above description.]

Schumann, R. Randall, ed., 1993i

Geologic radon potential of EPA Region 9, Arizona, California, Hawaii, and Nevada:

U.S. Geol. Survey Open-file Rept. 93-292-I, ii + 142 p.

[See above description.]

Schumann, R. Randall, ed., 1993j

Geologic radon potential of EPA Region 10, Alaska, Idaho, Oregon, and Washington:

U.S. Geol. Survey Open-file Rept. 93-292-J, ii + 146 p.

[See above description.]

Schumann, R. Randall, 1993k 
The radon emanation coefficient: An important tool for geologic radon potential estimations, in The 1993 International Radon Conference, Denver, Colo., Sept. 20-22, 1993:

Denver, Colo., Am. Assoc. Radon Scientists and Technologists, Rocky Mountain Chapter, Preprints, p. IV 40-IV 47

The fraction of radon atoms generated from radium decay that are released into a rock or soil pore space is defined as the radon emanation coefficient, or emanating power, of the material. The emanation coefficient of rocks and soils typically varies between about 0.05 and 0.70 , and an average value for soils is probably between 0.20 and 0.30 . Geologic, pedologic, and climatic factors, including radium content, grain size, siting of radon parents within soil grains or on grain coatings, and soil moisture conditions, determine the soil's emanating power and radon transport characteristics. Soils derived from similar parent rocks in different regions appear to have significantly different emanation coefficients due to the effects of climate on these soil characteristics. Data on soil radium content, permeability, and moisture content are available for many areas of the United States. With these and data on emanation coefficients, quantitative predictive models for radon generation in rocks and soils at regional to national scales can feasibly be developed. To predict radon generation from soils at a town, neighborhood, or building-site scale, however, would require data at a greater level of detail than currently exists.

Schumann, R. Randall, ed., 1994

Geologic radon potential of the District of Columbia, Guam, and Puerto Rico:

U.S. Geol. Survey Open-file Rept. 93-292-K, in preparation

[See description above for Open-file Rept. 93-292-A.]

Schumann, R. Randall, Sigrid Asher-Bolinder, and Douglass E. Owen, 1989

Factors influencing seasonal variations in soil-gas radon concentrations in a fine-grained soil [abs.]:

Geol. Soc. America, Northeastern Section, Abstracts with Programs, 21(2): 65

Although geologic and soil characteristics are primarily responsible for determining the concentration of radon-222 in a given soil, soil-gas radon concentrations at a site fluctuate under the influence of meteorologic factors. A long-term soil gas monitoring site was established at the Denver Federal Center (DFC), Colorado, to investigate causes of non-geologic variations in measured soil-gas radon concentrations. The dry climate and smectitic soil at the DFC site interact to form an extensive system of desiccation cracks that imparts significant permeability to what would otherwise be an almost impermeable soil. Moisture capping occurs when precipitation infiltrates the uppermost soil layers, causing the clays to swell and cracks to close, and radon accumulates to elevated levels beneath the capping layer. The capping effect is further enhanced during the winter, when moisture in the surface layer freezes. Radon concentrations in soil gas at the DFC site vary by as much as an order of magnitude between seasons, and by as much as $\mathbf{2 0 0}$ percent in response to day-to-day weather variations. The most important weather factors affecting soil-gas radon concentrations at the DFC site are: 1) precipitation (as it affects soil moisture); 2) barometric pressure; and 3) temperature, wind, and other factors. Effects of lower-ranked factors are more noticeable in the absence of higher-ranked ones, because the more dominant weather factors tend to overshadow the effects of those factors with weaker influences. The results of this study suggest that radon surveys based on soil gas data could be misinterpreted if seasonal and weather-related variations are not considered. Additional data from other soil types and climatic zones should be collected to provide a better base for interpretation of radon data.

Schumann, R. Randall, and Linda C.S. Gundersen, 1991

Regional differences in radon emanation coefficients in soils [abs.]:

Geol. Soc. America, Abstracts with Programs, 23(1): 125

The fraction of the total number of radon atoms genented from radium decay that are released into a rock or soil pore space from a radium-bearing grain is termed the emanation coefficient, or emanating power, of the material. The emanation coefficient of rocks and soils typically varies between about 0.05 and 0.70 , and an average value for most soils is probably in the range $0.20-0.30$. A soil's parent rock composition (mineralogy and chemistry) controls not only the initial amount and distribution of radionuclides in the soil, but also how 
the rock will interact with climate to form the soil, thus determining the soil's emanating power and radon transport characteristics. Soils derived from similar parent rocks in different regions appear to have significantly different emanation coefficients due to the effects of climate on soil characteristics including grain size, siting of radon parents within soil grains, and soil moisture conditions. A preliminary examination of data from field studies in which uranium or equivalent uranium concentrations in soils are compared with their corresponding soil-gas radon concentrations suggests that regional differences in the amount of radon released exist among soils formed in different climatic zones but with similar radionuclide concentrations. Field and laboratory data from soils in several areas of the United States suggest that the differences in soil weathering characteristics in different climatic zones and their subsequent effects on redistribution of radon parent radionuclides in the soil profile are primarily responsible for the observed differences in the amount of soil-gas radon released. Our understanding of these climatic and soil processes and their interrelationships forms the basis of a preliminary general model for radon generation and mobility in soils that can eventually be developed into a quantitative predictive model for radon occurrence in the geologic environment.

Schumann, R.R., L.C.S. Gundersen, S. Asher-Bolinder, and D.E. Owen, 1989

Anomalous radon levels in crystalline rocks near Conifer, Colorado [abs.]:

Geol. Soc. America, Abstracts with Programs, 21(6): A144-A145

An area near Conifer, Colorado, with known elevated indoor radon levels was investigated to determine the geologic factors controlling radon concentrations in rocks, soils, and water in crystalline rocks of the Front Range. More than 200 soil-gas radon concentration and 300 surface gamma radioactivity measurements were made along traverses and grids in an approximately $75 \mathrm{~km}^{2}$ area and correlated with observations of geologic and structural features. Locally uranium-rich (containing as much as $18 \mathrm{ppm}$ equivalent uranium) granites and gneisses provide sources for radon, especially where these rocks are fractured and/or intensely weathered or altered. Soil-gas radon concentrations greater than $185 \mathrm{kBq} / \mathrm{m}^{3}(5000 \mathrm{pCi} / \mathrm{L})$, compared with a median concentration for the study area of $22 \mathrm{kBq} / \mathrm{m}^{3}(600 \mathrm{pCi} / \mathrm{L})$ were measured in proximity to sheared and altered zones. Faults, shears, and fractures provide the necessary permeability for movement of soil gases, as well as providing pathways for percolation of water through the rocks, enhancing the weathering process. Redistribution of uranium by weathering, from sites of low emanation within mineral grains to sites of higher emanation on grain surfaces and grain coatings, occurs by two processes: (1) as mineral grains are physically broken down, more uranium is exposed as grain size decreases and surface area-to-volume ratio increases; and (2) chemical weathering of the rocks produces $\mathrm{Fe}, \mathrm{Mg}$, and $\mathrm{Mn}$ coatings on mineral grains and fracture walls that tend to preferentially adsorb uranium. These zones may be relatively enriched in uranium as other elements are leached from the system. Some uranium enrichment may occur along fractures and shears through contact with uranium-bearing near-surface ground waters.

Schumann, R.R., and D.E. Owen, 1988

Relationships between geology, equivalent uranium concentration, and radon in soil gas, Fairfax County, Virginia: U.S. Geol. Survey Open-file Report 88-18, 27 p.

Schumann, R. Randall, Douglass E. Owen, and Sigrid Asher-Bolinder, 1992

Effects of weather and soil characteristics on temporal variations in soil-gas radon concentrations, in Gates, Alexander E., and Linda C.S. Gundersen, eds., Geologic Controls on Radon:

Boulder, Colo., Geological Soc. America Special Paper 271, p. 65-72

Concentrations of radon-222 in soil gas measured over about 1 yr at a monitoring site in Denver, Colorado, vary by as much as an order of magnitude seasonally and as much as severalfold in response to changes in weather. The primary weather factors that influence soil-gas radon concentrations are precipitation and barometric pressure. Soil characteristics are important in determining the magnitude and extent of the soil's response to weather changes. The soil at the study site is clay rich and develops desiccation cracks upon drying that increase the soil's permeability and enhance gas transport and removal of radon from the soil. A capping effect caused by frozen or unfrozen soil moisture is a primary mechanism for preventing radon loss to the atmosphere. 
Schumann, R. Randall, R. Thomas Peake, Kevin M. Schmidt, and Douglass E. Owen, 1991

Correlations of soil-gas and indoor radon with geology in glacially derived soils of the northern Great Plains, in The 1990 International Symposium on Radon and Radon Reduction Technology, Atlanta, Ga., 19-23 February 1990:

Research Triangle Park, N.C., U.S. Environmental Protection Agency Rept. EPA600/9-91-026b, Proceedings, Vol. 2: Symposium Oral Papers, Paper No. VI-3, p. 6-23-6-36 [NTIS Order No. PB91-234450/AS]

A higher percentage of homes in parts of the northern Great Plains underlain by soils derived from continental glacial deposits have elevated indoor radon levels $\left(>148 \mathrm{~Bq} / \mathrm{m}^{3}\right.$ or $\left.4 \mathrm{pCi} / \mathrm{L}\right)$ than any other area of the United States. Soil-gas radon concentrations, surface radioactivity, indoor radon levels, and soil characteristics were studied in areas underlain by glacially derived soils in North Dakota and Minnesota to examine the factors responsible for these elevated levels. Clay-rich till soils in North Dakota have generally higher soil-gas radon levels, and correspondingly higher indoor radon levels, than the sandy till soils common to west-central Minnesota. Although the proportions of homes with indoor radon levels $>148 \mathrm{~Bq} / \mathrm{m}^{3}(>4 \mathrm{pCi} / \mathrm{L})$ are similar in both areas, relatively few homes underlain by sandy tills have screening indoor radon levels $>74 \mathrm{~Bq} / \mathrm{m}^{3}$ $(>20 \mathrm{pCi} / \mathrm{L})$, whereas a relatively large proportion of homes underlain by clayey tills have screening indoor radon levels $>74 \mathrm{~Bq} / \mathrm{m}^{3}$ ( $\left.>20 \mathrm{pCi} / \mathrm{L}\right)$. The higher radon levels in North Dakota are likely due to enhanced emanation from the smaller grains and to relatively higher soil radium concentrations in the clay-rich soils, whereas the generally higher permeability of the sandy till soils in Minnesota allows soil gas to be drawn into structures from a larger source volume, increasing indoor radon levels in those areas.

Schutz, D[onald] F., and J[onathan] F. Powell, 1987

The influence of geologic environment on the distribution of uranium/radium in New Jersey, in Radon and the Environment, Conference Proceedings, Mahwah, N.J., May 8-10, 1986, Makofske, William J., and Michael R. Edelstein, eds.:

Mahwah, N.J., Ramapo College of New Jersey, Inst. for Environmental Studies, p. 34-46

Schütz, M., and G. Keller, 1993

Diurnal and seasonal variation of radon concentration in the upper layer of the soil [abs.], in First International Workshop on Indoor Radon Remedial Action, The Scientific Basis and Practical Applications, Rimini, Italy, 27 June-2 July 1993:

Commission of the European Communities et al., Book of Abstracts, p. 72

The soil is known to be the main source of high radon concentrations indoors, which contribute about the half of the mean natural annual radiation exposure of the German population. It is an aim of precautionary radiation protection to get information of regions with an elevated radon content. In order to screen easily the radon potential of the interesting regions, a simple measurement of radon at the surface is desirable. But the upper layer of the soil is mostly influenced by meteorological factors as heating and rain. Some test series with an artificial soil column may simulate these daily varying parameters under laboratory conditions. It shows that there occurs a short-term increase of the radon concentration by $300 \%$ and more in the upper layer of the soil as a consequence of sudden rainfall. On the other hand, a slow and long-term increase of the water content of the soil may reduce the diffusion coefficient of the radon by several orders of magnitude. The daily heating of the atmosphere results in an advanced gas exchange between the upper layer of porous and dry soils and the air above. Consequently variations of radon concentration by a factor of 5 arise according to the intensity of the heating and the porosity of the soil. The outcomes of the laboratory tests are qualitatively confirmed on natural soils. The test series at different types of radon-rich soils show both extreme diurnal and seasonal variations of the radon concentration in the upper layers as a consequence of changing meteorological conditions. That fact excludes the use of radon measuring devices with integration times less than one day for the radon screening of any area. We suggest a combination of in-situ alpha spectroscopy and solid-state nuclear track detectors to scan the radon potential of a soil. This method is not expensive in equipment or in time, but is sufficiently accurate.

Schwenker, Charles, Jia-Yeong Ku, Charles Layman [Laymon], and Charles Kunz, 1992 
Correlation of indoor radon screening measurements with surficial geology using geographic information systems, in The 1992 International Symposium on Radon and Radon Reduction Technology, Minneapolis, Minnesota, September 22-25, 1992:

U.S. Environmental Protection Agency, Preprints [poster papers], v. 5, no. VIIIP-3, 14 p.

The State of New York has a growing database of over 50,000 homes for which radon levels have been measured. These data include information on home construction, type of heating, and location by address. We have looked at correlations with many home variables but have not been able to do a thorough analysis of radon-level relations to surficial geology, which requires accurate spatial relation of home location with surficial geology maps. We are doing this by using a Geographic Information System mapping program (GIS), to which we will add boundary maps of surficial geology, derived by digitizing existing maps. The indoor radon measurement data for Albany County have been linked to latitude and longitude coordinates using the U.S. Bureau of the Census Topologically Interpreted Geographic Encoding and Referencing (TIGER) database. The surficial geology boundary map has also been prepared for Albany County and relationships of indoor radon to surficial geology are discussed. Comparisons are made for mapping indoor data using county-wide averages, zip code averages and individual measurement mapping.

Scott, A.G., 1988

Proposed criteria to define Rn-prone areas from regional surveys [letter]:

Health Physics, 54(3): 351

[Building-code adjustments to the need for "radon-resistant" construction may eventually be made on the basis of geology, which is the most important determinant of indoor radon concentration. In the meantime, areas needing special building-code requirements could be designated on the basis of the percentage exceeding a certain indoor annual average radon exposure, for example, $50 \%$ above $150 \mathrm{~Bq} / \mathrm{m}^{3}$ or $20 \%$ above $750 \mathrm{~Bq} / \mathrm{m}^{3}$, by existing surveys. Survey densities of one measurement per $2.5 \mathrm{~km}^{2}$ should be adequate to characterize areas smaller than many jurisdictions with building-code authority. The actual criteria used should be determined by an optimization process.]

Scott, A.G., 1992

Site characterization for radon supply potential: A progress review:

Health Physics, 62(5): 422-428

[At costs of radon-resistant construction prevailing a decade ago, site characterization to determine whether such construction would be needed was considered to be a worthwhile effort when compared with the cost of surveying nearby houses with expensive indoor monitors. In the meantime, cheap means of indoor monitoring (charcoal canisters and alpha-track detectors) have resulted in an unanticipated large number of indoor measurements that give a good overview of radon distribution in the U.S., eliminating the need for prediction by means of site characterization. Several different methods have been proposed, the costs of which were not specified by their proposers, but are estimated by this author at $\$ 250$ to $\$ 500$. In addition to the lack of cost effectiveness, site characterization methods are not applicable to areas of fractured bedrock or expansive clays, which are common. In general, radon-prone areas are large enough to be defined by indoor surveys in existing houses, which are the best guide as to whether radon-resistant construction should be required.]

Sextro, Richard G., 1987

Understanding the origin of radon indoors-Building a predictive capability [from Conference on Characterization of Contaminant Emissions from Indoor Sources, Chapel Hill, NC, May 13-15, 1985]:

Atmospheric Environment, 21: 431-438 [Original Pub.: Lawrence Berkeley Laboratory Rept. LBL-20210, 21 p.] Indoor radon concentrations one to two orders of magnitude higher than the U.S. average of $\approx 40 \mathrm{~Bq} / \mathrm{m}^{3}$ $(\approx 1 \mathrm{pCi} / \mathrm{L})$ are not uncommon, and concentrations greater than $4000 \mathrm{~Bq} / \mathrm{m}^{3}$ have been observed in houses in areas with no known artificially enhanced radon sources. In general, source categories for indoor radon are well known: soil, domestic water, building materials, and outdoor air. The latter two source categories have generally been found to have low radon source strengths. Domestic water supplies also typically contribute little to airborne radon concentrations, although in certain localities water has been identified as a significant 
source. Soil, on the other hand, is thought to be a major source of indoor radon, either through diffusive (usually a minor component) or bulk flow of soil gas. While soil gas flow into residences has been demonstrated, no general understanding of the important factors affecting the source strength of radon from soil has yet emerged. Preliminary work in this area has identified a number of likely issues, including the concentration of radium in the soil, the emanating fraction, soil type, soil moisture content, and other factors that would influence soil permeability and soil gas transport. A predictive capability is needed that would help identify geographical areas having the potential for high indoor concentrations. The development of such a capability will require additional scientific study of the soil-related factors discussed above, along with an exploration of existing data bases that might provide indicators of radon concentrations. In addition to soilspecific factors, and examination of the coupling between the soil and the living space provided by various building types and substructures is needed and the role of local meteorology--rainfall, wind loading, barometric pressure changes, and building thermal loads--must be assessed.

Sextro, Richard G., and Ashok J. Gadgil, 1993

Modeling radon entry into buildings: Insights for radon control [abs.], in First International Workshop on Indoor Radon Remedial Action, The Scientific Basis and Practical Applications, Rimini, Italy, 27 June-2 July 1993:

Commission of the European Communities et al., Book of Abstracts, p. 45

A variety of analytical and numerical models have been used to examine the transport of radon through soils and into buildings. In many cases, the models are limited either by the assumptions used to simplify the mathematics, the mathematics, the data used to characterize the transport media, or both. Modelmeasurement comparisons are therefore very difficult to undertake. However, model results can provide very useful insights into the factors influencing radon transport and entry, either retrospectively when used in conjunction with well-designed and controlled experiments, or prospectively in parametric studies designed to identify and examine features that may employed in radon control. The following three examples will be discussed. 1. Model verification can stimulate additional investigations of the validity of assumptions and inputs used in the simulations. The disagreement revealed in a recent comparison of experimental results with simulations using a numerical model has led to further investigations of soil permeability as an explanatory factor. It appears that soil permeability may be dependent on length scale, which, when used as a model input, leads to resolution of much of the discrepancy. 2 . The ability to model complex geometries and flows has been recently demonstrated through comparison with experimental results. These results indicate that non-Darcy flow effects in highly permeable media can be important, both in interpretation of observations and in the design of sub-slab mitigation systems. These model simulations have also provided insights into failure modes of various sub-slab mitigation systems and ways to ensure that such failures are avoided. 3. Lastly, parametric examination of features of the building-soil system can illuminate system details and suggest novel system features that are important to the radon transport and entry process. As an example, a high-permeability sub-slab layer is often specified as part of new construction techniques as a means of enhancing the effectiveness of sub-slab ventilation systems. On the other hand, numerical simulations suggest that such a layer can significantly increase radon entry rates (in the absence of a control system). Model results have suggested that the placement of an impermeable sub-gravel membrane can greatly reduce this effect. Experimental tests to confirm this are planned.

Sextro, R.G., B.A. Moed, W.W. Nazaroff, K.L. Revzan, and A.V. Nero, 1987

Investigations of soil as a source of indoor radon, Chap. 2, in Hopke, Philip K., ed., Radon and Its Decay Products; Occurrence, Properties, and Health Effects:

Washington, Am. Chem. Soc. Symposium Ser. 331, p. 10-29

The predominant source of indoor radon in most single-family housing in the U.S. is the soil adjacent to the house substructure. We have examined factors influencing the production and transport of radon in soil and into buildings. A number of important parameters have been identified and their effect on radon production and migration assessed, including radium concentration, moisture content, air permeability, and grain size distribution of soils. The potential regional variations in parameters affecting radon have been evaluated by examining geographic data, including surface radium concentrations and general soil data. We have also 
investigated factors influencing radon migration into individual dwellings. Coupling between the building shell and the surrounding soil has been demonstrated experimentally, and pressure-field mapping and soil permeability measurements have been carried out.

Sextro, R.G., Nazaroff, W.W., and Turk, B.H., 1989

Spatial and temporal variation in factors governing the radon source potential of soil, in Osborne, M.C., and Jed Harrison, Symposium Cochairmen, The 1988 Symposium on Radon and Radon Reduction Technology, Proc., Vol. 1, Symposium Oral Papers:

Research Triangle Park, N.C., Radian Corp., U.S. Environmental Protection Agency Pub. EPA/600/9-89/006a [Springfield, Va., NTIS Order No. PB89-167480], p. 5-61--5-74.

Soil is the predominant source of radon in most U.S. homes, particularly for those homes with elevated indoor concentrations. Three factors help govern the indoor radon concentration, the radon production rate in the soil, the air permeability of the soil surrounding the building substructure, and the coupling between the soil and the building. In order to evaluate the spatial and temporal variability of the first two factors, soil permeabilities and soil gas radon concentrations have been measured at different locations and as a function of time. The spatial variability in permeability measurements at an individual homesite was seen to range from approximately a factor of ten to more than four orders of magnitude. Similarly, spatial variations in soil gas radon concentrations are less than a factor of two at some homesites to a factor of about 200 at others. The temporal changes in permeability and soil gas radon at a given sampling location are somewhat smaller, yielding variations ranging from less than a factor of two to a factor of about 90 in the case of permeability, and from less than a factor of three to a factor of about $\mathbf{4 0}$ for soil gas radon concentrations. A method of combining measurements of soil gas radon and air permeability to provide a characteristic parameter - the radon source potential - has been developed and is briefly reviewed. Calculated indoor radon concentrations, based on measured values of radon source potential at a few sample homesites, correlate with the measured indoor radon concentrations.

\section{Sherman, Max, 1993}

Simplified modeling for infiltration and radon entry, in Proceedings: The 1992 International Symposium on Radon and Radon Reduction Technology, 4th, Minneapolis, Minn., Sept. 22-25, 1992. Vol. 1, Symposium Oral Papers, Opening Session and Technical Sessions I-VI:

Research Triangle Park, N.C., U.S. Environmental Protection Agency Rept. EPA-600/R-93/083a, p. 6-57-6-78 U.S. Environmental Protection Agency, Preprints, v. 2, [no. VI-4], 22 p.

Air leakage in the envelopes of residential buildings is the primary mechanism for providing ventilation to those buildings. For radon the same mechanisms that drive the ventilation, drive radon entry. This paper attempts to provide a simplified physical model that can be used to understand the interactions between the building leakage distribution, the forces that drive infiltration and ventilation, and indoor radon concentrations. Combining both ventilation and entry modeling allows an estimation of radon concentration and exposure to be made and demonstrates how changes in the envelope or ventilation system would affect it. This paper will develop simplif: 1 modeling approaches for estimating both ventilation rate and radon entry rate based on the air tightness of envelope and the driving forces. These approaches use conventional leakage values (i.e., effective leak: ea) to quantify the air tightness and include natural and mechanical driving forces. This paper introdv simplified parameter, the Radon Leakage Area, that quantifies the resistance to radon entry. To be practical for dwellings, modeling of the occupant exposures to indoor pollutants must be simple to use and not require unreasonable input data. This paper presents the derivation of the simplified physical model, and applies that model to representative situations to explore the tendencies to be expected under different circumstances.

Singler, C.R., E.C. Abram, and I.U. Khawaja, 1993

A predictive model for determining indoor radon levels in northeastern Ohio, in The 1993 International Radon Conference, Denver, Colo., Sept. 20-22, 1993: 
Denver, Colo., Am. Assoc. Radon Scientists and Technologists, Rocky Mountain Chapter, Preprints, p. IVP 12-IVP 13

An indoor radon measurement program deployed $717 \alpha$-track detectors in homes across an area of $\approx 2266 \mathrm{mi}^{2}$ in eastern Ohio.....A geologic study was conducted to determine the lithology of bedrock, nature of the glacial cover, and thickness of glacial overburden. The bedrock was mainly sandstone and shale, with lesser amounts of limestone. The overburden was dominantly of glacial origin, except for the southern half of Columbiana County (the most southerly county), where mostly non-glacial soils and alluvium occurred. The glacial cover was chiefly till, with lesser amounts of lacustrine, kame, and outwash materials. Kame and outwash were treated as similar lithologies because of textural similarities....For the study area, the following conclusions were made: (1) In eastern Ohio, higher radon levels occur in a southerly direction; (2) where there is not a glacial cover, radon levels are significantly higher; (3) elevated radon levels occur in homes over kame and outwash deposits; lower values occur over till and lacustrine deposits; and (4) radon levels are higher over sandstone than over shale or limestone. [A second study, based on charcoal-canister measurements in houses over an area of $\approx 10,000 \mathrm{mi}^{2}$ of northeastern Ohio, yielded similar results.]

Siniscalchi, Alan J., Zygmunt F. Dembek, Barbara S. Weiss, Mary-Margaret Gaudio, Jennifer C. Kertanis, Ellen P. Morris, Laurie Gokey, Paul M. Schur, David R. Brown, and Margaret A. Thomas, 1992

Radon in schools: The Connecticut experience, in The 1992 International Symposium on Radon and Radon Reduction Technology, Minneapolis, Minnesota, September 22-25, 1992:

U.S. Environmental Protection Agency, Preprints, v. 2, no. III-1, 10 p.

[One objective of the Connecticut radon program was "...to determine the contribution of various bedrock units and surficial materials to radon exposure in schools...." In order of rank, data sources used to rank radon potential of Connecticut's 169 municipalities were (1) U.S. Geological Survey aeroradioactivity data, (2) the 1986-1987 EPA/Connecticut radon survey of 1157 households in 168 of 169 towns, (3) the 1987-1988 household testing program (3409 households in 38 municipalities), and (4) Connecticut Department of Health Services/USGS bedrock well sampling data for the top 25 towns. The data sources are all incorporated into a statewide geographical information system. Interim results showed that the ranking was fairly good with respect to residential basement geometric mean radon concentrations, but not in identifying schools with at least one room with a radon level $\geq 148 \mathrm{~Bq} / \mathrm{m}^{3}(\geq 4.0 \mathrm{pCi} / \mathrm{L})$. One confounding factor was identified as the use of larger amounts of imported fill for school construction than for housing.

Siniscalchi, Alan J., Lynne M. Rothney, Brian F. Toal, Margaret A. Thomas, David R. Brown, Maria C. van der Werff, and Carolyn J. Dupuy, 1991

Radon exposure in Connecticut: Analysis of three statewide surveys of nearly one percent of single family homes, in The 1990 International Symposium on Radon and Radon Reduction Technology, Atlanta, Ga., 19-23 February 1990:

Research Triangle Park, N.C., U.S. Environmental Protection Agency Rept. EPA600/9-91-026a, Proceedings, Vol. 1: Symposium Oral Papers, Paper No. IV-1, p. 4-1-4-14 [NTIS Order No. PB91-234443/AS]

[Excerpt from text, p. 4-3] Geologic, hydrologic, and household parameters were analyzed for their ability to predict radon levels. Figures 2 and 3 show the mean water and air radon levels, respectively, compared with the bedrock classifications as shown on the Connecticut part of a generalized bedrock mapping scheme of New England. Geology was a significant predictive factor of radon in both private well water and indoor air, with granitic and sedimentary formations associated with higher and lower radon levels, respectively. While the radon potential of bedrock may be generally characterized by such data, it is possible that water radon levels alone are sufficient to estimate the geologic radon potential. Indoor air radon measurements represent radon emissions not only from bedrock, but also from surficial materials and also appear to vary significantly with various household factors. Hydrologic factors, foundation type, and energy efficiency were examined. Only the depth of unconsolidated material overlying the bedrock had a strong positive correlation with private wellwater radon levels. Homes with block wall foundations had higher indoor air radon levels than those with other types of foundation. Homes characterized by the homeowner as being more energy efficient did not have higher indoor air radon levels than homes characterized as being less energy efficient. 
Slunga, E[ero], 1988

Radon classification of building ground:

Radiation Protection Dosimetry, 24(1/4): 39-42

[Ground on which buildings are to be constructed is classified with respect to indoor radon potential as negligible, normal, high, or very high. The basic consideration is the radium content of the soil and/or the radon content of the air in the pores of the soil, the respective ranges of radium content $(\mathrm{Bg} / \mathrm{kg})$ being $0-35$, $35-100,100-500$, and $>500$. A refinement is the "radon activity number," based on $\mathrm{C}_{\mathrm{sb}}\left(\mathrm{Bq} / \mathrm{m}^{3}\right)$, which is either the maximum radon content of the soil pores with the natural (annual average) water content or twice the radon content measured at a depth of $1 \mathrm{~m}$, whichever is greater, and the air permeability of the soil $\left(\mathrm{m}^{2}\right)$, by the relation, Radon activity number $\left(R n_{a}\right)=\log \left(6 C_{s b} / k^{-1 / 13}\right)-3$. Values of $R n_{a}$ of $0-1,1-2,2-3$, and $>3$ classify the ground by the respective classes above. The steady-state value of the radon content of the ground next to a building foundation $\left(\mathrm{C}_{\mathrm{ss}}\right.$, in $\left.\mathrm{Bq} / \mathrm{m}^{3}\right)$ can be estimated by $\mathrm{C}_{\mathrm{ss}}=10^{(\mathrm{Rna}+3)}$. (See Viljanen et al., 1987.) Examples of soils, radium and radon contents, soil thicknesses, and the rocks from which the soils are derived are given for each class.]

Smith, Douglas L., and John K. Hansen, 1989

Distribution of potentially elevated radon levels in Florida based on surficial geology:

Southeastern Geology, 30(1): 49-58

[Indoor radon potential in Florida is expected to be significant where members of the Hawthorn Group occur within $50 \mathrm{ft}(15 \mathrm{~m})$ of the surface. Subdivisions of the Hawthorn Group were evaluated for uranium content from available data and recent $\boldsymbol{\gamma}$-ray spectrometric measurements. Each county was then rated for "equivalent surface" of uranium presence according to the summation of $\left(A_{i} D_{i} C_{i}\right)$, where $A_{i}$ is the percentage of the county area in which the $i$ th geologic unit is exposed; $D_{i}$ is the depth of overburden above that unit, classified as 1 for surface occurrence, 0.75 for $10-30 \mathrm{ft}, 0.25$ for $30-50 \mathrm{ft}$; and $C_{i}$ is the uranium concentration evaluation for the unit, classified as 1 for $>10 \mathrm{ppm}, 0.5$ for $3-10 \mathrm{ppm}$, and 0 for $<3 \mathrm{ppm}$. A table gives the calculated equivalent surface areas of 29 counties, ranging from $65 \%$ for Desoto and Union Counties to $5 \%$ for Liberty County. Southeastern Florida, which showed definite evidence of radon potential in another survey, was not indicated to have significant radon potential from the Hawthorn Group.]

Smith, Geoffrey W., Royal H. Mapes, Robert J. Hinkel, and Rick L. Darr, 1989

Radon hazards associated with glacial deposits in Ohio [abs.]:

Geol. Soc. America, Abstracts with Programs, 21(6): A144

Examination of the distribution of uranium in Ohio indicates that the principal geologic controls of uranium occurrence are black shales of Devonian and Mississippian age and surficial glacial materials of Quaternary age. Recent studies indicate a direct correlation between uranium distribution and radon concentration in homes throughout the state. Glacial deposits of at least three glacial stages cover more than two-thirds of Ohio. These deposits include (a) glacial till, comprising ground moraine and end moraine, (b) glaciofluvial sediments, including kame deposits and outwash, and (c) glaciolacustrine sediments. The occurrence and distribution of these materials can be directly related to several factors controlling sediment deposition. Thirteen Ohio counties were selected for radon evaluation on the basis of the distribution of different glacial materials with about 50 homes per county being sampled. In addition, open air soil radon levels were measured, as were radon levels of bulk soil samples in the laboratory. Preliminary analysis of the data indicates that: (1) permeability of glacial materials is of first-order importance in controlling home radon concentrations, (2) composition of glacial materials, including both granitic erratics and locally-derived black shales is important in controlling local radon concentrations, and (3) glacial geologic factors, in most instances, override the effects of both underlying bedrock geology and aspects of house construction. The results of this study bear significantly on an understanding of the distribution of radon in glaciated regions of the United States.

Solomon, Barry J., Bill D. Black, Dane L. Finerfrock, and John Hultquist, 1993 
Geologic mapping of radon-hazard potential in Utah, in The 1993 International Radon Conference, Denver, Colo., Sept. 20-22, 1993:

Denver, Colo., Am. Assoc. Radon Scientists and Technologists, Rocky Mountain Chapter, Preprints, p. IVP 14-IVP 28

Geologic data were used to map potential radon hazard areas in Utah. The first statewide map identified rock uranium sources, but did not systematically evaluate populated areas underlain by unconsolidated valley fill. Subsequent indoor testing identified high radon levels in some of this valley fill. Detailed geologic studies and targeted indoor surveys were performed in six areas with high indoor-radon levels. Initially, these studies assigned hazard potentials to Quaternary geologic units, assuming that each unit was relatively homogeneous. Indoor radon levels were used for model validation. Later studies used overlays of specific geologic factors (uranium content, permeability, and ground-water depth) to derive a composite hazard map, with hazard categories independent of geologic units. Soil-gas radon concentrations were used for validation with exclusion isolines, a semiquantitative analysis technique that minimizes the effect of factors which differentially reduce soil-gas radon concentrations. Hazard potential maps derived from overlays effectively identify potential hot spots, and do not rely upon either geologic or artificial political boundaries to constrain hazard interpretations. The overlay method was used to revise the statewide radon hazard potential map, and assessments of hazard potential from detailed field investigations correlate well with those on the revised statewide map. Central Utah has the highest radon hazard potential, primarily due to uranium-enriched Tertiary volcanic rocks. Western Utah has the lowest radon hazard potential, due to limitations on radon emanation and migration imposed by impermeable soils and shallow ground water common in basins.

Southern Research Institute, [1989]

Florida Radon Research Program. Standard measurement protocols. Part 1. Soil measurements:

Birmingham, Ala., Southern Research Institute, 129 p.

[This report, prepared for the State of Florida Department of Community Affairs, is a compilation of procedures obtained from various sources, mostly from the American Society for Testing and Materials (ASTM), Philadelphia, Pa. They are: (1) Draft Protocol for Soil Gas Permeability and Radon Measurement and for Insitu Soil Density Sampling and Soil Sample Collection (Rogers and Associates Engineering Corporation, Salt Lake City, Utah); (2) [Draft] Measurement of Radium-226, Radon Emanation Coefficient and Moisture Content on Large ( $\approx$ Quart) Core and Surface Soil Samples (Department of Environmental Engineering Sciences, University of Florida, Gainesville, Fla.); (3) Protocol for Soil Density Profiling using a Barkley and Dexter Model HP-102 Penetrometer [incorporating ASTM D 1586-84 Standard Method for Penetration Test and Split-Barrel Sampling of Soils] (University of Florida); (4) ASTM D 2216-80 Standard Method for Laboratory Determination of Water (Moisture) Content of Soil, Rock, and Soil-Aggregate Mixtures; (5) Standard Proctor, incorporating ASTM D 698-78 Standard Test Methods for Moisture-Density Relations of Soils and Soil-Aggregate Mixtures Using 5.5-lb (2.49-kg) Rammer and 12-in. (305-mm) Drop; (6) In-situ Soil Density, incorporating ASTM D 2937-83 Standard Test Method for Density of Soil in Place by the DriveCylinder Method; (7) Soil Particle-Size Analysis, incorporating ASTM D 422-63 Standard Method for ParticleSize Analysis of Soils; (8) Specific Gravity of Soils, incorporating ASTM D 854-83 Standard Test Method for Specific Gravity of Soils; (9) Procedure for Laboratory Measurements of Air Permeability of Sub-Slab Land Fill (authorship not indicated); (10) Soil Classification, incorporating ASTM D 2487-85 Standard Test Method for Classification of Soils for Engineering Purposes, and ASTM D 2488-84 Standard Practice for Description and Identification of Soils (Visual-Manual Procedure); (11) Radon Diffusion Coefficient, incorporating NUREG/CR-2875, Comparison of Radon Diffusion Coefficients Measured by Transient-Diffusion and SteadyState Laboratory Methods, by D.R. Kalkwarf, K.K. Nielson, D.C. Rich, and V.C. Rogers (1982); and (12) Radon Flux, incorporating Radon Flux Measurement by Charcoal Cartridge, by C.E. Roessler, Health Physics Section, Department of Environmental Engineering Sciences, University of Florida, Gainesville, Fla. (1987).]

Spears, John W., Harry E. Rector, and David P. Wentlin, 1992

Evaluating radon-resistant construction practices in Florida, in The 1992 International Symposium on Radon and Radon Reduction Technology, Minneapolis, Minnesota, September 22-25, 1992: 
U.S. Environmental Protection Agency, Preprints, v. 4, no. XI-6, 20 p.

This paper discusses the results of an evaluation of the radon resistance of 20 new homes built in accordance with the Florida draft radon construction code provisions. This project is part of the ongoing Florida Radon Research Program. Preconstruction soil measurements included soil permeability, soil gas radon, radium content, and other physical properties of the soil. Postconstruction measurements included indoor radon, subslab radon, pressure differentials, pressure field extension, duct leakage, air infiltration, and air leakage. Radon entry rate or soil gas entry rate was estimated by using perfluorocarbon tracers (PFTs) buried in the soil arc measuring the soil-based PFT concentrations in the home. Recommendations on improving the code are given.

Speer, J. Alexander, Gregory T. Bertwell, Kevin W. Hoff, and Thomas J. Douglas, 1993

Using heat flow measurements to estimate and verify the total radon hazard potential of granites, southeastern United States, in The 1993 International Radon Conference, Denver, Colo., Sept. 20-22, 1993:

Denver, Colo., Am. Assoc. Radon Scientists and Technologists, Rocky Mountain Chapter, Preprints, p. IV 10-IV 19

Determining the radon hazard potential posed by large rock units can be done using large-scale soil gas and ground-water surveys. However, an easier approach or some independent demonstration that all radon is being inventoried is often desired. One method is to use existing geologic mapping, rock, and soil uranium contents, and to rely on the observed positive correlation between uranium and radon contents. However, heat-flow measurements can also be used. The most important modification of Earth heat flow from the mantle in the southern Appalachian Piedmont is the heat contributed by the average radioactive element content in the rocks within a few kilometers of a heat-flow measurement site. Thus the added heat flow is a crustal-scale measure of uranium, which is both an important contributor to crustal heat production and [a precursor] of ${ }^{222} \mathrm{Rn}$. Soilgas and ground-water radon contents for 10 heat-flow sites in North Carolina, South Carolina, and Georgia show an increase of ground-water and soil-gas radon with increasing heat flow. Those rocks associated with lower-than-expected radon contents are interpreted as having either uranium that was preferentially lost during soil formation or was unsuitably sited for radon emanation into the ground water and soil gas.

Sprinkel, Douglas A., 1988

Assessing the radon hazard in Utah:

Utah Geological and Mineral Survey, Survey Notes, 22(4): 3-13

[This article first gives a layman's overview of what radon is, why it is a health hazard, and the basic processes of radon emanation and movement. Then possible areas of high indoor radon potential are discussed in two basic categories: "point sources," known uranium occurrences, including uranium mines and prospects, other reported places of uranium enrichment, and geothermal areas; and "generalized sources," areas of rock types having elevated uranium concentration, and the Wasatch fault zone. A generalized radon potential map is presented at a scale of about 1:2.6 million. Procedures for making indoor radon measurements, following USEPA guidelines are given.]

Steck, Daniel J., 1988

Geological variation of radon sources and indoor radon along the southwestern edge of the Canadian Shield, in Marikos, Mark A., and Robert H. Hansman, eds., Geologic Causes of Natural Radionuclide Anomalies, Proceedings of the GEORAD Conference, St. Louis, Mo., April 21-22, 1987:

Rolla, Mo., Missouri Dept. Nat. Rexources, Div. Geology and Land Survey Spec. Pub. No. 4, p. 17-23

Radon source and indoor radon cosentrations were measured in 70 houses and a number of other sites along the southwestern edge of the Canadian Shield. Waterborne radon activity ranges from 400 to $3.6 \times 10^{5} \mathrm{~Bq} / \mathrm{m}^{3}$ (10 to $10^{4} \mathrm{pCi} / \mathrm{L}$ ), and appears to be log-normally distributed, with an average value of $8600 \mathrm{~Bq} / \mathrm{m}^{3}$ $(230 \mathrm{pCi} / \mathrm{L})$. Soilborne radon was determined by four techniques. In laboratory analysis, samples showed an average available radon emanation of $4 \mathrm{~Bq} / \mathrm{kg}(0.1 \mathrm{pCi} / \mathrm{g})$, and an average radon activity of $34 \mathrm{~Bq} / \mathrm{kg}$ $(0.8 \mathrm{pCi} / \mathrm{g})$. The in situ surface bismuth-214 activity ranged from 10 to $100 \mathrm{~Bq} / \mathrm{kg}(0.2$ to $2 \mathrm{pCi} / \mathrm{g})$ and the 
soil gas radon activity averaged $5 \mathrm{kBq} / \mathrm{m}^{3}(100 \mathrm{pCi} / \mathrm{L})$. Indoor airborne radon activity ranged from 20 to $1100 \mathrm{~Bq} / \mathrm{m}^{3}$ (0.5 to $\left.30 \mathrm{pCi} / \mathrm{L}\right)$ and varied with season, year, compartment, and local geology.

Steck, D.J., and M.J. Bergmann, 1992

Indoor radon and the radon potential of soils, in The 1992 International Symposium on Radon and Radon Reduction Technology, Minneapolis, Minnesota, September 22-25, 1992:

U.S. Environmental Protection Agency, Preprints, v. 3, no. VIII-1, 15 p.

Subsurface soil samples, collected adjacent to 110 Upper Midwest houses, were measured to determine radon emanation, diffusivity, and permeability. The soilborne radon characteristics of the samples of glacial till that covers most of the region varied by a factor of ten or more. A Monte Carlo model was used to calculate indoor radon concentrations in idealized basements sited in a homogeneous medium whose radon properties matched the soil sample properties. Measured basement radon concentrations correlate with the model predictions. The correlation is more useful to assess clusters of homes than individual dwellings.

Stieff, L.R., C.B. Stieff, and R.A. Nelson, 1987

Field measurements of in situ ${ }^{222} \mathrm{Rn}$ concentrations in soil based on the prompt decay of the ${ }^{214} \mathrm{Bi}$ counting rate: Nuclear Geophysics, 1(2): 183-195

Indirect field measurements of the in situ Rn-222 concentations in sealed samples of soil have been made based on the prompt decay of the Bi-214 counting rate in the 2-hr interval immediately following sample collection. Subsequent Bi-214 measurements yield estimates of the $\mathrm{Rn}-222$ lost during sample collection and the concentration of Ra-226 in the samples. These data may be used in the measurement of in situ Rn-222 concentration gradients, the characterization of the state of $\mathrm{Ra}-226 / \mathrm{Rn}-222$ equilibrium in soil samples, and calculation of $R \mathbf{n}-222$ surface flux.

Stieff, L.R., and H.B. Stieff, 1988

The use of in situ ${ }^{222} \mathrm{Rn}$ soil measurements in the characterisation of soil profiles:

Radiation Protection Dosimetry, 24(1/4): 73-77

Stranden, E., and A.K. Kolstad, 1985

Radon exhalation from the ground; method of measurements and preliminary results:

The Science of the Total Environment, 45: 165-171

Stranden, E., K. Ulbak, H. Edhwall, and N. Jonassen, 1985

Measurement of radon exhalation from the ground: A useful tool for classification of the radon risk of building ground:

Radiation Protection Dosimetry, 12: 33

Styra [Styro], B.I., T.N. Nedveckaite, and E.E. Senko [Sen'ko], 1970

New methods of measuring thoron (radon 220) exhalation:

Jour. Geophys. Research, 75(18): 3635-3638 [in Russian, 1969 (pub. 1972) in Inst. Eksp. Meteorologii Trudy, no. 25, pt. 2, p. 109-116]

Geophys. Abs. 288-385

Surbeck, H[einz], 1988

The search for radon sources, a multidisciplinary task:

Radiation Protection Dosimetry, 24(1/4): 431-434

Surbeck, H., and Piller, G., 1989

A closer look at the natural radioactivity in soils, in Osborne, M.C., and Jed Harrison, Symposium Cochairmen, The 1988 Symposium on Radon and Radon Reduction Technology, Proc., Vol. 1, Symposium Oral Papers: 
Research Triangle Park, N.C., Radian Corp., U.S. Environmental Protection Agency Pub. EPA/600/9-89/006a [Springfield, Va., NTIS Order No. PB89-167480], p. 5-13--5-26.

Enhanced indoor radon levels are frequently found in the western part of the Swiss Jura Mountains, a karst region. The Ra-226 activity in the limestone bedrock is low $(20 \mathrm{~Bq} / \mathrm{kg})$. In the thin soil overburden the $\mathrm{Ra}-226$ concentration is 2 to 3 times higher than in soil samples from the Swiss Plateau but on the average still below $100 \mathrm{~Bq} / \mathrm{kg}$. It is supposed that the radon problem in this region is due to the high permeability of the karst bedrock. A sampling device for radon in soil gas measurement is described that permits a coarse in-situ soil permeability determination. Specific activity vs. grain size measurements for some Swiss soils and the high activities found in heavy minerals are presented and a possible aeolian origin of the soils in the western Jura is discussed.

Surbeck, H., H. Völkle, and W. Zeller, 1991

Radon in Switzerland, in The 1991 International Symposium on Radon and Radon Reduction Technology, Philadelphia, Pa., April 2-5, 1991, Proc., Volume 2, Symposium Oral Papers, Technical Sessions 6 through 10: U.S. Environmental Protection Agency Rept. EPA/600/9-91/037B, p. 6-31-6-46

McLean, Va., Cohen (S.) and Associates, Inc. [Springfield, Va., NTIS Order No. PB92-115369]

[Preprints, v. 3, no. VI-3]

Based on measurements in nearly 1600 homes, representing $0.15 \%$ of the housing stock, we estimate that the Swiss live on the average in rooms with a radon concentration of $80 \mathrm{~Bq} / \mathrm{m}^{3}$ and that $5 \%$ of them are exposed to concentrations exceeding $200 \mathrm{~Bq} / \mathrm{m}^{3}$. Radon research in Switzerland started nearly a decade ago and shows that the building materials and household water use present no serious radon problems, the soil being the main source. The highest values are found in homes on highly permeable building grounds (karst terrains, rockslides). We discuss the results of the radon surveys and explain how we try to get a representative exposure estimate from biased data. We also present geological aspects of the radon situation in our country and outline the policy for the new decade that will see surveys concentrated on the search for hot spots....

Swedish Radon Commission (Radonutredningen), 1983

Radon in dwellings. Report from the Radon Commission [in Swedish]:

Stockholm, Ministry of Agriculture, SOU 1983:6, 145 p. [ISBN 91-38-07433-8]

[A translation summary of chapter 6 says that the factors affecting radon released from rocks and soils are uranium content, soil, particle size, weathering, type and siting of uranium within the rock minerals, moisture content, permeability, gas transport, and other items, in a complicated way. Houses built on eskers have a much higher probability of having high radon in them than do houses built on other materials, probably because of the high permeability in the rock and sandy materials in the eskers. Houses built over clay have on the average much lower radon levels, probably due to the (low) permeability of the clay soils. Alum shales, granites, pegmatites, and many glacial materials have high potential for causing elevated indoor radon. Experts believe that the average $15 \mathrm{~Bq}$ of radon/L of ground water in Sweden $(400 \mathrm{pCi} / \mathrm{L})$ is not a major contributor to the radon in the houses. Chapter 9 defines high risk areas as those having soils with radon levels $>50$ $\mathrm{kBq} / \mathrm{m}^{3}$, low risk areas $<10 \mathrm{kBq} / \mathrm{m}^{3}$, and normal risk in between. For clay soils, $>100 \mathrm{kBq} / \mathrm{m}^{3}$ would signal a high-risk area.]

Swedjemark, Gun Astri, 1982

Buildings with enhanced radioactivity in Sweden, in Vohra, K.G., U.C. Mishra, K.C. Pillai, and S. Sadasivan, eds., Natural Radiation Environment:

New York, John Wiley and Sons, p. 535-542, disc., 542-543

The $\mathrm{Ra}-226$ content of various house building materials and the radon levels indoors in Sweden have been evaluated. In houses built entirely of alum shale concrete the indoor radon levels were between 200 and $1200 \mathrm{~Bq} / \mathrm{m}^{3}(5-32 \mathrm{pCi} / \mathrm{L})$, and the indoor absorbed dose rates from gamma radiation were 35-69 $\mu \mathrm{r} / \mathrm{hr}$. Houses built in regions with enhanced radium content showed higher radon levels indoors. Various countermeasures have been adopted to reduce the indoor radon levels. 
Szarzi, S.L., G.M. Reimer, and J.M. Been, 1992

Soil-gas and indoor radon distribution related to geology in Frederick County, Maryland, in Cross, Fredrick T., ed., Indoor Radon and Lung Cancer: Reality or Myth? Twenty-ninth Hanford Symposium on Health and the Environment, Richland, Wash., October 15-19, 1990, Proceedings:

Columbus, Ohio, Battelle Press, Part 1, p. 437-448 [NTIS]

The two major physiographic provinces that occur in Frederick County, Maryland, are the Piedmont and the Blue Ridge. Soil-gas measurements were taken for a study designed to show the relationship between geology and soil-gas radon concentrations. The local geology causes varied soil-gas concentrations that contribute to radon availability for indoor accumulations. The western part of the county, where quartzites form the core of ridge and mountains, has a mean soil-gas radon concentration of $26 \mathrm{kBq} / \mathrm{m}^{3}(700 \mathrm{pCi} / \mathrm{L})$. The eastern part of the county, containing the phyllites of the Piedmont Province, has a mean soil-gas concentration of $59 \mathrm{kBq} / \mathrm{m}^{3}$ $(1600 \mathrm{pCi} / \mathrm{L})$. In the southeast part of the county, where soil-gas radon concentrations exceeded $75 \mathrm{kBq} / \mathrm{m}^{3}$ $(2000 \mathrm{pCi} / \mathrm{L})$, the average indoor radon concentration (from charcoal canister measurement) was $1.9 \mathrm{kBq} / \mathrm{m}^{3}$ $(50 \mathrm{pCi} / \mathrm{L})$. This observation supports previous work showing that the soil-gas radon concentration is a primary component in determining the coupling characteristics of radon transport between soils and homes. Data acquired by studies such as these throughout the United States are essential to identify regional radon "hot spots" which may produce elevated indoor radon levels of unquestioned risk. [From final program]

Taipale, T.T., and K. Winqvist, 1985

Seasonal variations in soil gas radon concentration:

The Science of the Total Environment, 45: 121-126

Tanner, Allan B., 1957

Physical behavior of radon, in U.S. Geological Survey, Geologic investigations of radioactive deposits, semiann. progress report, June 1 to November 30, 1957:

U.S. Geol. Survey Rept. TEI-700: 243-246

[Cells for measuring the $\alpha$ activity from radon in flowing soil gas were constructed of an open-ended aluminum can with its inside frosted, viewed by a type 5819 photomultiplier tube, a brass inlet tube leading through a hole in the closed end of the aluminum can to a discharge point near the face of the photomultiplier tube, a brass outlet tube leading from behind the closed end, and an outer "2-inch" diameter pipe and O-ring seals to provide hermetic sealing of the system, except for the inlet and outlet tubes. A soil-gas extraction probe, employing a two-packer system patented by G.L. Hassler (1940) and providing a guard against atmospheric dilution, was used with a laboratory vacuum pump, vinyl tubing, stopcocks, and gauges. The photomultiplier output was fed to a ratemeter and recorder. The system yielded $\approx 1$ count $/ \mathrm{min}$ per $40 \mathrm{~Bq} / \mathrm{m}^{3}\left(1 \mathrm{pCi}^{222} \mathrm{Rn} / \mathrm{L}\right)$ of soil gas. The system was used in a hand-augered borehole above a uranium deposit at 3-m depth in dry ground in Karnes County, Texas. A reduction in the radon concentration from $\approx 0.44$ to $0.13 \mathrm{MBq} / \mathrm{m}^{3}$ ( $\approx 12$ to 3.4 $\mathrm{nCi} / \mathrm{L}$ ) was found at a depth of $86 \mathrm{~cm}$, indicating that the radon was not migrating from the deposit itself. Alpha spectrometry of soil samples indicated that the radon was derived from local ${ }^{226} \mathrm{Ra}$ and ${ }^{230} \mathrm{Th}$ over distances of a few $\mathrm{cm}$.]

Tanner, Allan B., 1986

Geological factors that influence radon availability, in Indoor Radon, Proceedings of the APCA International Specialty Conference, Philadelphia, Pa., February 24-26, 1986:

Air Pollution Control Assoc., P.O. Box 2861, Pittsburgh, PA 15230, Pub. SP-54, p. 1-12

There is great need for the characterization of localities with respect to their potential for supplying radon to structures, especially where the number of existing structures is insufficient for valid sampling. Although the interaction between a structure and the ground is not quantitatively known, it is practical to assume that the ground can be characterized as to the rate at which radon can be drawn from it by a structure: a measure of radon availability. Radon availability is related mainly to the concentration of radon in the spaces in rock fractures and soil pores and to the permeability of the ground to gases. The fraction of radium disintegrations producing radon that reaches those spaces usually falls within the range of 0.15 to 0.55 . Permeability and the 
diffusion coefficient are reduced markedly as the sizes of those spaces are reduced and as the proportion of the spaces filled by liquids is increased. Coupling this knowledge with that of the geology, soil, hydrology, and topography of a locality should permit qualitative evaluation of radon availability. Rock types that usually have above-average concentrations of radon in the pore and fracture spaces include granites, some gneisses, phosphatic rocks, marine shales, and some recrystallized limestones and dolomites. Construction of buildings in contact with such rocks, if fractured, requires special radon barriers. Residual soils, notably terra rossas, are often enriched in radium. Ground with coarse grain size (such as gravels and coarse sands), particularly if well drained, is highly permeable and apt to make more radon available than would be expected on the basis of its radium content. At the other extreme, muds and clays tend to be of low permeability, especially if wet. Ground that does not pass a percolation test should have low radon availability unless enriched in radium. Buildings located on hillsides and ridges are more apt to be located on soils that are coarser and better drained than those in adjacent valleys. Other things being equal, radon availability should be greater on hillsides and ridges.

Tanner, Allan B., 1988

Measurement of radon availability from soil, in Marikos, Mark A., and Robert H. Hansman, eds., Geologic Causes of Natural Radionuclide Anomalies, Proceedings of the GEORAD Conference, St. Louis, Mo., April 21-22, 1987:

Rolla, Mo., Missouri Dept. Nat. Resources, Div. Geology and Land Survey Spec. Pub. No. 4, p. 139-146.

A method is under development to evaluate the intrinsic ability of the ground at a specific site to be a source of indoor radon. Radon availability, a quantity that indicates a practical upper limit to the amount of radon that can be drawn into a structure from the soil, is here defined as the radon concentration in the soil pores multiplied by the mean one-dimensional migration distance of radon in a homogeneous soil. This distance is calculated from the effective diffusion coefficient and a steady-state convection velocity calculated from the gas permeability of the soil in question, by using an arbitrary standard driving-pressure difference. From estimated extreme ranges of radon concentration, effective diffusion coefficient, and gas permeability, radon availability values should range from $10 \mathrm{~Bq} / \mathrm{m}^{2}\left(3 \times 10^{2} \mathrm{pCi} / \mathrm{m}^{2}\right)$ to $10^{8} \mathrm{~Bq} / \mathrm{m}^{2}\left(3 \times 10^{9} \mathrm{pCi} / \mathrm{m}^{2}\right)$, although it is unlikely that the higher end of the range would be realized. A practical method of determining radon availability is based on analyzing the radon concentration in air drawn from a small augered hole in the ground, simultaneously measuring permeability in situ, and estimating the effective diffusion coefficient by means of soil type and moisture content. Measurements are being made in places where indoor radon concentrations are known, in order to test the utility of the method and the spatial and temporal variations of radon availability.

Tanner, A.B., 1988

A tentative protocol for measurement of radon availability from the ground, in Natural Radioactivity, International Symposium on the Natural Radiation Environment, 4th, Lisbon, Portugal, December 7-11, 1987, Proceedings:

Radiation Protection Dosimetry, 24(1/4): 79-83

A procedure is being tested in order to determine its suitability for assessing the intrinsic ability of the ground at a particular site to supply ${ }^{222} \mathrm{Rn}$ to a basement structure to be built on the site. Soil gas is sucked from a borehole probe through an alpha scintillation chamber and flow meter by a pump. The permeability of the soil is calculated from the flow rate and the pressure difference between the atmosphere and the borehole at the intake point. The diffusion coefficient is estimated from the water fraction in the soil pores. The upward migration distance for radon in such soil during one mean life is computed for an arbitrary steady pressure difference. This mean migration distance, multiplied by the measured radon concentration, gives the "radon availability number." Measurements at sites of known indoor radon concentration suggest that numbers below $2 \mathrm{kBq} / \mathrm{m}^{2}$ indicate little chance of elevated indoor radon and above $20 \mathrm{kBq} / \mathrm{m}^{2}$ indicate that elevated indoor radon is likely. The range of uncertainty and the point-to-point and seasonal variations to be expected are under investigation.

Tanner, Allan B., 1988 
A tentative protocol for measurement of radon availability from the ground:

Northeastern Environmental Science, 7(1): 58-62

[A slightly revised version of the above paper.]

Tanner, A.B., 1989

Error in measuring radon in soil gas by means of passive detectors [abs.]:

Eos, Am. Geophys. Union Trans., 70(15): 497

Passive detection of radon isotopes depends on diffusion of radon atoms from the sites of their generation to the location of the detecting or collecting device. Examples of passive detectors are alpha-track and electret detectors, charcoal-canister and organic-liquid radon collectors, and gamma-ray detectors placed in nonradioactive permeable material thick enough to shield the detector from direct gamma rays from radon sources in the soil. Because some radon decays en route to a passive detector in soil, the radon concentration measured by the detector must be less than the radon concentration in the interstitial spaces of the soil where the concentration is undiminished by diffusion to the detector cavity. The maximum radon concentration measured by a passive method can be modeled by diffusion from an isotropic, homogeneous medium inward along the radii of a spherical cavity. The approximate minimum radon concentration can be modeled by diffusion along radii of a cylindrical cavity. Analytic solutions for diffusion in these models indicate that at less than about 80 percent water saturation there is little underestimation of the true soil-gas ${ }^{222} \mathrm{Rn}$ concentration if the detector cavity diameter is less than about $5 \mathrm{~cm}$, but the underestimation is serious in a cavity $1 \mathrm{~m}$ in diameter. The degree of underestimation is strongly dependent on the degree of water saturation of the soil pores; thus, some observed fluctuations of radon concentration in soil gas measured by passive detectors may be due entirely to variation in the water content of the soil.

Tanner, A.B., 1989

A tentative protocol for measurement of radon availability from the ground, in Osborne, M.C., and Harrison, Jed, Symposium Cochairmen, The 1988 Symposium on Radon and Radon Reduction Technology, Proc., Vol. 2, Symposium Poster Papers:

Research Triangle Park, N.C., Radian Corp., U.S. Environmental Protection Agency Pub. EPA/600/9-89/006b [Springfield, Va., NTIS Order No. PB89-167498], p. 3-15--3-24.

Tanner, Allan B., 1989

The source of radon in houses, in Harley, N.H., ed., Radon. Proceedings of the Twenty-Fourth Annual Meeting of the National Council on Radiation Protection and Measurements, Washington, D.C., 30-31 March 1988:

Bethesda, Md., Natl. Council on Radiation Protection and Measurements, Proc. ser., no. 10: 159-168

[Methods of estimating values of critical factors for radon potential mapping are discussed.]

Tanner, A.B., 1991

Error in measuring radon in soil gas by means of passive detectors:

Nuclear Geophysics, 5(1/2): 25-30

[Examples of passive detectors are $\alpha$-track, electret, and semiconductor cups; charcoal-canister and organic-liquid radon collectors; and $\boldsymbol{\gamma}$-ray detectors placed in nonradioactive permeable material thick enough to shield the detector from the direct $\boldsymbol{\gamma}$ rays from radon sources in the soil. Radon detection by passive methods depends primarily on diffusion of radon from the soil into the detector cavity. Because some radon decays en route to the cavity, the radon concentration in the cavity is necessarily less than in the gas phase of pores in the soil where the radon concentration is undiminished by migration to the cavity. The true radon concentration may be significantly underestimated in moist soils. Analytic expressions, based on models of spherical and cylindrical diffusion paths, are presented to permit calculation of the degree of underestimation.]

Tanner, Allan B., 1991

Methods of characterization of ground for assessment of indoor radon potential at a site, in Gundersen, Linda C.S., and Richard B. Wanty, eds., Field studies of radon in rocks, soils, and water: 
U.S. Geol. Survey Bulletin no. 1971, p. 1-18

The concentration and mobility of radon-222 in soil interstices control the potential of ground to supply radon to a structure. Radon mobility depends on its diffusivity and on the permeability of the ground to fiow of soil gas. Several soil-probe methods currently under development can be used to measure the radon concentration in soil gas and to obtain gas-flow characteristics from which the gas permeability of the ground can be inferred. The radon diffusion coefficient can be inferred from measurements of the porosity and pore water fraction of samples of soil removed for emplacement of the soil probe. General principles of soil development and tests made with a special soil probe indicate that layered soils are more permeable to gas flow in the horizontal than in the vertical direction, although cracking in soils can cause high vertical permeability along the cracks. Soil cracks and rock fracture systems pose problems of test-probe spacing and modeling that have not been resolved. Changes in the degree of pore water saturation can affect the radon concentration in the gas phase by as much as a factor of 4 and radon mobility by as much as 3 orders of magnitude. In order to lessen the effects of short-term meteorological and seasonal changes on characterization of the ground, soil-probe measurements should be made as deeply as is feasible, ideally to the depth of the slab of a building to be constructed at the site. For slab-on-grade and crawl-space house sites, the soil may be best characterized by means of soil-gas accumulators operated with a degree of suction comparable with that exerted by a house during the season in which the house is heated.

Tanner, Allan B., 1991

The role of diffusion in radon entry into houses, in The 1990 International Symposium on Radon and Radon Reduction Technology, Atlanta, Ga., 19-23 February 1990:

Research Triangle Park, N.C., U.S. Environmental Protection Agency Rept. EPA600/9-91-026b, Proceedings, Vol. 2: Symposium Oral Papers, Paper No. V-2, p. 5-21-5-32 [NTIS Order No. PB91-234450/AS]

Pressure-driven flow of radon-bearing soil gas is commonly accepted as the usual mechanism whereby radon moves from the exterior of a house foundation to cause an elevated indoor radon concentration. It is less clear how radon moves to the backfill-and-subslab zone just outside the foundation. Twenty-three houses having elevated indoor radon concentrations were investigated by the U.S. Environmental Protection Agency and its contractors. The permeability of the ground to gas flow was measured next to and several meters from each house foundation. For 6 of the 23 houses none of the permeability values exceeded $8 \times 10^{-12} \mathrm{~m}^{2}$, below which diffusion is likely to be the dominant mechanism of radon movement. Because it can be significant in unsaturated soils of moderate-to-low permeability, diffusion should not be ignored in considering radon movement to house foundations.

Tappan, J. T[ell], 1989

Passive radon reduction techniques for existing and new structures, in Osborne, M.C., and Jed Harrison, Symposium Cochairmen, The 1988 Symposium on Radon and Radon Reduction Technology, Proc., Vol. 1, Symposium Oral Papers:

Research Triangle Park, N.C., Radian Corp., U.S. Environmental Protection Agency Pub. EPA/600/9-89/006a [Springfield, Va., NTIS Order No. PB89-167480], p. 7-29--7-50.

[Open land was evaluated for a planned major residential development near Carefree, Arizona. Portable gamma survey of the granitic terrane indicated about twice normal background $(20 \mu \mathrm{R} / \mathrm{hr})$. Elevated indoor radon (to $241 \mathrm{~Bq} / \mathrm{m}^{3}$ or $6.5 \mathrm{pCi} / \mathrm{L}$ ) was present with the house heating system on for a $14 \mathrm{hr}$ period, but not with the house heating system off for a 14-hr period during which the indoor temperature was lower than the outdoor temperature.--ABT]

Terry, David B., and Robert D. Shumeyko, 1988

Geologic correlation with elevated indoor radon occurrence, Bergen County, New Jersey [abs.], in Radon in the Northeast: Perspectives and Geologic Research (conference), Troy and Albany, New York, May 31-June 2, 1988:

Northeastern Environmental Science, 7(1): 10 
More than 250 measurements of indoor radon concentrations in Bergen County, New Jersey, indicate strong correlation between elevated indoor radon levels and certain geologic environments. Specific geologic areas identified as having high radon production underlie nearly $95 \%$ of the homes with radon concentrations in excess of $148 \mathrm{~Bq} / \mathrm{m}^{3}(4 \mathrm{pCi} / \mathrm{L})$. Bedrock geology in the county comprises Precambrian granitic gneiss of the Reading Prong, fine- to coarse-grained sedimentary rocks of the Triassic Newark Basin, and diabase and basalt deposits also of Triassic age. The bedrock is in most places overlain by unconsolidated glacially deposited sediments of late Pleistocene age. The greatest percentage of homes having naturally occurring indoor radon concentrations exceeding the government-recommended standard of $148 \mathrm{~Bq} / \mathrm{m}^{3}(4 \mathrm{pCi} / \mathrm{L})$ are found in three geologic settings: (1) the Stockton-Lockatong Formation section, which comprises shales, sandstone, and argillite with higher-than-average uranium content; (2) the Valley-Fill Deposits sections, which contain thick deposits of coarse, glacially deposited sand and gravel; and (3) the Reading Prong section. Population density in the zones of elevated concentrations is concentrated in the Stockton-Lockatong Formation and Valley-Fill Deposits sections, where more than $45 \%$ of the homes tested exceed $148 \mathrm{~Bq} / \mathrm{m}^{3}$ ( $4 \mathrm{pCi} / \mathrm{L}$ ). Radon production in the Reading Prong appears to be high, but very few homes have been constructed in this section. Elevated radon ( $>148 \mathrm{~Bq} / \mathrm{m}^{3}$ or $>4 \mathrm{pCi} / \mathrm{L}$ ) occurrence in the remainder of the county was observed in only $4 \%$ of the homes tested. Although radon production in the Reading Prong and Stockton-Lockatong sections may be attributed largely to bedrock uranium enrichment, high soil permeability is considered the controlling factor in the Valley-Fill Deposits section.

Thomas, D[onald] M., J[eff] M. Cotter, and D[iana] Holford, 1992

Experimental design for soil gas radon monitoring:

Jour. Radioanalyt. Nuclear Chemistry, Articles, 161(2): 313-323

[In order to avoid disturbance of the soil-gas regime by automated sampling and counting of the soil gas, passive $400-\mathrm{mm}^{2}$ diffused-junction silicon detectors protected by aluminized mylar were used to continuously monitor ${ }^{222} \mathrm{Rn}$ in soil gas on the island of Oahu, Hawaii. Thoron $\left({ }^{220} \mathrm{Rn}\right)$ was excluded from the counting volume of the detector by means of a thin polyethylene diffusion-retarding barrier. The differences between pressure at the sampling depths and the atmosphere, soil moisture, rainfall, barometric pressure, and wind speed and direction were monitored simultaneously. Radon activities ranged from $\approx 0.7$ to $\approx 2.0 \mathrm{kBq} / \mathrm{m}^{3}$, which required integration times of $\geq 1 \mathrm{~h}$. At $1.5-\mathrm{m}$ depth, radon activity data, smoothed by a $4 \mathrm{~h}$ moving window, showed inverse correlation with 12-h-period atmospheric pressure variations due to solar tidal effects on the atmosphere (the S-2 pressure signal). Smoothing of the same data with a 12-h moving window showed correlation of the radon activity with pressure drops associated with the passage of storm systems across the island chain. The largest change in radon activity was associated with a rainfall of $\approx 0.75 \mathrm{~m}$ over a period of $\approx 60 \mathrm{~h}$, following which the radon activity increased $\approx 15 \%$; possible causes were $(1)$ sealing of the soil by hydration, reducing advective and diffusive losses of radon to the atmosphere, and (2) water displacement of radon from smaller to larger pores, increasing access to the detector. The relative magnitudes of diurnal radon variations were greater for one month after the greatest rainfall than before it; the most plausible explanation was that sealing of the upper soil layers caused greater "breathing" of the lower soil layers through the lined probe well in which the detector probe was emplaced. In a subsequent study, the detector holes were filled in almost to the levels of the probe tops, the probe bottoms being at depths of $0.5,1.3$, and $2.3 \mathrm{~m}$; the breathing effect was eliminated. Initial results from the new monitoring array tended to confirm the earlier findings that rainfall-induced changes in soil moisture have the greatest effect on soil-gas radon concentrations and that barometric pressure variations exert strong control over soil-gas advection from the shallow soil layers to the atmosphere.]

Thomas, M[argaret] A., and J.N. Hollis, 1988

Correlating radon distribution with geology and areal radioactivity in Connecticut [abs.], in Radon in the Northeast: Perspectives and Geologic Research (conference), Troy and Albany, New York, May 31-June 2, 1988:

Northeastern Environmental Science, 7(1): 10 
The Connecticut Department of Environmental Protection (DEP), through the Natural Resources Center (NRC), has been working with the Connecticut Department of Health Services (DHS) since 1985 investigating the occurrence of radon in the state. Through the DHS Connecticut Radon Survey (1985-1987) the bedrock well waters of 262 homes were tested. Additionally, 202 of these homes had long-term living-area radon tests and 34 homes had basement air radon screening tests. In the winter (1986-1987) the Connecticut-USEPA Indoor Radon Survey conducted 1562 basement air radon screening tests statewide. In summer 1986, the NRC conducted a carborne $\boldsymbol{\gamma}$-scintillation survey to map ambient radiation, traversing approximately $2200 \mathrm{~km}$ of roads across the major geological terranes [areas of a prevalent rock type] of the state. In addition, the NRC has digitized USGS published (1966) Connecticut aeroradioactivity mapping. Using the DEP's computerized geographic information system, the NRC is comparing measured indoor air and well-water radon data with bedrock geology and areal radioactivity (carborne survey and aeroradioactivity mapping). IA positive relationship was found between basement indoor radon and mapped aeroradioactivity. The percentage of radon tests $>148 \mathrm{~Bq} / \mathrm{m}^{3}(>4 \mathrm{pCi} / \mathrm{L})$ increased by approximately $10 \%$ with a 200 counts $/ \mathrm{s} \gamma$ increase in mapped aeroradioactivity. The percentage of homes $>148 \mathrm{~Bq} / \mathrm{m}^{3}(>4 \mathrm{pCi} / \mathrm{L})$ ranged from $0 \%$ in locations mapped as $<300$ counts/s $\gamma$, to $32.9 \%$ in areas mapped as $700-900$ counts/s $\gamma$. IFor the most part, aeroradioactivity mapping and carborne survey data for geological terranes correspond well with bedrock wellwater radon and indoor-air radon. Highest areal radioactivity and radon values were found within the stratified metamorphic rocks of the Merrimack Synclinorium, with $84.3 \%$ of the terrane $>500$ counts $/ \mathrm{s} \gamma$, and carborne data of $13.5 \%>60$ counts/s $\gamma$. For this terrane, $42.3 \%$ of the measured bedrock well-water radon was $>370 \mathrm{kBq} / \mathrm{m}^{3}(>10 \mathrm{nCi} / \mathrm{L})$, and $26.2 \%$ of the indoor-air radon was $>148 \mathrm{~Bq} / \mathrm{m}^{3}(>4 \mathrm{pCi} / \mathrm{L})$. The sedimentary rocks of the Newark Terrane had the lowest areal radioactivity, with $27.3 \%>500$ counts/s $\gamma$, and carborne data of $0.04 \%>60$ counts $/ \mathrm{s} \gamma$, with measured well-water radon of $2.1 \%>370 \mathrm{kBq} / \mathrm{m}^{3}(>10 \mathrm{nCi} / \mathrm{L})$, and air radon of $9.4 \%>148 \mathrm{~Bq} / \mathrm{m}^{3}(>4 \mathrm{pCi} / \mathrm{L})$. IWithin a single terrane, intrusive granitic units typically had a much higher geometric mean air (G.M.a) and water (G.M..$_{w}$ ) radon concentrations than stratified metamorphic units. Within the Connecticut Valley Synclinorium of western Connecticut, the Nonewaug Granite (G.M. $._{a}=160 \mathrm{~Bq} / \mathrm{m}^{3}, 4.4 \mathrm{pCi} / \mathrm{L} ;{\mathrm{G} . M_{\mathrm{w}}}=1.01 \mathrm{MBq} / \mathrm{m}^{3}, 27.169 \mathrm{nCi} / \mathrm{L}$ ) and Pinewood Adamellite (G.M.a $=160 \mathrm{~Bq} / \mathrm{m}^{3}, 4.4 \mathrm{pCi} / \mathrm{L} ; 1$ water sample only at $0.806 \mathrm{MBq} / \mathrm{m}^{3}, 21,778 \mathrm{pCi} / \mathrm{L}$ ) had considerably higher radon levels than the Ratlum Mountain Schist $\left(G_{.} ._{a}=70 \mathrm{~Bq} / \mathrm{m}^{3}, 1.9 \mathrm{pCi} / \mathrm{L} ; \mathrm{G} . \mathrm{M}_{\mathrm{w}}=0.154 \mathrm{MBq} / \mathrm{m}^{3}\right.$, $4.152 \mathrm{nCi} / \mathrm{L})$. This difference in radon levels is also reflected in the Merrimack Synclinorium in eastern Connecticut where granitic gneiss units of the Canterbury Gneiss (G.M. $._{a}=100 \mathrm{~Bq} / \mathrm{m}^{3}, 2.8 \mathrm{pCi} / \mathrm{L}$; G.M. $\left.{ }_{w}=0.10 \mathrm{MBq} / \mathrm{m}^{3}, 26,841 \mathrm{pCi} / \mathrm{L}\right)$ and the Eastford phase of the Canterbury Gneiss $\left(\mathrm{G} . \mathrm{M}_{\cdot \mathrm{a}}=170 \mathrm{~Bq} / \mathrm{m}^{3}\right.$, $\left.4.6 \mathrm{pCi} / \mathrm{L} ; \mathrm{G}_{\mathrm{M}} \mathrm{M}_{\mathrm{w}}=0.49 \mathrm{MBq} / \mathrm{m}^{3}, 13,217 \mathrm{pCi} / \mathrm{L}\right)$ contrast sharply with the Brimfield Schist $\left(\mathrm{G} . \mathrm{M}_{\mathrm{a}}=48 \mathrm{~Bq} / \mathrm{m}^{3}\right.$, $\left.1.3 \mathrm{pCi} / \mathrm{L} ; \mathrm{G}_{\mathrm{M}} \mathrm{M}_{\mathrm{w}}=0.036 \mathrm{MBq} / \mathrm{m}^{3}, 36,260 \mathrm{pCi} / \mathrm{L}\right)$. TRegardless of lithology and terrane association, a positive linear relationship $(r=0.85)$ between geometric mean well-water radon and indoor-air radon from 18 geologic units was found. From individual homes, paired radon analyses have shown a ratio of bedrock well-water radon to living area-air radon of $0.37 \mathrm{MBq} / \mathrm{m}^{3}(10 \mathrm{nCi} / \mathrm{L})$ to $59 \mathrm{~Bq} / \mathrm{m}^{3}(1.6 \mathrm{pCi} / \mathrm{L})$ (confidence interval 30 to $130 \mathrm{~Bq} / \mathrm{m}^{3}$ or 0.80 to $3.4 \mathrm{pCi} / \mathrm{L}$ ), and an estimated $18 \%$ contribution to indoor-air radon levels from wellwater radon. TCorrelation between areal radioactivity and measured radon data for geologic terranes have provided a useful overview for interpreting the occurrence of radon in the State. Correlations between measured radon data and individual geologic units have provided specific geographic detail. Future work will compare areal radioactivity with measured radon data for individual geologic units in order to permit more detailed radon potential evaluations. [See Siniscalchi et al., 1991.]

Tovedal, H[ans G.], 1984

Radon measurement activities and instruments designed at Studsvik Energiteknik AB:

Radiation Protection Dosimetry, 7(1-4): 215-218

Chem. Abs. 101:99845t

Tsang, Y.W., and T.N. Narasimhan, 1992

Effects of periodic atmospheric pressure variation on radon entry into buildings:

Jour. Geophys. Research, 97(B6): 9161-9170 
[(See Narasimhan et al., 1990, for preceding work.) Integral finite-difference modeling was used to estimate variations of radon entry into a basement house caused by atmospheric fluctuations superposed on a steady 5-Pa depressurization of the basement. Radon entry by both diffusive and advective means, and both a bare dirt floor and a slab with a $1-\mathrm{cm}$ perimeter crack were considered. Short-period, 30 -min fluctuations of $100-\mathrm{Pa}$ peak-to-peak amplitude, and daily fluctuations of 500-Pa peak-to-peak amplitude were chosen to be representative of real atmospheric pressure changes. For $10^{-10}$ to $10^{-13} \mathrm{~m}^{2}$ permeability of a homogeneous soil $5 \mathrm{~m}$ deep, above a water-table lower boundary, the modeling predicts increases of radon entry of up to $120 \%$ of that obtained by steady-state modeling. Short-period pressure pumping superimposed over a 5-Pa steady depressurization above a basement slab with crack over a homogeneous high-permeability $\left(10^{-10}-\mathrm{m}^{2}\right)$ substrate yields a radon entry a factor of 10 greater than that attributable to diffusion only. A higher-permeability aggregate beneath the slab and over the natural soil increases radon entry by pressure transients.]

Turk, Bradley H., Jed Harrison, Richard J. Prill, and Richard G. Sextro, 1990

Developing soil gas and ${ }^{222} \mathrm{Rn}$ entry potentials for substructure surfaces and assessing ${ }^{222} \mathrm{Rn}$ control diagnostic techniques:

Health Physics, 59(4): 405-419

[This paper describes procedures, developed at seven New Jersey research houses containing elevated radon levels, for diagnosis of radon infiltration paths and guidance of mitigation efforts. Although radon entry with soil gas is presumed, a thorough visual inspection of a house, measurement of radon exhalation from walls, and testing of the ${ }^{222} \mathrm{Rn}$ level in the domestic water supply are included in the procedure. Pressure changes caused by air-consuming or exhausting appliances are measured by cycling the appliances. Substitute doors containing strong fans ("blower doors") are used to determine a measure of air infiltration ("effective air leakage area") of the above- and below-ground zones of the house. Test holes through the foundation walls and slab are used to measure ${ }^{222} \mathrm{Rn}$ concentrations outside the foundation and flow rates through the test holes under controlled underpressures in the house. Soil permeabilities measured by means of soil probes emplaced around the houses had an aggregate geometric mean of $\approx 40 \times 10^{-12} \mathrm{~m}^{2}$ and a geometric standard deviation of 22.1 and ranged from $<\approx 1 \times 10^{-14}$ to $\approx 1 \times 10^{-8} \mathrm{~m}^{2}$. The permeabilities measured by probes in the backfill zones around the foundation walls tended to be greater than did the undisturbed ground, and there were extreme contrasts between the very high permeabilities of the subsalb gravel layers and the compacted ground below them. With the basements held at different controlled underpressures relative to the soil, the soil pressure fields were mapped by sensors in various test holes. Two terms are defined, soil gas entry potential, analogous to electrical conductance and measured in $\mathrm{m}^{3} \cdot \mathrm{Pa}^{-1} \cdot \mathrm{s}^{-1}$, and radon entry potential, equal to the product of the soil-gas radon concentration and the soil gas entry potential in $\mathrm{Bq} \cdot \mathrm{Pa}^{-1} . \mathrm{s}^{-1}$. Differences in radon entry potential from test hole to test hole at a house provides useful information to guide mitigation. It was found that the resistance of the soil to supplying radon to the foundation is generally greater than the resistance of the foundation to radon entry.]

Turk, Bradley H., Jed Harrison, Richard J. Prill, and Richard G. Sextro, 1991

Soil gas and radon entry potentials for substructure surfaces, in The 1990 International Symposium on Radon and Radon Reduction Technology, Atlanta, Ga., 19-23 February 1990:

Research Triangle Park, N.C., U.S. Environmental Protection Agency Rept. EPA600/9-91-026b, Proceedings, Vol. 2: Symposium Oral Papers, Paper No. V-3, p. 5-33-5-51 [NTIS Order No. PB91-234450/AS]

Measurement techniques and parameters that describe the potential for areas of a building substructure to have high soil gas and radon entry rates have been developed. Flows and pressures measured at test holes in substructure surfaces while the substructure was intentionally depressurized were used in a highly simplified electrical circuit to model the substructure/soil network. Data from four New Jersey houses indicate that (1) the soil was a factor of two to six times more resistant to soil gas flow than substructure surfaces, (2) concrete slab floors, including perimeter gaps, cracks, and other penetrations, were approximately five times more resistant to soil gas movement than hollow block walls, and (3) radon entry potentials were highest for slab floors. These indices of entry potential may be useful for characterizing the relative leakiness of below-grade substructure surfaces and for determining the selection and placement of radon control systems. 
Turk, B.H., R.J. Prill, W.J. Fisk, D.T. Grimsrud, B.A. Moed, and R.G. Sextro, 1987

Radon and remedial action in Spokane River Valley houses: Vol. 1: Experimental design and data analysis:

Berkeley, Calif., Univ. California Lawrence Berkeley Laboratory Rept. LBL-23430

Ulbak, K[aare], B. Stenum, A[rne] Sørensen, B[enny] Majborn, L[ars] Bøtter-Jensen, and S[ven] P[oul] Nielsen, 1988

Results from the Danish indoor radiation survey:

Radiation Protection Dosimetry, 24(1/4): 401-405

[Indoor radon was measured for 6-month periods with CR-39 $\alpha$-track detectors in 500 randomly selected Danish dwellings between April 1985 and March 1986. The annual (arithmetic) mean indoor radon concentrations were obtained by correcting the 6-month values according to which season they were made; single-family houses $(57 \%)$ and multi-family houses $(43 \%)$ together had a mean of $47 \mathrm{~Bq} / \mathrm{m}^{3}$. The maximum single value was $<600 \mathrm{~Bq} / \mathrm{m}^{3}$. Single-family houses primarily on moraine clay had a significantly higher mean than those on other soils, in agreement with measurements of radon emanation from Danish soils (Damkjær and Korsbech, 1985).]

\section{U.S. Department of Energy, 1979}

National Uranium Resource Evaluation, Interim Report:

U.S. Dept. Energy, Grand Junction Operations Office, Rept. GJO-111(79), 155 p.

[Plate 5: Areas identified as favorable but with insufficient basis for estimation of potential uranium resources (smaller scale copy of Preliminary Map No. 30, 1-1-79, same title)]

van Assendelft, A.C.E., and H.M. Sachs, 1982

Soil and regional uranium as controlling factors of indoor radon in eastern Pennsylvania:

Princeton, NJ, Princeton Univ. Center for Energy and Environmental Studies Rept. PU/CEES-145, 68 p.

High indoor radon concentrations in eastern Pennsylvania are associated with specific geological environments. For example, houses on the Beekmantown formation in the Great Valley [which extends approximately from Harrisburg to Easton] are likely to have high concentrations. Since the geology of uranium distribution is better known than that of radon, this study tested the utility of uranium data as predictors of radon concentrations. Neither available uranium data nor National Uranium Resource Evaluation (NURE) data proved good predictors in this region. We implemented protocols for uranium analysis in soils by paper chromatographic separation for fluorimetry. Analysis of 40 samples from the region showed that average values were relatively high $(3.5 \mathrm{mg} / \mathrm{kg}$ bulk), and that uranium concentrations in soils were not robust predictors of radon in nearby houses.

van den Boom, Günter, 1991

Fachbericht über die durchgeführten Untersuchungen im Rahmen des F \& E-Vorhabens: "Helium als Indikator zur Erfassung permeabler Trennflächen und offener Migrationswege in oberen Krustenbereich." [Technical report on continuing investigations in the scope of the F \& E projects: "Helium as an indicator for detecting permeable faults and open migration paths in the upper crustal region."]:

Hannover, Germany, Budesanstalt für Geowissenschaften \& Rohstoffe, Rept. 108 204, 46 p.

[Helium and ${ }^{222} \mathrm{Rn}$ in soil gas at $0.9-\mathrm{m}$ depth were measured by means of the Reimer (1990) technique in a $25-\mathrm{km}^{2}$ area in the vicinity of Soultz-sous-Forêts, France, about $37 \mathrm{~km}$ WSW of Karlsruhe, Germany. The program included $575 \mathrm{He}$ and 481 radon determinations. Radon concentrations in soil gas ranged from 2.5 to $312 \mathrm{kBg} / \mathrm{m}^{3}$ in a $\log$-normal distribution with a geometric mean of $48 \mathrm{kBq} / \mathrm{m}^{3}$, an arithmetic mean of $59 \mathrm{kBq} / \mathrm{m}^{3}$, and a standard deviation of $36 \mathrm{kBq} / \mathrm{m}^{3}$. From the contour map of radon distribution (Fig. 13), I estimate that soil gases in $\approx 5 \%$ of the area exceed $100 \mathrm{kBq} / \mathrm{m}^{3}$.]

van den Boom, Günter, and Matthias Ort, 1991 
Reconnaissance survey for determining radon and helium soil-air concentrations in the area of RonneburgSeelingstädt, Germany [abs.], in International Symposium on the Natural Radiation Environment, 5th, Salzburg, Austria, 22-28 September 1991, Abstracts:

Salzburg, Univ. Salzburg, Inst. for General Biology, Biochemistry and Biophysics, abs. no. 168

In October 1990, a geochemical reconnaissance survey was conducted in the area of Ronneburg-Seelingstädt (Thuringia), Germany, in order to determine the helium and radon concentration in soil air. This is an area that includes dump sites of tailings material from a uranium processing plant. The objectives of the study were to determine the influence of the uranium waste-product disposal on the soil-air radon concentration and to use helium concentrations to locate zones of higher permeability that may occur in the sediments underlying the waste disposal sites. The sample collecting method [see Reimer et al., 1989] is one that is relatively inexpensive and one that permits the rapid collection of the sample so analyses can be made in the field. The rapidity of sample analysis after collection is necessary for radon because that radioactive gas has a half-life of about 3.8 days. Samples were collected by pounding a hollow, thick-walled steel probe into the ground to a depth of $90 \mathrm{~cm}$ by means of an attached sliding hammer. After the probe is in place, a sample is collected by means of a hypodermic syringe with a needle inserted through an air-tight septum attached to the top of the probe. The sample in the syringe can be introduced directly into both the radon and helium analyzers. For radon analysis, a small, battery powered $\alpha$-particle scintillometer is used. The sample is injected into a pre-evacuated Lucas cell that has been previously calibrated at a radon calibration facility. The number of light scintillations detected by the machine is directly related to the radon concentration of the sample. Helium analysis is performed using a leak detector mass spectrometer that has a special inlet system designed to accommodate the injection of the soil-air sample. The instrument is calibrated frequently by using standard reference gases between soil-air sample analyses. The mass spectrometer can also be transported to the field location for rapid sample analysis. Soil air samples for both helium and radon analysis in the study area were collected on a regular grid with a spacing of $1 \mathrm{~km}$. In order to detect permeable zones in basins near Seelingstädt, additional sampling, with a spacing of $100 \mathrm{~m}$, for soil-air helium was performed on several traverses. The underlying geological units in the investigated area provide a natural background of radon to the soil air. The overall regional background for radon is $88 \mathrm{kBq} / \mathrm{m}^{3}$, and seems to be relatively high. It combines, however, geologic and anthropogenic influences, the latter mainly in the vicinity of the uranium- and radium-bearing tailings that fill the open pits west of Seelingstädt. Samples in areas where soil is derived from Ordovician "Lederschiefer" and undivided Silurian sediments show background values for radon greater than $100 \mathrm{kBq} / \mathrm{m}^{3}$. In areas where the "Schwarzburger Series" occurs, a rock unit which has no specific uranium mineralization, the average radon background drops to $57 \mathrm{kBq} / \mathrm{m}^{3}$ in soil air samples. For other samples collected above the same geological unit, but close to the dumps of the radioactive tailings, the average radon concentration is more than $125 \mathrm{kBq} / \mathrm{m}^{3}$. High average values $\left(>100 \mathrm{kBq} / \mathrm{m}^{3}\right)$ represent a potential for indoor radon accumulation possibly exceeding the action standard for radon concentrations in indoor air, which is established by the Commission of the European Communities at $400 \mathrm{~Bq} / \mathrm{m}^{3}$. Overall, the sampling at this grid density revealed quite well the soil air distribution related to the local geology and the contaminated sites. Towards the southern part of the survey area, near the location of the dump sites of the uranium processing plant, samples were collected for soil-air helium analyses. The sample spacing of $100 \mathrm{~m}$ revealed high helium concentrations that are consistent with zones of higher permeability caused by faults or open joints. However, the exact trace of these higher permeability zones could not be determined with this sample density. A higher density and additional traverses would have to be used to help delineate the extent of the higher permeability zones.

Vandrish, G., and A. Lebel, 1986

Techniques and equipment for residential radon monitoring, in Indoor Radon, Proceedings of the APCA International Specialty Conference, Philadelphia, Pa., February 24-26, 1986:

Air Pollution Control Assoc., P.O. Box 2861, Pittsburgh, PA 15230, Pub. SP-54, p. 244-250

[Soil probes for radon measurement are given brief mention.]

VanOrt, Susan, Charles Kunz, Laurence Keefe, William Condon, Kirk Fisher, and Karim Rimawi, 1992 
Indoor radon in New York State schools. Preliminary report, in The 1992 International Symposium on Radon and Radon Reduction Technology, Minneapolis, Minnesota, September 22-25, 1992:

U.S. Environmental Protection Agency, Preprints [poster papers], v. 5, no. VP-6, 18 p.

New York State is participating in a project to study radon in schools funded in part through a grant from the EPA. The program began in the spring of 1991 and is scheduled to run for three years. Candidate schools are selected from areas in which existing information suggests that there may be a high risk for indoor radon. These schools are invited to participate in an indoor radon survey that includes short-term screening measurements, one-month to three-month follow-up measurements in rooms $\geq 148 \mathrm{~Bq} / \mathrm{m}^{3}(\geq 4 \mathrm{pCi} / \mathrm{L})$, and oneyear measurements. Follow-up measurements will be made if a school is mitigated. Twenty-two schools are being surveyed in the first year (1991/1992) and forty in the second. The soils under and around about onethird of the schools surveyed will be characterized for indoor radon potential through soil-gas measurements and examined for correlation with indoor radon concentrations. The information presented in this paper details initial results of short-term screening measurements made in twenty-two schools and soil characterization in three of these schools.

Varley, N[icholas] R., and A.G. Flowers, 1991

The relationship between radon and geology in the south-west of England [abs.], in International Symposium on the Natural Radiation Environment, 5th, Salzburg, Austria, 22-28 September 1991, Abstracts:

Salzburg, Univ. Salzburg, Inst. for General Biology, Biochemistry and Biophysics, abs. no. 69

In the southwest of England many homes have been found with high indoor concentrations of radon. The annual effective dose equivalent received from the daughter products is now thought to represent $81 \%$ of the total radiation dose received by the population in this region. The high levels of radon are generally associated with parts of the region on or close to the areas of granite. The uraniferous granite is highly fractured and there are some major faults in the region. These offer a convenient pathway for the migration of radon originating in the bedrock. There may also be secondary uranium mineralization within the fractures or faults generating higher levels of radon at the source. The concentration of radon in the soil gas has been extensively measured at various geologically contrasting sites in the South-West. The methodology has been refined, with a thorough assessment of the scintillation methods used in the field to measure the concentration of ${ }^{222} \mathbf{R n}$ and ${ }^{220} \mathbf{R n}$. A correlation between the measured concentrations of radon in the soil gas and the underlying geological features has been established. High levels of radon (up to several thousand $\mathrm{Bq} / \mathrm{m}^{3}$ ) have been recorded over faults, whose position has been confirmed by other geophysical methods. Several homes have been investigated. It has been found that the measurement of soil-gas radon concentrations, used with geological data, has significant value as an indicator of high indoor levels.

Verger, P., Ph. Hubert, and S. Chéron, 1993

Use of field measurement in mapping [abs.], in First International Workshop on Indoor Radon Remedial Action, The Scientific Basis and Practical Applications, Rimini, Italy, 27 June-2 July 1993:

Commission of the European C. munities et al., Book of Abstracts, p. 79

Field measurement surveys ar essary when identifying radon-affected areas. The campaigns involve considerable effort. Neverth analysis prove to be necessary. This paper describes the work made on the data from French surveys; about 1700 measurements coming from 15 "departments" (French administrative areas) dispatched in various areas. The measurements were associated with a questionnaire permitting tracking some of the factors that may influence radon concentration. These factors (underground concentrations of uranium and thorium, soil transfer, housing characteristics, life style of occupants, season) may interact in a complex manner and are not fully retraced by the parameters collected in the questionnaire (location of the village, building material of the house, age of the house, room destination and location, number of windows and doors, duration of heating during the measurement period, duration and time period of the measurement). Various statistical models have been fitted in order to control those parameters when reconstructing "standardized exposures." Two goals were followed: First, the analysis aimed to reconstruct an average exposure after correcting for seasonal variations and type of room. This allows setting up an estimate of an actual exposure, given the actual houses. 
Then a further analysis was designed to estimate a potential exposure, that is, the exposure that would be experienced in a "standard house" located in the same places as actual houses. The first estimate is necessary in risk assessment and in identifying the need for remedial actions. The second estimate is more useful when addressing policies dealing with new houses or in comparing "exposures" with soil characteristics. Methods and results are presented and the advantages and limitations of field measurements are discussed.

Viljanen, Martti, Eero Slunga, Timo Lehtoviita, and Pekka Kanerva, 1987

Radon merkitys talonrakennustekniikassa. Radontekninen suunnittelu [Radon in building technology. Radontechnical design]:

Espoo, Finland, Helsinki Univ. Technology, Dept. Civil Engineering, Div. Structural Engineering Rept. 88, 147 p. This report on the design of buildings, their foundations, and ventilation can be used for both new design and remedial action. A radon-technical classification of foundation soil is proposed with instructions for defining low, normal, high, and very high radon classes on the basis of radon content and air permeability of the soil.

Voutilainen, Anne, and Ilona Mäkeläinen, 1991

The use of indoor radon measurements and geological data in assessing the radon risk of soil and rock in construction sites in Tampere [SW Finland], in The 1991 International Symposium on Radon and Radon Reduction Technology, Philadelphia, Pa., April 2-5, 1991, Proc., Volume 1, Symposium Oral Papers, Opening Session and Technical Sessions 1 through 5:

U.S. Environmental Protection Agency Rept. EPA/600/9-91/037A, p. 3-71-3-82

McLean, Va., Cohen (S.) and Associates, Inc. [Springfield, Va., NTIS Order No. PB92-115351]

[Preprints, v. 2, no. III-8]

The Finnish Centre for Radiation and Nuclear Safety has developed a model that allows the use of indoor radon measurements to assess the radon availability of soil and rock in construction sites. The effect of the geological nature of the construction site on indoor radon is distinguished from the construction effects of the house. The purpose is to divide the investigated area into more or less homogeneous subareas and calculate the percentages of houses exceeding 200 and $800 \mathrm{~Bq} / \mathrm{m}^{3}$ in future homes where no precautions have been taken against radon. In this study 867 indoor radon measurements from the city of Tampere (population 171,000) were used. The measurements were winter-time two-month averages. The soil and rock types for each house were determined from [usually surficial] geological maps and the structure of the buildings from questionnaire responses. A radon prognosis was made for four different construction sites. For each group of sites, Tampere was divided into 1 or 2 subareas. Within each subarea, the assessments were also made for different rock and foundation types. [The sites of most radon trouble in Finland are on eskers: long, narrow, steep-sided ridges formed of stratified sand and gravel by glacial rivers, that are excessively permeable to water and air. An esker runs through the center of Tampere. The questionnaires indicated that $14 \%$ of the houses were built on rock, $8 \%$ on moraine (sandy till), $17 \%$ on clay and silt, $53 \%$ on eskers, and $8 \%$ on other sand and gravel formations. Statistical analyses of the data from existing houses led to prognoses that, of houses built on rock, those showing by far the greatest frequency of exceeding the 200 or $800 \mathrm{~Bq} / \mathrm{m}^{3}$ levels would be those built on medium-grade metamorphic rocks (phyllite or schist), rock composed of volcanic and sedimentary detritus, and light-colored granites. The common chemical characteristic of the rocks is relatively high proportions of silica and potassium, the so-called "acid" rocks, which in general have the greatest amount of associated uranium. The prognosis for houses built on soils but not on eskers was that the highest to lowest expected radon levels would be found in slab-on-grade houses where the slab is poured between foundation walls, in houses on monolithic slabs with thickened edges (on grade), in houses with basements (contrary to U.S. experience), and in houses with crawl spaces. For houses sited on eskers, only crawl-space construction was expected to yield significantly lower values of indoor radon.]

Vulcani, Julie, and James R. Wood, 1993

Soil gas radon potential of the Upper Peninsula of Michigan: Houghton and Marquette Counties, in The 1993 International Radon Conference, Denver, Colo., Sept. 20-22, 1993: 
Denver, Colo., Am. Assoc. Radon Scientists and Technologists, Rocky Mountain Chapter, Preprints, p. IVP 29-IVP 36

Approximately 117 soil gas and 45 indoor radon measurements were made in the Houghton and Marquette Counties of Michigan, as part of the United States Geological Survey's (USGS) program to evaluate radon hazards in formerly glaciated terrain. Soil gas samples were taken using standard USGS procedures. Indoor radon samples were taken, using a standard charcoal canister, and sent to a commercial laboratory for measurement. Average readings from soils over four different formations in Houghton County were in the range 4.07 to $9.25 \mathrm{kBq} / \mathrm{L}$. Average measurements from Marquette County were in the range $48.1 \mathrm{kBq} / \mathrm{L}$ to $259 \mathrm{kBq} / \mathrm{L}$, and the highest soil-gas reading was $274 \mathrm{kBq} / \mathrm{L}$ over the Bell Creek Gneiss. The highest indoor radon reading was $2.96 \mathrm{kBq} / \mathrm{L}$ in the city of Hancock. Through the study of soils, the soil's radon content, and the bedrock geology, the area's radon potential was evaluated. Houghton County has a low radon potential, while the Republic area of Marquette County has a high radon potential.

Wanty, R.B., L.C.S. Gundersen, and R.R. Schumann, 1990

Geological factors affecting radionuclide mobility [abs.], in Gough, L.P. (ed), Proceedings of the USGS Environmental Forum 1990:

U.S. Geol. Survey Open-file Rept. 90-288, p. 15-16

A research program funded by the U.S. Geological Survey, Department of Energy, and the Environmental Protection Agency is being conducted to investigate the geologic factors affecting radionuclide mobility in the natural environment. The primary focus of the program is Radon-222 $\left({ }_{222}^{222}\right)$ in soil gas and ground water, and the contribution of ${ }^{222} \mathrm{Rn}$ in each of these media to indoor airborne ${ }^{222} \mathrm{Rn}$. When present in indoor air, ${ }^{222} \mathrm{Rn}$ is a suspected carcinogen. ${ }^{222} \mathrm{Rn}$ is a daughter in the uranium-238 $\left({ }^{238} \mathrm{U}\right)$ radioactive decay series; its immediate parent radionuclide is radium-226 $\left({ }^{226} \mathrm{Ra}\right)$. Our results show that an integrated approach, including geologic, geochemical, and pedologic studies, is the most effective in understanding ${ }^{222} \mathrm{Rn}$ distribution in the environment. We hope to gain a reliable means of predicting areas likely to have problems with high levels of ${ }^{222} \mathrm{Rn}$ by examining the processes governing the mobility of ${ }^{222} \mathrm{Rn}$ as well as its radioactive parents. IStudies have been performed in a number of areas around the United States, including the Reading Prong, Pennsylvania, the Piedmont and Valley and Ridge of the Appalachian Mountains, the Atlantic Gulf Coastal Plain, the northern Great Plains, and the Rocky Mountains. Our major conclusion is that there is a strong correlation between local geology and the potential for high ${ }^{222} \mathrm{Rn}$ in soil gas or ground water. IIn the Piedmont and Reading Prong, shear zones (in particular mylonite zones) produce high ${ }^{222} \mathrm{Rn}$ concentrations because uranium is redistributed during ductile deformation from resistate minerals, which have a low degree of emanation, to more highly emanating sites in foliations and associated fractures. Uranium commonly is associated with iron and titanium oxide grain coatings. The high emanation of ${ }^{222} \mathrm{Rn}$ from the rocks to the soil gas or ground water causes the very high concentrations of ${ }^{222} \mathrm{Rn}$ found in soils, ground water, and homes associated with shear zones. TIn areas underlain by sedimentary rocks, variable ${ }^{222} \mathbf{R n}$ concentrations have been found in soil gas. For instance, in the northern Great Plains, several types of continental glacial deposits were found to have high concentrations of ${ }^{222} \mathrm{Rn}$ in soil gas, resulting in a large proportion of homes with high indoor ${ }^{222} \mathrm{Rn}$ levels in lowa, North Dakota, and Minnesota. In the Coastal Plain of the eastern and southern U.S., generally low concentrations of ${ }^{222} \mathrm{Rn}$ are found in soil gas and homes. High soil-gas $\mathrm{Rn}$ occurs in glauconitic sandstones, phosphatic claystones and sandstones, black shales, and heavy mineral sand deposits. ISoil and weather characteristics have a marked influence on radon generation and mobility in soils. Results of a study at the Denver Federal Center (DFC) showed that as much as a tenfold difference in soil radon concentrations may occur seasonally as a result of moisture capping effects and formation and destruction of desiccation cracks in the soil. Shorter term, two- to threefold variations in soil radon concentrations can occur in response to precipitation, barometric pressure, and other weather factors. Soil type is important in determining the magnitude of the soil's response to weather factors. Smectitic soils such as those found at the DFC site are most susceptible to the moisture capping effects noted in the study. IInvestigations of ${ }^{222} \mathrm{Rn}$ in ground water supplies have shown that extremely high levels of dissolved ${ }^{222} \mathrm{Rn}$ occur in some areas. Equally important is the finding that high levels of uranium and radium also may exist in these areas. When present in high enough concentrations in drinking water, these elements pose a threat to human health. 
Adsorption processes appear to be the major control on the concentrations of uranium and radium, but radon concentrations seem to be limited by the degree of emanation from the rock to the water as it is produced by radioactive decay of radium. TFuture studies of radon in rocks and soils will concentrate on radon emanation and the climatic and geochemical parameters that most affect it. A nationwide study of granites and associated shear zones will attempt to further evaluate some of the most severe radon problems in the U.S. Studies of radionuclides in ground water will be directed toward a more thorough understanding of the geology, petrology, geochemistry, and hydrogeology of the rock-water system, and the chemical and physical factors influencing ${ }^{222} \mathrm{Rn}$ sources. In addition, a more reliable method for estimating the contribution of radon in domestic water to indoor air will be evaluated.

Washington, John William, 1991

Radon generation and transport in soils [Ph.D. thesis]:

University Park, Pa., Pennsylvania State Univ., Dept. Geosciences, 207 p.

In order to determine the extent and causes of radon variability in soil gas, repeated measurements of $\mathrm{Rn}$ $\left({ }^{222} \mathrm{Rn}\right)$ concentration, Tn $\left({ }^{220} \mathrm{Rn}\right)$ concentration, and soil properties including moisture, temperature, permeability, and diffusivity have been made at five sites in central Pennsylvania. $R n$ and $T n$ concentrations varied temporally in an annual, approximately sinusoidal pattern having a ratio amplitude of 2- to 10 -fold between the high and low values at all five sites. The annual pattern is recognizable over a variety of monitoring methods, soil drainage classes, and bedrock parent materials. शTemporal variability of $R n$ concentration is caused mainly by changes in soil moisture content and distribution. The action of soil water on $\mathrm{Rn}$ concentration is classified into two distinct regimes: 1) At low and moderate moisture contents, diffusion occurs dominantly in air-filled pores and $\mathrm{Rn}$ is distributed between air and water approximately at equilibrium. Under these conditions, $\mathrm{Rn}$ concentration in soil air increases with increasing moisture. 2) At high moisture contents diffusion occurs dominantly in water-filled pores and air/water equilibrium exists only near interfaces. Under these conditions, $\mathrm{Rn}$ concentration in soil air can be low. ISince $\mathrm{Rn}$ partitioning between gas and water is temperature sensitive, and because soil moisture and temperature change in annual cycles, much of the variability in $\mathrm{Rn}$ concentration occurs in annual cycles. As a result, knowledge of regional and temporal soil moisture and temperature patterns, which may be gleaned from soil maps, allows estimates of $\mathrm{Rn}$ concentration in soil gas. These estimates suggest $\mathrm{Rn}$ concentrations will be least elevated by moisture effects in cold, arid soils. Further, temporal variability in $\mathrm{Rn}$ concentration due to moisture effects is expected to be less pronounced in arid soils than in most others. IIn areas where the soil substrate has a significantly lower $\mathrm{Ra}$ concentration, emanation coefficient, or bulk density than the overlying soil, the substrate can act as a $\mathrm{Rn}$ sink with respect to the soil. Under extreme conditions the $\mathrm{Rn}$ concentration profile may actually display a decrease in concentration towards the rock. TThe effect of moisture on $\mathrm{Rn}$ exhalation to air-filled pores was evaluated experimentally in the laboratory by measuring $\mathrm{Rn}$ concentration in the gas phase of sealed soil cores having a range of moisture contents. This method generally exhibited a maximum air-phase concentration at intermediate moisture contents. The relatively low values in the dry range are attributed to lodging of recoiling $\mathrm{Rn}$ in adjacent soil particles. In contrast, the relative lows in the wet range are attributed to diffusion inhibition of water-filled pores as described above; thus, an assumption of equilibrium distribution between soil-air and bulk soil-water is often incorrect in wet soils. As a result, this method therefore provides a reasonable estimate of the combined effects of emanation and diffusion on $\mathrm{Rn}$ in soils. TBulk $\mathrm{Rn}$ diffusion coefficients measured at four field sites generally decrease by nearly an order of magnitude in individual soil profiles from the eluvial to the illuvial horizons. Coarsely textured soils such as sandstone-derived soils have generally larger diffusion coefficients than finely textured soils such as limestone-derived soils. ISoil permeability measured at the field sites decreases by about 2 orders of magnitude from the eluvial to the illuvial horizons in typical soil profiles. The permeability varies by up to 3 orders of magnitude as a function of moisture. TThe process of horizon formation during soil genesis significantly affects the vertical distribution of $\mathrm{Rn}$ production in soil through variability in $\mathrm{Ra}$, dry bulk density, and porosity. TA two-dimensional, steady-state finite difference code for $\mathrm{Rn}$ transport in soil has been written. It allows source ( $\mathrm{Ra}$, emanation coefficient, $R n$ from depth), transport (diffusivity, permeability), and sink ( $R n$ decay, atmospheric $R n$ activity) terms to be varied spatially so that heterogeneities can be defined. Observed summer and winter $\mathrm{Rn}$ profiles 
are both reasonably estimated by this model using measured values for $\mathrm{Ra}$, dry bulk density, emanation coefficient, soil moisture content, soil temperature, and soil diffusion coefficients.

Washington, John W., and Arthur W. Rose, 1988

Relations of soil gas radon to properties of soil and bedrock [abs.]:

Geol. Soc. America, Abstracts with Programs, 20(7): A354

The concentrations of ${ }^{222} \mathrm{Rn}$ and ${ }^{220} \mathrm{Rn}$ in soil gas have been measured biweekly by a Lucas-cell type radon detector in 3 soils developed over dolomite and 2 soils developed over sandstone in Centre County, Pennsylvania. Integrated monthly ${ }^{222} \mathrm{Rn}$ values have also been obtained using $\alpha$-track detectors. These values have been compared with soil morphology (USDA nomenclature), chemistry (U, Th, Ra, major elements), mineralogy, and physical properties (porosity, permeability, diffusion coefficient, temperature, moisture). Generally, ${ }^{222} \mathrm{Rn}$ increases with depth in a diffusion-like pattern to a maximum at $1-2 \mathrm{~m}$ depth in the strongly illuviated B horizon. Deeper values are slightly lower. Soil gas samples from $<1 \mathrm{~m}$ can significantly underestimate maximum values and are more highly variable than deeper samples over periods of weeks. ${ }^{222} \mathrm{Rn}$ values at depth in dolomite soils (3-8 ppm U) reach $110-170 \mathrm{kBq} / \mathrm{m}^{3}(3000-4500 \mathrm{pCi} / \mathrm{L})$ in summer and early fall. ${ }^{222} \mathrm{Rn}$ at depth in fall correlates well with $\mathrm{U}$ content at the 5 sites; the sandstone soils have $11-56 \mathrm{kBq} / \mathrm{m}^{3}$ $(300-1500 \mathrm{pCi} / \mathrm{L})$ and 1.5 and $2.5 \mathrm{ppm} \mathrm{U}$. A very large seasonal decrease is observed from summer to winter in the well-drained soils, the mid-winter values being only 10 to $30 \%$ of the summer/fall values. The decrease correlates with temperature difference between the deep soil and open air, and with moisture content, but the precise mechanism responsible is not clear. Soil permeability decreases by nearly 2 orders of magnitude through the A and upper B horizons. A new method for measuring emanation coefficient on soil cores at a range of water contents has been developed. Emanation coefficients are significantly lower than by previous methods. Permeability and diffusion coefficient are also measured with this method.

Washington, J.W., and A.W. Rose, 1989

Effects of variation in soil temperature and moisture on radon in soil gases [abs.]:

Geol. Soc. America, Abstracts with Programs, 21(6): A145

Radon in soil gases partitions between the air and water phases of soil. The partition ratio, $\operatorname{Rn}($ air)/ $\operatorname{Rn}($ water), depends strongly on temperature, ranging from 1.87 at $0^{\circ} \mathrm{C}$ to 2.73 at $10^{\circ} \mathrm{C}, 3.88$ at $20^{\circ} \mathrm{C}$, and 4.93 at $30^{\circ} \mathrm{C}$. For a soil with a given emanation coefficient, radium, and porosity, radon concentration in the air phase increases by a factor of nearly 4 at $20^{\circ} \mathrm{C}$ as the moisture saturation increases from 0 to $100 \%$. At conditions near saturation, changes in temperature and moisture can cause large changes in radon in the air phase. For example, cooling from $20^{\circ} \mathrm{C}$ and $99 \%$ saturation to $0.1^{\circ} \mathrm{C}$ and $50 \%$ saturation decreases radon in the air phase to about $37 \%$ of its initial value. In contrast, changes of temperature and moisture in the dry region have relatively little effect. Because of these effects, soils in humid regions that experience sub-freezing temperatures are characterized by significant seasonal variations in radon content. This behavior is observed for some soils from central Pennsylvania which typically are near saturation and $0^{\circ} \mathrm{C}$ to $3^{\circ} \mathrm{C}$ at $0.5 \mathrm{~m}$ and deeper during winter, and at $15^{\circ} \mathrm{C}$ to $20^{\circ} \mathrm{C}$ with moisture saturation of about 0.8 during summer. The lowest radon values are in the winter for these soils, which are dominated by temperature effects. In contrast, reported seasonal variations for soils that are less moist and remain well above freezing typically show highest radon in winter, interpreted to result from the increased soil moisture during winter. Radon entering homes is also expected to vary as a function of climate.

Washington, John W., and Arthur W. Rose, 1990

Regional and temporal relations of radon in soil gas to soil temperature and moisture:

Geophys. Research Letters, 17(6): 829-832

[Excluding losses of radon to the atmosphere, the concentration of radon in soil gas is controlled by the radium concentration, emanating power, dry bulk density, particle density, fractional water saturation, and temperature of the soil. In 5 sites in Pennsylvania, soil-gas radon concentrations were 2-10 times lower in winter than in late spring or summmer, which can be partly explained by the increased partition ratio, $C_{R n \text {,water }} / C_{R n \text {,gas, }}$, with decreased temperature of the soil water. A graph of soil temperature vs. fractional water saturation, divided 
into four soil temperature regimes and three soil moisture regimes, shows a family of curves of constant radon concentration in soil gas; combined moisture and temperature change along the curves (as from warm-dry to cool-moist) would yield less change in concentration than change normal to the curves (as from warm-moist to cool-dry). The graph enables one to see easily what seasonal trends should obtain in various climates.]

Washington, John W., and Arthur W. Rose, 1992

Temporal variability of radon concentration in the interstitial gas of soils in Pennsylvania:

Jour. Geophys. Research, 97(B6): 9145-9159

In order to determine the extent and causes of radon variability in soil gas, repeated measurements of ${ }^{222} \mathrm{Rn}$,

${ }^{220} \mathrm{Rn}$, and soil properties including moisture, temperature, permeability, and diffusivity have been made at five sites in central Pennsylvania. Concentrations of ${ }^{222} \mathrm{Rn}$ and ${ }^{220} \mathrm{Rn}$ to a depth of $2 \mathrm{~m}$ varied temporally in an annual, approximately sinusoidal pattern having an amplitude of twofold to tenfold at all five sites. The existence of the annual pattern is independent of monitoring method, soil drainage, or bedrock parent material. Radon variability is caused by changes in soil moisture content and distribution; the action of soil water on $\mathrm{Rn}$ is classified into two distinct regimes: (1) At low and moderate moisture contents, diffusion occurs dominantly in air-filled pores, and $R n$ is distributed between air and water approximately at equilibrium. Under these conditions $\mathrm{Rn}$ in soil air at depth increases with increasing moisture. (2) At high moisture contents diffusion occurs largely in water-filled pores, and air/water equilibrium exists only near interfaces. Under these conditions, $\mathrm{Rn}$ in soil air can be low. Since $\mathrm{Rn}$ partitioning between gas and water is temperature sensitive and because soil moisture and temperature change in annual cycles, much of the variability in ${ }^{222} \mathrm{Rn}$ concentration occurs in annual cycles. As a result, knowledge of regional and temporal soil moisture and temperature patterns allows estimates of ${ }^{222} \mathrm{Rn}$ concentration in soil gas. In areas where the soil substrate has a significantly lower $\mathrm{Rn}$ concentration, emanation coefficient, or dry bulk density than the soil, the substrate can act as a $R \mathbf{n}$ sink with respect to the soil. Under extreme conditions the [Rn] profile in the soil may actually display a concentration gradient toward the rock. The process of horizon formation during soil genesis significantly affects the vertical distribution of $\mathrm{Ra}$, emanation coefficient and porosity, and therefore $\mathrm{Rn}$ production in soil.

Washington, J.W., A.W. Rose, and D.J. Greeman, 1989

Effect of inhomogeneity of soil properties on radon transport in soil gases [abs.]:

Eos, Am. Geophys. Union Trans., 70(15): 497

Past concepts and models of radon in soil gas have assumed a depth distribution determined by diffusion and flow in soil with uniform radium content, emanation coefficient, porosity. diffusion coefficient, moisture content, and permeability. Measurements for six soil profiles in Pennsylvania and North Carolina show large variations in these properties; also, variation of moisture content with time causes variation of other properties with time. Field permeability measured with a $10-\mathrm{cm}$ diam. ring pushed $10 \mathrm{~cm}$ into pit walls commonly varies by xlO to $\mathbf{x} 50$ within a profile. The $\mathrm{A}$ horizon usually has much higher permeability than the $\mathrm{B}$ horizon. Diffusion coefficients measured in the field show a similar large range, correlating with permeability. Radium commonly varies by $\times 2$ within profiles. Moisture content varies widely with depth, and is generally much higher in winter than in summer. Emanation coefficients measured in the lab at a range of moisture tensions show values as low as 0.03 for near-saturated conditions, compared with values of 0.10 to 0.40 for disaggregated soils suspended in water. Both models and observations of radon activity in soil gas reflect these inhomogeneities by complex vertical profiles that change with time.

Washington, Paul A., 1988

Proper scaling of radon surveys: A perspective based on natural radon sources in southern Vermont, in Radon in the Northeast: Perspectives and Geologic Research (conference), Troy and Albany, New York, May 31-June 2, 1988:

Northeastern Environmental Science, 7(1): 40-44

Commercial exploration for uranium during the late 1970s discovered several uranium prospects and one thorium prospect in southern Vermont. At the same time, the federal survey [NURE] of uranium resources was finding 
very little evidence for uranium in the same area. Other than standard industrial secrecy, the reason for this discrepancy lies in the different scales at which the exploration was conducted and the sizes of the prospects. Uranium and thorium deposits in metamorphic rocks tend to be very limited in areal extent. The deposits in southern Vermont have map dimensions of up to $2 \mathrm{~km}$ long by no more than $200 \mathrm{~m}$ wide. They all have aspect ratios of 5 or more, with internal narrow linear zones of high concentrations separated by barren or nearly barren rock. Except where they cross streams or roads, they can be detected only by physically crossing them in the field. The commercial survey attempted to find them by first detailed sampling of stream sediments (to find those that cross streams) and road reconnaissance (to find those that cross roads), followed by detailed field reconnaissance of the likely areas. Because of fiscal constraints, the federal surveys were conducted on a statistical grid supplemented by easily accessed outcrops. The poor showing of the federal surveys attests to the areal limits of the deposits. The implications for radon surveys are that radon sources (such as uranium deposits) are often very localized, so large-scale surveys are generally of little use.

Wattananikorn, K., and T. Sri-Unyu, 1990

Seasonal variation of radon in dwellings in an area close to uraniferous fluorite veins in northern Thailand: Nuclear Geophysics, 4(2): 289-292

[One-month alpha-track (LR-115 type 2) measurements during each of 3 seasons (rainy, 16 August-19 September 1987; winter, 20-December-25 January 1988; and summer, 19 April-19 May 1988) in 60 dwellings in northern Thailand showed average winter concentrations about twice as great as those during the rainy season and three times as great as those in summer. House-to-house differences in radon concentration were also greater during the winter measurements than during the other periods.]

Wilkening, M.H., W.E. Clements, and D. Stanley, 1975

Radon 222 flux measurements in widely separated regions, in Adams, John A.S., Wayne M. Lowder, and Thomas F. Gesell, eds., The Natural Radiation Environment II, Internatl. Symnosium on the Natural Radiation Environment, 2d, Houston, Tex., Aug. 7-11, 1972, Proc., Vol. 2:

U.S. Energy Research and Development Admin. Rept. CONF-720805-P2, p. 717-730 [Springfield, VA, NTIS]

Wilson, Carole, 1984

Mapping the radon risk of our environment, in International Conference on Indoor Air Quality and Climate, 3d, Stockholm, August 20-24, 1984; Vol. 2: Radon, Passive Smoking, Particulates and Housing Epidemiology, Birgitta Berglund, Thomas Lindvall, and Jan Sundell, eds.:

Stockholm, Swedish Council for Building Research, Vol. 2, p. 85-92

Extensive regional surveys of radon daughters in dwellings, together with research into the causes, has revealed that radon in soil air is the primary source of indoor radon pollution in Sweden. Documentation of the natural radiation environment in a geological context is invaluable for tracing areas of high radon risk; for understanding the local causes of indoor radon problems; and for choosing suitable remedial measures, both for existing dwellings and for future building structures. Classification of areas into high, normal or low radon risk must take into account, not only the distribution of uranium and radium in the bedrock and soils, but also such parameters as soil permeability, water content and thickness of individual soil layers. Gravel in glacial eskers, for example, has proved in Sweden to give rise to a serious radon problem. On the other hand, clays, with approximately the same radium content, do not generally give rise to a radon problem in dwellings owing to their very low permeability to movement of soil air.

Wilson, Carole, 1985-1986

Radon - Geological aspects of an environmental problem:

[London Geol. Soc. \& Manchester Geol. Assoc.] The Amateur Geologist, Vol. XI, Pt. 2, p. 17-22, $27-33$

[From July 1979 to 1983 local health authorities in Sweden had measured radon daughters (RnD) in more than 40,000 houses, mostly those built with concrete containing aerated uraniferous black shale. In about $10 \%$ of the houses, $\mathrm{RnD}$ levels exceeded those that could be due to the radium in the concrete, and that a significant contribution was coming from the ground. Extension of measurements to houses not built of aerated concrete 
revealed that $11.6 \%$ of 3,545 houses contained $>400 \mathrm{~Bq} \mathrm{RnD} / \mathrm{m}^{3}$ of air $(0.02 \mathrm{WL})$. "Geological formations in Sweden that constitute a high risk for radon in dwellings due to radon in soil air are the Cambrian, uraniumrich black alum shale formation, and Pre-Cambrian uranium enriched granites and pegmatites. The alum shale formation with its unusually high contents of uranium, vanadium, molybdenum and organic matter is fairly well known. The uranium content can range from $50 \mathrm{ppm}-350 \mathrm{ppm}$. This formation, owing to its flat-lying occurrence, covers quite large areas in different parts of Sweden, areas that, owing to the fertility of the land, are densely populated."..."It is now accepted in Sweden that houses must be better sealed against the ground, but that the degree of remedial measures will vary with the risk involved. The Radon Commission has proposed (1983) that the concepts 'radon safe' and 'radon protective' should be introduced. A 'radon protective' construction should be employed on ground with normal radon contents in soil air (up to 50,000 $\mathrm{Bq} / \mathrm{m}^{3}$ ) to ensure that large volumes of soil air are not taken into a house. A 'radon safe' construction, on the other hand, is necessary where radon levels in soil air are high, and infiltration of only a small volume of soil air through the foundations would give rise to high indoor $\mathrm{RnD}$ levels. In areas where radon levels in soil air are very low, or the ground under the foundations is impermeable, conventional building techniques are permitted."

Wirth, Sharon J., Linda C.S. Gundersen, and R. Randall Schumann, 1992

Development of EPA's map of radon zones, in The 1992 International Symposium on Radon and Radon

Reduction Technology, Minneapolis, Minnesota, September 22-25, 1992:

U.S. Environmental Protection Agency, Preprints, no. VIII-4 [separate paper], 14 p.

A national radon potential map is being developed through a cooperative agreement between the U.S. Environmental Protection Agency and the U.S. Geological Survey (USGS), in cooperation with the Association of American State Geologists (AASG). This effort is mandated by the Indoor Radon Abatement Act of 1988 to assist in identifying high radon potential areas throughout the country. The principal audiences for the map are State and local governments and building code organizations. In addition to the Map of Radon Zones, a Radon Geologic Province Map and Regional Booklets are being developed to assist in the application of the map results. This paper discusses the development of the Map of Radon Zones from the technical evaluation of radon potential to the review process in which many organizations are participating.

Witcher, James C., and Rudi Schoenmackers, 1990

Time-integrated radon soil-gas surveys in geothermal exploration in the southern Rio Grande Rift, New Mexico. Volume 1: Final Report [to U.S. Department of Energy, Geothermal Technology Division, and New Mexico Research and Development Institute]:

Las Cruces, New Mex., New Mexico State Univ., Southwest Technology Development Institute

...This report evaluates time-integrated radon soil-gas surveys for convective low- to intermediate-temperature geothermal resource exploration in areas with variable soil development and arid climate. Convective low- to intermediate-temperature geothermal resources compose the largest resource base with immediate development potential in New Mexico. Significant growth in geothermally heated greenhouses is occurring in southern New Mexico. In fact, two of the largest geothermally heated greenhouses in the nation are found in this area. Results of this radon soil-gas study are expected to result in near-term geothermal greenhouse development. Also, the method for radon soil-gas surveying outlined by this report is widely applicable because arid climates, characterized by deep water tables, and active tectonic and geomorphic processes, associated with variable soil development, are common in the western United States. TThis report outlines a practical method for conducting and interpreting alpha-track detector (ATD) radon soil-gas surveys. The method determines field measurement deviation from an ideal model based upon pure diffusion in a homogeneous soil. By comparing actual field measurements of radon soil-gas with a diffusion model prediction of concentration, the effects of deep-seated radon sources and advective transport are resolved and evaluated. Use of the diffusion model as a data filter appears to enhance the value of survey results and make better use of radon as a natural tracer. An additional advantage of the method is that soil emanation values for the corrections to field data are measured directly with ATDs. IInitial radon soil-gas surveying was performed over a well-characterized geothermal system around Tortugas Mountain on the Las Cruces East Mesa geothermal field. Subsequent 
surveys were applied in a true exploration fashion near Radium Springs and Rincon in areas believed suitable for near-term development with potential for significant shallow convective geothermal resources. The radon surveys were evaluated with temperature-gradient studies. Two additional gradient boreholes...were subsequently sited to enhance the...temperature-gradient studies coverage. IFindings. Time-integrated or ATD radon soil-gas surveys provide a viable low-to-intermediate-temperature geothermal exploration tool. Data filtering and interpretation is facilitated by application of corrections to ATD measurements that are based upon a model of pure diffusion. Several geothermally important results fall out of this approach: [1] Most radon highs, not associated with advective or geothermal processes, are filtered out; [2] Anomalously high positive radon residuals, resulting from model corrections, have successfully identified faults and areas with higher temperature gradients; and [3] Diffusion model corrected ATD surveys appear to have excellent pathfinder potential for targeting shallow upflow zones of geothermal systems. The larger positive radon residuals discovered by this study are over or immediately adjacent to upflow zones and/or areas associated with very high temperature gradients. The positive radon residuals may result from advective transport of radon from the geothermal fluids or from radium enrichment in alteration halos at depth that are associated with these systems. TMany conclusions concerning radon soil-gas concentrations in arid soils are derived from this study: [1] Field ATD radon soil-gas measurements have log-normal distributions; [2] Lab ATD radon emanation measurements of the region's soils tend to follow log-normal distributions; [3] Results of field ATD radon surveys are not quantitatively repeatable; however, these surveys are repeatable in a qualitative sense; highs remain as highs and lows remain as lows; [4] A component of advective transport is probably observed in most of the survey area soils during the time intervals of the ATD measurements; [5] A correlation between higher lab soil-radon emanation and higher soil moisture is observed in the Rincon survey; percentages of silt and clay, as well as clay mineralogy, may play a role; partitioning of radon between gas and water in pore space may also be responsible; [6] Windblown sandy soils generally have higher lab soil radon emanation; and [7] Where bedrock is shallow or highly developed caliche [carbonate-cemented soil] horizons exist, consistently higher negative radon residuals are frequently observed. In areas of shallow bedrock, decreased diffusion coefficients and porosity substantially deviate actual field conditions from diffusion model assumptions. However, identification of positive advective residuals associated with faults and geothermal processes is apparently not affected. Costs of the radon soil-gas surveys described in this report are about $\$ 20$ to $\$ 25$ per sampling site, not including labor. This cost includes two alpha-track detectors, plastic cups, velcro, aluminum pie pans, plastic sheets, flagging, and mason jars. These costs are comparable with those of helium soil-gas surveys and are about twice the cost of soil mercury surveys. A major disadvantage of ATD radon surveying is the length of time required to obtain results. However, the ATD radon survey, coupled to diffusion model data reduction techniques, gives information with much greater interpretive value and better repeatability than other types of soil-gas surveys.... IRecommendations: Where time is not a crucial factor, time-integrated radon soil-gas surveying is a good geothermal exploration technique for reconnaissance in favorable geologic terrains in arid regions. Exposure times for detectors should be not less than 2 months. Detector spacing should not exceed $300 \mathrm{~m}$ for grid surveys. Closer spaced surveys increase the utility of survey results. Grid type surveys are preferable to profiling because more information on the sizes and shapes of the anomalies are obtained. The surveys should utilize the diffusion model corrections and approach. Also, interpretation should rely more on statistically derived anomalies of the corrected or residual values than on general trends in survey results. Follow-on temperature gradient studies of positive radon residuals should be sited to cover areas adjacent to the anomalies, because some positive residuals appear as halos around the areas of highest temperature gradients. Finally, as with most exploration methods, radon soil-gas surveys should be planned and used in concert with sound geologic reasoning and other geochemical and geophysical information.

Wollenberg, H.A., and K.L. Revzan, 1990

Radium regionalization in California:

Geophys. Research Letters, 17(6): 805-808

[Under the assumption that ${ }^{226} \mathrm{Ra}$ is in equilibrium with ${ }^{238} \mathrm{U}$ in California rocks and soils, comparison of data on the uranium concentration in the rocks and soils with ${ }^{214} \mathrm{Bi} \gamma$ radiation data from the National Aerial Radiometric Reconnaissance project of the National Uranium Resource Evaluation Program indicated a 
significant discrepancy in the radium concentration estimates in central California. In three $1^{\circ} \times 2^{\circ}$ quadrangles, the aeroradiometric radium estimates were higher by as much as a factor of 2 than those obtained by weighting the radium concentrations of rocks according to their areas of exposure. A traverse by a ground-borne $\boldsymbol{\gamma}$-ray spectrometer across two strong aeroradiometric anomalies in the San Jose quadrangle failed to confirm the anomalies, perhaps because of atmospheric inversion. Field checking of the aeroradiometric data is urged before using them to predict indoor radon potential.]

Wollenberg, H.A., and A.R. Smith, 1984

Naturally occurring radioelements and terrestrial gamma-ray exposure rates: An assessment based on recent geochemical data:

Berkeley, Calif., Univ. Calif. Lawrence Berkeley Lab. Rept. LBL-18714, 79 p. [Submitted to Environmental Geology and Water Resources]

A survey of the geochemical literature and unpublished data has resulted in the cataloging and characterization of the concentrations of the naturally occurring radioelements, $\mathrm{U}, \mathrm{Th}$, and $\mathrm{K}$ and their associated rock types. The purpose of this work is to aid in the planning and interpretation of airborne gamma-radiation environmental surveys of proposed and operating nuclear power reactors and other nuclear energy related sites. A data base of over 2500 entries has been assembled, and formulas relating gamma-ray exposure rates to radioelement concentrations have been applied to these data. The resulting tabulation and histograms illustrate the broad range of radioactivities encompassed by the various rock types. The gamma-ray exposure rates of igneous rocks generally vary with their silica contents, and, with the exception of shale, sedimentary rocks have lower $\mathrm{K} / \mathrm{U}$ and $\mathrm{K} / \mathrm{Th}$ ratios than most igneous rocks. By considering together radioelement ratios, relative abundances, and total gamma radioactivities, the general lithology of overflown terranes may be distinguished by airborne multi-spectral gamma surveys. In the course of this investigation an appreciable difference was noted between the overall mean terrestrial gamma-ray exposure rate calculated from rock radioelement concentrations $(\approx 8 \mu \mathrm{R} / \mathrm{hr})$ and the mean exposure rate from field measurements over soil (5.1 $\mu \mathrm{R} / \mathrm{hr}$ ). This difference may be explained by effects of the differences in density of rock and soil, the moisture content of soil, and the apparent depletion of $U$ in unsaturated near-surface material.

Yokel, Felix Y., 1989

Site characterization for radon source potential:

Gaithersburg, Md., Natl. Inst. Standards and Technology Rept. NISTIR 89-4106, 62 p.

There is need to identify and measure site characteristics which contribute to the emission of radon gas into the interior of buildings. In present practice this is usually attempted by in situ measurements of gas permeability and radon activity concentrations in the soil gas. These measurements are sensitive to transient conditions prevailing at any point in time: the gas permeability is sensitive to soil moisture content; and the radon activity concentration in the soil gas is sensitive to variations in soil moisture content, atmospheric pressure, temperature gradients, and wind speed. However, there are measurable invariant soil index properties (independent of moisture content and atmospheric conditions) which are related to the propensity of sites to generate and transport radon gas over time. This report deals with the site characterization for radon source potential using these invariant soil index properties. The advantage of this approach is that the measurements performed in a site exploration are repeatable, a necessary precondition for any measurement associated with a standard, and that the calculated source potential represents the propensity for radon generation, rather than the radon generation under a specific set of conditions, which may be transient. The site exploration procedures considered utilize established soil exploration and classification techniques to the maximum extent possible. TThe most important invariant soil properties identified are radium activity concentration $\left(A_{R_{a}}\right)$, inplace dry density and porosity of the subsoil $\left(\gamma_{d}, n\right)$, and the dry gas permeability coefficient of the subsoil $(k)$. These quantities can be either measured or estimated on the basis of soil index properties. Quantities $A_{\mathrm{Ra}}$, $\gamma_{d}$, and $n$ can be measured directly by various field and laboratory techniques. The permeability, $\mathrm{k}$, can be estimate: on the basis of grain size distribution, which in turn can be measured by established procedures. An in silu value of $\mathbf{k}$ (not corrected for moisture content) is presently measured by air injection or soil gas extraction. This measurement is strongly dependent on moisture content. In most instances a correction for the moisture content would have to be made if this measurement is used to determine dry gas permeability. 
While equations which correlate soil moisture content with gas permeability have been developed, presently available information does not provide a reliable basis for a moisture-content correction of gas permeability without the aid of additional, sophisticated laboratory tests. Alternatively, the coefficient of gas permeability can be derived from that for saturated water permeability, which in turn can be measured in the field and in the laboratory. ISeveral expressions for radon source potential have been proposed. An additional expression is proposed in the paper on the basis of data from New York State (Kunz et al., 1989). The dimensional correlation between the permeability and radon entry depends on whether the radon transport by convective flow is dominated by transient or by steady-state flow conditions. Several of the proposed expressions are derived from steady-state flow conditions. However, available data indicate that the radon concentration is approximately proportional to $\mathrm{k}^{0.5}$ (for instance, Kunz et al., 1989, Scott, 1985), a dimensional correlation which is closer to that predicted by transient flow conditions. There are insufficient data to draw conclusions, because it is difficult to separate the effect of $\mathrm{k}$ from that of other variables. ISome of the proposed expressions for radon source potential use invariant soil properties, while others are linked with site exploration procedures which measure in-place gas permeability and radon activity concentration in the soil gas without consideration of transient conditions. All these expressions could be modified to utilize measured invariant soil properties with a proper allowance for the effect of soil moisture content. TTwo exploration methods are proposed: (1) exploration by traditional test boring methods, such as the Standard Penetration Test, supplemented by $\gamma$ spectroscopy to determine $A_{\mathrm{Ra}}$ and by a procedure to identify fine-grained soils that are likely to develop fissures; and (2) a rapid field exploration procedure using a portable spectrometer to determine $A_{\mathrm{Ra}}$, a portable nuclear moisture-density gauge to determine $\gamma_{d}$ and natural moisture content, and retrieval of a small soil sample for laboratory particle size analysis and indirect determination of $k$. It is suggested that this latter field procedure could be combined with conventional percolation tests to provide more accurate information on permeability. Whether method (1) or (2) is used would depend on the scale of the exploration (one building or many buildings) and on the need for geotechnical data for other purposes (i.e., method (1) would be used if soil borings are also needed for other purposes). TA plan for further studies is proposed in order to develop exploration protocols, test the validity of radon source potential predictions, and prepare a draft standard. [Author's executive summary.]

Yokel, Felix Y., and Allan B. Tanner, 1992

Site exploration for radon source potential:

U.S. Natl. Inst. of Standards and Technology Rept. NISTIR 5135, $61+$ xv p.

[From executive summary]....The purpose of this report is to propose exploration and test methods for the characterization of the radon source potential of individual building sites and fill materials. In one of the most commonly used methods of assessing the radon source potential of building sites a volume of soil gas is extracted and the radon activity concentration in the extracted soil gas volume is measured in a scintillating cell. At the same time, the gas permeability of the soil is measured by a controlled soil gas extraction or air injection procedure, in which the required suction or pressure, and the flow rate of the extracted or injected gas are monitored. While this is an efficient procedure, the measured quantities are sensitive to transitory conditions, which include soil moisture content and pressure gradients in the soil mass during, and prior to, the time the measurements are taken. For this reason the measurements are not repeatable. In this report proposed test and site exploration procedures for the measurement of invariant soil properties are presented. A tentative protocol for the assessment of the radon source potential of building sites and fill materials is proposed, which is based on repeatable measurements of invariant soil properties, with corrections for typical prevailing environmental conditions. TThe measured or estimated soil properties are: the radium activity concentration per unit dry mass of the soil; the emanation coefficient; the in-place dry density; the porosity; and the dry gas permeability. The radium activity concentration is measured by $\gamma$-spectrometry and the emanation coefficient is estimated. However, as an alternative, $\boldsymbol{\gamma}$-spectrometry can be used to measure the emanation coefficient if a more accurate estimate is desired. The dry density is measured by retrieving a relatively undisturbed sample of known volume and establishing its dry weight. As alternatives, nuclear measurements or other established American Society for Testing and Materials (ASTM) procedures can be used to measure this quantity. The porosity can be calculated using an estimated value for soil particle density 
or, alternatively, a value determined by a measurement of the specific gravity of the soil particles by established ASTM procedures. The dry gas permeability can be determined by a particle size analysis and a recently developed correlation between gas permeability and particle size distribution. Alternatively, if the soil moisture content at the time of measurements is not too high, the dry gas permeability can be determined by a measurement of the moist gas permeability using the soil gas extraction method and a calculation of the dry permeability using a recently developed correlation between dry and moist permeabilities of granular soils. Some of the test methods considered are more accurate than others. In order to provide a means for resolving uncertainties and potential disagreements in the interpretation of test results, the test methods are ranked in a hierarchical order. Results obtained by more accurate methods would supersede the results obtained by less accurate methods. Three specific field exploration methods are proposed; however, the required measurements can be performed by many other exploration methods. The three proposed methods are: (1) The "SPT" method that utilizes the Standard Penetration Test (ASTM D 1586), which is presently the most commonly used method of performing soil borings. In addition to the standard procedure specified by ASTM, a relatively undisturbed core sample is retrieved for determining dry density, and additional undisturbed samples are saved to provide enough soil for spectrometry and particle size analysis. The SPT method is the preferred method in the case where a geotechnical soil exploration is planned for other purposes (such as foundation design or planning of cut and fill operations). (2) A manual procedure, whereby a soil sample is extracted from an auger hole, or some other type of excavation and saved for laboratory analysis. A rapid and low cost version of the manual procedure would use field spectrometry to determine radium activity concentration and visual-manual soil identification procedures or utilization of the results of percolation tests to determine permeability. (3) The soil gas extraction test, linked with measurements of in-place dry density and natural water content. The measured radon activity concentration in the soil gas and the measured soil gas permeability can then be interpreted on the basis of the soil saturation at the time the measurements were taken. IThe proposed test and site exploration procedures can be readily integrated with soil exploration and testing procedures used in present geotechnical engineering practice, and wherever possible present ASTM methods are utilized. In this way, maximum economy is achieved, particularly if a soil exploration has to be conducted for other purposes. IAn empirically based expression for radon source potential is proposed in which the radon source potential is estimated in terms of a "Radon Source Potential Index (Y)". This index is expressed in multiples of the present Environmental Protection Agency threshold of $150 \mathrm{~Bq} / \mathrm{m}^{3}(4 \mathrm{pCi} / \mathrm{L})$. The index is based on invariant soil properties, but can be adjusted for expected environmental conditions, such as characteristic soil water content, proximity of the groundwater table, and prevailing climatic conditions. On the basis of this index, radon potential is ranked as Low $(\mathrm{Y} \leq 0.5)$, Moderate $(0.5<\mathrm{Y} \leq 1.5)$, High $(1.5<\mathrm{Y} \leq 7)$, and Very High (Y $>7$ ). Similarly, the use of borrow material is ranked as unrestricted use (UU-no restriction), fill material (FM-can be used as fill under buildings but requires evaluation), potential resource (PR-can be used if diluted to FM level), building site restricted (BR-cannot be used under buildings), and Restricted Use (RU—cannot be used near ground surface, even for landscaping). A flow chart for the proposed field exploration procedures is provided in a summary in Section 7. The summary also contains an index of all the proposed testing procedures and examples of radon potential evaluations. TThe expression for the radon potential index must be considered tentative since it is derived from a limited data base. It is recommended to assemble additional data in order to test, and possibly refine or modify, the proposed radon source potential index and to examine the practicality and cost effectiveness of the proposed testing procedures by trial applications. It is also recommended to conduct additional studies on the effect of anisotropy of permeability and the determination of permeability coefficients on the basis of the particle size distribution and water content of soils.

\section{Zapalac, Geordie H., 1983}

A time-dependent method for characterizing the diffusion of ${ }^{222} \mathrm{Rn}$ in concrete:

Health Physics, 45(2): 377-383

The porosity and diffusion length of concrete have been determined by measuring the time-dependent diffusion of radon through a thin slab of the material. One surface of the slab is exposed to a large, fixed radon concentration beginning at $t=0$. The radon that diffuses out of a portion of the opposite surface is collected 
during several contiguous time intervals. The total activity collected over a set of intervals beginning at $t=0$ and the steady-state flux of activity are used to calculate the porosity and diffusion length. As a test of these parameters, they are then used to predict the activity collected during other time intervals and for other sample thicknesses. Samples from two types of concrete were tested: one type yielded a porosity of 0.068 and a diffusion length of $12.6 \mathrm{~cm}$; the respective values for the other were 0.32 and $16.9 \mathrm{~cm}$. The predicted and experimental results agreed well, thereby verifying the assumption that concrete may be treated as a homogeneous diffusion medium for radon.

Zeilinger, P. Robert, 1935

Über die Nachlieferung von Radiumemanation aus dem Erdboden [On the supply of radium emanation from the soil]:

Terrestrial Magnetism and Atmospheric Electricity, 40: 281-294

Geophys. Abs. 81-2972:

The amount of radon given off from the soil was measured by the method of P. Zupancic (1934) with certain improvements. During December 1933 to October 1934, 150 measurements were made at two points in a meadow near Hötting; observations were made alternately at these. The average value is $16.1 \mathrm{mBq} / \mathrm{m}^{2}-\mathrm{s}(43.5$ $\left.\mathrm{aCi} / \mathrm{cm}^{2}-\mathrm{s}\right)$. Considering the fact that very few measurements were made in the autumn, it must be concluded that the annual average is nearly $18 \mathrm{mBq} / \mathrm{m}^{2}-\mathrm{s}\left(50 \mathrm{aCi} / \mathrm{cm}^{2}-\mathrm{s}\right)$. This amount of exhalation agrees well with the results of Smyth (Dublin) and Wright and Smith (Manila) who obtained 27 and $7.6 \mathrm{mBq} / \mathrm{m}^{2}-\mathrm{s}$ (73 and 20.5 $\mathrm{aCi} / \mathrm{cm}^{2}-\mathrm{s}$ ), respectively. It is interesting to note that $\mathrm{P}$. Zupancic in the garden of the Institute in Innsbruck obtained an average exhalation of $8.5 \mathrm{mBq} / \mathrm{m}^{2}-\mathrm{s}\left(23 \mathrm{aCi} / \mathrm{cm}^{2}-\mathrm{s}\right)$ (December-July) that is, about half as much as the author on the meadow in Hötting where the soil was never mixed with fragments of brick, etc. It was found that the meteorological factors governing the exhalation of radon are not the same in different seasons of the year. In winter the influence of snow or ice on the ground prevails. The exhalation increases rapidly when the snow is melting. In spring rather large variations in the amount of exhalation were found corresponding to large differences of temperature, etc. A lawn-covered area gives off less radon than an area of the same soil without lawn. The highest values of exhalation were found in July and August. The relationship of exhalation to different meteorological factors is discussed. Wind decreases the amount of exhalation measured. This may be due to the removal of radon within the collecting vessel by the small rapid changes of barometric pressure during high winds. The daily variation of exhalation was studied and found in good agreement with the curve of P. Zupancic. Simultaneous measurements of the radon-content of open air showed a daily variation similar to that of the exhalation. [Graphs (p. 243) showing meteorological factors, rate of $R n$ exhalation, and $R n$ concentration, appear to me (ABT) to show correlation between falling pressure and an increased rate of radon exhalation].

Zupancic, P. Reginald, 1934

Messungen der Exhalation von Radiumemanation aus dem Erdboden [Measurements of the exhalation of radium emanation from the ground]:

Terrestrial Magnetism and Atmospheric Electricity, 39(1): 33-46

Geophys. Abs. 66-2138:

The amount of radon given off from the soil was measured by a new method. An area of $2800 \mathrm{~cm}^{2}$ of lawn as covered by a zinc cylinder filled with air completely free of radon at the beginning of each experiment. Twelve or 24 hours later the air from the cylinder after thorough mixing was introduced in an ionization-vessel calibrated in curies and measured in the usual way. From this measurement the amount of radon exhaled from the soil per square centimeter and second can be calculated. The average amount of this exhalation of radon as observed in the period December 1932 to July 1933, was $8.5 \mathrm{mBq} / \mathrm{m}^{2}-\mathrm{s}\left(23 \mathrm{aCi} / \mathrm{cm}^{2}-\mathrm{s}\right)$. Within the period mentioned the minimum of exhalation was found in January and the maximum in June. The exhalation during the day is about 1.5 times as much as in the night hours. The maximum value of exhalation during the observation period of about six months exceeds the minimum by about 100 times. Exhalation of radon is mainly governed by the temperature of the soil, increase of this temperature causing an increase of exhalation 
of radon. Freezing of the soil decreases the amount of exhalation almost to zero. Atmospheric pressure and its variations seem to be of secondary importance. 
APPENDIX B. LIST OF PERSONS OR INSTITUTIONS PRESENTLY OR RECENTLY ENGAGED IN RESEARCH RELATED TO MEASUREMENT AND DETERMINATION OF RADON SOURCE POTENTIAL OF SITES OR AREAS

[Telephone numbers are indicated for investigators of site-specific methods.]

[Titles are indicated where known only.]

Canada:

Dr. R.S. Eaton

Roger Eaton and Associates

35 Foothills Drive

Nepean, Ontario, K2H 6 K6

Canada

(613)828-2193

Dr. Robert L. Grasty

Geological Survey of Canada

601 Booth Street

Ottawa, Ontario K1A 0E8

Canada

(613)992-1236

Arthur G. Scott

2020 South Millway \#11

Mississauga, Ontario L5L 1K2

Canada

(416)828-2389

Czech Republic:

Ivan Barnet

Geological Survey, Prague

Malostranské nám. 19

11821 Praha 1

Czech Republic

Fax: 422533564

Martin Neznal

Radon Corp.

Hornická 318

47127 Stráž pod Ralskem

Czech Republic

004242555076

Josef Thomas \& Ladislav Moucka

Institute of Hygiers and Epidemiology

Praha, Czech Republic 


\title{
Denmark:
}

Dr. Anders Damkjær

Department of Electrophysics

The Technical University of Denmark

DK-2800, Lyngby, Denmark

45-42-88-11-88

Benny Majborn \& Claus Andersen

Risø National Laboratory

DK-4000

Roskilde, Denmark

45-42-37-12-12

Kaare Ulbak (Cand. Scient.)

Statens Institut for Strålehygiejne

378, Frederikssundsvej

DK-2700 Brønshøj, Denmark

45-44-94-37-73

\section{Finland:}

Olli Castrén, Anne Voutilainen, Raimo Mustonen, Hannu Arvela, Mika Markkanen

Säteilyturvakeskus (STUK)

Strålsäkerhetscentralen

[Finnish Centre for Radiation and Nuclear Safety]

PL/P.O. Box 268

SF-00101 Helsinki, Finland

358-0-08-2455

Eero Slunga \& Simo Liukkonen

Helsinki University of Technology

Rakentajanaukio 4 A

SF-02150 Espoo, Finland

358-0-451-2855

\section{France:}

\author{
Alain Rannou \\ Commissariat à l'Énergie Atomique \\ B.P.N. 6 \\ 92260 Fontenay-aux-Roses \\ France \\ Jaques Pradel \\ Commissariat à l'Énergie Atomique \\ Centre d'Etudes Nucléaires \\ Département de Protection Technique \\ B.P.N. 6 \\ 92260 Fontenay-aux-Roses \\ France
}


Michel Nowin \& Jean Luc Seidel

Commissariat à l'Énergie Atomique

B.P.N. 6

92260 Fontenay-aux-Roses

France

\section{Germany:}

\section{Gert Keller}

Institüt für Biophysik der

Universität des Saarlandes

D-6650 Homburg (Saar)

Germany

Ranier Lehmann \& Dr. Przyborowski

Bundesamt für Strahlenschutz

Waldowallee 117

O-1157 Berlin

Germany

Reine Müller

Bundesanstalt für Geowissenschaften \& Rohstoffe-Hannover

Stilleweg 2, 3000 Hannover

Germany

49-51-6432602

Prof. Dr. Agemar Siehl

Universität Bonn

Geologisches Institut

Nussallee 8, 5300 Bonn 1

Germany

0228732399

Dr. Günter van den Boom \& Dipl. Geol. Matthias Ort

Geologisches Büro ENMOTEC

Bismarckstr. 80

74000 Tübingen

Germany

49511738979

India:

Dr. T.V. Ramachandran

Environmental Assessment Division

Health, Safety and Environment Group

Bhabha Atomic Research Centre

Bombay -4000 085, India 
Ireland:

Dr. James P. McLaughlin

University College Dublin

Belfield

Dublin 4, Ireland

Italy:

L. Tommasino, S. Piermattei, A.F. Susanna, G. Torri

Laboratorio di Misure

ENEA-DISP

Via V. Vitaliano Brancati

Rome, Italy

39-06-8528-2076

\section{Hungary:}

Dr. Ilona Hunyadi \& József Hakl

Institute of Nuclear Research of the Hungarian Academy of Sciences

ATOMKI

H-4001 Debrecen

P.O. Box 51

Hungary

365217 266; Fax: 365216181

Japan:

Dr. Siro Abe

National Institute of Radiological Sciences

9-1, Amagawa-4

Chiba, 260

Japan

[Japan 472-51-2111]

Dr. Masami Fukui

Radiation Control Division

Research Reactor Institute

Kyoto University

Kumatori-cho, Sennan-gun

Osaka(590-04), Japan

Dr. Kazuko Megumi

Research Center of Radioisotopes

Research Institute for Advanced Science and Technology

University of Osaka Prefecture

Shinke-Cho 174-16, Sakai-Shi 593

Japan

072236 2221; Fax: 0722363876 
Netherlands:

Robert J. de Meijer

Kernfysisch Versneller Institute

Rijksuniversiteit Gronigen

9747 AA Gronigen

Zernikelaan 25

Netherlands

31-50-633600

Norway:

Erling Stranden

National Institute of Radiation Hygiene

Österndalen 25

N-1345 Österås, Norway

Slovenia:

Dusan Brajnik

Faculty of Electrical Engineering and Computer Science

University of Ljubljana

Ljubljana, Slovenia

U. Miklavžič

"J. Stefan" Institute

Ljubljana, Slovenia

J. Tomšǐ

Geological Survey

Ljubljana, Slovenia

Spain:

Prof. Luis Quindos Poncela

Departamento de Ciencias Medicas y Quirugicas

Facultad de Medicina

Universidad de Cantabria

39011 Santander, Spain

34-42-347500

Sweden:

Gustav V. Åkerblom

Swedish Radiation Protection Institute (SSI)

[Karolinska sjukhuset, Solna]

Box 60204

S-104 01 Stockholm, Sweden

+46872971 00; Fax: +4687297108 


\section{Bertil Clavensjö}

Bjerkings Ingenjörsbyrå $\mathrm{AB}$

Consulting Engineers

Box 2006

S-750 02 Uppsala, Sweden

+4618651100

Sven-Olov Ericson

AIB - Allmänna Ingenjörsbyrån AB

Consulting Engineers

Box 5511

S-114 85 Stockholm, Sweden

Hans Mellander

Swedish Radiation Protection Institute (SSI)

[Karolinska sjukhuset, Solna]

Box 60204

S-104 01 Stockholm, Sweden

+46872971 00; Fax: +4687297108

Per Norell \& Bjorn Varnestig

Gammadata Mätteknik AB

[Klostergatan 10]

Box 1815

S-751 48 Uppsala, Sweden

46-18 155870

\section{Bengt Rosén}

Swedish Geotechnical Institute (SGI)

[Olaus Magnus väg 35]

S-581 01 Linköping, Sweden

+461311 51 00; Fax +4613131696

\section{Eva Rydén}

National Board of Housing Building and Planning

P.O. Box 534

S-371 23 Karlsrona, Sweden

+4645553000

Switzerland:

R. Buchli and W'. Burkart

Radiation Hygiene Division

Paul Scherrer Institute

CH-5303 Würenlingen, Switzerland 
Dr. Heinz Surbeck

[Bundesamt für Gesundheitswesen]

[Abteilung Strahlenschutz]

[Sektion Überwachung der Radioaktivität]

Physikinstitüt

Pérolles

CH-1700 Fribourg, Switzerland

41-037/82 6436

\section{United Kingdom:}

Dr. T. Keith Ball, Tim Coleman

British Geological Survey

Keyworth, Nottingham

NG12 5GG, United Kingdom

44-060-77 6111; Fax: 060776602

Jonathan C. Miles

National Radiation Protection Board

Chilton, Didcot, Oxon

United Kingdom

\section{United States:}

Dr. Thomas E. Blue \& M.S. Jarzemba

Ohio State University, Department of Nuclear Engineering

Robinson Lab 209

20t3 West 18th Avenue

Columbus, Ohio 43210

614-292-0629

Dr. Robert S. Braman

Department of Chemistry

University of South Florida

Tampa, FL 33620

813-974-2365

Douglas G. Brookins [current status unknown]

University of New Mexico

Albuquerque, NM

Donald Carlisle

[Dept. Earth and Space Sciences, University of California, Los Angeles 90024; 213-825-1934]

Radon Systematics of California

1500 San Remo Drive

Pacific Palisades, CA 90272 
Dr. Robert L. Fleischer

General Electric Co.

Corporate Research and Development

Materials Laboratory

Schenectady, NY 12301

518-387-6238

H.D. Freeman, J.N. Hartley

Pacific Northwest Laboratories

Batelle Boulevard

P.O. Box 999

Richland, WA 99352

Dr. Darioush T. Ghahremani

Radon Survey Systems, Inc.

10357 Liberty Road

Twinsburg, OH 44087

L.T. Gregg

Atlanta Testing \& Engineering

11420 Johns Creek Parkway

Duluth, GA 30136

404-476-3555

Stephen T. Hall

Radon Control Professionals, Inc.

11920 Fieldthorn Court

Reston, VA 22094

703-471-9459

Dr. David E. Hintenlang, 904-392-1404

Dr. Genevieve S. Roessler, 904-392-1404

Department of Nuclear Engineering Sciences

University of Florida

Gainesville, FL 32611

Dr. Charles O. Kunz

New York State Dept. of Health

Wadsworth Center for Laboratories and Research, D-486

Albany, NY 12201

518-474-6649

Richard Lively

Minnesota Geological Survey

2642 University Avenue

St. Paul, MN 55114-1057

$612-627-4780$ 
Dr. Ralph A. Llewellyn

Department of Physics

University of Central Florida

Orlando, FL 32816

407-823-5513

Ned Mamula

Terradynamics Corporation

42C John Mosby Way

Route 1

Aldie, VA 22001

703-327-6500; 703-327-6480

Virginia T. McLemore \& John W. Hawley

New Mexico Bureau of Mines and Mineral Resources

Socorro, NM 87801

Dr. William W. Nazaroff

University of California

Department of Civil Engineering

Mail Code T878

Berkeley, CA 94720

510-642-1040; Fax: 510-643-5264

Dr. Kirk K. Nielson

Rogers and Associates Engineering Corp.

515 East 4500 South, Suite G-100

P.O. Box 330

Salt Lake City, UT 84110

801-263-1600

R. Thomas Peake

U.S. Environmental Protection Agency

Mail Code 6603J

401 M Street, SW

Washington, DC 20460

202-233-9765

Harry E. Rector

Geomet Technologies, Inc.

20251 Century Boulevard

Germantown, MD 20874

301-428-9898

Prof. Charles E. Roessler

Department of Environmental Engineering Sciences

University of Florida

Gainesville, FL 32611

904-392-0836 
Prof. Arthur W. Rose

The Pennsylvania State University

Department of Geosciences

218 Deike Building

University Park, PA 16802

814-865-7261

David Saunders

National Association of Home Builders

National Research Center

400 Prince George's Center Blvd.

Upper Marlboro, MD 20772-8731

301-249-4000

John Spears

Energy Conservation Management, Inc.

518 North Charles Street

Baltimore, MD 21201

410-332-0644

Dr. Stephen D. Schery

Physics Department

New Mexico Institute of Mining and Technology

Socorro, NM 87801

505-835-5328

Dr. Donald F. Schutz

Teledyne Isotopes, Inc.

50 Van Buren Avenue

Westwood, NJ 07675

201-664-7070

Dr. Richard G. Sextro, Dr. Karina Garbesi, Dr. Harold A. Wollenberg

Bldg. 90, Room 3058

Lawrence Berkeley Laboratory

University of California

Berkeley, CA 94720

510-486-6295; Fax: 510-486-6658

Dr. Daniel J. Steck

Physics Department, SC107

St. John's University

Collegeville, MN 56321

612-363-3186; Fax: 612-363-3202

Lorin R. Stieff

Stieff Research and Development Co.

9507 E. Stanhope Road

P.O. Box 263

Kensington, MD 20795

301-949-9508 


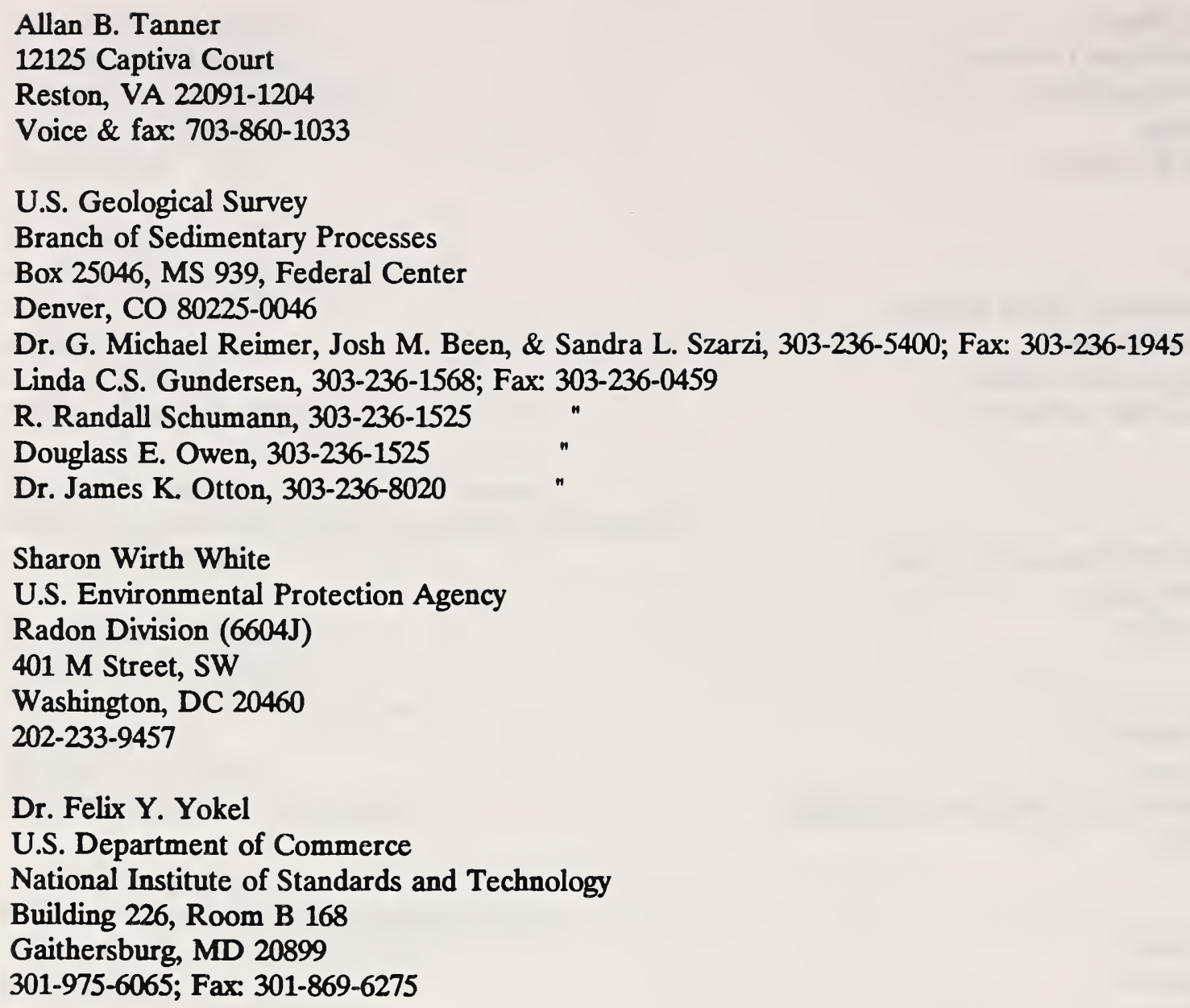

Dr. Felix Y. Yokel

U.S. Department of Commerce

National Institute of Standards and Technology

Building 226, Room B 168

Gaithersburg, MD 20899

301-975-6065; Fax: 301-869-6275 

